$$
\begin{gathered}
\text { ELEMENTARY } \\
\text { LESSONS IN ZOÖLOGY } \\
\text { JAMES G. NEEDHAM }
\end{gathered}
$$


IIIRTART

OF THE

UNIVERSITY

OF

CALIFORNII

IDOCATION IIBR.

No 638 





\section{ELEMENTARY LESSONS}

IX

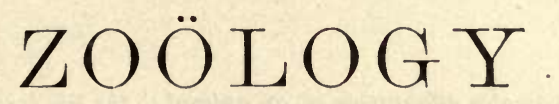

A GUIDE IN STUDYING ANIMAL LIFE AND STRUCTURE IN FIELD AND

LABORATORY

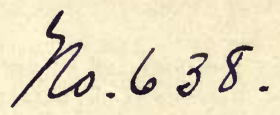

BY

JAMES G. NEEDHAM, M.S.

Instructor in Zoülogy, Knox College, Galesburg, Ill.

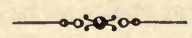

NEW YORK :: CINCINNATI $\because:$ CHICAGO

AMERICAN BOOK COMPANY 
"The invariable adaptation of an animal to the life it leads is one of nature's most instructive lessons, and can be discovered and appreciated by every pupil, but never through oral teaching or from reading of books. Better a child should learn to handle one animal, to see and know its structure and how it lives and moves, than to go through the whole animal kingdom with the best text-book under the best teacher, aided by the best charts ever made. The former would have learned what real knowledge is and how to get it, while the latter would have simply learned how to pass at his school examination."

ALPHEUS HYATT.

"Therefore $I$ would, in the name of education, urge students to begin naturally with what interests them, with the near at hand, with the practically important. A circuitous course of study, followed with natural eagerness, will lead to better results than the most logical of programs, if that take no root in the life of the student."

J. Arthur Thomson, in "The Study of Animal Life," p. 361.

\section{IMOCATION IIBRD:}

Coprright, 1895, 1896, вт

AMERICAN BOOK COMPANY.

NEED. ZOÖLOGY.

E-P 8 
to lie between being logical and being serviceable, the author has preferred that the arrangement should be serviceable.

The study of animals alive, and in their biological relations to their environment, is made a prominent feature. It is not morphology, or physiology, or natural history alone, that constitutes a proper elementary zoölogical course, but a comprehensive study of animals, that develops these sciences in their proper relations, and gives the elementary student a general view of the whole field, - a correct “zoölogical perspective." Morphology may, perhaps, like chemistry, be learned in the laboratory alone, but zoölogy may not. It has been a popular delusion that a term of dissections constitutes a proper elementary course. Such a course was an improvement on former methods : the study of dead animals is infinitely better than no contact with animals at all. But to study animals with nature and life left out is to omit a phase of the subject of deepest scientific interest, of highest educational importance, and of greatest pedagogical utility.

This book is written primarily for use in the interior: hence forms of life obtainable only at the seashore receive less attention than those found inlaud. The study of animal life is best begun with forms nearest at hand. The custom of sending to the seashore for specimens with which to begin the study, and neglecting a wealth of material at home, does not deserve to be encouraged. At the suggestion of many teachers who live where fresh marine material is available, a study of the starfish is inserted as the last chapter in the book. Believing that it will be used in some cases where material to illustrate it is insufficient, it contains fewer interrogation points, and more of explicit statement, than preceding chapters. A few diagrams of structures are inserted for the same reason.

All the work outlined in the following pages has been tested in the classroom, and has been repeatedly performed by the author while drawing up these lessons; and it is hoped by him that they may prove reasonably free from ambiguity and error. No animal is studied exhaustively: each one lends itself to some special purposes of illustration, and to such ends only is it used. Care has been taken to introduce no work beyond the capacity of the beginner. The illustrations given are intended to guide the student in finding and identifying for himself the animals recommended in the text for study. Few drawings are given of things which the student may reasonably be expected to draw for himself. If such are wanted, the reference books recommended are filled with them, and may be consulted with profit.

In the material presented herein the author can lay no claim to 
originality: he only wishes to be given credit for an honest effort at selecting, from the most available materials offered, that best calculated for introducing the beginner to the ideas and principles of zoölogical science. He respectfully invites the correspondence of teachers who find difficulty in using the book.

Finally, the author would gratefully acknowledge the assistance of many friends and teachers and of books which were teachers. He would speak of the cut on p. 212, which was kindly loaned by Professor Forbes of the Illinois State Laboratory of Natural History : and he would especially remember the assistance of Dr. E. A. Andrews of Johns Hopkins University, who read the manuscript of the text; of Professor J. H. Comstock of Cornell University, who read the proof sheets of the pages relating to insects; of Professor E. A. Birge of the University of Wisconsin, who read the proof sheets of the pages relating to crustaceans, mollusks, and vertebrates; of $\mathrm{Mr}$. Edward Potts of Philadelphia, who read the manuscript of the pages relating to the fresh-water sponge; of his honored friend and teacher, Professor Hurd of Knox College, who revised the etymological list of technical terms; and, last but not least, of his wife, Anna Taylor Needham, who made pen drawings for most of the illustrations.

J. G. N. 


\section{CONTENTS.}

Introduction . . . . . . . . . . . . 9

Protozonns . . . . . . . . . . . . . 12

The Amœba . . . . . . . . . . . . . 12

The Slipper Animalcule . . . . . . . . . 18

Celenterates . . . . . . . . . . . . . 22

The Fresh-water Sponge . . . . . . . . . 22

The Hydra. . . . . . . . . . . . . 26

InSECTS . . . . . . . . . . . . . . 34

Hexapod Insects . . . . . . . . . . . 36

The Butterfly . . . . . . . . . . . 36

The Dragon Fly . . . . . . . . . . 42

The Grasshopper . . . . . . . . . . . 48

The Squash Bug . . . . . . . . . . . 57

The Two-year Cicada . . . . . . . . . . 59

The Back-Swimmer. . . . . . . . . 61

The Bumblebee . . . . . . . . . . . 63

The Mud Wasp . . . . . . . . . . 70

The Paper Wasp. . . . . . . . . . . 72

The Honeybee . . . . . . . . . . . 73

The Black Blister Beetle . . . . . . . . . 74

The Bluebottle Fly . . . . . . . . . . 80

The Bee Killer . . . . . . . . . . . . . 84

The Cabbage Butterfly . . . . . . . . 86

The Life Process in Insects . . . . . . . . . . 93

A Review Exercise. . . . . . . . . . . 99

A Lesson in Classification . . . . . . . . . . 101

Arachnid Insects . . . . . . . . . . . 105

The Spider . . . . . . . . . . 105 
Myriapod Insects . . . . . . . . . . . . 109

The Chilopod or Centiped . . . . . . . . 109

Crustaceans . . . . . . . . . . . . . 111

The Crawfish . . . . . . . . . . . . 111

The Asellus . . . . . . . . . . . . . . . 125

The Cyclops . . . . . . . . . . . . . 126

Further Classification . . . . . . . . . 127

WorMs . . . . . . . . . . . . . 130

The Earthworm . . . . . . . . . . . . 130

Mollusks . . . . . . . . . . . . . . . . 140

The River Mussel . . . . . . . . . . . . 140

The Pond Snail . . . . . . . . . . . . . 154

Vertebrates . . . . . . . . . . . . . . . 161

The Catfish . . . . . . . . . . . . . 161

The Frog . . . . . . . . . . . . . . . 178

The Turtle . . . . . . . . . . . . . 198

The Snake . . . . . . . . . . . . 208

The English Sparrow . . . . . . . . . . . . 211

The Rabbit . . . . . . . . . . . . . . . 237

The Life Process in Vertebrates . . . . . . . . . 260

Echinoderms . . . . . . . . . . . . . 266

The Starfish . . . . . . . . . . . . 266

Appendix . . . . . . . . . . . . . 275

Prerequisites . . . . . . . . . . . . 275

Reagents . . . . . . . . . . . . . 276

Directions for the Preparation of Material for Study . . . 278

Accentuated List of Technical Terms . . . . . . . . 288

Suggestions to the Teacher . . . . . . . . . 302

INDEX . . . . . . . . . . . . . . 305 


\section{INTRODUCTION.}

The Study of Animal Life is begun when we first learn the names of our household pets, and begin to note the differences between them. It is continued so long as our eyes and ears are open to observe the nature and capacities of the animals with which our daily life brings us in contact. The horses that draw our carriage, the dogs that answer our call, the birds that delight our ears with their songs from the tree tops, the insects that flit before our eyes among the flowers of the garden, - all are continually illustrating phases of animal life, some of which cannot escape the notice of the most casual observer.

Every one knows that animals must have food. When they are young, they require food for growth; and when they are grown, they require food to furnish bodily strength. They require air also, - fresh air, containing oxygen, for the oxygen is the essential thing. A bird inclosed in an air-tight box with plenty of food, or a fish placed in a small quantity of clean water, soon dies, because the available supply of oxygen is soon exhausted.

Every one knows that, sooner or later, animals die, and that they leave descendants to perpetuate their race upon the earth; and every one should know that not all their young come to maturity, and that the number of their progeny is proportioned to the vicissitudes to which their life is exposed.

Every one knows that animals move, that most of them move freely from place to place, and that those which are 
fixed in their location, like the oyster, move freely some parts of their bodies in obtaining their food.

Every one knows that animals feel, that they respond to stimuli from without and to impulses from within, and that the most familiar animals exhibit varying degrees of instinct and intelligence.

These plain facts are fundamental. All the phenomena of animal life may be grouped under four heads :-

1. All those processes which are concerned with feeding and growth, - the taking of food, the preparation of it for the use of the body, the carrying of it in solution to the various parts, the building of it into the body structure, the exposure of it to oxygen derived from the air, and the removal of useless portions and of waste materials from the body (whether performed by simple means or by complex, whether without organs or by means of many separate organs), - all may be called phenomena of Nutrition.

2. All the phenomena connected with the reproductive process may be called phenomena of Reproduction.

3. All the phenomena of free and spontaneous movement may be called phenomena of Voluntary Motion.

4. All the phenomena of the senses of instinct and of intelligence may be called phenomena of Sensation.

It will then need to be borne in mind that this fourfold division is made for convenience; that the four groups of phenomena are not entirely distinct, but interrelated and interdependent.

In the beginning we must distinguish between that which is necessary and that which is only accessory in animal structure. The robin has a beak for eating, and wings for getting about; but beak and wings are not necessary for animal existence. Eating and moving are necessary, but these might be effected in other ways. The robin is a bird because of its beak and wings, an animal only because it eats and moves at will. 
In studying each animal, if we ask, (1) What is its food, how obtained and how used? How does it get oxygen from the air? How does it get rid of waste and worn-out material from its body? (2) How does it reproduce its kind? How numerous are its progeny and to what danger exposed? (3) How does it move? What are its specially movable parts? (4) What powers of sense, of instinct, and of intelligence has it, and what sort of a nervous system as the seat of these powers? - and if we follow patiently where Nature leads until we have found satisfactory answers to these questions, - we shall arrive at a better comprehension of the animal's activities, and in the end shall have learned many lessons of perennial interest and profit. This fourfold division of animal phenomena will be of service as an outline for our future study, leading us to learn for each animal all we can about

I. Nutrition, and its subservient organs.

II. Reproduction, and the adaptation of the reproductive process to varying conditions of life.

III. Voluntary Motion and motor organs.

IV. Sensation, as manifest through a nervous system in senses, instinct, and intelligence. 


\section{PROTOZOANS.}

\section{THE AMCEBA.}

The Amœba is selected as the first animal for study, because of its extreme simplicity. In it we are dealing with animal life at its lowest terms.

It is very small, usually less than a hundredth of an inch in diameter, and can be studied only with the aid of a microscope. Examine one that has been taken up in a drop of water, mounted on a glass slip, covered, and placed in the field of a microscope. ${ }^{1}$

First find it. This will be task enough for a moment for a beginner, even if the amœeba be in the field; for it presents so little likeness to familiar animals, that it might as readily be taken to be anything else. It appears like a little drop of jelly spreading out on a flat surface, translucent in its central portion, and very transparent around its border. Reference to the accompanying figure will aid in recognizing it. That it is alive will not be ascertained at the first glance, but may be learned from watching its slowly changing outline for a moment or two. After finding it, and after learning by a few trials how, by moving the glass slide, to bring it back into the center of the field when it moves out, and how to keep it in focus by turning the adjustment screws on the microscope, then study its general structure and its movements.

1 If the student be working alone, he will follow the directions given to the teacher (see Appendix, p. 278) for collecting amœbas, and preparing them for examination. 
Observe: 1. A granular, translucent central portion (the endosarc), with something of the appearance of ground glass.

2. A transparent outer border (the ectosarc), so clear it is liable to be overlooked the first time an amœba is seen, and the endosare taken for the whole animal.

3. Irregular, blunt projections (pseudopodia, or false feet), which are slowly pushed out from the body wall, or drawn into it. Observe that in all of these there is the

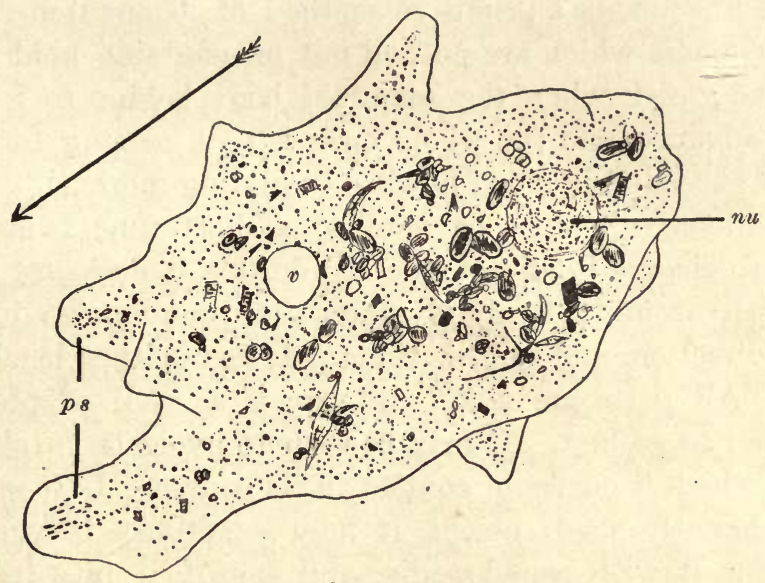

Aмсква $(\times 500)$, drawn while moving in the direction of the arrow : $n u$, nucleus; $v$, vacuole; $p s$, pseudopodia.

same clear border and granular central portion; and this is true of their appearance when they protrude vertically, as well as when extended laterally. If we can roll an amceba over, we shall see the same arrangement of parts; so that we must conclude that the ectosare forms a complete outer layer about the whole animal.

Pseudopodia. - Watch the formation of pseudopodia. See first a protrusion of the clear ectosare, then the flowing of the more fluid granular endosarc out into it. - Observe 
that, while pseudopodia are pushed out in all directions, they grow principally in one direction, and that the direction in which the amœba is traveling. Observe that about as fast as pseudopodia are formed in one direction, the body follows them, all its granular content flowing into their bases, swelling them, and uniting them.

Watch also the withdrawal of pseudopodia, first a flowing toward the center of the granular part, leaving an emptied projection of ectosarc, which follows on in the rear.

Such is amœba's primitive method of locomotion. The pseudopodia which are pushed out on one side hold their ground; and, when the semifluid body begins to follow, they advance, and the whole mass is seen setting forward in an exceedingly slow, flowing or gliding motion.

If an active amœba be watched a short time, it may be seen to change its direction. To do this it does not need to turn around: it simply puts out pseudopodia in the new direction, and follows them. It has neither head nor tail. All parts are alike, and one is as well adapted as another to go first. It may be seen to avoid large objects with which it comes in contact in its course. If it meet a conveniently small object, it may sometimes be seen to encircle it with pseudopodia, and ingulf it into its soft body mass, - swallow it, so to speak, - after which the object may be seen within the granular endosare, where it is lodged as food for digestion. If it prove indigestible, it is gotten rid of in a correspondingly simple way. The body mass flows away from it, and it is left behind.

If the amoba be irritated in any way, as by touching the cover glass, it immediately draws in its pseudopodia, and assumes a more or less spherical form. If not injured in any way, it soon resumes activity.

Make a series of half a dozen outlines of an amœba, drawn at intervals of a minute or two, or less if it be moving actively, to show the changes in form. 
Minute Structures. - If the currents in an active amøba have been watched carefully under high power, certain minute structures will have been discovered within the body. Three of these are normally present, though not always easily made out:-

1. A nucleus, a discoid or spherical body slightly more transparent than the surrounding endosarc, and usually located toward the posterior end of a moving amœba.

2. A contractile vesicle, a round clear spot within the ectosarc. It may sometimes be seen to contract, and disappear temporarily, and will then be certainly recognized.

3. Ingested food particles. These appear darker than the surrounding endosarc; or if colored food particles have been taken, microscopic green plants, etc., the color will shine through. These are of various sizes.

These structures may be more readily made out in a specimen that is stained with iodine. Place a drop of iodine solution on the slide at one edge of the cover glass, and place a bit of blotting paper at the opposite edge. The blotting paper, by its absorbent action, will draw the iodine solution under the cover glass, where it will penetrate and stain and kill the amœba. The nucleus will be more brightly stained than the other parts.

Make an enlarged drawing of an amœba prepared in this way, showing all the points of structure you have been able to see.

By mixing some very finely powdered carmine or indigo in the drop of water containing amœbas before covering, their feeding may sometimes be better observed.

Occasionally an amœba may be found dividing into two. Such should be watched carefully.

The Life Process. - The jelly-like living substance which makes up the body of the amœeba is protoplasm. It is 
an almost structureless and colorless substance, in chemical composition much like the albumen of an egg. It is the physical basis of life. Neither animal nor vegetable life is known to exist apart from it. It is everywhere present in the growing parts of animals and plants. It is capable, as life's agent, of producing the most complex structures. The nucleus within the amœba is but a bit of the protoplasm of slightly firmer consistency than the rest; but it is, perhaps, the most essential part.

Simple as the amcoa is, and wanting in parts, it yet leads an animal life, and exercises all the essential animal functions.

I. Nutrition. - That the amœba takes food has been seen already. Having neither mouth nor stomach, it ingests and digests its food at the most convenient point. Its proper food consists of the smallest microscopic plants. These, when found within the body of a living amœba, may, by continued watching, be seen to dissolve away as they are digested. The small amount of mineral food and the larger amount of oxygen necessaly for the amoba are already in solution in the water in which it lives, and need but to be absorbed. These dissolved foods penetrate freely to every part of the protoplasmic mass, and by a process called assimilation they are incorporated into it, and become a part of it. But this process means more than the mere storing of digested food: it means that the food is built up into complex chemical compounds, like those which are the constituents of protoplasm, and that it then becomes a part of the protoplasm, like any other part, in all its properties. The necessary result of this process is that the animal grows.

But this process also makes possible the animal's activities. The complex chemical compounds formed in this constructive process are highly charged with potential energy and are very unstable, like a single tier of bricks 
that is piled too high, or like a train of gunpowder that is ready to be discharged. As a light touch will upset the bricks and cause them to fall with great force, or as a spark will ignite the gunpowder and cause a violent explosion, so, in a small way, a slight stimulus to the amoba will cause some of these complex molecules in the protoplasm to break up into simpler ones with the liberation of the forces manifested in the animal's activities.

The simple compounds (carbonic-acid gas, water, etc.) formed in this destructive process are of no use to the amœba, and must be removed. The name of the process is excretion. These waste products pass out directly through the body wall into the surrounding water. It should be noted that there is an important difference between this true process of excretion and the mere egesting of an indigestible bit of carmine: the latter does not become a part of the animal's structure at all. Many such particles are ingested in the course of feeding. It shows little choice in the selection of food, ingulfing any object of convenient size with which it may come in contact.

II. Reproduction. - The common method of reproduction in amœba is simple division. First the nucleus divides into two. Then the body elongates, and the nuclei move apart toward the ends. A furrow then appears across the body, between the nuclei. This furrow deepens until it entirely separates the body into two pieces, each of which is at once an independent, perfect amœba.

The converse of this process has been observed. Two amœbas have been seen to fuse together into one. It is believed that this process (conjugation) is necessary for the continued existence of amœbas. It has been proved to be necessary in the case of some other microscopic animals which reproduce ordinarily by dividing.

III. Voluntary Motion. - Protoplasm is contractile, i.e., sapable of extending in one direction by shortening in NEED. ZOöL. -2 
another. But the movements of amœba, simple as they are, are yet more than the independent automatic contractions of protoplasm; for they are controlled and coördinated to certain ends, - to reaction in response to stimuli from without, to locomotion and to securing food in response to impulses from within.

IV. Sensation. - These latter acts indicate spontaneous activity, and show that the amœba possesses in a low degree sensibility, the dawning of faculties which are the highest endowment of animal life.

The Cell. - The cell in biology is a minute mass of protoplasm containing a nucleus with or without a cell wall. The amoeba is a single cell that has developed about itself a very delicate and pliant cell wall.

The cell is the unit of all organic structure. Every plant and every animal begins its existence as a single cell. This cell grows and divides repeatedly; and the cells thus formed remain together, and with their products compose the bodies of the higher plants and animals. The cellular character of the growing parts of all animals may be easily recognized under the microscope.

When the amœba divides, its parts separate. It therefore retains this simple condition, never becoming more than a single cell.

\section{THE SLIPPER ANIMALCULE.}

\section{(Paramecium.)}

Study of Live Specimens. - Examine a drop of water containing slipper animalcules. They appear as minute white specks rapidly moving to and fro through the water, just large enough to be seen without a lens.

Examine under the microscope a drop that has been mounted on a slide in cotton fibers, or, better, in cherry- 
gum solution, and covered. ${ }^{1}$ Use low power at first, and make a general survey of the contents of the drop. Several kinds of animalcules may be present. The slipper animalcule (Paramecium) may be recognized by its elongated, somewhat slipper-shaped form, and by its rapid progression with one end always forward.

Study its actions. Observe that paramecium, unlike amœba, when it reverses its direction of travel, turns around; that it has anterior and posterior ends. Yet it can and does move backward when cornered, as may be seen when one swims into a narrow space between two cotton fibers, and has to bark out.

Find one that may be retained within the center of the field, and examine it, magnified 300 to 500 diameters. Observe:-

1. That paramecium has a definite, permanent, though unsymmetrical shape.

2. That its body is a single minute mass, without partitions or divisions; i.e., that it is a single cell.

3. That its body mass is made up of two layers, -

(a) An outer, transparent ectosarc.

(b) An inner, granular, and more fluid endosarc.

4. That the whole body is covered over with delicate, transparent processes, shaped somewhat like eyelashes, and hence called cilia. In an active paramecium, these cilia are moved so rapidly, they may be seen but dimly, like the spokes of a rapidly revolving wheel. It is by means of these cilia that the paramecium swims. They are used as a boy's arms are used in swimming: they are struck backward quickly and forcibly, and are drawn forward again more slowly. It must be noted that they are not hairs, but only delicate projections from the body wall.

Observe also, focusing up and down to bring into view the parts at different levels, -

1 See Appendix, p. 279. 
5. An oblique groove (peristome) extending from the anterior end halfway along one side of the animal, and so

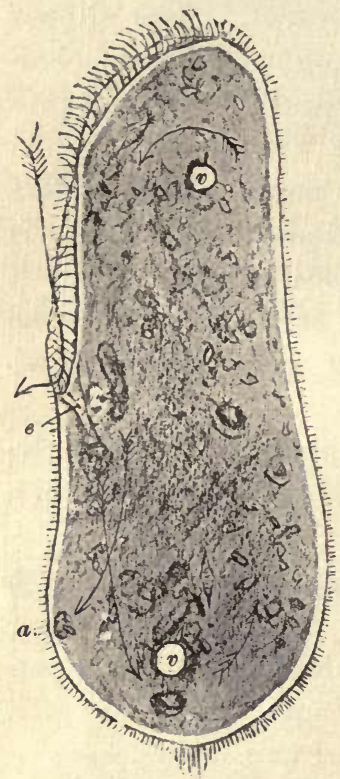

Paramactum $(\times 300)$. The water curlent is driven in the direction of the large arrow by the lashing action of the cilia of that region. Food particles pass down the funnel-shaped esophagus $(e)$, and collect in little round pellets at the bottom. Then they circulate about the body in the direction of the arrows, and indigestible portions are ejected at $a$. Two contractile vacuoles (v) are seen near the ends of the body, and an elongate nucleus $(n)$ may be seen after staining. twisted that its edges form an elongated 8-shaped figure when viewed from the side (see cut).

6. A fringe of cilia, longer and stronger than those of the body, all around the edge of this groove. These set up currents in the water, which may be seen, if there be any loose sediment in the water, setting toward the posterior end of this groove.

7. A funnel-shaped chamber (vestibule, or mouth) in the posterior end of this groove. Toward this the currents in the water tend, and into it they drive the particles they sweep along.

Near to this chamber, and in the central portion of the body, is an elongated, often spindle-shaped nucleus, often hardly visible without staining.

In one or two places in the body there is a clear, round spot of considerable size (usually one near each end), which regularly appears and quickly disappears several times a minute. Each of these is a contractile vesicle. If one of these be watched very closely, it will be seen to have minute, radiating tabes appearing around it when it contracts.

The remaining objects seen in the endosarc are food 
balls and minute fat globules, and various foreign bodies that have been swept into the mouth with food. The feeding habits of the animal are best studied after putting some finely powdered earmine or indigo into the drop of water with it. Bits of these indigestible substances will be seen swept along the groove by its cilia, through the mouth, if they be small enough, for this is the only entrance requirement, and down a sort of short rudimentary esophagus, at the bottom of which they collect into a little pellet before being ingulfed by the protoplasmic mass of the interior. Then they may be seen to circulate slowly about the body, and, after considerable time, to collect at a point about halfway between the mouth and the posterior end of the body, where they are egested directly through the body wall.

The Life Process. - This is essentially as in amœba; but there are some interesting differences in its details.

When any part of an animal becomes so modified as to be better fitted for doing some one thing, that part is said to be specialized. Thus in paramecium the cilia are specialized for locomotion. One circlet of cilia - that fringing the groove leading to the mouth - is still more highly specialized for setting up currents in the water as a means of capturing food. A mouth and short esophagus are specialized for receiving food, and contractile vesicles are specialized for circulating the fluids of the body. Every time a vesicle contracts, it drives its liquid contents out into the surrounding body mass. These specialized parts in the one-celled paramecium foreshadow the locomotor, digestive, and circulatory systems of the many-celled animals.

Amceba and paramecium are representatives of the Protozoa, a large group of microscopic unicellular animals of wide distribution. 


\section{CCELENTERATES.}

THE FRESH-WATER SPONGE.

(Myenia fluviatilis.)

Study of Live Specimens. - Examine fresh specimens. ${ }^{1}$ Note:-

1. Their form.

2. Their attachment: upon what kind of surfaces they

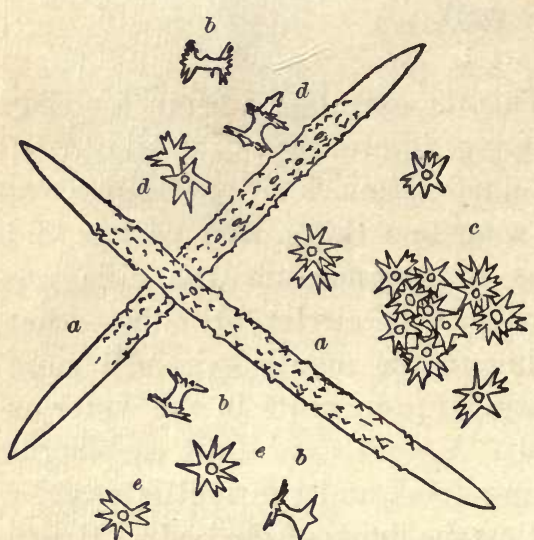

Spicules of Fresh-water Sponge ( $M y$ enia fluviatilis): $a$, skeleton spicules; the others, gemmule spicules seen sidewise at $b$ and $d$, endwise at $c$ and $e$. are found growing.

3. Their color.

4. Their odor, peculiar, not unpleasant in life, but rapidly becoming very disagreeable if any specimens have died. This rapid decomposition of the sponge flesh betrays its animal nature.

Examine the surface of the sponge with a good lens to find the osteoles (or exhalent openings), out of which, in

life, currents of water are continually flowing.

Examine it still more closely to find the minute but multitudinous pores (or inhalent openings) which cover

1 Directions for collecting are given in Appendix, p. 279. 
almost the whole surface, and through which the water enters the sponge.

The sponge flesh is called sarcode. Press upon it, and note its consistency.

Examining it again with a lens, note that it is bristling with the points of very minute spicules, which are arranged somewhat in lines, so as to form a sort of skeleton, running through and supporting the sarcode. These skeleton spicules are about $\frac{1}{100}$ of an inch long.

The sarcode is permeated everywhere by minute canals, which convey the water, taken in at the pores, to large canals communicating with the osteoles. At certain places in the smaller canals there are enlargements, which are lined with cells bearing cilia. The water currents are believed to be due to the lashing action of these cilia.

Gemmules. - Imbedded in the sponge flesh, and most abundant near the base of the sponge, observe a large number of small, round, yellowish or brownish seedlike bodies; about the size of the smallest mustard seeds. These are called gemmules.

Study gemmules which have been cleared and mounted for examination. ${ }^{1}$ Under low power of microscope, observe the thick, yellowish coat of the gemmule opening at one side by a foraminal aperture (called, usually, simply the aperture). In the outer coat of the gemmule observe spicules which differ markedly from the skeleton spicules in form. These gemmule spicules vary greatly in form in different fresh-water sponges. If the sponge named at the beginning of this section furnished the gemmules now under examination, the spicules found in their outer coat will be of the form of a spool, with the discoidal ends of the spool notched to form radiating points, and with the

1 This preparation and the one following it, the student may make for himself, if desired, by following directions found in Appendix, p. 280. 
slender axis of the spool produced into a short point (umbonate) at each end. The axes of these spicules are directed toward the center of the gemmule, so that, on looking at the surface of the gemmule, only the radiate disks on the distal end of the spicules are seen. Looking at the cut edge of the outer coat of a gemmule which has been divided in halves, a lateral view of some of the spicules will be obtained, and their somewhat spool-shaped (birotulate) outline will be recognized.

For a better view of both skeleton and gemmule spicules, examine some which have been isolated with nitric acid and mounted separately. Draw typical spicules of both kinds.

Make an outline drawing of the whole sponge. Fill in the details in a part of the drawing so as to show osteoles, pores, and gemmules.

The gemmules are reproductive bodies; and their outer coats, strengthened with beautiful spicules, however interesting in themselves, are of value to the sponge only as they form a protective covering for the protoplasmic contents of the gemmule. ${ }^{1}$ When, in winter, the old sponge dies down, and the gemmule has been set adrift, the protoplasmic cells of its interior in some favoring situation escape through the aperture, associate and attach themselves in a relatively compact mass, and begin to take food from the surrounding water, and to grow up into a new sponge.

In watching the development from gemmules, note the following. ${ }^{2}$

1. The protoplasmic contents of the gemmule may be seen to issue by amoboid efforts, to grow and develop sar-

1 The gemmule is formed (Marshall) by a number of free amœboid sponge cells which come together at some point in the sarcode, and secrete a thin pellicle about themselves. 'The surrounding cells secrete the outer coat of the gemmule, with its supporting spicules.

2 For methods of preparation for this, see Appendix, p. 281. 
code with its supporting spicules, its pores, osteoles, and communicating canals. The abundant secretion of sili. ceous spicules by this simple protoplasmic mass, and the arrangement of them in definite lines to form a skeletal structure, are easily seen, and are somewhat remarkable phenomena.

2. The sarcode masses produced from few or many separate gemmules may be seen to meet and coalesce to form a single sponge, showing further the aggregate nature of the animal.

The Life Process. - When the amøba divides, its cells separate as independent animals; but when the protoplasmic mass of the sponge gemmule divides off new cells, these cells remain aggregated together. Although they arrange themselves so as to inclose water canals when their whole mass becomes too great for contact of all parts with the water, and although they coöperate in the formation of spicules in more or less definite lines, they yet lead in some respects an independent existence, in that each cell lives, eats, assimilates, grows, excretes, and divides for itself. The life process in each cell is therefore not greatly different from that of the single cell of amœba, save that the sponge cell is more limited in its search for food, being compelled to take such as the water currents bring to it. But this loss of power to the single cell is obviously to the advantage of the sponge as a whole. And just in proportion as the individual cells lose their individuality, and become arranged and ordered for the good of the animal they compose, the animal ceases to be a mere aggregate of cells, and becomes an integrate organism.

Differentiation is the term applied to the way cells have of growing different, - of becoming unlike in form when 
combined together to form an animal of more than one cell (a metazoan). Thus the ciliated cells in the water cavities of the sponge have become differentiated from those which possess no cilia. ${ }^{1}$

\section{THE HYDRA.}

\section{(Hydra viridis?)}

Study of Live Specimens. - In an aquarium or glass jar in which hydras are kept ${ }^{2}$ study the creatures alive. Observe:-

1. Their shape, - elongated, cylindrical, with the body attached at its posterior or foot end to some support, free at its anterior end, and crowned with a circle of long, radiating tentacles.

2. Their color.

3. Their position: if all are in the same position; if all are attached to the same kind of a support; in what part of the vessel they are most numerous.

4. Their actions. Note the swaying-about of the long tentacles in the water. 'These capture food. A minute animal that has been captured may sometimes be seen, before it is carried to the mouth, sticking to one of the tentacles. Touch the tentacles, and see them contract.

If the hydra jar be so placed that light reaches it strongly from but one side, after some time the hydras which are on the opposite side of the jar will move toward the light, when their slow and very peculiar looping locomotion may be seen.

1 For a further study of this and of related sponges, the student is referred to Potts's Monograph of Fresh-Water Sponges. For a good discussion of the relations and differences between plants and animals, he is referred to Parker's Elementary Biology.

2 See Appendix, p. 282. 
5. Their three methods of reproduction:-

(a) By buds. These are blunt processes often seen sticking out at right angles to the body of the parent hydra, outgrowths from its sides, destined to become perfect hydras, and, when well grown, to separate, and lead an independent existence. All stages of the budding process may usually be found, from the incipient bud without tentacles, to the fully formed hydra ready to drop away.

(b) By true sexual organs, - minute cone-shaped or dome-shaped eminences on the sides of the body, just visible without a lens.

(c) By a sort of vegetative reproduction, like the starting of a new plant from a slip or cutting taken from an old one. To see this will require a carefully conducted experiment, costing a little time and trouble, but worth both. Cut out a piece of leaf with three hydras on it, and place it and them in a separate vessel of water. With a pair of thin, sharp scissors, cut off a tentacle from one of the hydras, to see it reproduced. Cut the second hydra in two crosswise, and slit the third one into two pieces lengthwise. If properly done, the pieces will live, and each will develop into a perfect hydra. The progress of these specimens should be watched daily, and as much oftener as is convenient.

Detach a hydra from its support, take it up with a dropping tube, and place it in a watch crystal containing water under the microscope, and examine with low power. Observe:-

1. The broad or flattened foot by which it was attached.

2. The flexible cylindrical body (often distended in places by food, or extended into buds).

3. The tentacles: their number; their knotted appearance; their action.

4. The cone-shaped prominence (hypostome) at the anterior end, between the bases of the tentacles. 
5. The mouth, which is at the top of this prominence, and may be seen in favorable positions; i.e., when it is turned upward and opened.

Structure. - Mount the hydra alive in a drop of water upon a slide. Place two minute slips of paper or two threads alongside the hydra, and lower a cover glass upon these. Examine first with low, and afterward with higher power, to make out the following points of structure :-

1. The body is a hollow tube with but one opening to the exterior, the mouth. The interior of this tube is the gastric cavity. Observe that this cavity extends out into the buds, when present, and into the tentacles. When the tentacles are fully extended, food particles may be seen in them.

2. The body wall is double. Its outer coat (the ectoderm) is made up of small transparent cells; its inner coat (the endoderm), of larger, darker cells. The body is therefore a double-walled sac, both walls of which are pushed outward to form buds and tentacles.

3. In the ectoderm, in parts of the body, and especially in the swollen parts of the tentacles, are certain conspicuous round or oval cells surrounded by smaller ones. These larger ones are called thread cells, lasso cells, or nettle cells, because they contain a long, spirally coiled thread, which can be thrown out at will, and is used in capturing prey. When the long, swaying tentacles approach some animal suitable for food, as a water flea, these threads are thrown out, and, coming in contact with the flea, they seem to paralyze it. It hangs apparently stunned, adhering to several of these threads, and is quickly swept into the mouth. If a drop of acetic acid, magenta, or methyl green be drawn under the cover glass, and the tentacles watched at the same time, the throwing-out of these threads may be seen. Afterward some of these lasso cells 
may be found entirely dislodged from the tentacle, and showing, beside the long stinging filament, a flask-shaped base, with minute retrorse spines at the neck of the flask whence the filament springs.

4. The sexual reproductive elements are developed in low elevations upon the sides of the body. These are of two kinds : -

(a) Spermaries, - conical, pointed elevations near the anterior end of the body, just behind the tentacles, of

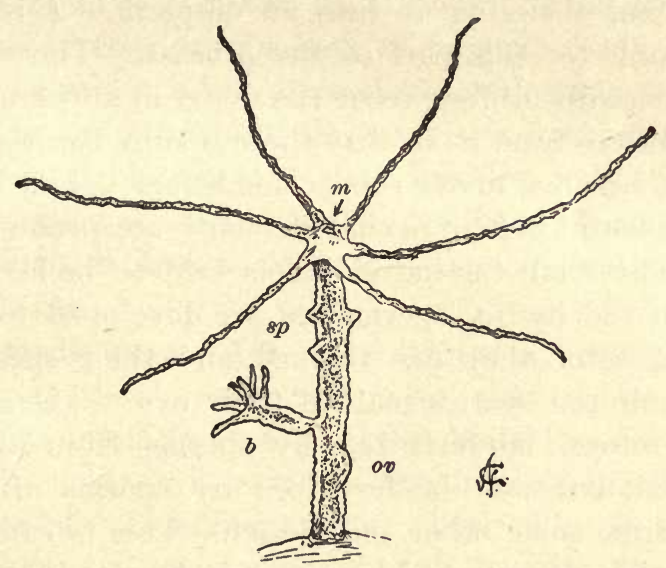

HydRA $(\times 6): m$, mouth; $s p$, spermaries; ov, ovary; $b$, bud.

variable number. In the transparent apex of a ripe spermary, the sperms may be seen swimming actively about or breaking out into the surrounding water.

(b) Ovaries, - rounded, obtuse elevations nearer the foot, rather larger than spermaries when ripe, usually fewer in number, and each containing but a single ovum.

Both spermaries and ovaries are developed from the ectoderm, as might be inferred from their position and from their transparency. 
Sexual Reproduction consists in the production of male and female reproductive elements, sperms and ova, and in their union to form oösperms, and in the development of the oösperms into new individuals. At first certain cells are separated off from the other cells of the body, and in certain parts of the body, specialized for the purpose, are developed into sperms and ova. Then the sperms of the hydra escape out into the water, and swim actively about until some of them come into contact with the ova of another hydra. One sperm enters and coalesces with each ovum, changing it into an oösperm. Fertilization is the name for this part of the process. The resultant oösperm hardly differs from the ovum in appearance, yet vitally differs from it, in that the oösperm has the potentiality to become, under proper conditions, a new hydra.

When both kinds of sexual elements are produced in a single individual, the individual is said to be hermaphrodite. In the hydra, spermaries are developed first; and not until after they are ripened, and their sperms discharged, do the ovaries mature their ova. The ova cannot, therefore, be fertilized by sperms from the same individual, but will be fertilized by sperms of a later growth from some other individual. This is called cross

- fertilization: it seems to be essential to the healthy continuance of most animals.

The Life Process. I. Nutrition. - In the hydra we have our first example of an animal with a distinct gastric cavity, in which food may be received and retained until digested. We find, also, better means of securing food than in any protozoans. After the food is taken by the tentacles and the extensible mouth, it is pressed down into the digestive eavity, and there the endoderm cells do most, if not all, of the work of reducing it to soluble form. These lining cells are large, and capable of considerable amœboid 
motion, which may be seen in thin transverse sections cut from a living specimen. Their combined motions probably have much to do with comminuting the food. Their secretions probably act on it chemically to digest it; but when it is digested, it must pass out to all parts of the body by simple osmosis from cell to cell, and by the slight propulsion given by the moving of the parts of the body upon one another, for there are no circulating vessels. There being but one external opening to the digestive tract, the indigestible portion of the food must be cast out, as it is taken in, through the mouth. The absorption of free oxygen and of mineral foods in solution in the water, takes place directly through the body wall. The assimilation of these various foods from various sources, the building of them into the body structure, and the removal of the waste products of activity, these things, in hydra, as in all animals, each cell does for itself.

II. Reproduction. - That the hydra is hermaphrodite has already been seen, and also that it reproduces greatly by budding. Did these buds remain permaIiently attached, as in some of the hydra's marine relatives, instead of falling away when fully grown, we should have it developing a peculiar treelike form. Hydra does not divide of itself into two equal parts, but, when so divided artificially, the parts may each become a new hydra with all lost parts reproduced. Pieces much smaller than half the animal may grow into perfect hydras. It seems to be only necessary that all the essential structures be represented, and probably is most essential that the ectoderm (the reproductive layer) and the endoderm (the digestive layer) be present and in their proper relations together.

III. Voluntary Motion. - The hydra is another of the animals that "move without muscles." Yet its move- 
ments are varied and interesting. They are ceaseless, too, as may be seen by watching its continually changing form. Though all its individual cells have the power of motion, some cells, as those in the tentacles, move more freely than others. The lasso cells are capable of a very sudden and remarkable and highly specialized act, - the throwing-out of their paralyzing filament.

IV. Sensation. - No nervous system is developed in the hydra; but a few nerve cells, developed between the bases of the ectoderm cells, are known to exist. There is a marked advance in the powers of sensation of this animal over those previously studied, seen in greater reaction from disturbances, in greater skill in securing food and more choice in selecting it, in preference for light, etc.

Tissue and Organ. - The cells of the ectoderm in hydra, being much alike in form and in the work they have to do, constitute a primitive tissue. The cells of the endoderm constitute another such tissue. A tissue may be defined as an aggregation of similar cells, together with whatever intercellular substance may be developed from the cells.

When any part of an animal is set apart for a particular - work, that part is called an organ, and the work it has to do is called its function. 'Thus the tentacles of the hydra are organs, and their function is reaching out after food.

Differentiation becomes very evident in the hydra. The thread cells of the tentacles are very unlike the digestive cells of the endoderm in the digestive cavity. In the work they have to do, there is quite as great difference as in their form. The thread cells are given a specific work to do, - the capturing of food. Other cells do the digesting, and can do it better for being relieved of the work of capturing the food. This is what is meant by a physiological division of labor. This sort of spe- 
cialization, so evident in the development of animals, has its parallel in the development of civilization or in the development of a trade. For example, the early cobbler tanned his own leather, whittled his own pegs, made his own thread, lasts, etc., and then made the shoe. But, as the trade of shoemaking developed, one man began giving his whole time to making the leather; another, to making the lasts, etc.; and another, to making the shoe. To see how much further than this the division of labor in shoemaking has gone in our own time, we need only to visit a modern shoe factory.

When the cobbler gave up to the tanner the making of the leather, he became a more skillful shoemaker, but lost his skill at tanning. So, when the thread cell of the hydra becomes differentiated for capturing food, it excels in that one thing, but it loses its capacity for doing other things. Here we come upon the universal principle, that precise adaptation to any one thing involves limitations in other things.

Division of labor develops greater skill and better products in a trade, higher powers and capacities in animal life. While there are many things which cells and cobblers may leave to be done by others, to the advantage of all concerned, there are yet other things which each must continue to do individually. For example, the thread cell, though it may be relieved of the work of digesting its food, must continue to absorb the digested food as it is furnished, and assimilate it; must absorb oxygen, and must excrete waste oxidized materials for itself, so long as it continues a living cell.

The hydra and the sponge are representations of the Coelenterata, a large and important group of animals, almost exclusively marine. 


\section{INSECTS.}

Collecting. - Insects are abundant in nearly all localities throughout the interior of the United States. There need, therefore, be no lack of material at the proper season. And because this group illustrates well the principles of zoölogy, and furnishes animals of

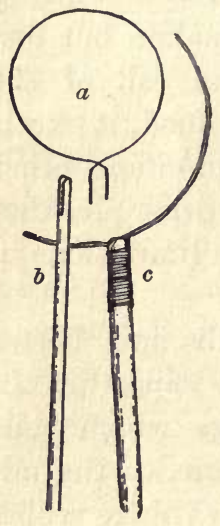

FraMe For INSECT NET: $a$, loop of wire; $b$, handle; $c$, wire and handle in place. singular beauty, variety, interest, and importance, it may profitably be studied as long as the limitations of time will permit.

Three special pieces of apparatus will be needed, - a collecting net, a cyanide bottle, and a collecting basket.

The net is for catching insects. To make it, get a light, wooden handle two or three feet long, a piece of heavy wire (about No. 8) two feet and a half long, several feet of small wire (broom wire will do), and a square yard of "Swiss" or mosquito netting. Bend the heavy wire in a circle, crossing the ends and bending them parallel. Cut a groove in the end of the handle, and continue it down the sides. Place the crossed ends of the wire in this groove on opposite sides of the handle, and wrap them there securely with the small wire. Make a bag of the netting, of the same diameter as the wire circle, and about two feet deep. Sew this on the wire circle, and the net is complete. With a very little practice, it can be used suc- 
cessfully. When by a stroke the insect is caught, a quick turn of the hand makes a fold in the net, and prevents its escape.

The cyanide bottle is for killing insects that are to be preserved as specimens. Get a wide-mouthed bottle of a capacity of at least a pint, half an ounce of potassium cyanide, a handful of plaster of Paris, and a poison label. Break the cyanide into small pieces (avoid its poisonous fumes), and place them in the bottom of the bottle. Pour in just enough water to cover them. Add plaster of Paris until it remains dry over the entire surface. The plaster will quickly set, forming a porous poison cake in the bottom. Let the bottle stand uncorked for half a day; then shake out the surplus plaster, wipe clean the sides, cork, affix the poison label, and keep out of the way of children. Most insects, when shut inside, die at once. 'To transfer a captured insect from the net to the bottle, push the uncorked bottle carefully up inside the folded net.

The collecting basket is for carrying insects home alive. A close-woven basket with a netting cover will answer every purpose. Any kind of basket will do, if lined with netting. A place must be fixed at the edge for putting in and taking out the insects.

In collecting, always observe the following rules:-

1. Collect no more specimens than will probably be used. The taking of more is but the wanton destruction of life.

2. Get for preservation the finest specimens obtainable, and preserve them with utmost care. Fine specimens are always a delight, and poor ones are of no credit to any one.

3. Keep live specimens supplied with food, water, and fresh air. To let an animal die a lingering death for want of either of these common necessities, is extreme cruelty.

4. Make each collecting trip an opportunity for studying animal life under natural conditions. Make note of 
the haunts of each animal, of its animal associates, of its food, of its shelter, of its natural enemies, of its home, in short, of the life it leads. Such study will lead to important general truths relating to all animal life, including that of man, and is best begun in the field.

5. Remember that fear is inherent in most animals, and that flashy colors, loud noises, and quick and careless movements will frighten them, and cause the loss of opportunities for observation. Hence wear quiet colors, avoid noise, avoid haste, and keep your eyes wide open.

\section{HEXAPOD INSECTS.}

\section{THE BUTTERFLY.}

\section{(A Preiminary Lesson.)}

Characteristics. - The common sulphur butterfly (Eurymus philodice ${ }^{1}$ ) will serve well for a beginning in the study

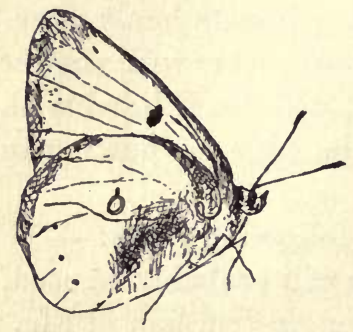

The Sulphur Butterfly, Eurymus philodice (natural size). of insects. It may be known by its yellow wings bordered with black, and by a silvery spot set in a patch of pinkish brown on the lower surface of the hind wings. Like other butterflies, it may best be collected about midday. Any clover field or meadow will probably furnish a supply. Any other buttertly that can easily be collected will answer the present purpose quite as well.

Study of Live Specimens. - Collect specimens for immediate use and for preservation, ${ }^{2}$ and while collecting study the living butterflies and their haunts and habits, noting:-

1 Colias philodice of some authors.

2 Observe that all the specimens captured are not in equally good con- 
1. The species of the flowers on which you find them feeding.

2. The manner of their feeding: whether they, like humming birds, obtain their food while on the wing.

3. The kind of food: it is the nectar of the flowers, the raw material for honey. To prove its presence in the flowers, pluck a few corollas from a head of red clover, and press their bases between your lips: you will taste the sweet nectar.

4. The organ used in obtaining this food: its position when in use and when not in use; its shape; its length.

5. The natural enemies of the butterfly; to what dangers its life is commonly exposed.

6. Its animal associates; with what other animals it shares its food.

When you get home, liberate a live butterfly before a closed window, and study its motions.

Observe: 1. The position of its wings when at rest.

2. The unity of their action when in motion.

3. Its irregular flight.

4. Its jerky walk.

5. The number of its feet; the number moved at a time while walking.

Take time to admire the beauty and harmony of its form and coloration, the alertness of its posture, and the exquisite velvet of its wings.

It is at once apparent that in its activities and capacities the butterfly far surpasses amœeba, sponge, and hydra. The first few steps up the grade of animal life we took in their proper order; but now, for the sake of convenience, we

dition. Some have their wings rubbed and torn. Place such in the basket, and take them home for further study alive. Put the best in the cyanide bottle. It is well to have two cyanide bottles, - one to kill and one to carry specimens in, - for the fluttering of live specimens put into the bottle may rub and mar the beauty of former captives which have not been removed. See note on mounting insects, in Appendix, p. 283. 
pass by those which would succeed in logical order, to study a group of animals that is highly specialized.

Plan of Structure. - A superficial study of the external features of the butterfly will give a general idea of the insect plan of structure. Examine a butterfly which has been killed in the cyanide bottle, and observe its horny incasement, - an outside skeleton covering the whole surface, but thickest and hardest on those parts of the body

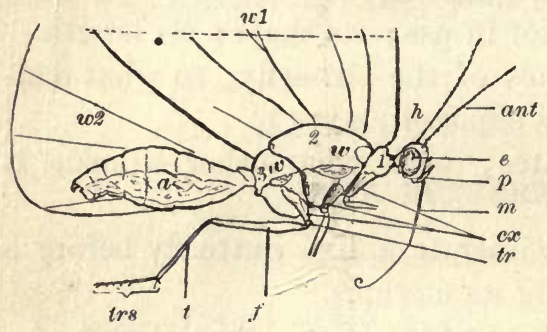

Diagram of Sulphur Butterfly $(\times 2)$, denuded of scales, right wings removed: $h$, head; 1, prothorax; 2, mesothorax; 3 , metathorax; $a$, abdomen; $w 1$, left fore wing; w 2, left hind wing; black w's indicate the points of attachment of right wings; ant, antenna ; $e$, eye ; $p$, palpus ; $m$, "tongue;" $c x$, coxæ of right legs; $t r$, trochanter of right hind leg; $f$, femur; $t$, tibia ; trs, tarsus or foot.

most exposed. This is a very different exterior from that of the sponge or the hydra: such animals, if exposed to the air, would soon die of evaporation, if from no other cause. This hard exterior is an adaptation to aërial life, as well as a protection against injury. This coat of mail in insects is an outgrowth from the skin, and is composed of a horny substance called chitin. It is very light and very tough, two important requisites in the armor of a flying animal.

Place the butterfly in its erect position, with the head away from you, and compare the right and left sides with reference to the arrangement of parts. Observe that the parts correspond, that the sides are symmetrical. Bilateral symmetry is the term used in zoölogy to designate such arrangement of parts. What animals have you seen that are not bilaterally symmetrical? 
Observe that there are three somewhat distinct regions in the body. These are named, in order, head, thorax, and abdomen.

Observe that the entire body is made up of rings or segments. How many segments are there in the thorax? In the abdomen?

Note now the external parts and appendages.

I. The Head. - 1. The long projections on the front of the head are antennce. These also have segmented structure. Study them with the aid of a lens, and count their segments.

2. The large hemispherical prominences on the sides of the head are the eyes, called also facets or compound eyes, because they appear under magnification to be made up of clustered simple eyes placed side by side.

3. The two more or less hairy appendages in front of and below the eyes are the labial palpi. Count their segments, and find their point of attachment to the head.

4. The coiled organ between the palpi is the sucking organ (or proboscis). Uncoil it: how many turns in it? Notice the permanent bend near the middle of it. Observing that there is no oral opening on the surface of the head, what structure will you expect to find within this proboscis?

With the microscope examine:-

1. A cross section of the proboscis. ${ }^{1}$

2. A tangential section of the surface (corneal layer) of the eye. ${ }^{2}$ Observe that the corneal layer seems to

1 To make the cross section, place the proboscis uncoiled in a split cork or between two pieces of elder or cornstalk pith, and, holding it firmly there, with a razor or a very sharp knife shave off thin sections at the end, shaving the holder and the proboscis together.

2 Cut a section from the surface of the eye. Holding the section with forceps by one edge, scrape out the dark-colored pigment from its inner concave surface. Place it on a slide, convex surface uppermost, and it is ready for examination. Use low power. 
be composed of many hexagonal corneas. Make a drawing of a portion of it as seen under the microscope. Count the corneas in a certain visible space. Estimate what part this space is of the whole corneal layer, and calculate the number of corneas in the whole layer.

II. The Thorax. - Note that the thorax is composed of three segments.

1. The small first segment, to which the first pair of legs is attached, is the prothorax.

2. The large second segment, to which the second pair of legs and the first pair of wings are attached, is the mesothorax.

3. The third segment, to which the third pair of legs and the second pair of wings are attached, is the metathorax. Owing to the consolidation of meso- and metathorax, the boundary between these segments may not be very plainly seen.

Observe that the thorax is in cross section more or less quadrangular, showing more or less flattened dorsal, lateral, and ventral surfaces. The dorsal surface is called the notum, each lateral surface a pleurum, and the ventral surface the sternum. The convenience of this notation will be seen in the ease with which, by using it, any part of the thorax may be designated. The upper or lower part of the prothorax may be referred to as pronotum or prosternum; corresponding parts of the metathorax, as metanotum or metasternum, etc.

Examine one of the legs. Note that it, too, is made up of segments, which, like those of the body, have a hard outer shell of chitin. Flex and extend, and study the action of the joints.

1. The first small segment, the one by which the leg articulates with the body, is the coxa.

2. The next is a very small quadrangular segment, not always easily made out, the trochanter. 
3. The next is the largest segment of the leg, the femur.

4. The next is a slender segment about as long as the femur. It is the tibia.

5. The remaining segments comprise the foot (or tarsus). Count these tarsal segments. Note what appendages are present, and on which segments. Examine the lower surface of these segments. Discover by what means the butterfly is able to walk on the lower surfaces of leaves.

Examine the wings, noting:-

1. Their action.

2. Their form.

3. Their overlapping.

4. Their covering of hairs and dust-like scales.

5. Their structure, - each a triangular expanse of thin membrane supported by chitinous veins. Find five principal veins starting outward from the base of a wing. These are named ${ }^{1}$ from front to rear, costal, subcostal, median, submedian, and internal. Their branches, when present, are called veinules or veinlets. The subcostal and median are branched in butterflies. The costal and internal are simple. The internal is often very short and inconspicuous in the fore wings.

Make a drawing of the butterfly as seen from one side, with wings closed, first arranging antennæ and feet in a natural position. Make a drawing of it as seen from above, with wings extended.

With the microscope examine:-

1. The foot.

2. A cross section of one of the larger veins of the wing.

Rub off a few of the dust-like scales of the wing, and examine, first with moderate and then with high power, -

1. A bit of the wing with scales attached.

2. A bit of the wing with scales rubbed off.

3. The detached scales. Draw.

1 See footnote, p. 87. 
III. The Abdomen. - Observe the form of the abdomen; its markings; the absence of lateral appendages. Count the abdominal segments, and, by bending slightly, observe how they are fitted together. Observe a longitudinal groove on either side of the abdomen. Just above this groove, in each segment, is the opening (more or less completely covered by scales) of a breathing pore (or spiracle).

Make a drawing of the abdomen, lateral view.

\section{THE DRAGON FLY.}

\section{(Diplax.)}

Haunts and Habits. - The young of the dragon fly lives in the water on the bottom of brooks and shallow ponds. The adults live in the air, and may be seen through the day, poised on glistening wings above the water, or darting hither and thither with great swiftness. The adults may be collected with a net, but some little dexterity will be necessary to catch the larger species. A small brown species (Diplax rubicundula), with amber-tinted wings, is abundant in most places throughout the interior, and is easily captured about wet meadows, and is a good example for class use. It is always well to collect a number of species for comparison. While collecting, observe:-

1. The places frequented.

2. The habit of flight.

3. The hours of flight.

4. The food sought.

The adult female dragon fly may sometimes be seen hovering low above the water, dipping the end of her abdomen occasionally beneath the surface, there depositing eggs. If captured unhurt, and held gently by the fore wings while the dipping is done artificially in a tum. 
bler of clean water, the eggs will usually be deposited there. They should be collected and taken home in water, and their development studied.

The young of the dragon fly are called nymphs. They are commonly found sprawling on the bottom of shallow brooks or ponds, or clinging to submerged trash or to aquatic plants. Easy marks of recognition are the wide head and thorax, very rudimentary wings, and a muchenlarged and armed lower lip, which covers the mouth as a shield. A water net will capture such as cling to submerged green plants. Those found in trash fallen in the water's edge may be raked ashore with the trash and picked up by hand, their active efforts to return to the water making them easy to find. All may be carried home in a small pail of water. They live upon aquatic insects ; and a supply of their insect food should be collected at the same time, and placed in the pail with them. A few strokes of a water net through a pool will usually catch a supply of suitable food. A few submerged green water plants should also be placed in the water with them, to furnish oxygen. The contents of the pail may be turned out into a bowl or other improvised aquarium at home, and there the nymphs will live and grow, and finally transform into adult dragon flies.

Study of the Adult. - Liberate a live dragon fly in a -closed room (it has no sting, and is in no way hurtful to man), and study its actions. Note:-

1. The position of its wings in motion and at rest.

2. The position of its legs.

If you can time its passage across the room, make an estimate of its speed in number of times its own length per second. Compare this with the speed of a fast horse reduced to the same terms.

Put a live dragon fly into the cyanide bottle, and as 
soon as it is thoroughly stupefied by the poison, but not killed, turn it out again upon a paper, and study its respiratory movements. Note the regular expansion and contraction of its abdomen, and search with a lens for

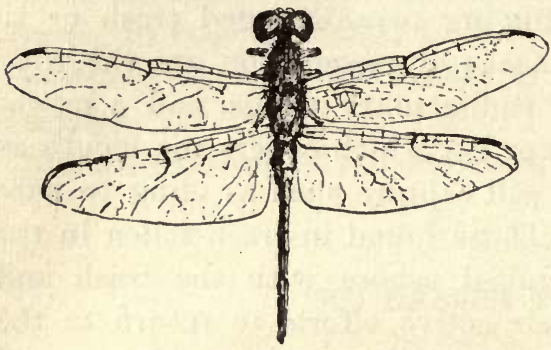

Dragon Fly (natural size). the minute openings of spiracles on each abdominal segment. Two larger spiracle orifices may be found on each side of the thorax.

Observe the spindle-shaped body; the rounded head, concave behind; the wide

thorax; the angled and tapering abdomen.

I. The Head. - Note the enormous development of the eyes.

Find a minute single eye (ocellus) above the base of each antenna, and another on the median line slightly farther forward.

Remove an antenna entire, and examine with a microscope. Compare with the antenna of a butterfly. Draw.

Turn to the mouth. Find an upper, movable lip (the labrum) and a larger, two-cleft, lower lip (the labium). Turn back the labrum and the labium, and find just beneath the labrum a pair of toothed, horny mandibles. Beneath. these find another pair of jaws, also working horizontally (the maxilloe). Remove a maxilla entire, and examine it, first with a lens, and afterward with low power of the microscope. Note that it is a compound organ, made up of a two-jointed basal portion bearing two terminal appendages. The inner appendage is the cutting or chewing part of the maxilla (the lacinia, or blade); the other appendage, standing behind or beside the lacinia, is the palpus. 
If these parts are difficult to see, compress a maxilla between two glass slips, and examine it under slight magnification. Compare this mouth with the mouth of a butterfly. To what method of feeding is this mouth adapted?

II. Thorax and Abdomen. - Find in thorax and abdomen all the parts as mentioned for the butterfly, noting these special points :-

1. The relative development of the thoracic segments. Which is smallest, and which largest?

2. The approximation of the legs. Why are the three pairs thus bunched together; i.e., what advantage is there to the animal in such arrangement?

3. The richly veined, naked, transparent wings. The costal vein is on the anterior margin of each wing, and the subcostal and median veins are parallel with it as far as the middle of the wing. There a stout cross vein (the nodus) crosses these three, dividing the wing in halves. On the costal margin beyond the nodus is a thickened dark spot (the wing spot, or pterostigma).

The close correspondence between the appendages of the dragon fly and those of the butterfly will have been noticed ere this by every student. That the legs and wings and other parts have essentially the same structure in the two animals, is very apparent. Had the origin of these parts been studied in the developing young of each animal, a similar correspondence would have been noted. When the parts of two animals show correspondence in structure and origin, such parts are said to be homologous; when they correspond merely in use, and not in either structure or origin, they are said to be analogous.

The legs of a butterfly are analogous with the cilia of a slipper animalcule, because both structures have similar use as locomotive organs; but they are not homologous. The wings of the dragon fly and of the butterfly are homologous, although very different in appearance; for they 
have essentially the same structure, - a double fold of membrane supported by chitinous veins, - and they are very similar in development.

Study of the Nymph. - Place a large nymph in a small dish with just enough water to cover it, and study it alive, with the aid of a good lens. Observe :-

1. Its sturdy form.

2. Its large eyes.

3. Its short antennoe.

4. Its enormous lower lip, covering the lower and front parts of the head. Seize the edge of it with fine-pointed

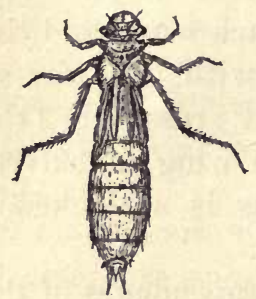
forceps, and pull it forward for examination. Note that it is so jointed to the head that it can be extended far forward, and quickly retracted. Note that it is two-lobed, that the lobes are triangular, that each bears an incurved hook at the apex, that each is toothed along its inner margin, and that the A Dragon-rly Nrmpr. whole is a very formidable grasping organ.

5. Its mouth, with well-developed mandibles and maxillæ inside the labium.

6. Its rudimentary wings. Compare with those of the adult.

7. Its well-developed legs. Compare them in position with the legs of the adult.

8. The regular expansion and contraction of its abdomen in respiration. Note the striking unlikeness of the respiratory methods in the adult and in the nymph. The adult lives exclusively in the air ; the nymph, exclusively in the water. Both must get oxygen from the air. Internal branching and intercommunicating air tubes, which open exteriorly at the spiracles in the adult, con- 
vey currents of air throughout the body. But the nymph must utilize the air which is in the water, mixed with the water, or held in solution by it. To get this air, the water is alternately drawn into the abdomen at the anal opening, and forced out again. In passing in and out, the water flows over a number of modified air passages, called tracheal gills, which are situated just within the anal opening. ${ }^{1}$ 'These tracheal gills have very thin walls, easily permeable by gases. They contain air to be purified. In respiration, osmosis (or exchange of gases through the thin walls of the tracheal gills) takes place; carbonic-acid and other noxious gases from the body passing out into the water, and oxygen from the air contained in the water passing in.

To prove the passage of water into and out of the abdomen, with a small pipette pass a fine stream of red ink or other colored fluid close by the anal opening, and see it alternately drawn and repelled by the water currents.

Keep some large nymphs half a day without food. Then put into the water with them an abundance of the inse̊cts they feed upon (such small ones as a net will catch in any pond), and observe how they capture, hold, and devour their prey.

Development. - The egg hatches, and a nymph comes forth. It is at first very small; but it eats voraciously, and grows rapidly. It develops a delicate chitinous coat; and when this gets too small, it splits down the back, and the nymph crawls out, and grows another of larger size. This molting takes place a number of times before maturity is reached. On the bottom of a vessel in which nymphs have been kept for some time, a number of empty nymph skins (exuvioe) may usually be found.

1 Some species have external tracheal gills. 
When the nymph is fully grown, it crawls out of the water upon some convenient rock or reed, and fastens its feet firmly, preparatory to the last and most remarkable transformation of all, - the transformation which fits it for an aërial life.

Keep some of the largest nymphs, supply them with proper food, and watch their final transformation.

Make a series of drawings of the egg, of nymphs of different sizes, and of the adult, of one species. This will be a pictorial life history of the species.

The dragon flies constitute the group Odonata.

\section{THE GRASSHOPPER.}

Haunts and Habits. - A large gray species, properly called the Carolina locust (Dissosteira carolina), is abun-

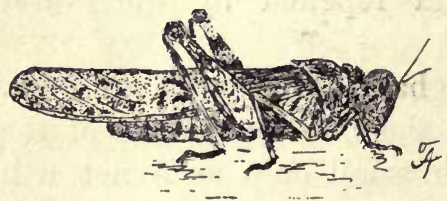

The Carolina Locust, Dissosteira carolina (natural size). dant by every roadside, and will serve well for class use. It may be recognized by its large yellow-bordered hind wings, exposed in flight. It may be taken with a net, and killed with a cyanide bottle. Nymphs will be found in the same situations as the adults. They resemble the adults quite closely in form, but are smaller, and lack fully developed wings.

Collect nymphs in all stages.

Collect adults of different species for comparison.

Collect for dissection a few of the very largest specimens obtainable, of any species.

Study in the field (for the Carolina locust) :-

1. Its protective coloring.

2. Its several methods of locomotion. 
3. The sounds (stridulation) made by some individuals (males) while on the wing.

4. Its hours of activity.

5. Its natural enemies.

6. The effect of temperature upon its activity. Go out some frosty morning for this purpose.

Place a live specimen under a tumbler, and study :-

1. Its respiratory movements. Observe the opening and closing of two lips that guard the entrance to a large spiracle just above the base of one of the middle legs. Find other active spiracles.

2. The size and arrangement of its legs in relation to the locomotor habits of the animal; which legs are most serviceable in walking, in leaping.

3. Its manner of feeding. Place some fresh leaves of clover or of lettuce under the tumbler with the insect, and watch it eat. If kept without food for half a day, it will eat greedily.

Liberate an active specimen in a warm room, and measure its longest leap in number of times its own length.

External Anatomy. - Observe the relative development of head, thorax, and abdomen.

Examine, as before, the upper parts of the head, eyes, ocelli, and antennæ.

I. Mouth Parts. - Study the mouth parts with especial care; for in the grasshopper all the typical mouth parts of an insect are present and well developed. Find, proceeding from the front:-

1. A large, two-lobed labrum.

2. A pair of toothed, horny mandibles, covered by the labrum.

3. A pair of maxilloe, jointed, compound organs, each bearing at its summit three appendages.

$$
\text { NEED. zoöL. }-4 \text {. }
$$


(a) The lacinia (or blade), the innermost part, the part used in biting.

(b) The galea, spoon-shaped, and covering the lacinia externally.

(c) The maxillary palpus, a jointed, tactile organ outside. Count its joints.

4. A two-lobed labium (or lower lip), bearing below a pair of jointed labial palpi.

5. A fleshy tongue, between and below the maxillæ.

Separate these mouth parts, and examine each with a lens. Draw.

II. Thoracic Segments. - Note the relative size of the three thoracic segments. Note their peculiarities of form, color, and surface markings. Locate their spiracles.

III. Wings. - Study the wings. Seize the fore wing by its costal margin, draw it forward, and fasten it at right angles to the body. Then in the same manner draw the hind wing forward. Note how it is folded. Compare the two wings in form, color, size, texture, position, and use. The dry, horny fore wings of grasshoppers are called tegmina. Find in one of the tegmina five principal veins, - costal, subcostal, median, submedian, and internal, - starting outward from its base. Observe that each of the tegmina is marked off into three areas, - the costal, median, and internal areas. The median area lies between the subcostal and submedian veins; the costal area, anterior to the median; the internal area, posterior to it.

Make an enlarged and accurate drawing of a tegmen, naming all the veins and areas upon the drawing.

It is by rubbing together the lower surfaces of the tegmina, and the upper surface of the costal vein of the hind wing, that the males of this species produce the sounds called stridulation, in flight. Examine these surfaces with a lens. 
IV. Legs. - Compare the first and second pairs of legs with the third pair, in color and surface markings, position, size, and use.

Find in one of the hind legs the usual segments, coxa, trochanter, femur, tibia, and tarsus. Note:-

1. The large club-shaped femur. Within it are the powerful muscles used in leaping.

2. The double row of spines on the sides of the tibia.

3. The two pairs of spurs at its lower end.

4. The tarsus. Examine its lower surface and the hooks at its tip.

What is the advantage of all these spines and hooks and pads?

Make an enlarged drawing (lateral view) of one of the hind legs in its natural resting position, naming all the parts in the drawing.

V. The Abdomen. - Count the segments of the abdomen as seen on the ventral surface. In the female there are eight, and in the male nine. The abdomen of the female terminates in an ovipositor, having four subequal points, which are used for making holes in the ground for the reception of eggs. The four points are repeatedly pressed together, pushed into the ground, and there separated, thus pressing the earth aside, until a hole is made of sufficient depth, when the eggs are deposited in the bottom. An elongated, bilobed, subgenital plate at the ventral surface terminates the abdomen of the , male.

Observe on either side of the abdomen a longitudinal groove, and just above it a row of evident spiracles.

Observe on either side of the first abdominal segment a semicircular depression, across which is stretched a thin membrane. This is called the tympanum, and is supposed to be an organ of hearing. 
Internal Anatomy. - Select for dissection large female grasshoppers, the larger the better. On the Western plains the lubber grasshopper (Brachystola magna), and in the South the American locust (Schistocera americana), will be obtainable, and will serve better than the Carolina locust, because larger. Have specimens freshly killed in the cyanide bottle.

Do not begin a dissection when tired or nervous, for eager eyes and steady nerves are necessary to success. Should you injure some one organ in the first dissection, and so not see it satisfactorily, make a special dissection to find it in another specimen.

Dissect the grasshopper on a shingle or bit of board. ${ }^{1}$ Place it back uppermost, and head from you. Spread the wings, and pin them so. Pin the last segment of the abdomen firmly to the shingle. With sharp, fine-pointed scissors, make a shallow cut through the skin of the abdomen, from the ovipositor forward, keeping some distance to the left of the median line, and continue the cut forward to the head along the thorax at the bases of the left wings. Then with forceps gently lift the right-hand edge of the skin above the abdomen, and look beneath it for a delicate, whitish vessel, the dorsal vessel, sometimes improperly called the heart. It is but a series of thinwalled chambers, into which the blood flows through lateral valves, and through which it progresses forward toward the head. You will find the colorless blood bathing all the internal organs. A microscopic examination of a drop of it will reveal its white corpuscles. The dorsal vessel lies close to the roof of the abdomen, is very liable to be injured in the opening of the skin, and may sometimes be best approached by a dissection from the ventral side. Make a second cut similar to the first, on the right of the median dorsal line of the body, and 1 Or under water, if preferred. See Appendix, p. 283. 
carefully remove the roof of skin included between the two cuts. Observe the thin, longitudinal muscle fibers lining the roof of the abdomen, and the heavy wing muscles completely filling the upper part of the thorax.

I. Tracheæ and Ovaries. - Press the body walls lightly outward, and observe the numerous white air tubes (trachece). Observe that the tracheæ arise from the spiracles; that their larger branches unite to form longitudinal passageways along the sides of the body; and that the smaller branches ramify throughout the entire body, conveying air to all parts. Observe a loose, whitish mass of these smaller branches now lying exposed in the abdomen, on top of other organs. Place a small portion of this mass in a drop of water on a slide. Cover it lightly with a cover slip, and examine with low power to make out:-

1. The branching tracheal tubes.

2. The spiral elastic fiber which is coiled around the wall of each to keep it open.

Two large and conspicuous yellow egg masses are usually present in the abdomen of the female. These contain many cylindrical eggs, piled like cord wood in ricks or in tierlike masses. Separate the two masses by pushing a dull instrument between them on the median line. Observe that each egg mass (ovary) has a white tube (an oviduct) leading down to the ovipositor. Carefully remove the egg masses, and pin back securely both free edges of the skin.

II. Organs of Digestion. - Study the digestive system. The alimentary canal, dark-colored and conspicuous, will be easily seen extending through the body lengthwise. Beginning at the mouth, make out the parts of it, together with the accessory organs, as follows:-

1. The mouth opens into an esophagus which extends upward into the head, then backward into the thorax, bending at right angles. 
2. The esophagus dilates posteriorly to form the ingluvies (or crop), a large food reservoir, and an important organ of digestion. Its interior surface is furnished with many ridges and conical processes which aid in comminuting the food.

3. On the sides of the esophagus lie the delicate, white, branching salivary glands. These communicate with the mouth by means of two salivary ducts that run forward along the sides of the esophagus.

4. The proventriculus (or gizzard) is the portion of the food canal next succeeding the crop. Between the two there is no separating constriction, such as there is in many other insects. The proventriculus has thick, muscular walls, also armed within for the comminution of food.

5. A circle of conspicuous appendages (the gastric coeca) marks the posterior boundary of the proventriculus. 'These are spindle-shaped appendages extending lengthwise of the food canal, and attached laterally, having both ends free. Each is, in fact, composed of two cone-shaped glands placed base to base. The function of these glands is to secrete a digestive fluid.

6. Posterior to these is the ventriculus (or stomach), hardly distinguished by its external appearance in the grasshopper from adjacent portions of the alimentary canal.

7. At its posterior end arises a circle of long, slender, inconspicuous tubes (the Malpighian vessels) which float free in the body cavity. Their function is urinary.

8. The remainder of the alimentary canal is the intestine. A study of the parts here disclosed will give a general idea of the digestive system for all insects.

Let us now review the digestive process. The food is first masticated by the mandibles and by the laciniæ of the maxillæ in the mouth, is acted upon by the secretions of the salivary glands as it passes from the mouth into the 
esophagus, is further comminuted and in part digested in the crop and gizzard, is acted upon by the secretions of the gastric cæca as it passes into the stomach, where digestion is in the main completed. The digested food passes out through the walls of the alimentary canal directly into the blood, which bathes all the organs, and supplies them with constructive material thus obtained from the food. The Malpighian vessels reach out into the blood and absorb from it noxious waste products of the body, which they pass along out through the intestine, together with the indigestible portion of the food. The blood gets oxygen, necessary for both constructive and destructive processes, by absorption of it (endosmosis) through the tracheal walls.

III. Nervous System. - Remove carefully the alimentary canal and its appendages, and look on the floor of the body cavity for a double nerve cord extending the length of the body, the two threads of it connecting on nearly every segment with a double ganglion (a little, roundish mass of nervous matter). Observe the nerve fibers that radiate from each ganglion. These go to supply nerve force to all parts of the body, and to supply nervous communication between the parts. Trace the double nerve cord to the head; then turn the head on one side, and pin it firmly there through the front; cut away the upper parts until you discover a large ganglion situated above the beginning of the esophagus, the cephalic ganglion (or brain). Observe that the double nerve cord begins here and passes one thread around each side of the esophagus to the first thoracic ganglion, and thence to the others of the system.

Development. - The development of the Carolina locust may easily be traced, if the specimens of nymphs collected alive are placed under a bell jar or glass dish, kept supplied with fresh clover or lettuce leaves and water, and 
watched. With no more apparatus than this, specimens may be reared from the egg to the adult condition. Since this would require much time, it is better for the student to get developing nymphs in as many sizes as possible, and keep them long enough to see different molts gone through with by different individuals.

Study the molting process, and by careful observations get at the answers to such questions as the following :-

1. Has the nymph, when first hatched from the egg, any wings? (Use lens in determining.)

2. Where does the nymph skin split open when molting occurs?

3. What part of the insect comes out first?

4. Does the insect have any difficulty in withdrawing any parts of its body from the old skin?

5. What signs that molting is about to occur are discoverable in the appearance or actions of the nymph?

6 What is the condition of the insect's exterior before molting, and after?

7. What organs are relatively best developed and what least developed in early stages, and for what organs has the newly hatched nymph most use?

Life-History Box. - Make a life-history box for the Carolina locust. Get a neatly lined cigar box, and mount ${ }^{1}$ in it a complete series of specimens from egg to adult, inclusive. The specimens should all be mounted on pins stuck in thin sections of cork glued fast to the bottom of the box. The eggs will need to be fastened with mucilage to a bit of paper, through which the pin may be thrust. The very smallest nymphs will need to be mounted in the same way. The larger ones will have the pins stuck vertically through the middle of the thorax. In addition to nymphs of all sizes, exuviæ should be mounted

${ }^{1}$ See note on mounting insects, in Appendix, p. 283. 
separately. One or two nymphs should also be taken while emerging from the exuviæ, killed in the cyanide bottle, and mounted in that condition. Then two adults of each sex should be included, - one of each mounted with its wings closed; another, with wings fully spread. All the specimens should stand two thirds of the way up the pins. Such a box is easily prepared. It tells the story of the development of the species. If the Carolina locust is not so easily obtained in full series as another species, any other grasshopper will do as well.

All the grasshoppers and locusts belong to the group Orthoptera (or straight-winged insects).

Other Orthoptera are crickets, katydids, walking sticks, mantes, cockroaches, etc. Some of these should be studied, and compared with the grasshoppers in size, in relative development of organs, in relative powers of locomotion, in food, in habits, in instincts, and in economic importance. A good general idea of the group will thus be obtained.

\section{THE SQUASH BUG.}

\section{(Anasa tristis.)}

Haunts and Habits. - This insect is an annoying pest of the kitchen garden. Adults, young, and eggs may all be collected from the same vines of squash, cucumber, or pumpkin. The adults are blackish brown above, and dirty yellow beneath. The nymphs are smaller, and relatively shorter and more rounded, than the adults. The eggs are laid in little clusters on the young leaves.

No net will be needed for collecting these

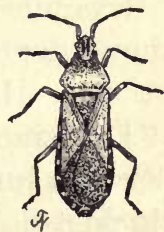

Squash Bug. bugs. They may be pushed directly into the cyanide bottle. While collecting, observe the following points. 
1. Their position on the leaf while feeding.

2. Their manner of feeding.

3. The effect of their operations on the leaf.

4. Under what conditions one leaf is ordinarily deserted for another.

\section{Study of a Live Specimen. - Study the adult.}

Examine the head with a lens. Note the position of its parts. Find eyes, ocelli, and antennæ.

Observe that the mouth parts are modified into a jointed proboscis (the rostrum). Count its joints. Note its position. At the base of the rostrum above is the rudimentary labrum. Mandibles and maxillæ are represented by two pairs of bristles within the sheath of the rostrum. The sheath itself is supposed to be the modified labium consolidated with its palpi. The whole rostrum is well adapted to making punctures, and to sucking up through them the juices of plants.

Observe for the thorax its shape and the relative development of its segments.

On the mesosternum at either side, near each middle coxa, find a small pore (an osteole) surrounded by a small granular space (the evaporating surface). From these osteoles is exuded the fluid which gives the squash bug its peculiar odor. This odor is protective, because it makes the bug a less dainty morsel of food for other animals.

Examine the legs. For what kind of locomotion are they adapted? Find coxa, trochanter, femur, tibia, and tarsus. How many joints in the tarsus?

Examine the wings. Observe carefully the difference between inner and outer halves of the fore wing, the former thickened and horny, the latter membranous and traversed by numerous veins. Compare fore and hind wings in form, size, texture, and position. Draw the wings of one side (enlarged). 
Make a life-history box for the squash bug.

The squash bug is a representative of the group Hemiptera (or half-winged insects).

Other Hemiptera. - All the "bugs," properly so called, belong in the order Hemiptera, together with plant lice, bark lice, tree hoppers, cicadas, etc. But two other types will be selected here for study.

\section{THE TWO-YEAR CICADA OR DOGDAY HARVEST FLY.}

\section{(Cicada tibicen.)}

Haunts. - This is the insect commonly but improperly called "locust." It may be found about shade trees in late summer and autumn. Its colors are black and green, powdered with white beneath. The adults may be followed by ear to their resting places $\bullet$ on the boughs of shade trees, their shrill cries being the most prominent and the best known of the various insect sounds of late summer and of autumn. The nymphs are seldom seen; but the exuviæ which they shed at their last molt are large, and conspicuous objects of common observation. They are found clinging

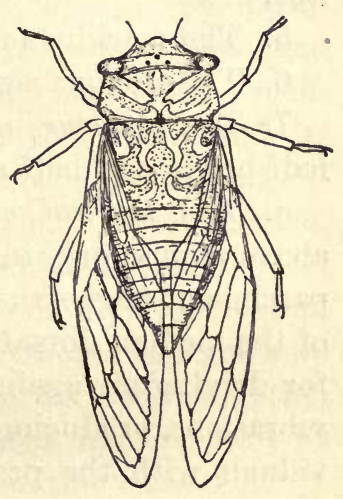

Two-Year Cicada. to weeds, bushes, trees, or fences in early summer. The eggs are laid in slits made in the twigs of trees. When hatched, the young drop to the ground and bury themselves, and feed upon the juices obtained by puncturing the roots of trees. Two years are required to complete their growth. The second summer following hatching, 
the nymph comes above ground, crawls a little way up a convenient reed or board, fastens its feet firmly, and is ready to transform. The skin splits down the back of both head and thorax; the perfect insect steps out, rests awhile, and expands and dries its wings, and then flies away with a noisy "whirr" to its new home in the tree tops.

Study of a Live Specimen. - Get an adult specimen for study, and observe:-

1. The shape of its body as a whole.

2. The point where the rostrum arises from the head.

3. The position of the eyes and ocelli.

4. The absence of any neck, and the consequent approximation of cheeks and coxæ of the anterior pair of legs.

5. The markings on the top of the thorax.

6. The sloping position of the wings.

7. The structure of the fore wings, - that they are not half horny and half membranous, but wholly membranous.

8. The musical organs at the base of the abdomen above (found only in the males), - two ribbed and plaited parchment bags situated in depressions, one on either side of the median dorsal line, provided with powerful muscles for driving air against the fluted surfaces. This sets up vibrations, producing sounds, which vary in different individuals with the proximity and form of the spaces and ribs.

If the large rostrum of the cicada be dissected, the two pairs of punctorial bristles will be easily found within the sheath.

Compare adults of cicada and squash bug with reference to shape of head; place of origin of rostrum; length of neck; structure, position, and method of folding, of wings. 
Get an exuvia of a cicada, and study it carefully. Do not fail to note how completely the hard, external skeleton, together with its internal projections, is shed. Compare it with the adult in form and relative development of locomotive organs.

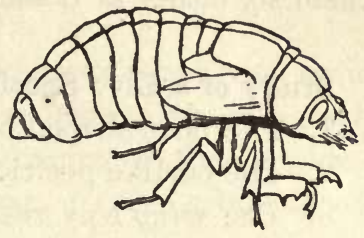

NympH of Harvest Fly.

\section{THE BACK-SWIMMER.}

\section{(Notonecta.)}

Haunts and Habits. - This insect is abundant in the pools of brooks and in ponds. It is a little over half an inch in length. It may readily be recognized by its inverted position in the water. It swims on its back, and

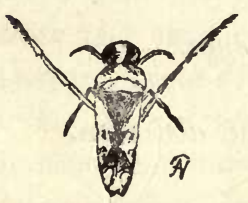

BACK-SWIMMER, Notonecta ( slightly enlarged). rests with its wing tips just touching the surface of the water, and its long hind legs poised forward and extended on either side. When startled, it darts away toward the bottom : but it will rise again immediately when it stops swimming, unless it holds to some submerged object; for its body, together with the air inclosed beneath its wings and between its thoracic segments, is much lighter than the water.

Back-swimmers are easily taken in a net. All stages will be found together. They may be kept at home in a bowl of water, and their habits studied. Care should be exercised in handling them, for they will sometimes inflict wounds with their sharp and strong rostrum. When it is necessary to take one alive with the fingers, it may safely be picked up by the sides of the body. Backswimmers present many interesting adaptations to aquatic 
life, and are especially worthy to be studied alive. Study them so, either at home or in their native pools.

\section{Study of a Live Specimen. - Observe :-}

1. The boat-shaped body.

2. The oarlike position and action of the long hind legs.

3. The wing tips reaching the surface, and admitting beneath the wings a supply of air, which may be breathed when the insect is at the bottom.

4. The thin layer of air surrounding the thorax (easily seen at the joints when the body is bended).

Place one on a dry surface: see it walk.

Throw an adult up into the air: see it fly. It can arise in flight direct from the water.

Study the external features in order, as outlined for other insects, noting especially :-

1. The junction of the head with the prothorax.

2. The position of the antennoe.

3. The shape, size, and position of the eyes.

4. The absence of ocelli.

5. The sharp, lateral edges of thorax and abdomen.

6. The hairiness of parts.

7. The form, size, and position of the legs.

8. The structure of the tarsi (use a lens).

9. The structure and position of the wings.

10. The relation between the spiracles and the air inclosed beneath the wings.

Then answer these questions :-

1. What advantages are secured to the back-swimmer by the peculiar shape of its body?

2. Need locomotive organs be more complex for progression in the water, or on the land? Why?

3. What other devices for aquatic respiration have you studied, and what points had each in common with the respiratory method of this insect? 


\section{THE BUMBLEBEE.}

Haunts and Habits. - A field of blossoming clover, or a fence row grown up with bergamot or other mints, is a good place to observe something of the habits of the bumblebee, - to learn something of its part in the economy of nature, which may not be so well learned anywhere else. A half hour spent in studying the bumblebee among the flowers from which it feeds may be made most profitable. It will not behave normally in confinement; but it will not resent

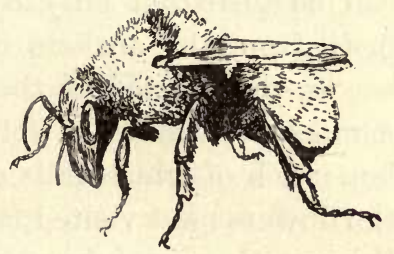

BUMBLEBEE (slightly enlarged). close scrutiny while free, and feeding from its favorite flowers, if it be approached quietly. Watch a bumblebee on a head of red clover. See how roughly it tramples over the tops of the corollas. Observe that it collects two products of the flowers:-

1. Nectar, from the bottom of the corolla tubes, which it stops momentarily to sip as it passes over. Note the position and shape of the organ used in sucking up the nectar.

2. Pollen, the yellow dust which falls from the anthers of the flowers when they are shaken. This is collected into the pollen baskets on the hind legs. The yellowish lumps of pollen will be conspicuous on some of the individuals seen.

Note whether the bumblebee visits one species of flower, or several, in a single trip out from the nest. Follow one from flower to flower, until you ascertain what is its habit in respect to this.

What other insects have you studied that feed upon red clover? The life of quite a number of very common 
insects and other animals is more or less dependent on red clover. The bumblebee is an animal on which the life of red clover is more or less dependent. The bumblebee gives value received for all the nectar and pollen it takes from the clover.

Clover must produce seed, or soon die out. The flower must be fertilized in order to produce seed. The flower can be fertilized only by means of pollen carried to its pistil from the anthers of another flower. The bumblebee is the carrier of the pollen. Its rough-and-tumble manner of feeding is well adapted to dislodging the pollen, much of which falls on its body, and is scattered over the flowers next visited, securing their fertilization. Thus the insect's wasteful method of gathering the pollen is seen to be exactly adapted to the requirements of the plant.

Spray a bumblebee with water, and note the effect on its power of flight. What becomes of one when caught out in a shower?

Compare a bumblebee with a butterfly in :-

1. Speed and directness of flight.

2. Relative size of body and wings.

3. Rapidity of wing strokes.

Catch a bumblebee in a net, and observe that the pitch of its humming when captive is higher by several tones than when free. Why? Collect with net and cyanide bottle a few large specimens for use in studying its anatomy.

External Anatomy of the Adult. - Study carefully to make out the parts, as mentioned already for other insects. The same parts are present, and in the same relative,positions, but modified to meet the needs of an animal of different life and different habits.

I. The Head. - Make a drawing of the head as seen from above, showing accurately eyes, ocelli, and antennæ. 
Study the mouth parts, observing another modification and arrangement of them, as follows :-

1. A short, firm labrum.

2. A pair of strong, horny, biting mandibles.

3. A proboscis (or sucking organ), bent backward at the middle, and resting against the lower surface of the head and thorax when not in use, and composed of -

(a) A long, hairy, tubular ligula (or central piece) of the labium (centrally).

(b) Two margined blades of the maxilloe (above).

(c) Two thin, narrow, elongated labial palpi (below). Separate, and examine these parts with a lens. Draw.

II. Wings and Legs. - Compare fore and hind wings in form, size, and position.

Draw the fore wing forward by its costal margin, and observe that the hind one moves with it. Find the little hooks (hamuli) which hold the two together, securing their unity of action.

Find coxa, trochanter, femur, tibia, and tarsus in one leg of each pair. How many segments in the tarsus? Which segment of the tarsus is largest? On which segment of the hindmost legs are the pollen baskets? Observe with a lens the surfaces to which the pollen masses adhere, and the means by which they are protected in position. Make a detailed drawing of a hind leg.

III. Thorax and Abdomen. - Study the attachments of both wings and legs of the hindmost pair, to ascertain the posterior boundary of the thorax and the beginning of the abdomen. Scrape off the hairs from the top of the thorax, and observe that the metathorax is a narrow segment (antero-posteriorly); and a wider segment without appendages, the first abdominal segment, is solidly welded to it. The second segment of the abdomen is but a short and narrow stalk-like ring, attaching the ovate hinder portion of the abdomen. Note how the abdominal 
segments are fitted together, and how great freedom of movement is secured by this arrangement.

At the posterior end of the abdomen the slender point of the sting may be seen protruding. Seize it with forceps, and pull it out full length. Examine with low power. Observe that it is hollow. Find the poison glands at its base. The sting itself makes but a slight puncture, which would hardly be noticed by the larger animals were it not for the poison poured from these glands into the wound. These, together with the great mobility secured by the structure of the abdominal segments already noticed, make it a formidable weapon of defense.

Development. - The development of the bumblebee may be studied throughout in a single well-stocked nest. Find a bumblebees' nest, and take it with all its occupants. This will not be hard to do in summer or autumn. Two methods are recommended :-

1. Having located the nest, go out for it after sunset or before sunrise, when all its inhabitants are "indoors." Pour chloroform or ether into the nest. Wait a moment for the bees to become stupefied. Then take up the nest entire, keeping the chloroform or ether at hand, ready to be dashed into the nest should the first not have been sufficient. But little of it will be required, if judiciously administered. Care should be exercised, in taking up the nest, to keep it in good shape for further study of its structure and arrangement.

2. Another method, and one by which the nest may be taken during the day, is the following: Set a clean jug, uncorked and with some water in it, close by the nest. Then disturb the nest (if possible, without injuring its structure), and retire to a good place from which to watch. The bumblebees will attack the jug, and then 
fly into it and get into the water, where they must remain. When all have gone into the jug, or settled, disturb the nest again. Repeat once or twice. Then all those of the occupants which have been accustomed to defend the nest will be in the jug; and the few remaining may be sprinkled with water, and picked up while wet and unable to fly, or caught singly in a net. Obviously, the entire population of the nest will not be caught in this way, for in the daytime some are absent foraging in the field. Why do the bumblebees go into the jug?

Whatever the method of taking the nest, all its occupants, as well as the nest itself, should be preserved for future study. The bumblebees will not all be killed at once by either of the methods suggested; but they may be killed in alcohol or in a cyanide bottle. Those taken in a jug may be poured out with the water, and picked up with forceps before their wings have dried.

Study the adult bumblebees found in the nest. Find among them four sorts of individuals :-

1. Numerous small ones, built for activity, - the workers (undeveloped females).

2. Others of larger size, but of the same general shape as the workers, - the small females.

3. Others about the size of the small females, or somewhat larger, but thicker, clumsier, and more hairy, - the males (or drones).

4. A few very large ones (an inch long), the large females (or queens). Until late in the season, but one of these will be found in each nest.

The Nest. - Study the nest. Note:-

1. The location of it.

2. The materials used in its construction.

3. The structure of it.

(a) The entrance to it. 

(b) The passageways inside.
(c) Its roof: will it shed water?
(d) Its floor.

Within the nest find : -

1. Yellowish food masses of mixed pollen and honey, containing -

(a) Small clusters of white, oblong, or elliptical eggs.

(b) The young which have hatched from other eggs, white, wormlike creatures of various sizes, feeding on the pile of common food.

2. Cells:-

(a) Standing open, like yellow pots (or sometimes filled and closed), containing stored honey.

(b) Capped over, and containing young.

Within the nest may often be found some of the smaller insects, which are parasites of the bumblebee.

Life History. - Here in the nest is disclosed the life history of the bumblebee. In its life there are four stages.

The first stage is the egg.

The second stage is the wingless, footless, wormlike creature which we call the larva. The larva is very small when it emerges from the egg, but it grows rapidly, for its sole business is eating; and. when it is fully grown, it spins a silken cocoon about itself and enters upon the next stage.

The third stage is the pupa. In the pupa stage it remains quietly concealed within its cocoon, over which the workers spread a thin layer of wax, making a cell out of it. But though inactive, very important changes are taking place in the pupa; for when, after a time, it cuts a way for itself through the top of its cell, it comes forth, not the wormlike larva which went in, but a fully developed bumblebee. 
The fourth stage is the imago, the adult bumblebee.

Select one of the largest larvæ for comparison with an imago. Note their resemblances and their differences in structure.

Open a number of the cells, and examine the pupæ contained in them. Observe the gradual evolution of the perfected organs of the imago. Since the adult partakes only of soft food, what use has it for horny, biting mandibles?

Make a series of drawings showing the life history of the bumblebee. ${ }^{1}$

Compare the transformations of the bumblebee with those of other insects studied. When, as with the bumblebee, there are four stages, —egg, larva, pupa, and imago, the metamorphosis is said to be complete. When, as with the grasshopper, there are but three distinct stages, - egg, nymph, and the perfect insect, - with no pupal or resting stage and with greater likeness to the adult in the second stage, the metamorphosis is said to be incomplete.

The History of a Colony of bumblebees, that is, of a single nest and its occupants, is about as follows: In the spring each colony is founded by one of the adult females (or queens) which alone survive the winter. Such may be seen in spring, searching the meadows over for a place to establish a nest. When proper food flowers open, each bumblebee takes possession of a suitable bunch of dried grass, or preferably of an old mouse nest, and carries into it pollen and honey, and deposits beside the food a few eggs. All the work of providing food and shelter, and of caring for this first brood, is done by the queen. 'The bees of this first brood are workers, and as soon as they come forth from their pupal cells they assume most of the

1 In its preparatory stages, the insect is best preserved in alcohol. For a suggestion as to the use of alcohol, see Appendix, p. 277. 
duties of the colony, the queen continuing to lay eggs, and the colony growing rapidly in numbers. In midsummer a brood is produced of small females and males. The broods of autumn produce only large females (or queens), and only these survive the winter. With the coming of cold weather, all others perish.

A study of the life of a colony explains the scarcity of bumblebees in spring and early summer. Considered in connection with their fertilizing agency for red clover, it explains the scarcity of seed in the first crop, and gives a reason why the second crop (the late crop) is always the one to be cut for seed.

The bumblebee is a representative of the group Hymenoptera (or membrane-winged insects).

Other Hymenoptera are ants, bees, hornets, wasps, sawflies, gallflies, etc. The three mentioned below are perhaps most easily procurable.

\section{THE MUD WASP (OR MUD DAUBER).}

The Mud Wasp is a solitary hymenopter. The adult female lives and labors alone. The nests may be found

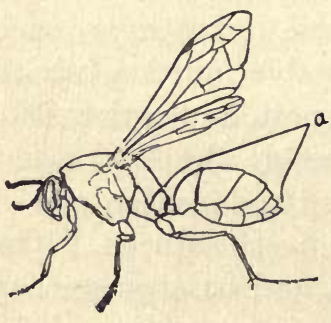

Outline Drawing and DiaGRAM OF A WASP (wings and legs of right side not shown): $a$, abdomen. in abundance, adhering to the rafters in any barn loft or woodhouse attic, and are too familiar to need description.

In very dry weather in summer or autumn, the adults may be observed by any krookside, at the edge of the water, rolling up little balls of mud and flying away with them. The same operation may often be seen beside a well 
where water has been spilled, converting the dust into mud. The peculiarities in the flight and walk of the wasp may be studied in such places; and specimens for study may easily be taken with net and cyanide bottle.

Study the external anatomy of the adult, noting the development of all the parts, and especially of the mouth parts and the first three abdominal segments.

Study of a Live Specimen.- - Go into loft or attic, or other place where these insects are building their nests of mud, and watch them at work. They will not sting unless much molested, and they seem to have little objection to being watched. Find one that is bringing in a ball of mud, and follow it to its nest. Observe :-

1. How the ball of mud is carried.

2. How it is deposited and worked into place.

3. The peculiar sound the wasp makes while at work, and how this sound is made.

4. The position and attachment of the nest.

5. The arrangement of its cells.

The nest may easily be removed, when the old wasp is absent, by pushing a knife blade under it. Study the development of the insect as shown in the contents of the nest. Examine the contents of all the cells. Their walls may easily be cut away with a knife. Find :-

1. A cell or cells unfinished, and containing at the bottom a single egg.

2. Cells uncapped, and partly filled with little spiders or other insects. These are for the food of the larva that will hatch from the egg in the bottom of each cell. Note the condition of the spiders, - not dead, but paralyzed. A number of days elapse after they are put into the cell before the larva is ready to eat them, and they would decompose if killed outright. The mother wasp stings them in such a manner, that they are only paralyzed, and remain 
alive but inactive till wanted, - a wonderfully successful way of providing her offspring with "fresh meat."

3. Cells in which there is a larva feeding on the spiders.

4. Cells in which the spiders have all been eaten (save their skins, which are pushed to the bottom of the cell), and in each of which there is a larva fully grown, or perhaps transformed into a pupa, and lying quiescent within its thin brown pupa skin.

5. Other cells showing a gradual approximation to the adult form.

6. A cell from which an adult has just emerged; leaving pupa skin and spider skins behind in the cell.

If all these stages be not found in a single nest, several nests should be examined. Is the metamorphosis of the mud wasp complete, or incomplete?

\section{THE PAPER WASP.}

The Nest consists of a single tier of gray, papery cells opening downward, and attached above by a short stalk to the eaves of a building, or to a fence, or to the horizontal twig of a small bush. This description ought to be sufficient for identifying so common an object. The adult wasps are always found upon the nest. It is an easy matter to obtain the nest, not so easy to get all the wasps.

Get a nest. It may be detached with a long pole. When it falls, all the adult wasps leave it. Should it be a large and heavy nest, located high above a hard surface, some soft material, as straw, should be placed below it to break its fall; otherwise many of the cells will be injured.

Study the nest.

I. Construction. - Note the size, shape, and position of its cells, and the attachment of its stalk. Draw.

II. Material. - Examine with a lens the paper of its cells. It is made from fibers of wood torn from boards 
and splintered trees. The fibers are treated with salivary secretions, and reduced to a pulp in the mouth of the wasp. The pulp is then fashioned into cell wall, where it quickly dries and hardens. How is paper made from wood in paper factories?

\section{Contents :-}

1. Is there any food stored in it?

2. Where is the egg placed in the empty cell?

3. Is the larva shut up with a store of food, or given food as it needs it?

4. At what stage in the life of the young is its cell capped over?

Study the metamorphosis, as before directed for the mud wasp, and make a serial drawing showing its life history.

\section{THE HONEYBEE.}

The Honeybee is the best known of the Hymenoptera. It may be sought wherever there are flowers.

Make a study of its foraging habits and of its structure, following the directions given for the bumblebee. Then get a bee-keeper friend to show you through a movableframe hive in his apiary. Ask him to show you the solitary female called queen, and the clumsy males called drones. Ask him about the swarming habits. If you have not this privilege, then read in Quinby's "New Bee Keeping," or Professor Cook's "Manual of the Apiary," the chapters on the natural history of the honeybee.

The Comb. - Examine a piece of empty honeycomb, and note :-

1. The shape and arrangement of the cells on one side.

2. The meeting, at their bases, of cells on opposite sides of the comb. What mechanical and economical advantages do you discover in such construction? Does this 
INSECTS.

indicate high or low rank in the insect's instinctive endowments?

Compare together all the Hymenoptera studied.

Which eat animal food? Which vegetable? Which both?

Which live in the largest colonies?

Which show the highest instincts in the construction of their nests? In the care of their young? In the division of labor in the colony?

Which are the best walkers? Which are swiftest of flight?

Which are of most importance to man?

Compare as to the relative development of all the parts.

If the paper wasp bites wood, and the honeybee bites nothing harder than wax, which should you expect would have the stronger mandibles? Is it so in fact? Have you discovered that there is a similarly close relation between the structure of all organs and the work they have to do?

\section{THE BLACK BLISTER BEETLE.}

\section{(Epicauta.)}

Haunts. - This beetle is very common in autumn, and is very easily collectible. It will answer well for class

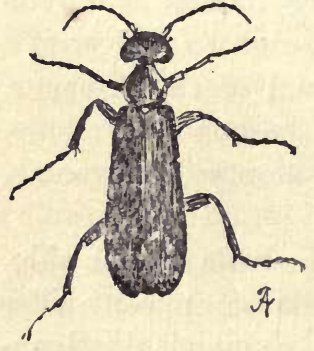

Black Blister Beetle (Epicauta), $\times 2$. use, though a larger species, if available, might be more satisfactory for a first examination. It is narrowly oblong in outline, uniform jet black in color, and is found on the flower clusters of goldenrod, thoroughwort, and ragweed, and not infrequently on the vines of potato, tomato, and clematis. In some localities this beetle is replaced by re- 
lated species, which resemble this one closely in size and form, but which are variously striped. These are all blister beetles.

Blistering Property. - In collecting and studying them, they should be handled with forceps and needles, and not with the fingers; for, when handled, there exudes from the joints of the abdomen a yellowish fluid secretion containing cantharidin, and possessing the power of blistering the skin when coming in contact with it in sufficient amount. This property is retained even when the insects are dried, making them valuable to the apothecary.

Collecting. - A bottle is all the apparatus needed for collecting this insect, - an empty bottle for live specimens, or a cyanide bottle for dead ones. They may be pushed from the flowers or leaves directly into the bottle with its stopper.

Study the Live Insect. - Observe the nature and extent of its injury to the plants on which it feeds. Has it any competitors for the food these plants supply?

Observe the action of its wings. Pick up with forceps a live specimen by an antenna, and observe how it opens and uses its wings. Put it down again, and observe how it folds them up.

Study specimens from the cyanide bottle.

External Features. I. The Head.-Observe that the head is narrowed behind, to form a sort of neck at its junction with the prothorax.

Observe the size and position of eyes and ocelli.

Examine an antenna, and study its structure and action. Draw.

Find in the mouth parts labrum, well-developed mandibles, maxillæ with prominent palpi, and labium with 
shorter palpi. Separate and draw. For what kind of feeding is this mouth adapted?

II. The Thorax. - Note the relative development of the thoracic segments. Which is largest? Observe the contour of the surface of the thorax at the junction of the legs and of the wings with the body. The cavities into which the coxæ are fitted are called the coxal cavities. The coxal cavities of the fore legs are open behind; i.e., not surrounded posteriorly by the thoracic wall.

III. The Legs. - Examine the legs. Flex and extend them, and observe the action of the joints. Find in each, leg coxa, trochanter, femur, tibia, and tarsus. How many segments in the fore and middle tarsi? How many in the hind tarsi? Which segment of the hind tarsi is largest? Observe that the two claws of each tarsus are cleft to their bases, and appear as four claws.

IV. The Wings. - Lift the chitinous sheaths (wing covers or elytra) which meet by smooth edges along the median dorsal line, completely covering the posterior part of the body.

Extend them at right angles to the body, and examine the wings. Observe how they lie folded. With forceps seize a wing by its costal margin, and draw it forward. Observe how it opens automatically when drawn forward. Compare this method of folding with that already studied in the grasshopper.

V. The Abdomen. - Study the abdomen. Compare upper and lower surfaces. Count the segments. Compare this abdomen in form and structure with that of the Hymenoptera studied. Why has the beetle less need for flexibility in this part than the bee?

Development. - From July to October inclusive, the eggs of the black blister beetle are laid in masses of more than a hundred in shallow excavations in the soil. The 
warm, sunny locations frequented by locusts are usually chosen. The eggs are usually covered lightly with earth, and are left to hatch.

The metamorphosis of blister beetles is very peculiar and exceptional. An active larva (triungulin), with good legs for getting about, is hatched from the egg. It runs about, searching the ground over for a buried cluster of locust or grasshopper eggs. At this stage it possesses great powers of endurance, being able to live a fortnight without food. If successful in finding an egg cluster, it settles down, and begins to eat the eggs. After two molts, it becomes a heavy, footless larva. After several additional molts, and after attaining its growth, it quits the remains of the egg cluster, goes deeper into the soil, and transforms into a pupa. Later it emerges as the imago already studied. For a full account of the transformations of this and of other blister beetles, read the articles by Dr. C. V. Riley, in Vol. XII. of the "American Naturalist."

If eggs of the blister beetle, and also the locust eggs on which it feeds, can be found and suitably placed, all the transformations may be seen taking place in the course of a few weeks.

This insect is a representative of the group Coleoptera (or sheath-winged insects).

No. 1.

Other Beetles. - Perhaps no other beetle is so easily obtainable in autumn, in supply sufficient for class use, as the black blister beetle; yet, lest it should not be found when wanted, cuts of four other common beetles, which will answer equally well for study here, are subjoined:-

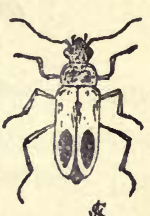

Soldier BeEtle (Chauliognathus).

No. 1 is a soldier beetle, closely resembling the black blister beetle in structure, and frequenting the same haunts. It is yellowish brown in color above, with a 
large black spot on each elytron, and another on the pronotum. It is found on the flower clusters of many

No. 2.

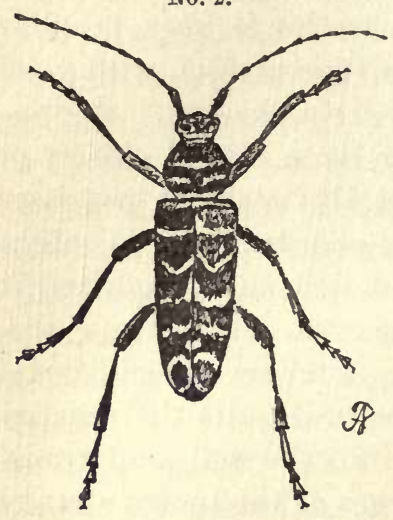

Compositoe, and may confidently be looked for on thoroughwort ${ }^{1}$ blossoms.

No. 2 is an elegant black beetle, beautifully banded with yellow. It is often found in the clusters of goldenrod, or on the leaves of locust trees, in which it deposits its eggs.

No. 3 is a brick-red beetle, with round, black spots. It is found singly, or a very few together, on the leaves of the LOCUST BORER BEETLE (slightly larger species of milkweeds. ${ }^{2}$ enlarged).

No. 4 is a smooth, black beetle, with polished head and prothorax, and striated elytra. It is often seen running about brick walks in No. 4.

No. 8.

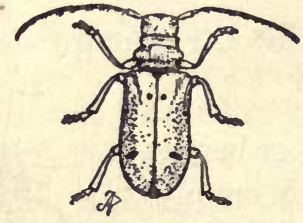

Red MrLkweed Beetre, Tetraopes (natural size).

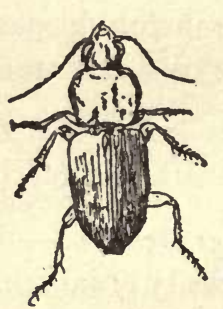

harpalus Beetle (slightly enlarged).

damp weather, and is nearly always to be found by overturning boards, logs, stones, etc.

Situations for Collecting. - Beetles are found everywhere, and are easily recognized by their elytra and
1 Eupatorium. 2 Asclepias. 
biting mouth parts. A number of the common forms should be studied and compared, in order to get a good general idea of the group. A number of species, both large and small, are attracted by a light at night. If a strong light be placed in a window, they may be expected on the screen outside, together with swarms of moths and other insects. Beetles are very commonly found under the bark of logs and stumps and in decaying wood. They may be found along a railroad track, under discarded "cross-ties" or "sleepers." Some gayly colored little beetles are found on flowers; others are common in shallow ponds, where they may easily be taken with a net. These are among the most interesting and attractive of aquarium specimens. "Whirligig beetles" may usually be found on the surface of still water, gyrating in large companiès.

Study a number of the most diverse forms obtainable, following the outline given for the black blister beetle. Then make a comparative study of the structure of all the beetles collected.

Other common larval forms may be found, as "grubs" and "wire worms" in the soil, and as "borers" in wood. Some larvæ may easily be dug with a strong knife from a well-rotted log or stump.

Pupæ will often be found in similar situations.

Test of Strength. - Select one of the stoutest-looking live beetles to be found, and make this simple test of its strength: Mold a saddle of stiff putty that will just fit over its back without interfering with the action of its legs. Hollow this out above, and pour shot into it. Make the load all that the beetle can walk away with. Then, with delicate scales, weigh the load, and also the beetle. If a man weighing one hundred and fifty pounds were as strong in proportion, how much could he carry? 


\section{THE BLUEBOTTLE FLY.}

\section{(Lucilia coesar.)}

Characteristics. - This is the loudly buzzing fly that gets into our pantries and cellars. Its body, especially its abdomen, is of a brilliant bluish-green color. It is larger than the common house fly, and therefore better for a first examination.

If a bit of fresh meat be exposed out of doors in warm weather, in a very few minutes a number of these flies will be attracted to it. They may be taken with a net.

Study of a Live Specimen. - Note the sound of their buzzing in ordinary flight. Then catch one, and, being

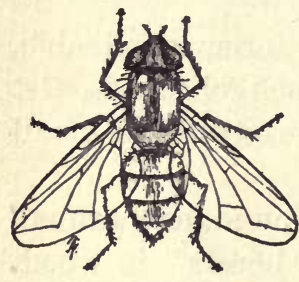

BLUebotthe FLy (Lucilia cresar). careful not to disable it in any way, hold it by the feet, leaving its wings free. Note that the buzzing is in a higher key. Then hold both wings and legs so that neither can move, and note that the sound still continues, and that the pitch is again raised. This last sound is probably produced by vibrations set up in the spiracles by manipulation of the currents of air.

Study its feeding habits. It is not shy: it will eat freely from a bit of meat held with the fingers. Watch it with a lens. Study the appearance and action of its proboscis. Observe that it is somewhat two-jointed; that the first joint is somewhat retractile into a cavity in the base of the head; that the second joint folds up on the first with a hingelike action when not in use; and that the second joint ends in blunt expansion, which consists of two flaps, that are separated in feeding, and applied to the surface of the food. 
The action of these flaps may be studied under the microscope. For this purpose the common house fly is better, being smaller. Proceed as follows: Wet one side of a large crystal of granulated sugar, place it on a slide, and let it dry fast. Place the slide on the stand of the microscope, blocking up one edge at a decided angle. Focus on the crystal of sugar with the lowest power of your instrument. Take your apparatus thus prepared into a room, or other place where there are many hungry flies, and wait for one to alight on the slide, and apply the opened leaves or flaps of the end of its proboscis to the sugar. Focus carefully, and record your observations on the action of this part.

Examine a bluebottle fly that has been freshly killed in a cyanide bottle.

External Anatomy. - Observe the general contour of the body, the shortness of the abdomen, and the specialization of the thoracic region.

Note the shape of the head, the freedom of its movements, the position and size of the eyes and ocelli.

Find the short antennæ. Remove one, being careful to get it off entire, and examine it with the microscope. Find in it six segments, as follows:-

1. A small subquadrate first or basal segment, bearing on one side, near its base, four conspicuous bristles.

2. A roundish second segment, bearing one stout, straight bristle, and a number of smaller ones.

3. A large, oblong segment, much the largest in the antenna, its surface sprinkled with minute pits and hairs. This segment at first appears to be terminal, but it is in fact much produced laterally.

4. Two minute segments, attached near the base of the third segment, and forming a sort of pedicel for the terminal segment.

NEED. ZOÖL. -6 
5. The terminal segment, which is expanded into a long, feathery tip. Draw.

Mouth Parts. - The study of the mouth parts is not so easy. The parts, being soft, are difficult of separation. That they are all combined into a sort of proboscis has been seen already. The sheath of this proboscis consists of labium and labial palpi, grown together, and split down the median line of the second joint of the proboscis in front. At its tip are the two flaps already noticed. The structure of this tip may be studied as follows: Kill a fly in the cyanide bottle, and at once cut off its head. Place the head flat on a slide, face upward, and apply pressure to the center of the head with the point of a pencil. This will cause the proboscis to expand fully. When so expanded, apply a drop of turpentine and a cover glass to its tip, and fasten the cover glass down with a clip before removing pressure. The inner surfaces of the two flaps will be fully exposed, and may be studied at leisure. Observe the nearly parallel ridges on these surfaces. Observe that they run transversely. Consider, then, that the proboscis is moved backward and forward in feeding, and you will see that the structure of these parts explains their action, and that the rasping, back-and-forward motion utilizes the rasping surfaces formed by these transverse ridges. Draw.

Within the sheath of the proboscis there are two small, elongated organs, one above the other, channeled along their inner faces, making a tubular passage, through which food is sucked into the pharynx. Mandibles are wanting. Maxillæ are represented by rudimentary, one-jointed palpi, which arise from near the middle of the basal joint of the proboscis.

Thorax, Abdomen, and Appendages. - Observe the shape of the thcrax, and the extreme specialization of its middle 
segment. Remembering that the top of the thorax contains the wing muscles, can you see any reason for the specialization of the mesothorax, and for the suppression of the other segments?

Observe the shape, size, position, and texture of the single pair of developed wings. Observe that these are produced backwards at their bases in two short membranes (the alulets). Draw.

On the sides, half concealed by the alulets, find a pair of knobbed, threadlike appendages (the halteres, or balancers). Observe that these spring from the narrow metathorax. They represent the second pair of wings. Remove, examine with low power, and draw.

Observe the size and position of the legs. For what kind of locomotion are they adapted? Examine one with a lens, to find the usual parts. How many segments in the tarsus? Observe the two claws at the end of the terminal segment, and the pulvilli (or sucking disks) beneath it. It is by means of these pulvilli that a fly walks up a windowpane or across the ceiling. Count the segments of the abdomen externally visible. Three terminal segments are withdrawn within the end of the abdomen, and concealed like the small joints of a spyglass within the large one. Search the sides of both thorax and abdomen for spiracles.

Development. - The development of this insect can be watched with less time and trouble than that of almost any other; and, although its early environment is far from being attractive, it teaches an important lesson in the economy of nature. We cannot know the important place this fly fills without knowing something of its larval life. This is true of all insects.

The eggs of the bluebottle fly are laid on flesh, ordinarily on the carcasses of animals that have fallen 
in the woods and fields, - and the larvæ hatched from them are popularly known as maggots. These render great service in the speedy removal of offensive substances.

The developmental changes may be studied without discomfort, as follows: Expose out of doors a bit of lean meat, so that the eggs may be laid upon it. Fill a flowerpot or tin can or small box with sand, and on a chip in the center of it place the bit of meat with the eggs on it. Invert a tumbler over it, and push the rim of the tumbler down into the sand. This will prevent the escape of offensive odors, should such arise; and the whole can easily be arranged so that the developmental changes may be witnessed through the glass. In a few hours the eggs will hatch, and in a few days the larvæ will be fully grown. They will probably crawl beneath the chip or into the sand, to transform into pupæ. Upon the disappearance of larvæ, the oval pupæ may be looked for. They may transform speedily, or may continue as pupæ through the winter, according to the temperature and the season.

The bluebottle fly is a representative of the group Diptera (or two-winged insects).

Other Diptera in general may be recognized by their having but one pair of developed wings. They are always and everywhere abundant except in winter. Many beautiful and interesting species will be found about the flowers of autumn. The following illustrative form is recommended for further study here.

\section{THE BEE KILLER.}

(Asilus.)

Characteristics. - This is the dust-brown insect that flits by our path in summer and autumn with such sudden and high-pitched sound of wings. This sound 
alone, once heard, is sufficient for recognition of the insect. It is one of the largest and fiercest of our Diptera. It is an inch or more in length. It feeds principally on honeybees, pouncing upon them with great swiftness while on the wing. It frequents dry pastures where bees are feeding. It is oftenest seen when startled from its resting place upon a stick or stone beside our path. It may be captured by dexterous

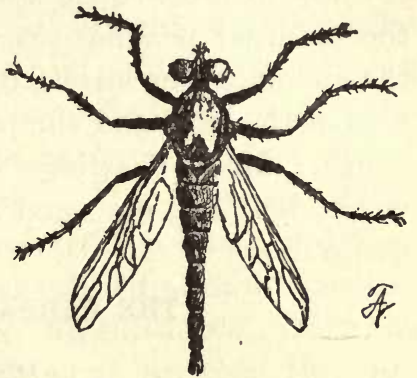

BeE KILLER, Asilus (natural size). use of the net. It should be introduced into the cyanide bottle without handling, for its beak is powerful enough to wound the fingers.

Study of Live Specimens. - Having flushed a bee killer from its resting place, it may be followed at a proper distance, and something may be seen of its predaceous habits. Take time, while in the field collecting, to observe :-

1. The character of its flight as to speed, directness, etc.

2. The length of time spent on the wing at one flight.

3. The course of its flight. After one of its swift sallies, does it usually return to the same resting place from which it started out, or to a new one?

4. The purpose of its flight. Does it seem to be intent on catching a bee at every flight, or does it sometimes seem to fly for sport?

5. Its feeding habits. Try to see one catch a bee and carry it away to be eaten. Wait quietly by until the bee killer has finished its repast; then go and look for the remains of the bee. What part is left? Search the spots from which other bee killers are flushed, fur the re- 
mains of other bees. In this way you will get an idea of the extent of its depredations on the population of the hive.

Capture a few good specimens to be used in studying the external peculiarities. Note specially the length of the abdomen, the strength of the beak, the size and roughness of the legs, and the position, size, and strength of the wings. Make drawings of antennæ, mouth parts, legs, wings, halteres, etc., and compare with those of the bluebottle fly.

\section{THE CABBAGE BUTTERFLY.}

\section{(Pieris rapoe.)}

This is the small white butterfly with black wing tips, too abundant about our gardens. Something of its habits

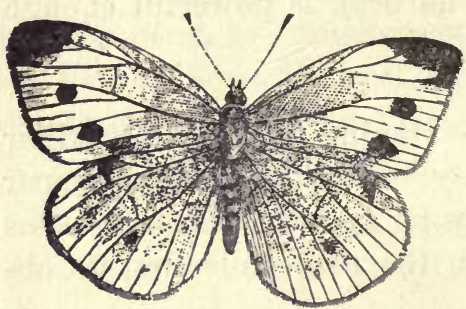

Female Cabbage Butterfly, Pieris rapæ (from Riley). will have been seen already, for it is commonly found feeding with the sulphur butterfly. Collect now a number of specimens to be used in studying it.

\section{External Anatomy. -} Follow the plan of study laid down in the "Preliminary Lesson" for the sulphur butterfly. When studying the mouth parts, note that the coiled organ, which has been called the tongue, consists of two elongated organs, grooved on their inner edges, and placed side by side, so that the grooves meet, and form a tubular food passage between them, and that these two organs are, in fact, the much modified lacinia of maxillæ.

A few convenient descriptive terms applying to the wings need to be learned here. The wings, being somewhat triangular in outline, present three margins and three angles. The anterior margin is called the costal 
margin, or more commonly the costa; the margin farthest from the body is called the outer margin; the other margin is called, on the fore wings the hind margin, on the hind wings the internal margin. The angle by which the wing joins the body is called the base; the angle between the costal and outer margins is called the apex; the other angle is called the posterior angle on the fore wings, the anal angle on the hind wings. The branches of the subcostal vein are called the subcostal veinules, and likewise those of the median vein are called median veinules; and both are numbered first, second, third, etc., from the front. On the basal half of each wing, between the subcostal and median veins, is an obovate inclosure, called the discal cell, or more often simply the cell. The space outside this, occupied by the terminal veinules, is called the discal space, or often simply the disk. Extending across the Ulisk from the cell to the outer margin of the wing is a short, straight vein situated about halfway between the subcostal and median veins, but appearing not to be a branch of either, and hence called the independent vein. ${ }^{1}$

1 The names of veins here given are those found in nearly all our descriptive works on butterflies and moths. There has been little uniformity hitherto in the names used by writers in the different groups, each of the principal groups having developed a nomenclature of its own. Professor Comstock has proposed for the veins of the wings of all insects a uniform nomenclature which seems likely to be adopted. Applying this system to butterflies and moths (Lepidoptera), the principal veins are as follows:-

Costa. - On the costal edge of the wing.

Subcosta. - Improperly called the costa by writers on the Lepidoptera.

Radius.'- Improperly called the subcosta by writers on the Lepidoptera.

Media. - The base of this vein is wanting, and its branches are joined to adjacent veins. It is three-branched. Its middle branch is the so-called independent vein.

Cubitus. - This vein is two-branched, but appears to be three-branched in most butterflies, as the third branch of media is joined to it.

Anal Veins. - There may be one, two, or three of these. In most butterflies there is one anal vein in the fore wing, and there are two in the hind wings.

Costa, subcosta, and the anal veins are simple in all Lepidoptera. 
Make an enlarged drawing of both wings of one side, naming all these parts on the drawing.

Development. - In almost any cabbage patch during summer and autumn this insect may be found in all stages of development. Collect and observe :-

1. Eggs. These will be found attached singly, usually to the lower surfaces of cabbage leaves. They are quite

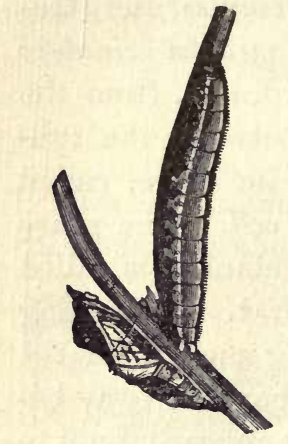

LARVA AND PUPa OF Cabbage ButterFLY (from Riley). minute, and are pale yellowish in color. They should be taken with the leaves to which they are attached, and not removed from the leaves until they are to be studied.

2. Larvo. These are found most abundantly on the fresh but slightly expanded leaves and on both surfaces. Some will be found feeding, others resting. All sizes will be found commingled.

Lift one that is resting, from the leaf, to observe the layer of silk in which its feet are entangled. This silk is spun from a spinneret (modified labrum) below the mouth. A small larva may sometimes be seen actively, and even somewhat violently, swinging its head from side to side as it lays down this layer of silk, thread by thread.

Watch a large larva that is feeding, to see how methodical is its habit.

How does a larva walk? Can it walk more easily on the side, or on the margin, of a leaf?

Observe the nature and extent of the injury done to the cabbages by these larva.

Observe later their hours of feeding.

Observe whether they are found in the same positions on sunshiny as on cloudy days. 
Observe the effect on them of wet weather and of dry; of hot weather and of cold.

Collect larvæ of all sizes, and keep them supplied with cabbage leaves until wanted for further examination.

3. Pupce or chrysalides. These have an angular, chitinous case, something less than an inch long, and pale and inconspicuous. One will occasionally be found attached to a cabbage leaf, but more often to the under side of a fence board, or to a post some few yards distant from the cabbages. There is little or no attempt at concealment; but, if one be not found readily, it may easily be obtained in a few days by keeping in confinement a few full-grown larvæ, and this will afford opportunity for observing the transformation. For this purpose a few of the largest larvæ (they should be more than an inch long) may be placed in an ordinary jelly glass, with pieces of fresh cabbage leaves, covered with the tin top to prevent the drying-up of the leaves, and left there until the transformation takes place.

When a chrysalis has been obtained, note its location and attachments. At its posterior end is a circlet of hooks, called a cremaster, fastened firmly into a button of silk that was spun by the larva. Around its thoracic region is a supporting loop of silk attached at both ends to the support above. How does a thing so inert become suspended in such a peculiar fashion?

4. Imagoes. These should be obtained from the chrysalides. All that is necessary is the keeping of the chrysalides in a moderately warm place, and in a good place for observation, for a short time. This will be advantageous on two accounts : (1) it will afford an opportunity for observing the final transformation, - the rupture of the chrysalis, the emergence of the imago, and the expansion and drying of its wings, - a truly wonderful transformation, that ought to be seen by every one ; and (2) it will 
afford an opportunity for seeing something of the effects of certain parasites of the cabbage butterfly, chief among which is a little black ichneumon fly. This fly lays its eggs in punctures in the skin of the larva. The eggs hatch out little fly larvæ, which feed upon the vitals of the butterfly larva. The latter, if not killed by these parasites before attaining its growth, becomes a chrysalis, inside which the fly larvæ continue their growth and transformations. Finally there issues from the chrysalis, not a butterfly, but a swarm of little black ichneumon flies. If half a dozen chrysalides be kept, an infested one, or several, will probably be found. If a chrysalis looks much blacker than the others, it is surely infested; and, if placed in a small vial, the ichneumon flies may be caught when they issue forth.

Immature Stages. - Study the three preparatory stages.

I. The Egg. - Study the egg to make out:-

1. Its attachment to the leaf.

2. Its shape.

3. Its surface markings.

II. The Larva. - Study the larva. Observe:-

1. The plainly distinguishable head.

2. The cylindrical body, without distinguishable thorax and abdomen. Count the segments.

3. Three pairs of true legs on the first three body segments. These mark the portion of the body which is later to become the thorax.

4. Five pairs of false legs, called prolegs (abbreviated from "prop legs"), borne on the sixth, seventh, eighth, ninth, and last body segments.

5. Spiracles, a pair on each of the body segments except the second, third, and the last two, opening at the sides. The absence of spiracles on the second and third segments marks these as the ones which are to bear the 
wings. Powerful wing muscles are to be developed within them.

Kill a large larva by placing a drop of chloroform upon its head, or by any other convenient method, and with a good lens examine :-

1. Its head, as seen from the front and from beneath. Make out:-

(a) Ocelli situated on the front of the lateral prominences of the head. How many, and how arranged?

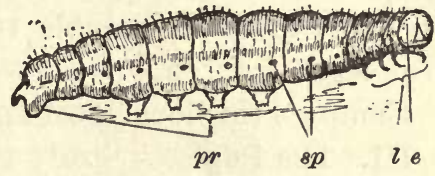

Diagram of Larva $(\times 2): e$, simple eyes on the front of the head; $l$, jointed legs attached to the three thoracic segments; $s p$, spiracle openings; pr, prolegs.

(b) A labrum, a little flap of membrane above the mouth.

(c) A pair of rather prominent biting mandibles which meet by serrated edges.

(d) On either side of these a very rudimentary stump of an antenna, here found situated lower on the head than in the perfect insect.

(e) Below the mandibles, a pair of very rudimentary maxilloe. They are but fleshy prominences here, made recognizable by a pair of minute appendages (palpi) at the tip of each.

$(f)$ Between and below the maxillæ is the larger labrum with its very minute rudiments of palpi, and a median appendage of special structure (a slender horny tube, which serves as a spinneret). Through it is exuded, from glands in the head, a liquid, which dries, immediately on exposure to the air, into the silken thread which the larva spins over the leaves.

Compare this mouth with that of an adult.

2. The covering of the skin. What kind of outgrowths can you find with a lens?

3. Its thoracic legs. Make out:-

(a) That they are jointed. 
(b) That they end in a horny, hook-like tip.

4. Its prolegs. Make out:-

(a) That they are more membranous.

(b) That they end in a circlet of minute hooks exactly adapted for catching into a layer of silken threads, and probably more serviceable to the caterpillar than are its true legs.

Compare this locomotor apparatus with that of an adult. III. The Pupa. - Study the chrysalis. Observe :-

1. The consolidation of head and thorax.

2. The relative freedom of the abdomen and its capacity for a slight twisting motion.

3. The shape and surface markings of the chrysalis, and the structure of the cremaster, in which the abdomen terminates.

4. The chitinous sheaths or cases of the appendages of the body overlapping on the ventral surface. The central ridge is that formed by the tongue ease. Those next on either side of it cover the first pair of legs. The next cover the second pair of legs. The next are the antennæ cases. The next and largest are the wing cases. The third pair of legs is concealed beneath the wing cases. When the chrysalis is first formed, these parts are soft and easily separable, but they become very solidly coherent in an old chrysalis.

5. The spiracles of the abdomen in their normal position. The one on the first thoracic segment has been crowded backward until it appears between the first and second segments.

From a comparison of larva and imago, it becomes evident that the quiescent pupal period is the period of greatest developmental changes. It should be noted, however, that these changes have been begun in the larva; that the insect begins its pupal period in possession of the rudiments of its perfect organs. 
It should be noted also, in comparison of larva and imago, that there is an entire change of life habits and of instincts. That there is no traceable connection between the instincts of the larva and those of the adult, is an interesting fact.

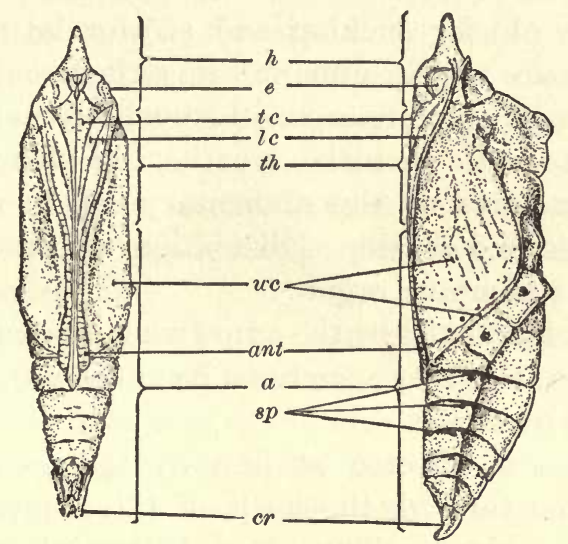

PUPA $(\times 3): h$, head; $e$, eye case ; th, thorax; ant, antenna case; $t c$, tongue case; $l c$, cases of front and middle legs; $w c$, wing cases; $s p$, spiracles; $a$, abdomen ; $c r$, cremaster.

Butterflies and moths constitute the group Lepidoptera (or scaly-winged insects). Capture a few of the moths that are attracted to a light at night, and examine them, to discover wherein moths differ from butterflies.

\section{THE LIFE PROCESS IN INSECTS.}

I. Nutrition. - The food of insects is so various, that diverse organs are necessary for seizing and preparing it for digestion. The mouth parts normally present are (1) a labrum; (2) a pair of mandibles; (3) a pair of maxillæ, each with three free appendages, - lacinia, galea, and palpus; and (4) a labium, with its jointed palpi. Any of these parts may be specialized, modified, or suppressed, according to the needs of the animal. 
The seizure of food is effected by some or all of these parts, assisted in a few cases by armed fore legs. Mastication, when necessary, is effected by the mandibles and laciniæ of the maxillæ.

Two types of insect mouths may be noted, adapted respectively (1) for sucking and (2) for biting. Suctorial mouths are widely different in structure, some being armed for making punctures, others wholly unarmed. In some insects with suctorial mouths, the pharynx (sometimes other parts of the alimentary canal) is provided with muscles, and capable of distention, and, thus modified, it becomes a pumping organ.

Digestion is effected by the crop (when present), gizzard, and stomach, aided by secretions from the salivary glands and gastric cæca.

Circulation is effected at first by the passage of the digested food through the walls of the alimentary canal, out into the blood. The blood bathes all the internal organs, taking to each the material needed for cell construction. It courses posteriorly through the body cavity, enters the dorsal vessel by lateral valves, is propelled forward, and passes out toward the head through the single rudimentary artery.

Respiration is effected either by spiracles or by tracheal gills. The former are adapted for aërial, the latter for aquatic, respiration. Spiracles are situated on the sides of the body, and open into tracheæ, which unitc into longitudinal lateral trunks, and send their numerous branches to every vascular part of the body. Some aquatic insects have aërial respiration; i.e., they obtain their air supply from above the surface of the water. In these the spiracles usually open beneath the wings, where air is stored that has been obtained at the surface and carried down below.

Tracheal gills are adapted for breathing the air that 
is mixed with the water, or held in solution. These are delicate expansions of the body wall, and contain tracheæ, which divide and subdivide until the smallest branches are separated from the water only by exceedingly thin membrane. Through this the air in the trachere effects exchange of gases with the air in the water outside, and is thus purified and fitted for respiration. Tracheal gills are usually situated on the abdomen, and must, of course, project into the water.

By either of these means, oxygen from the air is supplied to all parts of the body; and that is the essential thing in respiration.

Assimilation of food is the business of each individual cell. As no division of labor in society can relieve any person of the necessity of eating, sleeping, and taking exercise, so no physiological division of labor can exempt any living cell in the body from the necessity of taking from the blood supplied the material necessary for its own growth. Each individual cell of the insect must, like the one cell of the amœba, absorb and assimilate food and excrete worn-out material for itself.

It is oxygen that puts the body material in shape for excretion. The food of animals, being organic, is made up of complex chemical compounds, of which carbon and hydrogen are abundant elements. Oxygen, in combining with these elements, forms simple compounds, and breaks up the complex ones, liberating their potential energy in the form of various physical and vital forces, - heat, electricity, nerve force, etc.

The commonest products of oxidation are carbonicacid gas and water. These have to be removed from the body.

Excretion is the name of the process, and it is effected by various organs. Such gaseous molecules as escape into the minute air tubes may be exhaled through the tracheæ. 
Such as get into the blood may be removed through the secreting action of the Malpighian vessels, or may escape by osmosis directly through the walls of the alimentary canal.

II. Reproduction. - All insects are diœcious; i.e., the sexes are distinct. Paired generative organs are found in the abdomen beneath the dorsal vessel.

Nearly all insects are produced from eggs. For the few remarkable exceptions, and for the presentation of the interesting questions connected therewith, the student is referred to the larger works on entomology.

Of the metamorphoses of insects there are two general types: 1. When incomplete, there emerges from the egg a nymph, which differs from the adult principally in size, and which, when grown, transforms directly into a perfect insect; 2. When complete, the egg produces a larva, usually a little wormlike creature with little external likeness to its parents. This, when grown, transforms into a pupa, which, after a quiescent period, again transforms when an imago issues.

It must be borne in mind that a few transformations will not conform strictly to either of these types, also that there is no difference in kind between the two types. Convenience is the best reason for naming the growing stage of the one nymph, and of the other, larva.

It must be observed that the growth of the insect is completed during the larval or nymph stage. Eating is the sole business of nymph or larva. But of adults, some do not eat at all, and those that eat to keep alive do not grow. To reproduce their kind, to fulfill their part in some one of nature's little groups of diverse forms of life, and perhaps to enjoy their brief existence, seem to be their mission.

It will be noticed, that of the inhabitants of field, forest, 
garden, and orchard, popularly called worms, the great majority are not worms at all, but the larvæ of winged insects. The student needs to be reminded here, that little or nothing is known of the preparatory stages of many of our native insects, and that in consequence neither their place in nature, nor their importance to man, can be rightly understood and appreciated.

III. Voluntary Motion. - The muscular system of insects consists, for the most part, of isolated muscular fibers, attached to prominences on the inside of its hollow, chitinous skeleton. Those fibers which move the body segments are seen, upon dissection, arranged in whitish bands along the sides of the body cavity. The strong wing muscles fill the top of the thorax. Some of the fibers that move the appendages of the body are attached to tendons.

The usual movable appendages of the insect body are antennæ, mouth parts, legs, and wings. The adaptations of legs and wings to the habits of their possessors are not less striking than those of mouth parts. Insects have been studied which have legs adapted by their size, position, and arrangement, for standing, for walking, for running, for jumping, for swimming, and for seizing prey. The most striking modifications of wings are the very common ones already studied, - the tegmina of Orthoptera, the fore wings of many of the Hemiptera, and the halteres of Diptera.

But no account of muscles and motive organs will convey any adequate notion of insect activity. This needs to be seen to be appreciated; and half an hour spent in the open field on a warm afternoon, "amid hurrying wings and scurrying feet," in careful observation of the doings of these tiny creatures, will be of profit in learning a few of the valuable lessons that cannot be put into NEED. ZOöL. - - 
books. The athletic powers of a few insects, the student has had an opportunity to test for himself. When size is taken into account, it is probable that the champion athletes of the world will be found to be insects, at least in running, jumping, and flying.

IV. Sensation. - The nervous system consists of a double chain of ganglia, extended lengthwise on the floor of the body cavity, and connected anteriorly with a large cerebral ganglion in the head by a nerve each side of the gullet. From the cephalic ganglion or brain, nerves go to the eyes and other parts of the head, while each segment of the body is supplied with nerve fibers from a subjacent ganglion.

The five senses known to us are probably possessed by all insects. The sense of touch, while common to most parts of the body, is somewhat specialized in antennæ, palpi, and various tactile hairs. Organs of sight have reached a wonderful development in the compound eyes. We have no means of knowing what may be the limits of the power of vision in such organs. The sense of smell (or some other to us unknown sense) is undoubtedly present, enabling insects to find hidden food. Certain microscopic structures in the antennæ are believed to be organs of smell. No undoubted organs of hearing are yet known; but it is probable that insects can hear, for many of them possess elaborate sound-producing apparatus. Supposed organs of taste have been found in the labium and lower side of maxillæ.

The instincts ${ }^{1}$ of insects are the subject of many books. They are shown in manifold ways, and in no two species of insects in precisely the same way. They are too diverse to admit of summarizing here. But the instincts

1 “ An instinct is a propensity prior to experience, and independent of instruction." - PALEY. 
perhaps most commonly noted are those which guide to proper methods of seeking security from enemies, to the selection of proper places for depositing eggs, and to the construction of nests in which to properly provide for their young. The hunted moth, alighting on a leaf of her own color, and remaining motionless, concealed; the aërial dragon fly, immersing her eggs beneath the water; the butterfly, depositing her eggs upon the leaves of a plant which has furnished her, as an adult, no food; the wasp, making cells of mud, and stocking them with paralyzed spiders; and the bee, constructing her mathematical cell, and feeding daily by hand her growing young, - all are but the commonest illustrations of a faculty which culminates in the social order of some ant communities.

\section{A REVIEW EXERCISE.}

1. Which of the insects studied have mouth parts adapted for biting? For sucking? Which of the latter have mouth parts armed for puncturing, as well as adapted for sucking? Which have the mouth parts adapted for both biting and sucking?

2. What mouth parts are specialized in seven of the insects studied (one from each group), and what is the advantage to the insect of such specialization? What is the food of each?

3. Which of the insects studied breathe by spiracles? Which of these are aquatic? Which breathe by tracheal gills?

4. Give examples of insects having legs adapted (1) for standing, (2) for walking, (3) for running, (4) for leaping, (5) for swimming, and (6) for seizing prey.

5. Bring together the drawings that have been made of legs, of wings, of mouth parts, and of antennæ, and, 
placing like parts together, study them comparatively, to note the diverse modifications of parts that are homologous.

6. Bring together, for comparative study, the drawings that have been made of entire insects, and note which body segments are specialized in each. Dissection of these insects would have revealed a corresponding diversity in the development of the internal organs; and the study of all shows one plan of structure, with great variety in the details of its execution.

7. Study the drawings to ascertain whether the modifications of wings and legs, and other organs, is always in harmony with the habits of the insect. Does the insect do with its locomotive appendages just what they seem fitted for doing? Could you not tell, by looking at an unknown insect, whether it spends the greater part of its time afoot, or a-flying?

8. Special organs of touch (antennæ and palpi), and special organs of sight (eyes and ocelli), are evident in the insects studied. In the adult dragon fly, the eyes are specialized, and the touch organs reduced. Which of these two senses is probably more serviceable to the dragon fly, and why? Why are the eyes reduced, and the tactile organs specialized, in some beetles?

9. Take some unfamiliar insect collected and killed by another person, and after studying carefully the development of its parts, and their probable uses, write out some inferences - not guesses, but inferences from facts of structure observed - as to the habits of the insect, particularly as to its habits of feeding and of locomotion. Then compare your inferences with the facts as you can learn them from later observations, on the insect alive, or from reading.

10. Compare the wings of a grasshopper, bug, and beetle. Observe that in the first two the fore wings are protective coverings. as well as organs of flight. And do not 
fail to note, that, just in proportion as they become serviceable for protection, they become useless for flight. This is a good illustration of the universal law, that precise adaptation to one thing brings limitations in other things. Observe, also, that with the decrease in usefulness of the fore wings, there is an increase in size of the hind wings, - that the hind wings become disproportionately large, and have to be folded when at rest. Compare their several methods of folding.

11. Which of the insects studied have complete, which incomplete, metamorphoses?

12. Which are injurious to vegetation, and during what stage of metamorphosis are they most injurious? Which are directly beneficial to man?

13. Which eat different food in different stages of life?

14. Which are most musical (or noisy, if you please), and by what means do such produce their sounds?

15. Mention examples of the dependence of insects upon mimicry for protection. Which of the insects studied show the highest instincts in the care of their young? In the construction of their nests?

\section{A LESSON IN CLASSIFICATION.1}

Have a good supply of butterfly specimens on hand, before beginning the following work; the more different kinds, the better.

1 This lesson outlines a simple and natural introductory method which has proved very serviceable. First steps in classification may be illustrated with other insects as well as with butterflies, perhaps better with some others. The teacher will probably find this method most serviceable when applied in the group with which he is best acquainted. In applying the method to butterflies, the groups as laid out in the works most commonly found in school libraries have been recognized here as sufficiently answering the purpose of this lesson. Recent changes and improvements in the classification of butterflies may be introduced when they have made their way into available literature. 
The Species. - Select two of the large swallow-tail butterflies (the large black ones with tailed hind wings) that differ plainly in coloration, markings, outline, etc. These are two different species. Find out all you can about the two species, first by studying them, and afterward by reading about them (you will find them described in French's "Butterflies of the Eastern United States"), and note the kind of differences between them :-

1. Differences of color and markings throughout all stages, - very obvious differences, but not alone sufficient for distinguishing species, for color is a very variable and somewhat unreliable characteristic.

2. Slight differences in outline, in external ornamentation, etc.

3. Differences in size.

4. Differences in habits.

5. Differences in food of larvæ.

6. Differences in egg, larval, and pupal periods, etc.

Such minor differences as these are the ones commonly used for distinguishing species. Make a list of the points that distinguish the two species selected.

Get the two common kinds of cabbage butterflies. The most prominent mark, within the border of the fore wings, is in one a black spot, and in the other a black dash. Compare these, and observe that the differences are of the same kind as before. These are two species.

The Genus. - Now compare a swallow-tail with a cabbage butterfly. Note that while the two are alike in the possession of relatively broad wings and slender bodies, and in having six fully developed feet, their differences are yet greater than those which distinguish species. Note the differences:-

1. In the shape of the hind wings.

2. In their position in relation to the abdomen. 
3. In the structure of the second segment of the body of the larvæ, etc.

Such differences are used to distinguish genera. The swallow-tails belong to one genus, the genus Papilio; and the cabbage butterflies to another, to the genus Pieris. Make a list of the characters which distinguish these two genera.

Every species has two names, - the name of the genus to which it belongs, and its own specific name. A man has two names, - a surname and a given name. The surname corresponds to the name of the genus; the other, to the name of the species. Just as there may be several Johnsons (John, Henry, and Eleazar), so there may be several Papilios, - Papilio asterias, Papilio troilus, Papilio turnus, etc. The surname serves to locate the man among the Johnsons; the generic name Papilio locates the butterfly among the swallow-tails. And just as the name John tells which Johnson is meant, so the name asterias tells which Papilio is meant. Observe that the names are written, as men's names are written in a directory, surname first. Which species of the genus Papilio have you had for comparison?

The Family. - Get, for comparison with these, one of the small, thick-set, swift-flying "skipper" butterflies, which rest with wings thrown backward until the costal margins of the two pairs are side by side. Compare and observe the marked difference in form, - a difference of the kind used to distinguish families. This skipper butterfly is not only of a distinct species and genus, but its diverse form shows a relationship still more remote. It is of a different family, the family Hesperidce. The genera Papilio and Pieris are members of the family Papilionidoe. Make a list of the characters which distinguish these two families. 
The large, red-brown milkweed butterfly, with dark markings along the veins, is of the family Nymphalidoe. Compare it with a representative of each of the two other families mentioned.

Notice that all the names of families end in -idoe.

The Order. - Note that the smallest group among animals is the species, and comprises those animals which are essentially alike. Note that as species are put together to form a genus, so genera are put together to form a family. Families, in like manner, make up an order. The three families mentioned, together with several other families of butterflies and moths, comprise the order Lepidoptera (or scale-winged insects). The names of orders usually end in $a$.

This grouping of animals is called classification.

Note that all groups are founded upon certain likenesses in structure and development. A system of classification, therefore, expresses the structural and developmental relationships which exist between animals.

Seven of the orders of insects have been studied in a few of their representatives. Write the names of these orders in a column, and opposite each write the characters peculiar to that order. Your list should approximately define these orders.

Then make a list of the characters which all these have in common. ${ }^{1}$ Your list should characterize approximately the group Hexapoda (or insects proper).

${ }^{1}$ If there be time enough, each student so disposed should select, with the advice of the instructor, some small group of insects for a little special study, - some genus which offers a number of local species, and one the metamorphoses of which can be followed through in reasonably short time, and one for which systematic works that will enable him to identify the species are at hand. If undertaken at all, the group should be studied as thoroughly as possible, especially as to its metamorphosis, and its place in the economy of nature and of man. Full notes should be made of the things observed during this study; and at its close an account 


\section{ARACHNID INSECTS.}

\section{THE SPIDER.}

Haunts. - This much-maligned insect is a very interesting one when we come to study its habits and the wonderful silken web it spins. Because it bites sometimes in self-defense, and because it sometimes spins its web where a web is not wanted, it is very generally hated. But its bite is seldom serious to human flesh, and may be avoided by simply avoiding handling the live spider. And its web (out of doors) is a thing of beauty.

No one needs to be told where to find spiders in warm weather, for they are everywhere abundant. The largest ones are best for a first examination. The spiders which spin their rich geometrical webs in the spaces in garden fences or in tangled shrubbery, or the ones which spin their calla-shaped

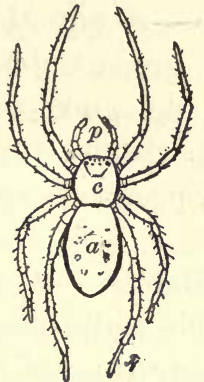

SPIDER (Semidiagrammatic) : $a$, abdomen; $c$, cephalothorax ; $p$, palpi.

webs on the ground, spreading the free border out over the grass at the edge of a sidewalk or beside the foundations of buildings, or the fleet-footed spiders common in

should be written of the genus, stating all the points of structure, haunts, habits, economy, and development, which all its local species have in common. This should be concluded with descriptions of each of the species, for which the following outline is suggested:-

I. Names (scientific, common).

II. Measurements (length, extent of wings, etc.).

III. Structure (points not already stated in the account of the genus).

IV. Coloration (a detailed description).

V. Haunts and habits.

VI. Preparatory stages (a full account). There is yet room for pioneer work in this line.

VII. Economic importance of the species. 
long grass, which lay no snares at all, but catch their prey in a fair chase, will serve well for study. There is a large and gayly colored spider very abundant sometimes in stubble fields, and often the one most easily obtainable for class use. It spins a small geometrical web between the weeds that overtop the stubble; and when its web is jarred by the shaking of the weeds, it drops to the ground, and feigns death. It may then be picked up with forceps, and dropped into a cyanide bottle or into alcohol.

In winter, spiders may be found under the bark of dead trees, or aquatic species may be taken with a net among the green, submerged plants that grow on the borders of brooks and ponds. But in winter there will be scant opportunities for observing their habits or their webs.

Specimens are best preserved in alcohol.

Habits. - Observations on the habits of spiders are best made while out collecting. The following are but meager suggestions of what may be done in field study.

1. To see how its silk is spun, pick up a live spider by a hind leg with forceps, and watch for the formation of a thread from some blunt protuberances (spinnerets) beneath and near the posterior end of the abdomen. Draw this thread out with a pencil, and observe that it is composed of separate strands. Put at least one spinning spider into a vial or pill box, and take it home alive.

2. Various methods of spinning may be easily observed. Certain small spiders will be seen aimlessly trailing a thread after them as they run about over the grass or fences, making, not a web, but a tangle of threads; but those that make webs of artistic patterns have a uniform and very curious method of procedure, easily seen where such spiders are abundant.

3. On a hot afternoon certain very small spiders may be seen floating in mid-air upon a few gossamer-like 
threads. This spider climbs to the top of some pile of boards or of brick, on which the sun has been shining until a current of hot air is arising from it, elevates its spinnerets, and starts a thread, which is caught up by the rising current of air, and drawn out to a length sufficient, by its buoyancy, to support the weight of the spider. The spider then lets go of earth, and sails away.

4. Of webs, and especially of those in which the spiders spend most of their time, the shape, position, location, and construction should be noted. A pair of spiders will often be found on different parts of one web. The male is usually much smaller than the female. Of flat webs not placed vertically, it should be observed whether the spider walks on the upper, or on the lower, side of the web. It should be noted that the webs which show the greatest skill in their construction are made of the fewest threads.

5. That the web is a snare for capturing prey, must not be forgotten. Note the position of the spider on its web while waiting for its prey. Throw a small grasshopper nymph against the web, and watch the spider's method of securing its prey. Examine such insects as you find entangled in webs, and note whether they are dead or alive. Note the kinds of insects you find snared by spiders.

6. Examine such old and tattered webs as you find clinging to fences, and to rafters in attics, for the exuviæ of young spiders. These skins will show the close resemblance in form of young and adult.

7. The eggs of most spiders are inclosed in a round silken capsule which is hidden beneath the bark of posts and logs, or buried among rubbish, or, in a few species, carried about by the mother attached to her spinnerets. It is often a third of an inch in diameter, and of a grayish or dirty yellowish color. Within it the young ones are hatched, and live for a time by eating one another. 
Structure. - Observe that the body is divided into two regions. The anterior one is the cephalothorax. As the name indicates, it corresponds to both head and thorax of insects proper. The posterior region is the abdomen. Observe the relative size and shape of the two divisions, and on the lower side of the body find the pedicel connecting them.

I. Cephalothorax. - On the anterior prominence of the cephalothorax find the eyes. With a lens make out their number, kind, and arrangement.

Examine the two large mandibles that hang down from the front of the cephalothorax, attached above, and free below. Study their action. Find a strong, incurved poison fang at the lower end of each. These fangs are hollow, and into the wounds they make is poured a poison secreted by glands situated in the bases of the mandibles.

Observe (from below) a pair of jointed maxillary palpi arising behind the mandibles, and extending forward, appearing like a pair of dwarfed legs. Observe that their basal segments are movable upon each other, and closely surround the mouth. These, by rubbing together, assist in comminuting food, and are called maxilloe. Find, in all, six segments in each palpus.

Find eight legs, and in each one seven segments. Observe the size and arrangement and action of the legs.

Examine the terminal segment to discover by what means the spider is able to run easily over webs which hopelessly entangle other insects. Find two pectinated claws, and (sometimes) a third, which fits, forceps-like, against them.

II. Abdomen. - On the under side, just behind the hindmost pair of legs, and on either side of the median ventral line, find two smooth, hard patches covering the openings to a pair of breathing organs. Each breathing organ is a sort of rudimentary lung, through the leaves of which the blood flows for aëration. 
On the median line, usually a little farther back, are the openings of the reproductive organs.

Near the posterior end are the spinnerets, usually three pairs of blunt protuberances, each of which, when magnified, appears to be covered with hollow, jointed hairs. Through these tubular hairs a fluid substance, secreted by glands within the abdomen, is exuded; and the fluid is of such a nature that it immediately hardens on exposure to the air. When the spider spins its web, it simply exudes this fluid through the hundreds of openings; and the liquid streams, uniting and hardening, form a silken cord of very many delicate strands. A good way to see these strands is to allow a live spider, brought in from the field, to attach its web, when it begins spinning, to the middle of a glass slip, and then to examine the point of attachment under the microscope.

Development. - The development of the spider cannot well be traced in the time allotted to a beginning course in zoölogy; suffice it, therefore, to say, that the young spider, which hatches from the egg and molts a number of times in coming to maturity, shows much resemblance to the adult in both form and habits. Its palpi are proportionately longer, more closely resembling true legs, of which they are modifications.

\section{MYRIAPOD INSECTS.}

\section{THE CHILOPOD OR CENTIPED.}

Haunts and Habits. - Overturn boards, logs, or stones that have been lying on the ground for a long time in one place, and you will find beneath them often numbers of elongated, wingless insects, of a brownish color, with linear bodies and numerous laterallv extended feet. Find speci- 
mens with long antennæ and stout feet, mostly a single pair to each body segment. These are popularly known as centipeds. They may be picked up with forceps and put into the cyanide bottle.

The seclusive and predatory habits of the live chilopod should be studied, and also the use of its antennæ, and the order of moving its feet in walking.

Thousand-legs will be found in similar situations, distinguishable by its smaller size, shorter antennæ, two pairs of legs (apparently) to each segment, and by its disposition to curl up when touched. Specimens should be collected for comparison.

External Features. - Write a description of the chilopod which shall embody the answers to the following questions : -

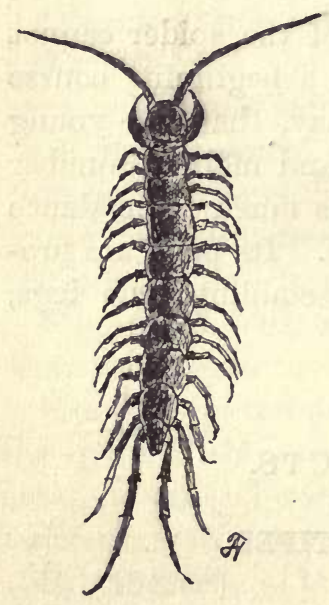

Chilopod or Centiped $(\times 2)$.

1. How is the body divided into regions, as compared with other insects?

2. How many segments in the body?

3. How many eyes are there, and of what sort?

4. What is the shape of an antenna, and how many segments in it?

5. How many appendages has the first segment back of the head, and of what sort?

6. Where are the poison fangs situated?

7. Of what character are the mandibles?

8. Why are not the legs underneath the body?

9. What adaptations do you discover of the shape and structure of the body to the life the insect leads? 


\section{CRUSTACEANS.}

\section{THE CRAWFISH.}

\section{(Cambarus.)}

Haunts. - In warm weather this animal may be found crawling upon the bottom of brooks and natural ponds. The largest specimens will be found in creeks and in ponds which are not dried out in summer. A water net will be of service in securing specimens. Large specimens may often be obtained in abundance under rocks in shallow

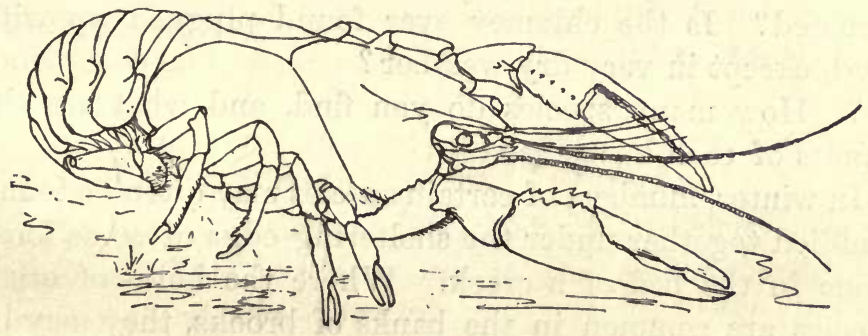

Crawfish, natural size (after Morse).

rapids of creeks. A bright light on the bank of a creek at night will attract many to the edge of the water, where they may be taken with a dip net. This is perhaps the easiest way to obtain a supply. It requires only a little waiting and careful watching. The light should be so placed, that, as it shines down into the water, the bottom is visible. Different species will be found in different 
situations. Some live in holes in the soil; others do not. Some of the former build chimneys of mud about the entrance to their holes; others do not. Some live at the surface of ponds, on the floating or submerged leaves of aquatic plants.

In many localities throughout the interior the species that live in holes are very abundant. The following questions suggested for field study of their habits may be useful :

1. What are their hours of activity?

2. At what depth of water do you find them?

3. Do they live singly, in pairs, or in communities?

4. Do those that live in holes make the holes for themselves? Are their holes ever found sheltered beneath stones and tree roots?

5. What is the general shape, size, and direction of these holes, and at what level do they terminate below?

6. In such as build chimneys, how is the chimney constructed? Is the chimney ever found plugged up with mud, except in very dry weather?

7. How many species do you find, and what are the haunts of each?

In winter, numbers of certain species may often be found huddled together under the sheltering edge of some loose stone in the bed of a creek. Where the holes of other species are common in the banks of brooks, they may be dug out when the ground is not frozen.

Habits. - Live specimens may be kept for a long time in any sort of aquarium supplied with food. They will eat snails and insects greedily, and will live on almost any kind of flesh.

Startle a crawfish at rest upon the mud, and observe the cloud it raises in the water, behind which to escape.

Watch a crawfish walking about in an aquarium, and 
see how many feet it walks with, and in what order they are moved.

Startle it by thrusting a stick toward its eye, and see its rapid locomotion backward. How is this effected?

Observe its feeding habits.

Place a live crawfish in a small dish, and barely cover it with water. Take hold of its body with forceps, and observe its way of defending itself.

Observe that its eyes are stalked and capable of protrusion outward.

Gill Currents. - Observe that on each side of the body that portion of the hard crust beneath which the legs are attached is marked off from the rest by a shallow curved groove. Within the portion so marked off at the base of the legs is the gill chamber, containing true gills. This chamber is open at both ends for the passage of currents of water. Determine the direction of the currents by placing a drop of ink or other colored fluid in the water near each end of the chamber, and watching it move.

Study the structure of a crawfish which has been a short time in alcohol.

Plan of Structure. - The body is divided into two regions. The anterior one is the cephalothorax; the posterior one, the abdomen.

Observe that the body is made up of a series of segments. These segments are very evident in the abdomen, but not so plain in the head and thorax, where they will have to be looked for on the ventral surface. It will be seen that each pair of legs, at least, is attached to a single segment, though no traces of segments may be discoverable on the dorsal surface.

Observe that every distinguishable segment, except the hindmost, bears on its lower surface a pair of appendages, NEED. ZOÖL. -8 
and that these appendages vary greatly in size on the different segments.

I. Cephalothorax. - The hard shell, which entirely covers the cephalothorax in its normal position, is the carapace. The stout beak extending forward from the front of it, between the eyes, is the rostrum. Observe that the whole is divided into portions corresponding to head and thorax by a shallow cervical groove that runs transversely across the top of the earapace, and extends obliquely forward along the sides. The two longitudinal grooves on the carapace back of the cervical groove, which mark the line of separation of the two gill chambers from the thorax proper, have been noticed already.

II. Abdominal Segments. - Note the number and form of the abdominal segments. Flex and extend the abdomen, and study their action. Take the third or fourth abdominal segment as a type, and in it locate the parts as named. The convex dorsal plate of the segment is the notum or tergum; the projecting plate that hangs down on either side like the eaves of a roof is the pleurum; the ventral transverse bar between the bases of the two appendages is the sternum. The appendages themselves are jointed, and two-parted at the tip.

Observe the soft membranous parts connecting the abdominal segments, and the pivotal joining of the segments together at their lateral edges, facilitating the flexion and extension of the abdomen, but preventing lateral motion.

At the posterior end of the body is the tail fin, and its central piece is the serminal segment of the body, and the seventh abdominai segment, called the telson. It bears no appendages, and has but slight external resemblance to the other body segments, being much modified to suit a special purpose. The two pairs of similar broad flaps, which, together with the telson, eomprise the tail fin, are 
the specialized two-parted tips of the appendages of the sixth abdominal segment.

Dissection. - The remaining parts to be mentioned are best seen upon dissection. 'The crawfish is best dissected under water. ${ }^{1}$ Pin it to the bottom of your dissecting pan, with the right side of the body upward, and the head from you. Fasten one pin through the base of the rostrum, draw the body out full length, and fasten another pin through the left appendage of the sixth abdominal segment. Cover the specimen with water, dissect slowly and carefully and as directed, and change the water as of́ten as it becomes cloudy.

I. Appendages. - Begin with the series of appendages, and, for convenience in dissecting, proceed from the posterior end forward. Remove each appendage of the right side in order, and be very careful to get each one off entire. Preserve all in their proper order for drawing.

The absence of appendages from the terminal segment has already been noted. The broad finlike character and the extension backward of the appendages of the sixth abdominal segment have also been noted. The smaller appendages of the remaining five abdominal segments are extended forward, close under the abdomen, and are called swimmerets. Each consists of a short pedicel of two segments, with a pair of jointed and fringed filaments at the tip. The swimmerets of the fifth, fourth, and third abdominal segments are very similar, but those of the second and first segments.are reduced and smaller, or the first entirely wanting in the female, while in the male they are specialized, bent forward strongly under the thorax, and variously forked, hooked, or twisted at the tip.

The next five pairs of appendages are the legs, and belong to the thorax. Before removing these, it will be

1 See Appendix, p. 283. 
well to remove that part of the carapace which covers the right gill chamber at their bases. To do this, cut through the carapace with fine-pointed scissors, along the groove that marks the boundary between the branchial chamber and the thorax proper. Begin at the posterior end of the carapace, and cut forward along this groove to the cervical groove, and obliquely forward to its anterior end. Turn down and break away the cover of the gill chamber, and expose the gills. Observe their feathery appearance. Observe that they fill the chamber, and come in contact with all the water that passes through it. Move the legs backward and forward, and note the effect on the gills. Observe that the gills are arranged in vertical series corresponding in position with the legs. Observe that they are also arranged in longitudinal series, the lower series being attached to basal segments of the legs, and the upper series (a double series) attached to a membrane extending between the wall of the thorax and the legs.

Examine with a lens, and compare in structure, the gills of one complete vertical series. 'Tear a small gill to pieces with needles, under water, to make out its structure.

Remove now each leg, with its attached gill, proceeding from the rear. To do this, place a knife blade between the bases of the leg to be removed and the one in front of it, and, by prying, break its hard attachments, and then, with a sharp knife or scalpel, cut its membranous attachments. Of the five pairs of legs, the first is used for prehension and defense, and the others for walking. The openings of ducts from the reproductive organs are little pores perforating the inner angles of the basal segments of a pair of legs, - in males, the fifth or hindmost pair; in females, the third pair.

Having removed the five legs of the right side, study the foremost. Note its great size. Flex and extend it, and study the structure and action of its joints, especiallv 
of the powerful forceps at its end. Why are the blades of the forceps roughened on their inner edges?

Is there any part in the foremost leg that is not present in the other four?

There yet remain three pairs of small thoracic appendages. These are the maxillipeds (or foot jaws). They cover the mouth, being directed forward. The mouth opens directly upward: probe between the maxillipeds to find it. These maxillipeds, by the rubbing together of their opposed segments, assist in the comminution of the food.

Remove the hindmost maxilliped, and compare it in structure with the typical abdominal appendage already studied. Observe that it has a pedicel of two small segments, bearing two branches; that it has (and the swimmeret has not) a gill on the inner side of the basal segment. Remove the second maxilliped, and find in it all the parts present in the third.

Remove the first maxilliped, and find the same parts found in the other two, except the gill. In the place of the gill, there is a broad plate, on the inner side of its basal segment. The vertical series of gills begins with the second maxilliped. Observe that the second and first maxillipeds are much smaller and softer than the third.

The remaining appendages are believed to belong to the head.

Closely following the maxillipeds, and covered by them, are two pairs of very thin and delicate maxillæ. These are small, and closely appressed, and in removing them care must be taken to separate them, and to take them with the forceps by their basal segment.

Before removing the maxillæ, the gill scoop attached to the second one should be seen in place. It is a curved plate, attached to the outer side of the maxilla; it plays backward and forward in the anterior opening of the gill chamber, and by a sort of sculling action propels the water 
forward, out of the chamber. Watching it closely, pull the maxilla of the opposite side backward and forward, and you will see how it acts. Because it keeps the water moving, it is a very important accessory organ of respiration. The water that bathes the gills must continually be renewed, in order that sufficient oxygen may be obtained from it for the needs of the body.

In front of the maxillæ, find a pair of short, hard, toothed mandibles, each with a small, three-jointed palpus lying in a groove on its anterior surface. Study the action of the mandibles. Find a thin, leaf-like, unjointed plate (the metastoma), fitting closely against the posterior surface of the mandible. This is not considered as a true serial appendage, but only as an outgrowth from the border of the mouth.

On the front of the head are two very long antennæ. Draw one of these downward, and find a large, basal segment, bearing on one side a light-colored, conical process. In this process the duct from an excretory gland in the head terminates. Find, also, a blade-like branch of the antenna beneath the eye. What is it there for?

The evidently two-forked, short appendages above the antennæ are the antennules. Beneath the eye, in the base of each antennule, is a so-called ear sac.

Compare in structure an antennule with an antenna; with a mandible; with a maxilla; with a maxilliped; with a leg; with a swimmeret. Observe that they all exhibit modifications of one type of structure; and the type is a two-jointed pedicel, bearing (normally) a pair of jointed branches. In the legs, one of the branches is suppressed, and the other is enormously developed to form the part of the leg comprised in the five terminal segments. In all the thoracic appendages, except the first and the last, there is an internal process from the basal segment, forming a gill. 
Preserve all these appendages in their proper order until the dissection is finished.

II. The Eye. - Examine the eye. Pull - it outward with forceps, and note the length of its stalk. Its stalk is muscular, and capable of turning the eye, when protruded, to look in any direction, - an admirable compensation for the stiffness of the creature's neck. Examine a section of its cornea with low power, to make out whether it is a compound eye or an ocellus.

III. Internal Organs. - Now carefully dissect away from the thorax the wall that is uppermost, and cut away all of the carapace as far, at least, as the median dorsal line, taking care not to injure any of the delicate organs that lie beneath. Cut away, also, all the part that is uppermost of the notum (tergum) of the abdomen; also the right pleurum.

(1) Organs of Circulation. - In the inner wall of the branchial chamber, observe the vertical canals which convey the blood from the gills toward the heart. These canals may sometimes be seen through the wall before dissection of this part.

The heart lies in the top of the thorax, under the center of the carapace, in a sort of membranous inclosure called the pericardial sinus. When the carapace is cut away, beneath it should be found the thin, upper wall of this cavity. Cut through this, and expose the heart, a thin transparent, angular sac, suspended normally in the colorless blood that fills the sinus. Find five small arteries starting from its anterior end. Three of these, the central ones, proceed directly forward toward the head; and the other two, the lateral pair, proceed downward and forward toward the lobes of the liver, which they supply with blood. Find a large artery starting from the posterior end of the heart, and immediately dividing into two branches, one of which continues backward along the upper side of 
the abdomen, while the other turns downward toward the ventral surface. All these arteries convey blood out from the heart directly to the tissues, through their many minute branches. The blood has no such channels for return, but finds its way back to the gills by percolating through the interspaces of the tissues and internal organs. It comes back, necessarily, laden with carbonic-acid gas, the product of oxidation in the tissues, and must needs go to the gills to exchange this noxious gas for a fresh supply of oxygen. There is a passageway for the blood up one side of the central supporting portion of the gill, and down the other; and to get from one into the other, the blood must flow through very delicate capillary tubes that lie out in the most delicate gill filaments, and connect the two passages. In passing through these capillary tubes, the blood currents on the inside of them are separated from the water currents outside only by very thin membrane, through which the necessary exchange of gases takes place. The blood is then returned from the gills through the vertical canals already noticed in the thoracic wall. to the pericardial sinus. It reënters the heart through six apertures which are guarded by valves inside. One of these apertures may be seen on each side of the heart, a pair on its upper surface, and a pair on its lower surface. Find them, using a lens. When the heart is filled with blood, it contracts; and the blood, being prevented by valves from flowing back into the pericardial sinus, is forced out through the arteries. When the heart relaxes again, the valves fly open, and the blood from the sinus rushes in and fills it, and is driven outward through the arteries at its next contraction. The currents coming up from the gills continually renew the supply in the pericardial sinus.

Several delicate fibrous bands may be seen connecting the heart with the walls of the pericardial sinus. 
(2) Organs of Reproduction. - The reproductive organs will be found just beneath the floor of the pericardial sinus, whitish in the male, and with a pair of very long convoluted tubes or ducts (one on each side), yellowish (sometimes dark colored from the presence of eggs), in the female, and with a pair of short, descending ducts.

(3) Organs of Digestion. - Study next the organs of digestion, the alimentary canal and its appendages. Dissect away all the organs that cover it. In doing this; observe in the abdomen a thin layer of muscle above the straight intestine, and a thick layer below it. The upper muscle extends to the abdomen, and the lower flexes it. What reason is there for the much greater size of the flexing muscle? Make a shallow cut along the median line of this lower muscle, and remove the upper half of it. It will separate easily, if taken in a single long roll.

A pair of big forceps, three pairs of maxillipeds, two pairs of maxillæ, and one pair of mandibles, have already been found to be the external agents for the communication of food. The food passes from the mouth directly upward through a short esophagus, into a large, bag-like stomach, which nearly fills the head cavity, and extends backward a little way into the thorax. It is divided into two chambers by a constriction. On either side of its posterior end are a pair of large yellow or brown glands, which are accessory organs of digestion, called liver. Find the ducts by which they pour their secretions into the alimentary canal. Posterior to these is the straight intestine.

The comminution of the food is continued in the stomach, the internal surface of which is armed with hard teeth and ossicles, which make it a grinding organ. Cut it open, and find these hard parts. The food passing out from the stomach is mixed with secretions from the liver, and is digested. It then passes through the walls 
of the intestines, directly into the blood, and is ready for distribution, and for use in the cell construction.

Tear a bit of liver to pieces in water on a slide, and examine with low power to make out its structure.

In the base of the head, in front of the mouth, are two small excretory glands of light-greenish color. The ducts from these open on the basal segments of the antennæ, as already noticed.

IV. Nervous System. - Find now the parts of the nervous system. On the floor of the abdomen a longitudinal chain of nervous ganglia will be readily seen. Count the ganglia of the abdomen. Observe the delicate white nerve fibers radiating from them.

In the thorax, the chain seems to disappear in a sort of canal formed on the ventral surface by the hard plates arising from the floor, and forming a sort of internal skeleton. These plates are for the attachment of the powerful muscles of the legs and of the abdomen. By carefully cutting away the hard parts that hide the nerve chain, it may be followed forward to the head. A large ganglion will be found just behind the esophagus, and a larger cephalic ganglion or brain will be found just behind, and a little above, the bases of the antennules. These two large ganglia are connected by fibers passing on either side of the esophagus, and forming the esophagal nerve collar. From the cephalic ganglion, nerves may be traced to the eyes, antennæ, and antennules.

V. Concluding Work. - If any of the paired organs mentioned have not been found thus far, they may be looked for in what remains of this dissection (the left side), or in another specimen. Finally remove carefully the series of appendages belonging to the left side of the body.

Gather together in pairs all the appendages of the body, in order, as follows:- 
One pair of antennules.

One pair of antennæ.

One pair of mandibles.

Two pairs of maxillæ.

Three pairs of maxillipeds.

Five pairs of legs.

Six pairs of swimmerets.

Draw all these accurately and in order, twice natural size. If the parts of the smaller appendages are not easily made out, place such between two glass slips, and examine with low power of microscope.

Make a diagrammatic drawing of a longitudinal section of the body, showing the relative size and position of the principal internal organs.

Make a drawing of a crawfish in its natural position, as seen from above.

Serial Homology. - Observe the striking similarity in structure which underlies the great diversity in size and use in all the appendages. Similar likeness in the arrangement of the parts of the segments which bear the appendages is also evident; and these things, together with a more marked correspondence during the early stages of development, indicate that each segment is homologous with every other. The segments being serially arranged, this is called serial homology.

Development. - If crawfishes be collected in early spring, the females will be found with large, berry-like clusters of small, round, dark-colored eggs, glued fast to the swimmerets. As these are lashed backward and forward through the water, the eggs are continually washed, and kept free from mud and other impurities. When the eggs hatch, they split in halves, and the emerging young, already armed with well-developed forceps, cling to the 
swimmerets. The young, when hatched, are nearly a quarter of an inch long, almost transparent, and in structure show much resemblance to the adults. The points of their forceps are variously hooked, enabling them the better to hang on to the maternal swimmerets. In the process of development, molting takes place several times. The carapace splits down the back, and the animal crawls out limp and defenseless. It has great difficulty in withdrawing its legs, and sometimes breaks them off; but new ones will grow out from the broken stumps. Specimens will be found occasionally with one forceps smaller than the other: the smaller one is replacing one that has been lost.

The time of each molt is a critical period in the life of the animal; for when its hard coat of mail is gone, its muscles overwrought with the struggle of extrication, and even its defensive weapons soft and pliant, it becomes an easy prey to even its weaker enemies. It therefore seeks the closest seclusion at such times.

The exuvia of the crawfish is not broken in molting, except by the one longitudinal slit; and after the animal emerges, the edges of this slit come together again elastically, and the exterior looks much as it did before the molting. The hard parts of the stomach are shed also at every molt.

Crawfishes live a number of years. They grow rapidly during the first season, after attaining a length of an inch and a half. They grow more slowly in later years, and rarely attain a length of more than five or six inches.

Crawfishes belong to the group Crustacea.

Other Crustaceans. - Two other very common crustaceans are excellent subjects for study here, as they illustrate important differences in crustacean structure. These are the Asellus and the Cyclops. 


\section{THE ASELLUS.}

Haunts. - This animal lives amid the submerged plants of our streams and ponds. It is about an inch long, and of a uniform slaty gray or pale-brown color. If plants be drawn out of the water, it will be found clinging to them, and may be picked up with forceps, and dropped into alcohol for preservation. Live specimens should be kept in a glass jar, in water, with aquatic plants, in order that their feeding habits and method of getting about may be studied.

External Features. - Place a live asellus in a watch crystal with water. Add a few drops of chloroform or ether. Observe as to its general form the following points :-

1. A nearly linear body, much flattened dorsally.

2. A distinguishable head, with a pair of sessile eyes, and greater and lesser antennæ, easily seen from above.

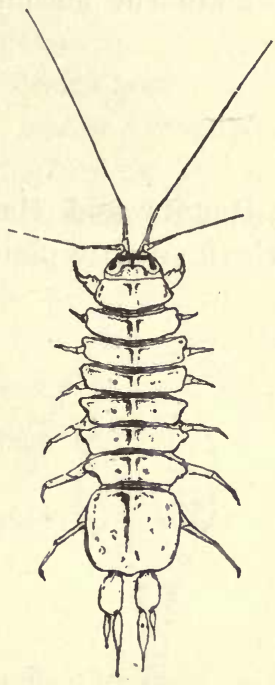

Asellus.

3. A long, distinctly segmented thorax, bearing seven pairs of legs.

4. A short, broad abdomen, with a pair of terminal stylets projecting posteriorly.

As soon as the animal has become quiet, place the watch glass on the stand of the microscope, and with low power (100 diameters) focus upon various parts of the abdominal stylets. They are sufficiently transparent to permit the blood in them to be seen circulating.

Obtain a specimen which has been a short time in alco- 
hol, and examine the gills (which are beneath the abdomen in this crustacean) and the mouth parts. Then remove all the appendages of the body, arrange them in order in glycerine upon a slide, cover with another slide, and make a serial drawing of them as seen, magnified 10 to 25 diameters. Make a larger drawing of the terminal segments of one of the first pair of thoracic legs, and explain the action of these parts.

\section{THE CYCLOPS.}

Haunts and Habits. - The water of an aquarium in which aquatic plants have been growing is almost certain to contain this animal. It is large

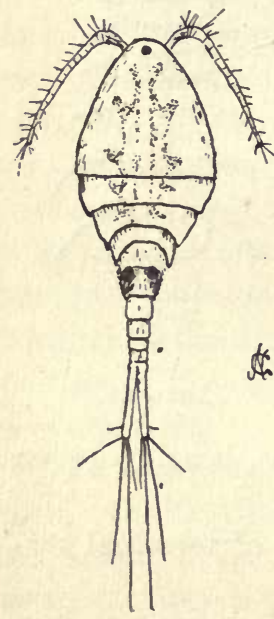

Cyclops $(\times 120)$. enough to be seen without a lens (about a twenty-fifth of an inch long). It appears as a white speck in the water, is very active, and swims with a peculiar jerky movement. Each large female cyclops will usually carry a pair of egg sacs attached at the sides of the abdomen.

External Features:- Take up half a dozen such specimens with a dropping tube, place them in a watch glass with water, and add a little ether. Place them under the miscroscope, and, having found one that presents a good dorsal view, study it with low power, to make out the following points as to its general form :-

1. An oval body, tapering posteriorly.

2. A dome-shaped carapace, covering the front of the 
cephalothorax, followed by four free thoracic segments of gradually decreasing width.

3. A tapering abdomen terminated by a pair of long, bifurcated stylets.

4. A pair of relatively large egg sacs attached to the first of the four apparent abdominal segments. This first segment is really composed of two segments which have grown together in the development of the female, but which remain distinct in the male (see cut).

On the extreme front of the carapace find a pair of eyes so close together that they appear as one under low power.

At the front find also two long, conspicuous first antennce, and just beneath them a pair of small second antennoe.

The remaining appendages may be seen in a ventral view of the animal. They are a pair of blunt, darkcolored mandibles, and two pairs of bristling maxilloe, surrounding the mouth, and some distance behind these five pairs of thoracic appendages (legs), the fifth pair rudimentary.

Note the absence of breathing organs. Respiration takes place through the skin. ${ }^{1}$

\section{FURTHER CLASSIFICATION.}

We have illustrated, by examples, species, genera, families, and orders, among animals. We have said that the species is the smallest zoölogical group, and comprises animals that are essentially alike. We have combined related species into a genus, related genera into a family, and related families into an order. And now we have extended our study far enough to have material for illustrating the higher groups. Orders are in the same way

1 Read "Anatomy and Metamorphosis of Cyclops," in Brooks's Handbook of Invertebrate Zoölogy. 
combined into classes. The centiped, spider, and all the orders of six-footed insects already studied, belong to the class Insecta. Make a list of the characters which all these have in common. This will approximately characterize the class.

The crawfish, asellus, and cyclops represent separate orders, which are included in another class, the class Crustacea. Make a list of the characters these have in common.

Classes are in like manner combined to form branches. Thus the two classes, Insects and Crustaceans, constitute the branch Arthropoda (or jointed-footed animals).

Branches are the primary divisions of the animal kingdom.

All animals having the body made up of a definite number of rings or segments with the hard parts outermost, and with jointed appendages, comprise the branch Arthropoda.

All arthropods that breathe by tracheæ (or tracheal gills) comprise the class Insecta.

All insects with scaly wings and complete metamorphosis comprise the order Lepidoptera, etc.

It often happens that the constituent members of one of these groups show different degrees of relationship toward each other. For example, in the class Insecta the orders of six-footed insects show much closer relationship to each other than they show toward the orders to which the spider and the centiped belong. In a case like this it is convenient to recognize intermediate groups. Accordingly all the orders of six-footed insects are combined into a subclass, Hexapoda; the spiders are placed in another subclass, Arachnida; and the centiped and thousand-legs, etc., are placed in still another, the subclass Myriapoda (or many-footed insects). So intermediate groups, when found in nature, may be interpolated between any of the other groups. 
Do not fail to learn that these groupings are but the result of an attempt to represent systematically the likenesses and differences of animals. The boundaries of the groups were but roughly laid out by the early systematic zoölogists. They have had to be changed in the past as the structural and developmental relationships of animals have become better known. They are changing now, and are liable to further change with increasing knowledge in the future. Any proposed system of classification, to be acceptable, must be natural; i.e., founded on existing important relationships.

NEED. zoöL. -9 


\section{WORMS.}

\section{THE EARTHWORM.}

\section{(Lumbricus.)}

Haunts and Habits. - This animal is familiar enough to the man who tills the soil, and to the boy who goes fishing and digs his own bait. It is common in garden soil everywhere. It is strictly nocturnal in its habits. In warm weather it may be observed, with the aid of a lantern at night, extending itself from its burrow, and searching the ground over. within a radius of its own length.

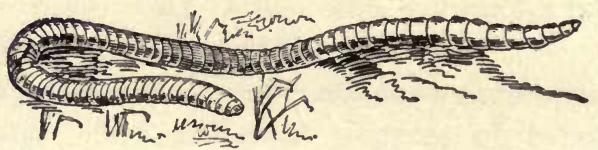

EarthWorm (Lumbricus terrestris).

It swallows earth in great quantities, and, having extracted from it whatever organic matter it contains, ejects it again in the form of castings. These broken vermiform castings are familiar objects to every observing person, for there is hardly a path in garden or meadow that is not strewn with them. They are often found abundantly, late in autumn, under piles of fallen leaves. The worms in this way bring great quantities of subsoil to the surface, and greatly increase the porosity of the soil by eating holes through it. 
Specimens for study may be obtained by digging, and at night by simply picking them up when they are out of their burrows and extended on the ground. At sunrise they may be seen in the mouths of their burrows, or partly extended, not having retired for the day. This explains why "the early bird catches the worm."

\section{Field Study. - In the field, observe :-}

1. The quickness with which they retreat when disturbed by a heavy step on the earth near their burrow.

2. The force with which they cling to their burrows when an attempt is made to drag them forth.

3. Their insensibility to sounds, however loud, and their slow sensibility to light.

4. The size, direction, and depth of their burrows.

5. The plugs found stopping the mouths of the burrows in the daytime, the materials used, and the skill shown by the worms in their method of plugging.

In winter, specimens obtained by digging may be placed in a box, or large flowerpot, of earth, and kept in a warm place, where they will quickly resume activity. They may be fed on bits of raw meat, preferably fat, of onion, celery, cabbage, etc., thrown on the surface of the soil; and when they are feeding at night, their habits may be observed with a lamp. By hiding bits of food beneath the surface of the soil, the student may determine whether worms have anything corresponding to the sense of smell, enabling them to find food with which they would not ordinarily come in contact.

Study of a Live Specimen. - Place a live worm on a sheet of wet paper, and observe:-

1. In its body-

(a) Definite anterior and posterior ends.

(b) Correspondence of right and left sides (bilateral symmetry). 
WORMS.

(c) The numerous similar transverse segments composing the body.

(d) The absence of appendages.

2. In its motions -

(a) Rhythmic contractions and corresponding changes in form of its body.

(b) Irregular progression forward.

Place the worm on a smooth, clean pane of glass, and observe, that, while its contractions continue, its progression ceases.

Draw the worm backward across a finger, to feel the minute seto (or bristles) by means of which it holds its ground on any except the smoothest surfaces.

Observe how it crawls backward when touched near the anterior end, pe.forming reflexly the acts which under its ordinary conditions of life would carry it to a safe retreat within its burrow.

Turn it over on its back and observe what follows.

Tap the paper, or jar the table, on which it lies, and note the result.

External Features. - For a study of the general structure of the earthworm, use specimens that have been anæsthetized with chloroform. Select the largest specimen obtainable, and dissect it under weak alcohol ; but, before dissecting, observe with a lens the following among its external features:-

1. The darker color of the dorsal surface.

2. The greater length of the body-segments at the tapering anterior end.

3. The dorsal flattening of the posterior end of the body.

4. The mouth at the anterior end, and the prostomium projecting forward above it, from the dorsal side of the foremost segment. 
5. A swollen region (the clitellum) between the thirtieth and fortieth segments (counted from the front), embracing several segments.

Find a pair of small pores on opposite sides of the median ventral line of the fifteenth segment, and another similar but smaller pair on the fourteenth segment. These are the external openings of the reproductive organs. Two other pairs of pores may be made out, sometimes with difficulty, on opposite sides of the median ventral line, - a pair on the groove between segments 9 and $\mathbf{1 0 ,}$ and another pair on the groove between segments 10 and 11. These are the openings of the seminal receptacles, (accessory organs of reproduction).

A row of pores is present on the median dorsal line, one at the anterior edge of each segment, opening directly into the body cavity. These are not very evident.

Find two pairs of setie (or locomotor bristles) on each side of each segment, - one pair at the edge of the flattened ventral surface; the other a little higher, on the side of the body. Observe that these are arranged in four longitudinal double rows.

Pin the specimen down for dissection beneath weak alcohol, with one pin through the prostomium only, and another through the last segment, with the body slightly stretched between the pins. Very great care will be necessary to successfully complete the following dissection. Cut no more than directed.

Dissection. - With thin, sharp scissors make a shallow, longitudinal cut through the body wall, along the dorsal surface, the entire length of the body, taking care not to injure the organs which lie beneath. At the middle of the body draw the edges of the cut apart, and observe the septa (or partitions) which extend transversely across the body cavity. Observe that these correspond in position 
with the depressions between segments seen on the exterior, and show internal segmentation. Observe that each of the septa is perforated at the center for the passage of the alimentary canal and other vessels. Observe, also, that the segmentation of the body extends to the alimentary canal, which in this region is somewhat expanded in each segment.

Beginning at the anterior end, cut the septa close to the body wall on each side down to the uppermost row of setæe, and pin back the flaps, exposing the internal organs. Most conspicuous among these will be the large-lobed, white seminal vesicles, nearly filling the body cavity between the tenth and the fifteenth segments, and the darker-colored alimentary canal extending straight through the center of the body longitudinally.

Find a dorsal blood vessel extended along the upper side of the alimentary canal, with five pairs of aortic arches extending downward from it in segments 7 to 11, and meeting below the alimentary canal in the ventral blood vessel, which extends backwards longitudinally.

I. Organs of Digestion. - Beginning at the posterior end, lift out the alimentary canal, carefully dissecting it free from the septa, and avoiding disturbing other organs. Make out in the alimentary canal the following parts :-

1. A wide pharynx, posterior to the mouth, with many radiating muscle fibers extending from its walls to the outer body walls. When the soft margins of the mouth are applied to any object that is to be seized, these muscle fibers, contracting, dilate the pharynx, creating within it a partial vacuum, and exerting a powerful sucking action upon the object seized.

2. An esophagus, a slender, thin-walled tube, extending backward from the pharynx.

3. Three pairs of minute yellowish white calciferous glands attached to the esophagus in segments 10 to 12 . 
These secrete a milk-white fluid of unknown function, containing carbonate of lime.

4. The crop, a thin-walled dilatation of the alimentary canal in segments 15 and 16.

5. A muscular gizzard, lined with membranes elevated in chitinous ridges, usually occupying segments 17 to 19 . This is the principal organ for grinding and comminuting the food.

6. The remainder of the alimentary canal is the intestine. It probably possesses digestive functions throughout its length.

II. Organs of Reproduction. - Cut the alimentary canal in two at the back of the pharynx. Leave the pharynx in place, but remove the remainder of the digestive tract. After it is lifted out from between the lateral lobes of the seminal vesicles, these organs will be fully exposed. These cover the male reproductive organs; and a pair of ducts extend backward from them, to open to the exterior at the pores already noticed on segment 15 .

The earthworm is hermaphrodite, and ovaries will be found (sometimes with difficulty) on the floor of the body, - a pair of minute, whitish bodies on either side of, and close to, the median ventral line of segment 13 . The disconnected oviducts, posterior to the ovaries, penetrate the septum between segments 13 and 14, and open to the exterior at the pores already noticed on segment 14.

Attached to the septa, between segments 9 and 10 and 10 and 11, are two pairs of minute, whitish sacs, which open, directly downward. These are the seminal receptacles, the accessory organs of reproduction already noticed. In them the sperms from another individual are stored until the time when the eggs are laid; for, though the earthworm is hermaphrodite, cross-fertilization seems to be the invariable rule. 
III. Nervous System. - Remove the seminal vesicles. This will entirely expose the nerve cord which lies-extended along the floor of the body cavity its entire length. Observe the ganglion-like swellings in each segment. Observe the nerves given off from it to each segment. Trace it forward to the pharynx. Observe that it forks, surrounds the pharynx, and unites again abore in the cephalic ganglion (or brain). Compare this arrangement of the central nervous system with that already seen in crustaceans and insects.

IV. Organs of Excretion. - Observe the segmental organs (nephridia), - little, tangled, thread-like bodies, attached to the posterior side of each septum, one on each side of the body in each segment. Each of these organs opens to the exterior by a minute pore, not heretofore noticed, and not easily discovered. Each opens internally at the end which floats free within the body cavity, by a minute ciliated orifice (discoverable only by careful microscopic examination). These are excretory organs, and drain out waste and worn-out materials from the body.

V. The Body Wall. - Spread out the body wall perfectly flat, and pin it so. Observe its muscular lining. Note that the longitudinal, fibrous bands are discontinuous, as such, along the lines occupied by the locomotor setæ. These setæ are moved by small muscles of their own, not the least in importance in the animal's mechanism. Strip up some of the longitudinal muscles, and observe the circular ones that lie beneath. Outside these is a layer of epidermis.

VI. The Body Cavity. - Cut a clean transverse section of another specimen which has been hardened in alcohol, using a very sharp knife or scalpel, and examine the cut end with a lens. Note that the body is made up of two tubes, one within the other, - the inner one, the diges- 
tive tract, muscular on its outside; the outer one, the tube formed by the body wall, muscular on its inside. Note that the body cavity between these two is bridged by the numerous transverse septa. Compare the earthworm with the crawfish and the grasshopper in respect to this structure.

Microscopic Examination. - Obtain another anæsthetized worm. Insert a slender pointed pipette through a puncture into the body cavity, and draw out a drop of the fluid filling that cavity. Place the drop on a slide, cover, and examine with high power of microscope to discover :-

1. Chloragogue cells, large and irregular, and yellowish in color. These cells form a layer surrounding the alimentary canal for a great part of its length. They are believed to perform the functions which the liver performs in higher animals, at least to the extent of secreting a fluid to aid in the digestion of food.

2. Amoeboid blood corpuscles, so transparent they may be overlooked at the first glance. These show pseudopodia, and, if kept warm, may be seen to be in action, like amœba, whence the name. It must be borne in mind that these cells do not have an independent existence like amœba, but that they are constituent cells of a manyceller animal, dependent for their life upon conditions supplied by other parts.

3. Sperms. Lay open the body cavity. Puncture one of the seminal vesicles, and take from it with a pipette a drop of its fluid contents. Mount, cover, and examine this with high power of microscope. It should contain many minute filiform sperms, some of which may be seen actively swimming about. They may often be better seen (but not in motion) after running a drop of magenta under the cover. 
Mechanical Movements of Blood Vessels. - The mechanical action of the parts concerned in nutrition can best be understood by studying them in a live worm. Small specimens can be found so nearly transparent, that the blood vessels can be seen from the outside, and their pulsations watched with a lens. But it will be found more satisfactory to study these things in a large living specimen that has been stilled with chloroform or ether. Pin the specimen out in the dissecting pan in a $\frac{3}{4}$-per-cent salt solution, as before directed, and open it by a longitudinal cut a little to one side of the median dorsal line.

Expose the blood vessels, and observe their contractions. Note that the contractions pass along the vessels in successive waves, which mark the course of the blood in them. Their red color is due to the blood they contain, and the color of the blood is in its liquid part (plasma), and not in its corpuscles.

These and other contractions, sometimes observable in the alimentary canal, are performed by the automatic action of muscles within the walls of the organs themselves. These, contracting, push the contents forward, much as water in a rubber tube would be pushed forward if the tube were drawn tightly between the fingers.

Development. - The eggs of the earthworm are laid in May or June, and may be found at that time, a number together, inclosed within ovate, tough, yellowish or brown capsules, in. loose earth, beneath logs and stones. These capsules are formed in the following peculiar manner: Certain glands of the clitellum become very active at this season, and pour out on the surface of the body a fluid which hardens into a tough membrane, forming a girdle about the body. A thick jelly-like fluid is retained within this girdle, between it and the body. The girdle is gradually worked forward, toward the head. When 
it passes the openings of the oviducts on segment 14, ova are discharged into it; and in passing segments 11 to 9 it receives sperms that have been stored in the seminal receptacles. When it is passed off over the head, it closes elastically at both ends, forming a capsule. Within this capsule fertilization takes place, and the fertilized ova develop, and give rise to little worms, which feed upon the nutrient fluid in which they float, until they are able to make their own way in the world. ${ }^{1}$

1 Read Darwin's Formation of Vegetable Mould through the Action of Worms. 


\section{MOLLUSKS.}

\section{THE RIVER MUSSEL.}

\section{(Unio.)}

Haunts. - This animal is common in all our rivers and small lakes. It is found on the bottom, usually partly buried in sand or mud. As it moves about, it makes a trail through the mud or sand, - a shallow groove, with abruptly sloping sides; and, by observing its track at the edge of the water, it may often be more easily found. Occasional specimens may be picked up at the bank, but usually larger ones will be found farther out. They may be raked ashore with a long-handled garden rake, or drawn up with a long-toothed lawn rake from a boat, or, in warm weather, most rapidly obtained by wading out on a submerged sand bank and picking them up by hand. The dead and empty shells strewing the banks will be a guide to the best places to search for live specimens.

When a river is falling after a flood, many mussels will be found close to the banks, and many others may be seen out on the banks, where they have been left high and dry by the receding waters, and where they have died. This is a casualty of a very common kind among the lower animals.

Specimens collected in the field may be carried home in a bucket of water, and kept alive in an aquarium improvised from a tub or a water-tight box, with a layer of sev- 
eral inches of sand in the bottom and several inches of water above the sand. Here something of their habits may be seen.

Study of a Live Specimen. - Take a live specimen in hand, and note :-

1. That the animal has entirely withdrawn itself within its shell.

2. That its shell is composed of two equal pieces called valves.

3. That the valves are hinged together at one side.

4. That they are firmly held together at their free margins. Try pulling them apart.

5. That there is a central prominence in each valve (the beak or umbo) near the hinge.

6. That each umbo is a center of growth, with lines of growth arranged concentrically around it.

Now observe one of the mussels that have been placed on the sand in the aquarium, - one which, having been left for awhile to itself, has gotten up on edge and started to travel. Observe :-

1. That the hinge is up. It is on the back or dorsal margin.

2. That the free margins of the valve are down. They form the ventral margin.

3. That they are slightly separated, and that the animal is partly extended between them.

4. The direction in which the mussel is traveling. Take some measured observations and compute its rate of speed.

5. That the umbones are nearer the forward or anterior end. Looking at the moving mussel from behind, the valve on the right hand is the right valve; the other, the left valve.

6. That the animal moves by a succession of pulls. Find out what does the pulling. 
7. That there are two round fringed openings at the posterior end of the dorsal margin. These are the siphon openings. If the water be shallow enough, there may be seen near these a play of wavelets on the surface, indicating currents. Place a drop of india ink or other colored fluid in the water near these openings, and discover the direction of the currents in each of them. Record the result.

8. That there is an exserted membrane fringing the free border of each valve all around. This is the edge of the mantle. Touch it in various places, and note its sensitiveness.

9. That there is a white, flexible, muscular foot protruded downward and forward between the mantle margins into the sand. By quietly placing a finger horizontally in the sand in front of the mussel, and directly in its course, and waiting for the animal to travel over it, you may discover how the foot is used.

Pick up an active mussel quickly out of the water, and see how quickly the foot is retracted.

Place a sheet of tin or a pane of glass on the sand, and lay a mussel on it at its center. Note how the animal protrudes and uses its foot, in its efforts to rise.

Explain its inability to rise on edge and move away.

Discover by experiment whether the fringes of the siphons are sensitive to light.

Structure. - In dissecting a river mussel, the first thing to be done is to get the shell open so as to get at the animal so securely locked inside. The valves are held together by two stout, transverse muscles. Select a live specimen of large size for the first dissection. Place it for a few moments in water as warm as the hand can bear. This will relax the muscles. The valves may then be opened slightly, and a block inserted between them to keep them so. 
Observe a soft, whitish membrane, with a narrow, darkcolored, ruffled border lining each valve. It is the mantle. Loosen the edge of the mantle from the edge of one valve by pushing a knife blade between the two, and drawing it entirely around the free border of the valve. Keep the point of the blade close to the shell. Observe that the mantle clings to the valve along a line within and parallel to its margin. Observe that the point of the knife blade meets with an obstruction near the dorsal sur-

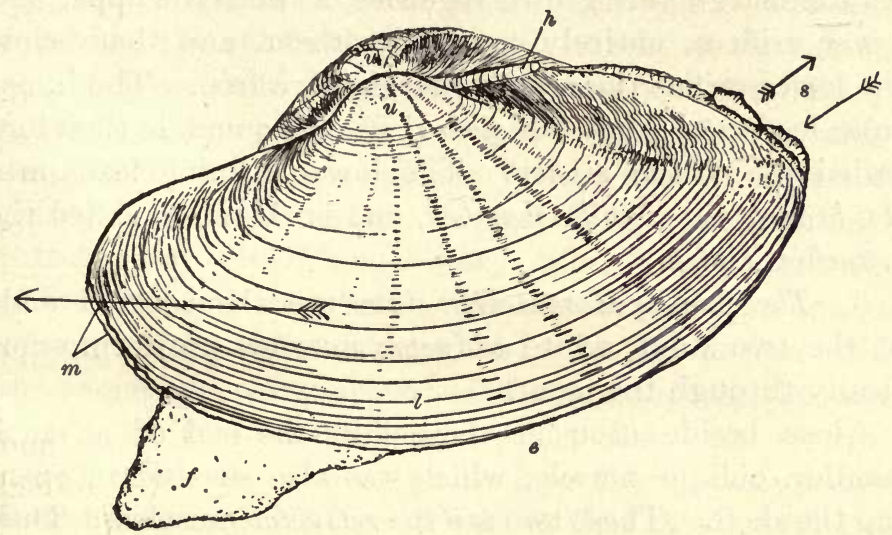

Diagram of Unio: $u$, umbo; $h$, hinge; $s$, siphons; small arrows indicate the direction of the water currents; large arrow indicates direction of travel, and also depth to which the animal is usually found buried in the sand in locomotion; $f$, foot; $e$, edge of the valves; $l$, concentric lines of growth; $m$, mantle margins extruded in front.

face, at both anterior and posterior ends: it encounters the strong muscles which hold the valves together. Cut these off close to the valve. Notice the valves spring apart when these are severed. Free the one valve from all connection with mantle and muscles, and turn it back like the lid of a watch case.

I. The Different Parts. - Study the following parts, doing no more dissecting than is absolutely necessary:1. The mantle. Observe the thinness and transpar- 
ency of its inner part, and the sensitiveness and mobility of its border.

Observe that it consists of two lobes corresponding in size to the two valves of the shell, and that its border is continuous from one to the other.

Observe how loosely it infolds the body, and covers it above and on the sides.

2. The siphons. Observe that the siphon orifices are formed from the edge of the mantle, and that the adjacent mantle margins are grown together between the upper and lower orifices, entirely separating them, and that below the lower orifice the mantle margins are free. The upper tube leads out from the cloacal chamber, and is therefore called the cloacal siphon. The lower opening leads into the branchial (or gill) chamber, and is therefore called the branchial siphon.

3. The principal muscles. Observe the severed ends of the two stout, white adductor muscles projecting vertically through the mantle.

Close beside each of these find the end of a much smaller, oblique muscle, which was also severed in opening the shell. These two are the retractor muscles. They retract the foot. Prick the point of the foot, and watch the posterior adductor muscle. Prick the back part of the foot, and watch the anterior adductor muscle. If these were fast to the shell, instead of being drawn down, they would draw the foot up, as may be seen later by pricking the retractors of the other side, near their origin, before severing them from the valve.

In the thickened border of the mantle are many muscle fibers, to which its mobility is due, and by which it was attached to the shell along the pallial line.

4. The gills. Turn the loose part of the mantle back upon the dorsal surface, and expose the gills. They hang suspended in the branchial chamber at the posterior part 
of the body. Observe that they are thin, ribbed and perforated folds of membrane extending longitudinally beside the body, a pair on either side. Between the two pairs observe the soft, white, muscular abdomen, extending downward and forward, and terminating insensibly in the retracted and minutely wrinkled foot.

Examine the surface of the gills with a lens.

Lift with forceps the lower edge of one of the gills (if the outer gill appear dark and distended, lift the inner one), stick a sharp knife or scalpel through it, and make a vertical slit out to the edge. Then look at the cut edge of the piece held in the forceps, and see that the gill membrane is double and $V$-shaped in cross section, and is suspended by the arms of the $V$ from above. Insert the point of a knife blade into the end of the piece held in the forceps, and split it lengthwise. Then take a small piece of the single gill membrane thus obtained, and mount, and examine it (without cover glass) with low power. Note the shape and arrangement of the openings in the membrane, the location and action of the cilia.

Pass a bristle or other probe into the cloacal chamber from its siphonal orifice. Observe that this chamber lies entirely above the gills, and that it has no communication with the branchial chamber below, except through the gills.

Lay open the cloacal chamber for half an inch by a single cut with scissors through the wall of the cloacal siphon. Observe the minute openings leading from the floor of the cloacal chamber down into the gills. Pass a bristle into one of these, and observe that it ends blindly at the lower edge of the gill.

Make a short longitudinal cut through the posterior part of the attachment of both gills to the cloacal chamber. Then lift with forceps the cut edge of the outer layer of the outer gill, and observe the numerous septa or partitions extending transversely between the outer 
and the inner layers, connecting the arms of the V. Observe also that the inner layer of the outer gill is continuous with the outer layer of the inner gill.

Having already observed that the water passes in at the branchial and out at the cloacal siphon, give now an explanation of the course it takes, and of the manner in which it is propelled onward in its course.

5. The blood vessels. Turn the free lobe of the mantle down again, and loosen the dorsal portion from both valves. Then pull downward gently on the free lobe so as to bring the dorsal aspect of the body better into view. The dorsal portion of the mantle is very thin and transparent, and through it may be seen, in the part that was directly beneath the hinge, an oval or elongated transparent vessel regularly but slowly pulsating. This is the ventricle. Pinch up the mantle with forceps, and cut it away from this region, and the parts will be better seen. The blood comes to the ventricle from a pair of auricles located one on either side. Each auricle lies directly between the gills and the ventricle, and is somewhat conical in form, with the apex of the cone toward the ventricle. A branchial vein brings the blood from the gills to the lower end of the auricle. The ventricle is emptied principally through a pedal artery which curves forward and downward toward the foot.

Observe that the dark-colored intestine runs directly through the ventricle, like a draught pipe through a locomotive boiler, there being no open communication between the two vessels.

Observe the pulsations of the heart. ${ }^{1}$ First the auricle

1 A very satisfactory demonstration of the action of the heart may be made by cutting away with bone snips the portion of the shell which immediately surrounds the hinge, and covers the heart, leaving the animal intact within. A thin-shelled specimen should be selected for this. If kept under water, or, better, under $\frac{3}{4}$-per-cent salt solution, the pulsations may be observed for a long time. 
swells up with limpid transparent blood from the gills, and then it contracts and fills the ventricle, which then contracts in turn, sending the blood out through the pedal artery.

II. Digestive System. - On either side of the front part of the abdomen observe two soft triangular flaps narrowing toward the front. These are the labial palps. Between them, directly in front, is the mouth, which leads through a short esophagus into the stomach. The stomach is surrounded by a dark brown mass called liver, easily seen when the mantle is removed. The course of the digestive tract is difficult to trace in a fresh specimen, but may be followed more readily in one that has been hardened in alcohol. Posterior to the stomach there are several turns of the intestine ${ }^{1}$ before it emerges from the abdomen to pass into and through the pericardial cavity, where it has already been noticed running through the ventricle. It terminates in the cloacal chamber. If the heart and the part of the intestine posterior to the abdomen be removed, two dark-colored renal organs will be seen below them. These organs open below into the cloacal chamber, and above into the pericardial cavity, thus connecting the body cavity with the exterior, as do the renal (segmental) organs in the earthworm.

III. Nervous System. - This will be studied with extreme difficulty in a fresh specimen. It will require less time and patience if a specimen which has been hardened in alcohol or by boiling be used. It may best be studied in a specimen which has been soaked for a few days in 10-per-cent nitric acid.

Remove the mussel entirely from its shell, and pin it in a dissecting pan, with its dorsal surface down. Sepa-

1 It may be demonstrated by injecting the alimentary canal through the mouth with starch mass (see Appendix, p. 284) colored with lampblack, and dissecting away the sheet of overlying muscle of one side. 
rate the two pairs of gills on the median ventral line, and find directly beneath the posterior adductor muscle a pair of yellowish ganglia more or less united. These are the visceral ganglia. Trace from them as a center a pair of lateral nerves to the gills, a pair of posterior nerves to the edges of the two mantle lobes, and a pair of very long commissural nerves forward, to join a pair of cerebral ganglia which lie near the surface at the bases of the labial palps, on either side of the mouth. From these ganglia trace a pair of nerves downward to the pedal ganglia, which lie deeply imbedded where the foot joins the abdomen. The nerves appear as fine white threads; the ganglia are usually more easily seen because of their yellowish color. These three pairs of ganglia, with their connecting commissures, constitute the central nervous system of the mussel, and of a large group of animals of which it is a type.

IV. Reproductive Organs lie in the posterior part of the abdomen, one on each side, and each opens by a slit on the upper surface just above the long commissural nerve traced forward to the cerebral ganglia.

The eggs of the river mussel are passed into the cavity of the outer gill, where they hatch, and where the young are retained for a time. If there be found a specimen in which the outer gills appear swollen and dark colored, open one of them, and mix a little of the contents with a drop of water on a slide. Examine with low power, and look for little mussels. Draw several of them. Notice whether any of them move about.

V. The Shell. - Remove all muscles from the inside, and dirt from the outside, of the shell, and observe again the concentric lines of growth about the umbones. Hold the shell up toward the light, and observe the fine lines radiating from the umbones.

Inside the shell, notice the large adductor muscle scars, 
and close beside them the smaller but often deeper scars of the retractor muscles. Observe a narrow linear muscle impression, - a curved line marked around the free border of the valve, about half an inch from the edge. This is the line along which the mantle was found clinging. It is therefore called the pallial line.

Observe the hinge teeth between the dorsal edges of the two valves. Open and close the valves, and see how these interlock. They hold the valves together very firmly, when closed. The blunt, irregular, serrated ones between the umbones are the cardinal teeth. The long, narrow, shelf-like folds of pearl beneath the hinge are the lateral teeth.

Observe that the shell consists of three layers:-

1. An outer layer of horny, brownish, or greenish epidermis, which was continuous at the edges of the shell with the border of the mantle. The hinge at the back is a modified and very elastic portion of the epidermis.

2. An inner, pearly layer. This is seen, under magnification, to consist of thin, flat layers of pearl, the edges of which appear as fine, sinuous lines. These cause interference in the light waves that fall upon them, and give rise to all the singularly beautiful colors seen within the fresh shells of some Unios.

3. A darker middle layer, seen, under magnification, to consist of polygonal prisms placed perpendicular to the surface of the shell.

Dissolve out the mineral matter from a shell by placing it for a time in dilute acid. What properties has the remaining part?

Burn out the animal matter from a number of shells. Weigh them before throwing them into the fire and after taking them out, and note the proportional loss. Pick a burned shell to pieces, and note the disposition of layers in its thickened part. 
The Life Process. - Since, in connection with each of the organs studied, the work it has to do has been already mentioned, it only remains to summarize these various operations as parts of the process by which the life of the animal is maintained.

I. Nutrition. - This part of the process is dependent to a marked extent upon the aquiferous system, and the water currents it keeps up. The siphons are the most conspicuous part of this system; but the cilia lining the openings into the gills, although the least conspicuous, are the most important part of it, for it is by their lashing action that the water is drawn into one siphon and driven into and through the gills and out through the other siphon. In the gills the usual exchange of carbonic-acid gas for oxygen takes place between the water flowing freely over the thin-walled blood vessels distributed throughout the gills and the blood flowing inside those vessels. In other animals that breathe by gills this exchange seems to be the sole purpose of the water currents, but in the mussel these currents also assist in the procuring of food and in excretion. The food consists chiefly of low plant organisms found free in the water. These are carried into the branchial chamber by the entering current. The current does not all enter the gills, but a branch of it is driven forward toward the anterior end of the body, and the bits of food carried along by it are directed by the labial palps into the mouth. Excreta are expelled with the current passing through the cloacal siphon. Thus all the operations connected with nutrition are more or less directly dependent on the water currents.

For convenience in summarizing, we may say that nutrition is effected in the river mussel through the agency of the following interdependent systems of organs :-

1. A digestive system, comprising the alimentary canal and the large accessory gland called liver. 
2. A circulatory system, comprising (1) veins which collect blood from all the tissues and convey it to the gills; (2) other (branchial) veins, which convey the aërated blood from the gills to the heart; (3) auricles, which receive the blood from the gills, and, contracting, pass it on into (4) the ventricle, which in turn contracts, and drives it through (5) the arteries, out into the tissues again.

Four important changes take place in the blood during its course through the body:-

(a) It is enriched by the digested food, which it receives directly through the walls of the alimentary canal.

(b) In the tissues the cells with which it comes in contact take from it whatever material they need for growth, and return to it their waste products of oxidation.

(c) On its return to the gills, part of the blood passes through the renal organ, where nitrogenous waste products are taken from it for excretion.

(d) In its passage through the gills it loses waste carbonic acid, and absorbs oxygen.

3. A respiratory system, comprising the gills, with their numerous small blood vessels.

4. An aquiferous system, comprising the siphons and the ciliated passageways through the gills.

5. An excretory system, of which the renal organs and the gills cemprise the most important part.

Metabolism is in this, as in all other animals, performed by the individual cells.

Certain of the mantle cells take calcium carbonate from the blood, and deposit it as a precipitate, thus forming the mineral part of the shell. The soft inner part of the mantle thus continues through life to deposit on the inside of the shell a layer of pearl. If a foreign body get into the substance of the mantle, or get between the mantle 
and the shell, it will be covered with a layer of pearl. This is the way that the pearls of commerce are produced; and inferior pearls are often found in dissecting our common river mussels.

II. Reproduction. - The eggs, as already noticed, are fertilized, hatched, and the young are nurtured for a time in the outer gills of the female. Their number is prodigiously great. The young, when found in the gills (then called glochidia), differ very markedly in appearance from the adults, in their widely gaping, triangular valves, hooked at the tip. When they are expelled from the gills into the water, to shift for themselves, they fasten themselves by means of these hooks to some floating or swimming object, preferably to the fins of a fish or to the tail of a tadpole, where they lead for a time apparently a parasitic existence. Later they fall to the bottom, and begin life independently. Doubtless multitudes of those that fall to the bottom are buried in the shifting mud and sand; many more are eaten by other aquatic animals before their shells have attained sufficient size and strength to afford them protection; and even in adult life some are eaten by minks and otters, and very many are left out on the banks by receding floods to die of evaporation: so that the vast number of eggs produced appears, in the end, after taking all casualties into account, to be only sufficient to maintain for the species its accustomed numbers, and to keep up the biological balance in the life of the river beds.

III. Voluntary Motion. - The muscular system serves the river mussel the double purpose of performing its movements, and of holding it in its shell. The strongest muscles are the adductors, which close the shell. Opposed to these is only the hinge ligament, which, upon their relaxation, opens the shell automatically.

The foot is principally a muscular organ consisting of 
longitudinal fibers of the oblique pedal muscles, capable of retracting it, or of moving it sidewise, and of circular fibers capable of extending it. It is adapted for plowing through mud or sand, and for no other kind of locomotion. Only by sinking the foot into mud or sand is the animal able to rise to its erect position. Blood is forced down the pedal artery through the center of the foot into its point, as an additional aid to its extension; and by the distension of its tip a firmer hold is obtained in the sand, to aid in locomotion. The flat muscle of the mantle is capable of moving its entire margin.

IV. Sensation. - The nervous system of the mussel consists of the three pairs of ganglia already noticed, and of nerves radiating from each pair extending to every vascular part of the body, giving sensibility to every part, and furnishing nervous communication with every other part.

The senses are not very acute. Touch is well developed, and is most acute in the point of the foot and in the mantle margin, particularly in the part which forms the outer border of the siphons. Taste and smell are probably developed slightly, and aid the animal somewhat in the selection of food. Sight and hearing are developed but feebly, if at all. There is a so-called ear sac in the foot, near the pedal ganglia. That it is an organ of hearing is very doubtful. It seems more probable that it is an organ of the sense of equilibrium, enabling the animal to distinguish between a flat or inclined position and an erect position. Though incapable of hearing sound, the animal may feel vibrations when they become sufficiently intense. The siphon fringes are so sensitive to light, that a heavy shadow thrown across them will cause them to be retracted.

The instincts of this animal are of a low order: they seem to be limited to self-preservation and the selection 
of food. A complete retreat within its shell is its only means of defense. But the hard, closed shell is protection, strong in proportion as the instincts are weak.

The river mussel is a representative of the group Mollusca (or soft-bodied animals).

Other Mollusks. - There are three forms of snails, very common throughout the interior: (1) land snails, found under the fallen leaves and decaying logs in hardwood groves, and easily collectible in warm weather; (2) pond snails, found on the submerged vegetation of ponds throughout the year; (3) river snails (operculates), found in the same situations with river mussels. The most available of these for study in the winter is the pond snail.

\section{THE POND SNAIL.}

\section{(Limnea.)}

Haunts. - This animal may be found in almost every natural small pond, adhering closely to the stems and leaves of aquatic plants, to the dead stems of "cat-tail flags," to sticks, boards, old boots, etc. ; in fact, to almost anything that may have chanced to get into the water. These things may be slowly drawn out of the water, and the snails picked off them by hand.. The only apparatus necessary for collecting pond snails is a small vessel of water to carry them home in.

Aquarium Study. - They may be kept in an aquarium, or, better for study, in a bowl, or dish, or fruit jar, in water. The vessel should be kept clean, and they should be fed daily with leaves of cabbage or lettuce. They are very easy to keep; there is much that is novel and interesting in their habits that is quite easy of 
observation; and every student should keep a number of them awhile for his own study.

In a fully extended specimen, observe, first, the three distinctive and obvious characters of mollusks: (1) the foot beneath the body, (2) the mantle covering its back, and (3) the shell secreted by the mantle. The foot is the broad, flat disk on which the animal creeps; the mantle edge is just visible within the edge of the shell.

The Shell. - Study the shell. Observe that it is in one piece (univalve), whereas the shell of the mussel is in two pieces (bivalve). Its parts are named as follows:-

1. The apex is the pointed end.

2. The aperture is the opening at the large end.

3. The lip is the outer edge of the aperture.

4. The lines of growth are parallel to the lip.

5. The suture is the spiral groove on the outside.

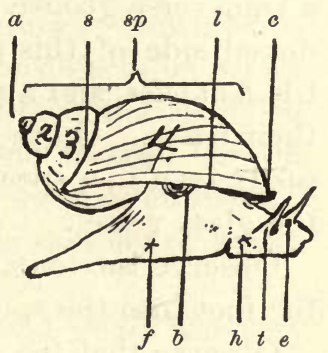

Diagram of Pond SNaIL: $a$, apex; $s$, suture ; $s p$, spire; $l$, lip; 1, 2, 3, 4, whorls of shell, the larger ones showing lines of growth (the aperture is filled with the body of the animal); $c$, collar (edge of mantle) protruding beneath the lip; $h$, head; $f$, foot; $e$, eye; $t$, tentacle; $b$, breathing aperture.

6. The spire comprises all the whorls or turns of the shell taken together.

7. The columella is the axis of the spire.

If, when holding the shell with the apex toward you, the whorls, as they proceed from you, turn to the right, above the axis of the spire, the spire is right hand, or dextral; if they turn the other way, it is left hand, or sinistral.

In the river snails an operculum will be found, - a lidlike piece which completely closes the aperture when the animal is retracted within the shell. 
External Features. - Study the external features of the snail by careful inspection of live and active specimens moving about in a glass vessel. Observe that the foot is bilaterally symmetrical, that it tapers to an obtuse point behind, that it is squarish or truncated in front, and that its foremost part is marked off from the rest by a transverse groove on the ventral side. Observe, on the dorsal side of this part, a pair of long motile and retractile tentacles, 'and a pair of eyes appearing as dark spots at their bases. On the ventral side of this part is the mouth, easily seen in a specimen that is crawling on the side of the glass vessel.

Observe the long, flexible body, extending upward from the foot into the spire.

Observe that the mantle is thickened at its edge where it lines the edge of the aperture. This part is the collar.

Observe in snails, at the surface of the water, a conspicuous orifice in the collar at the right side of the body. This is the respiratory orifice. The mantle is pushed in at this point, and distended within into a sort of baglike rudimentary lung, in the walls of which the minute blood vessels are distributed.

Habits. - Study the actions of the snail. How is its peculiar crawling, creeping, or gliding locomotion effected? Note that it moves with equal ease on the bottom, on the sides, and in inverted position along the surface of the water. It will be seen to come to the surface at more or less regular intervals for a fresh supply of air, and may sometimes be seen expelling a bubble of impure air before taking in a fresh supply. It will be seen to close its respiratory orifice before going down again. Occasionally a snail may be seen to let itself down from the surface by a floating thread of mucus secreted by glands in the foot. When a number of snails going in opposite direc- 
tions meet, one may sometimes be seen using its shell as a means of offense, clearing its track by striking about with its spire. If the mouth of one that is crawling on the side of glass be watched with a lens, its ribbon-shaped radula, covered with rows of minute, recurved teeth, may sometimes be seen slightly protruded. By means of muscles attached at both ends, the radula is drawn backward and forward like a rasp across the objects on which the snail feeds. Cabbage leaves on which the snail has been fed will show areas which have been "scraped" by the radula. All these things and many more may be seen by carefully watching a few live snails in a tumbler of water.

Development. - The eggs of the pond snail are very easily procured, and they offer exceptionally fine advantages for the study of those stages of development which immediately succeed fertilization. They are laid in gelatinous, transparent capsules, half an inch to an inch in length, flattened, and linear or oblong in outline. After a few snails have been kept a short time in a small vessel of water with their appropriate food, these egg capsules may be looked for on the bottom and sides of the vessel, or closely adherent to the stems or leaves of plants placed in the water. They are so transparent as to be easily overlooked.

Detach one of these egg capsules by pushing a thin blade between it and its support. Place it in a watch glass with a little water, for examination.

Examine it with a lens, and draw it. How many eggs does it contain? How are these eggs arranged in the capsule? What is the shape of each egg?

Note that each egg contains a minute oösperm (or fertilized ovum), which is less transparent than other parts. It is the development of this oösperm that especially invites our study. 
I. Segmentation. - Place the watch glass upon the stage of the microscope, and examine the eggs with low power. If a freshly laid capsule has been obtained, the oösperm of each egg will appear perfectly spherical in form, and slightly yellowish in color, from the large number of minute food-yolk granules distributed through it. If it be kept covered with water, and watched at intervals of half an hour or less during the first day, and at intervals of half a day thereafter until hatched, the following changes may be confidently expected:

The oösperm is practically a single large cell, formed by the fusion of two specialized reproductive cells called ovum and sperm. The fusion of the two we have already called fertilization, and have said that it is essentially the same process in all animals except the protozoans. Fertilization necessarily precedes and initiates the changes which we are now to study.

The oösperm divides, and becomes two spherical cells instead of one; after a short quiescent period, the two divide, and become four; after another short period, the four divide, and become eight; and so on, with decreasing regularity. This process is called segmentation.

If all the eggs in a freshly laid capsule be examined, some of the oösperms will be sure to show a lighter and a darker side. This is owing to a greater accumulation of yolk granules at one side of the sphere. Some will show, also, one or two minute transparent polar bodies pushed out from the middle of the lighter side. That pole of the sphere at which they appear is called the formative pole. In segmentation, a groove first appears at the formative pole, extends meridionally around the oösperm, and deepens until two separate cells are formed. These cells appear to partly coalesce again, before the next division. Then a second groove starts at the formative pole, and extends meridionally around the two cells at right angles to 
the first groove, and deepens until the two cells are divided into four. Then an equatorial groove at right angles to both first and second grooves divides the four cells into eight. This last division is an unequal one, however; for the groove is not at the equator of the sphere, but nearer the formative pole. It therefore pinches off four small cells at the formative pole, and leaves four large ones, composing the greater part of the sphere.

It must be observed here that these grooves are but the external evidence of processes going on inside. They are the result, and not the cause, of the division. The cell material separates into two portions ; and the two portions, moving apart, leave grooves between.

After the eight-cell stage has been reached, the cells divide with less regularity. The small, active cells, of nearly clear protoplasm, at the formative pole, divide very rapidly; the large, yolk-encumbered cells divide very slowly, so that the later stages in segmentation are obscured, and sixteen-cell, thirty-two-cell, sixty-four-cell, etc., stages are not discoverable. But the one-cell, twocell, four-cell, and eight-cell stages are very plain, and easily followed; and these illustrate the process of segmentation.

II. Later Stages. - Two later stages, which are common to most of the higher animals, may be observed in the development of the snail. These are:-

1. The blastula stage, in which the segmentation process results. In this stage there is a hollow sphere of cells, its walls a single layer. The blastula is not quite spherical, and its walls are not of uniform thickness, being formed of a few large cells on one side, and of more numerous small ones on the other.

2. The gastrula stage, in which one side of the hollow sphere has become pushed in, as it were; the other side extending its edges, forming a cup-shaped depression. 
This depression deepens, its aperture narrows, and a more or less spherical form is again assumed. It is obvious now that the sphere has double walls, and that its cavity has an open communication with the exterior. It is now called a gastrula.

Compare the gastrula, as to the type of its structure, with a hydra stripped of its tentacles.

The later stages within the egg are not such as are common to most of the higher animals. They are difficult of study, and they will not be described here in detail. The student will readily see that the gastrula grows, transforms into a creature less simple, and begins to turn round and round in the albumen of its egg by means of a circlet of cilia which it has acquired. As it increases in size, dorsal and ventral surfaces become distinguișhable, a transparent matrix of a shell appears, and a foot, with a head imperfectly marked off at its anterior end. A pair of blunt processes at the sides of the head foreshadow tentacles, and two very black pigment spots represent the eyes. A pulsating heart becomes visible through the shell, and near it a tubular esophagus; and by the time it has eaten all the egg contents, and is ready to come forth, most of the adult structures are recognizable.

It will, no doubt, be more convenient to find all these stages in eggs taken from different capsules than to try to follow the transformations through with a single capsule. If a goodly number of capsules are obtainable, it is quite possible to find all these stages at one time.

The young snail within the egg is called an embryo, and all the transformations by which it comes, from being a simple, undifferentiated cell, to the possession of permanent and serviceable organs, constitute its embryology.$^{1}$

1 Tryon's Structural and Systematic Conchology is recommended for reference, and for use in making a further study of mollusks. 


\section{VERTEBRATES.}

\section{THE CATFISH.}

- The following directions are written with special reference to the common channel cat or white catfish (Ictalurus punctatus), but they are general enough to be applied without difficulty to the study of any other common catfish.

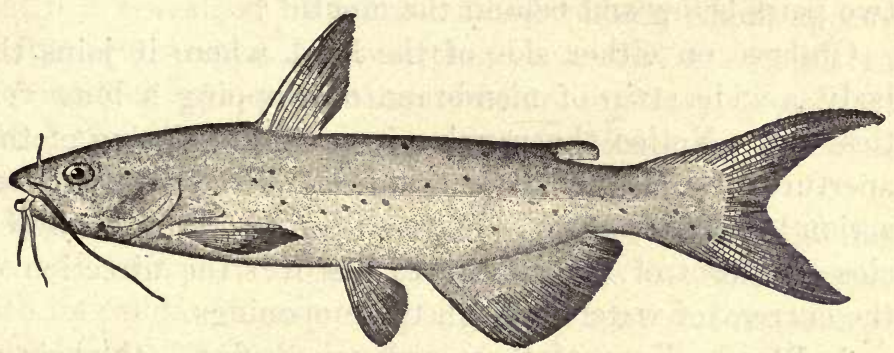

The Channel Cat (after Todd, by permission).

Description. - The channel cat is abundant in all our rivers and small streams. It has the characteristic catfish contour of body, which needs to be seen but once to be remembered. It is olivaceous above, and whitish below, with silvery sides; and its tough, scaleless skin is sprinkled with many small, round, dark olive spots. It may be angled for at the proper season, and may be obtained in the market or from fishermen at all seasons, for it is a good food fish.

Like all the other catfishes, it is very tenacious of life, and there is little trouble in obtaining live specimens from NEED, ZOöL. - 11 
a distance, when this is necessary. Specimens are often seen alive in the markets, in cool weather, twenty-four hours or more after they have been taken from the water.

Aquarium Study. - Study a live specimen that has been placed in an aquarium, or tank, or tub of water. Observe its form, its coloration, its markings, its method of getting about. What adaptations can you discover in its form to locomotion in water? To living on the muddy bottoms in river channels?

Observe the large eyes, the mouth opening directly forward, the long barbels at the corners of the mouth, a pair of smaller barbels above and behind the mouth, and two pairs below and behind the mouth.

Observe on either side of the head, where it joins the body, a wide strip of membrane overlapping a long vertical slit. Notice the regular opening and closing of this aperture, and also of the mouth, and note the concerted action between the two. Place a drop of ink in the water, close in front of the mouth, to discover the direction of the current of water through these openings.

I. Fins. - Four of these are paired fins, - the pair at the sides of the body, just back of the head, are the pectoral fins; the pair low down on the sides of the body, much farther back; are the ventral fins, - the others are single or unpaired fins. The two fins on the median dorsal line are dorsal fins. The one on the median ventral line is the anal fin. The large one at the posterior end of the body is the caudal fin.

As the fish swims about, watch it to discover the use of each of these fins. That the large caudal fin is the one principally concerned in locomotion will be seen at once. To learn the use of the pectoral and ventral fins, catch the fish with the hand, avoiding the sharp spines at the front of pectoral and anterior dorsal fins; fold the pectoral fins 
backwards, flat against the sides of the body; pass a rubber band back over the head and around these fins, to keep them so. Keep the fish under water while attempting to depress the pectoral spines, for in air it will keep them rigidly erect. Pass another rubber band about the ventral fins. Then liberate the fish, and watch it. What position does its body assume?

Release the paired fins, and fasten down the dorsal and anal fins with rubber bands. Liberate the fish again, and observe how it gets along without the use of these fins. What kind of a course does it take through the water?

II. Circulation seen in Fins. - Observe that the broadly expanded part of the fin is very thin and transparent, and that it is traversed by minute blood vessels, which appear as fine red streaks. Connecting these that are visible to the unaided eye, are many smaller capillary vessels in which the circulation can be advantageously studied with a microscope, as follows:-

Wrap the fish in a wet towel, leaving the caudal fin exposed, and place it on a low box beside the microscope, with its caudal fin extending across the center of the microscope stage. Spread the fin out flat on a glass slip upon the stage, so as to bring a thin portion of it into the field, and examine it with low power. If the fish refuses to lie quietly, pour a little chloroform on the towel near its mouth.

Observe the conspicuous, dark, irregular pigment cells scattered throughout the epidermis of the fin.

III. Blood Vessels. - The larger ones are of two kinds : (1) arteries, bringing blood out into the fin, and (2) veins, conveying the blood back to the body again. The smaller ones are the capillaries, connecting the arteries with the veins, and distributing the blood throughout the tissues of the fin.

Observe that the blood consists of a fluid plasma, in 
which float numerous corpuscles. Observe that the blood appears red in the arteries and veins, where the corpuscles are accumulated, but only slightly reddish or yellowish in the capillaries, where corpuscles form but a thin layer.

Does the blood travel faster in the arteries and veins, or in the capillaries?

Place a bit of cover glass over a very thin portion of the fin, and study it with higher power. Find two kinds of corpuscles in the blood: (1) red corpuscles (red only when a number are seen together), very numerous, and carried along in the center of the larger currents closely packed together; and (2) white corpuscles, resembling the amœboid corpuscles of the mussel and earthworm, not very numerous, and usually seen trailing along the edges of the blood currents, or escaping out into the tissues.

External Features. - Kill the fish with chloroform, and make a closer study of its external features.

Observe the exact correspondence of the two sides, perfect bilateral symmetry.

Observe the broad head, dorsally depressed, the absence of neck, and the long, tapering body.

On the upper surface of the head, just behind the mouth, find four nostril openings, the posterior pair close behind the barbels of this surface. Probe these openings with a bristle to see whether they have any connection with each other or with the mouth.

Examine the bases of the large barbels at the corners of the mouth, to find the bones which extend out into them from the head.

Examine the eyes. Are there any eyelids or other means by which they may be closed? Press on the edges of the eyeball to discover how far it may be turned to look in different directions. Press with a finger against the 
roof of the mouth inside, and observe how the eyeball is affected.

I. The Mouth. - Stretch the mouth wide open, and look into it. Observe a band of numerous sharp, small teeth extending across its margin, above and below. Rub a finger across these teeth to discover in what direction they point. What advantage to the animal in their inclination?

The bone which forms the border of the lower jaw is called the mandible. The bone of the upper jaw which bears the teeth is called the premaxillary. In other fishes several-bones of the roof of the mouth bear teeth. One of these is the maxillary, which in the catfish is reduced to the pair of rudiments already found supporting the bases of the lateral barbels.

The tongue is a slight angular elevation on the floor of the mouth. Its boundaries are marked out by corresponding grooves on the lower surface of the head.

The posterior funnel-shaped part of the capacious cavity seen on looking into the mouth is the pharynx. The pharynx tapers into the esophagus "in the distance." On the floor of the pharynx are two large prominences covered with teeth. Rub a finger across these teeth to discover their direction.

On either side of the pharynx are the gill arches, bearing the gills on their outer convex edges, and separated by five vertical slits. Pass a pencil in at the mouth, and out through one of these slits to the exterior. On the outside observe that the pencil has lifted a semicircular flap, which is divided by an oblique groove into two portions. The lower marginal portion is the operculum, and the upper anterior portion is the proe-operculum. The latter is directly behind the eye, and forms the cheek of the fish. The inner surface of the operculum is covered by a soft lining membrane called the branchiostegal 
membrane, which is supported by bony rays called the branchiostegal rays (or simply branchiostegals). When the operculum is lifted, the four vertical series of red gills may be seen inside. They may be studied more advantageously after dissection.

Observe a longitudinal lateral line on each side of the body of the fish.

II. Structure of the Fins. - Study the structure of the fins. Each is made up of a double fold of membrane sup-. ported (except in the posterior dorsal fin) by bony rays. The rays are wanting in the posterior dorsal fin, and usually fat is deposited between the folds of membrane, whence it is called an adipose fin. The first ray in each of the pectorals and in the anterior dorsal fin is hard and unjointed. It is developed as a stout, sharp-pointed spine, with two serrated edges. It is articulated with the bones of the pectoral arch by a beautiful joint, which secures it great rigidity when erected, and makes it a formidable weapon of defense. The other rays are soft and jointed. Examine them carefully with a lens. Observe that they are branched or split into parallel, jointed strips at their outer ends. Make an enlarged drawing of one of the pectoral fins, and another of the caudal fin.

The two pairs of paired fins are homologous with the two pairs of limbs of higher animals. The pectoral fins are articulated upon a bony pectoral arch and the ventral fins upon a smaller and more rudimentary pelvic arch, which in the catfish is unconnected with other parts of the skeleton.

Dissection. - Dissect the fish under water, and study its internal structure: If a prepared skeleton be at hand for reference in locating bony parts, it will be of great assistance in the following work. With a pair of stout bone snips or shears, or with a hatchet, cut off the dorsal 
spine, so that the fish may be placed on its back in the water. With forceps pinch up a transverse fold of the tough skin of the ventral surface opposite the anterior dorsal fin, and cut through the fold with sharp scissors. Continue the cut backward to the vent, and forward to the bones of the pectoral arch, taking care not to injure or displace any of the organs which lie directly beneath the thin body wall. Turn back the flaps and expose these organs. Observe a silvery membrane, the peritoneum, lining the body cavity.

Internal Features.--The large red organ close up under the pectoral arch is the liver. Two conic-pointed lobes run from it forward and downward; and two broad, flat lobes extend backward. Turn these latter forward, and observe under the one on the right side of the body a capacious yellow gall bladder.

Under the other, the left lobe, the esophagus extends backward to the stomach, which lies entirely posterior to the liver. Pass a probe into the stomach from the mouth. The intestine arises from the left side of the stomach, and curves forward and to the right side, and posteriorly around the stomach, and makes a number of irregular turns in passing through the posterior part of the body cavity.

Behind the stomach it is partially concealed by the reproductive organs, - whitish organs in the male; large, yellowish organs in the female, - varying much in size with the age of the specimen and with the season.

Observe that the intestine is looped up, and held in place by a transparent membrane (the mesentery). Lift this, and observe the blood vessels in it. Observe the blood vessels and the nerve branches spread out over the anterior end of the stomach. Turn the stomach over to the right side, and observe an elongated, narrow, white organ, the pancreas, lying along its dorsal side. 
Observe two ducts entering the intestine together, near its origin, appearing to come directly from the liver. One of these comes from the gall bladder, and the other from the pancreas. The former may be recognized, if distended with bile forced into it by squeezing the gall bladder. The other should be traced from its origin by dissection.

Posterior to the pancreas is a conspicuous dark-red organ, abundantly supplied with blood vessels, - the spleen.

Remove the reproductive organs. Cut through the bones of the pectoral arch. Open wide this incision by pressing downward on both pectoral spines at once. Wash out any blood that may have flowed from the last incision. Turn backward the anterior lobes of the liver, and observe that the peritoneum rises at this point to meet the pectoral arch, and is perforated by the esophagus, and by the blood vessels extending forward from the liver. Trace the blood vessels through it to the heart. In the heart observe three principal divisions: (1) a postero-lateral, irregular, thin-walled part, the auricle; (2) a larger, oval, muscular, strongly contractile, central part, the ventricle; (3) a smaller, oval, anterior portion of lighter color, and noncontractile, the arterial bulb. This is continued forward into the branchial artery, which soon divides, sending one branch (aortic arch) to each gill.

Cut off the branchial artery at its origin, and remove the heart. Cut off the esophagus close to the pharynx. Notice how muscular its walls are. Remove the digestive tract entire, beginning with the esophagus, and proceeding posteriorly, cutting only the peritoneum where it meets the body wall. Observe other internal organs lying dorsal to the peritoneum. Central among these is a large, white bag filled with air, the air bladder or swim- 
ming bladder, an organ by means of which the specific gravity of the fish may be increased or diminished at will. Find a duct connecting it with the esophagus. In a few fishes its walls contain capillary blood vessels in which the blood is aërated. It is homologous with the lungs of higher animals.

In front of the air bladder is a dark, reddish-brown organ called the pronephros (or head kidney). Its function is not well understood.

Cut the duct of the air bladder, and lift out the digestive organs. Three parts of the intestine not heretofore noticed are easily distinguishable: (1) A wide portion immediately succeeding the stomach, called the duodenum. Into this part the ducts from the liver and from the pancreas enter. (2) A narrow, much convoluted portion, not well marked off from the preceding, called small intestine. (3) A wider terminal portion, well marked off from the latter by a hoodlike fold in the walls of the canal, and called large intestine.

Entirely remove the peritoneum, and find the special excretory organs, the kidneys, lying dorsal to its posterior portion. These are of a dark purplish or brownish color, and are more or less united into one mass. They send back a duct to communicate with a small white urinary bladder beneath the vent, and to open to the exterior by a separate pore a little farther back.

A string of irregular, fatty bodies is often found extended lengthwise on either side of the median line, near the kidneys.

The Axis of the Body. - Remove all these organs, and observe the bones, now partially laid bare on the dorsal side of the cavity they occupied. A chain of bones constituting the spinal column extends along the median line from the head to the posterior end of the body. The 
separate bones of the spinal column are the vertebroe. The slender, curved bones extended laterally, a pair from each vertebra, are the ribs. Between the ribs observe the white spinal nerves, coming out from the spinal cord, which is a part of the central nervous system located in a hollow that extends longitudinally through the center of the spinal column.

Gills. - Study the gills. Continue the ventral incision forward exactly on the median line to the mouth. The narrowed, anterior portion of the chest between the gill openings is the isthmus. Observe the branches of the branchial artery going to each gill. These will be better seen in an injected specimen. ${ }^{1}$ Deepen the cut until it divides the upper wall of the pharynx, the floor of the mouth, and the mandible. Then draw the edges of the cut apart, and expose the white gill arches. Observe the vertical series of teeth on the concave side of each arch. These are the gill rakers. Note their position, and the size of the teeth on the different arches. What is their probable use?

Raise and depress the floor of the mouth of one side, and study the action of the gill arches and the rakers. Observe the joints in the arches.

Cut through the isthmus of one side between the first gill and the branchiostegal membrane, and expose the red gills on the back or convex side of the gill arches. Observe that they are in a double row on the back of each arch.

Find on the branchiostegal membrane an elongated reddish patch, which is a rudiment of an anterior gill. With sharp scissors cut out of a gill arch a thin transverse section bearing one or two pairs of gill filaments, and examine the section under lowest power of a micro- 
scope. Observe in the groove on the gill-bearing surface of the arch the two blood vessels, branches of the branchial artery and vein. Observe the distribution of the minute blood vessels in the gill filaments. Examine the fifth gill arch. How does it differ from the other four?

The Dorsal Surface. - Turn the fish over. The bones of the head constitute the skull. Observe that the thick, dark skin of the dorsal surface rests directly upon the top of the skull. Find a narrow backward process from the skull extending to the dorsal spine.

Cranium and Cranial Nerves. - Remove the skin from the right side of the body and head, and from the whole upper posterior portion of the skull. Then cut away the top of the skull and expose the brain. Remove the bone, with great care not to injure the soft, nervous tissues beneath it. The bony cavity in which the brain lies is the cranium. When the top of the cranium is cut away, it will be seen that the white brain does not fill the cranial cavity, and that it is surrounded within the cavity by a transparent, semifluid substance.

Study the brain as to its general features.

Observe that it tapers posteriorly into the spinal cord, which has been already noticed, extending through the spinal column.

Observe the nerves that start out from the brain. Arising within the cranium, these are called cranial nerves. Observe that the cranial nerves are paired. Several pairs of them may be easily distinguished. The two extending forward from the brain nearest the median line are the olfactory nerves, or nerves of smell. Cut away its bony covering, and trace one of these to its termination in an olfactory bulb, beneath the communicating nostrils.

The Optic Nerve and the Eye. - Just behind the olfactory nerves is a larger pair of optic nerves extending direct 
to the eyes. Trace the course of one of these. Examine the location and attachments of the eyeball. The bony socket in the skull in which it rests is the orbit. Find six delicate whitish bands of muscle extending outward from the orbit, and attached to the sides of the eyeball. Observe that four of these are straight, and two are oblique, in their attachment; and that all are in pairs, opposed in their action. Determine in what direction the contraction of each would move the eyeball.

A small cranial nerve (the oculomotor) is distributed to these muscles.

Cut away the muscles, and observe that the optic nerve gives off no branches, but runs directly into the posterior part of the eyeball. It is the nerve of sight.

Observe the tough outer coat (sclerotic coat) of the eye, transparent over its anterior portion, where it is called cornea. Looking at the eyeball from the front, observe a dark hole (the pupil) through which the light enters the black-lined eyeball, and around the pupil a motley colored circular band (the iris). If the eye be cut open, the clear, double-convex crystalline lens will be found suspended in the humors of the eye. It is the part which brings the rays of light to focus on the terminations of the optic nerve, and causes sight.

Other Cranial Nerves. - Behind the optic nerves, a pair of large, conspicuous nerves (the trigeminal nerves) will be seen extending forward, and sending off large branches to the upper jaw, barbels, palate, etc. Some of its branches may be easily traced. A pair of large nerves arise from the posterior part of the brain, and extend posteriorly into the body cavity. These are the vagus nerves, whose branches have already been seen distributed over the anterior wall of the stomach.

Between the vagus nerves, which extend posteriorly, 
and the several pairs, which, we have seen, extend anteriorly, are one or more pairs which extend laterally, and send branches to a pair of thin-walled swellings at the base of the hinder part of the skull. These swellings are the ear capsules. Each of these, if cut open, will be found to contain a membranous sac filled with liquid in which floats an ear bone. Each is an organ of hearing, capable of being affected by vibrations, which are so readily transmissible through water.

Make a drawing of the brain and cranial nerves in place, as seen from above.

The Brain. - Cut off the cranial nerves half an inch from the brain. Lift out the brain, place it in alcohol, and study to make out its parts.

1. Looking at the dorsal surface of the brain, observe a large, squarish, anterior division of softer, more satiny appearance than the rest, divided by a shallow median groove into two lateral halves. This is the cerebrum, and its halves are the cerebral hemispheres.

2. Looking at the ventral surface of the cerebrum, observe two conical swellings at the base of the olfactory nerves. These are the olfactory lobes, the foremost portion of the brain.

3. Close behind the cerebrum are the two smooth, roundish optic lobes, which are continued downward into two inferior lobes, that are easily seen from one side or from below. Observe the optic nerves taking origin from this part, and crossing ere they leave the cranium. Which side of the brain receives impressions through the right eye?

4. On the median dorsal line, close behind and above the optic lobes, observe a conspicuous, roundish single portion, the cerebellum. This part extends backward and downward in two posterior lobes, which surround a deep median depression, the fourth ventricle. 
5. That portion of the brain below and behind the cerebellum is the medulla. It tapers posteriorly into the spinal cord.

Preserve this brain for comparison with that of other animals yet to be studied.

Muscles of Body Wall. - Make a longitudinal cut close beside the dorsal fins, and down to the spinal column. Extend this incision backward to the caudal fin, and forward to the pectoral arch. Remove the great flap of flesh thus partly freed from one side, dissecting it away from the ribs and from the inferior projections of the vertebræ posterior to the ribs. Observe the arrangement of the white bands of muscles, of which it is principally composed.

Separate two of the vertebræ, and find the spinal cord extending longitudinally through them.

Plan of Structure. - Consider well the arrangement of parts as you have found them in the fish. Here $\mathrm{i}^{-}$a new plan of structure. The hard parts (bones) are inside, and the muscles are attached to prominences on their exterior. What general arrangement of skeleton and muscles have you found in the other animals studied?

The central parts of the nervous system are inclosed within a bony canal which extends along the dorsal side of the body. The anterior end of this canal is expanded into the wide cranium; the remainder of this tube is the neural canal, which extends backward through the vertebræ. The part of the nerve center occupying the cranium is called the brain; the part occupying the neural canal is called the spinal cord. There are apertures throughout the length of this bony tube for the passage of nerves outward through its walls to all parts of the body.

Ventral to this tube of bone, which holds and protects 
the central nervous system, is another immensely larger tube, the body cavity, which contains the organs of nutrition and reproduction. The walls of this latter tube are largely membranous, but they are in part supported by the ribs and by the lower bones of the skull. A transverse section of the body of the fish, therefore, shows two tubes, one above the other. How does this arrangement of nerve center and nutritive organs differ from the arrangement studied in insects? In the river mussel?

The Bony Skeleton. - A few points respecting the structure and arrangement of the parts of the bony skeleton must be studied here. Use a prepared skeleton for reference, and study the parts in a disjointed skeleton, which, if not furnished you, you can easily prepare for yourself. 1

I. The Spinal Column. - Study the spinal column. This is the most important and characteristic part of the skeleton. Observe that its constituent vertebræ are not all alike. Their differences are such as to make two regions distinguishable in the spinal column. The anterior portion extending backward as far as the hindmost pair of ribs is the body region, and the remaining posterior portion without ribs is the tail region. Isolate one of the middle vertebræ of the tail region, taking care not to injure any of the small bony processes that arise from it, and examine it. Observe a thick, solid, hourglassshaped central portion, concave on both anterior and posterior faces, and perforated for the passage of the spinal cord. This is the centrum (or body of the vertebra). Observe a pair of processes arising from the dorsal surface, one on either side of the median line, and soon uniting to form a long, sharp neural spine. By their union they form an arch above the centrum, in which

1 For the method, see Appendix, p. 287. 
lies a large artery. A similar pair of processes arise, and unite in a similar way on the ventral surface, to form a long hemal spine. Another large artery is lodged in the arch at the base of this spine. Notice that both spines are directed backward. Find four small processes on the anterior margin, and four on the posterior margin, of the centrum. These are articulating processes (zygapophyses). They join corresponding processes on adjacent vertebræ, and serve to hold the several vertebræ more firmly together. Study the relation between these processes in vertebræ that have not been disarticulated.

Draw a vertebra as seen from one side, and as seen from one end.

II. Ribs and Interneurals. - Compare this vertebra with others both before and behind it in the tail region. Observe that in several of the foremost vertebræ of this region the large processes of the ventral side do not unite to form a single hemal spine, but, diverging, form two spines. Proceeding forward into the body region, observe that there they no longer form a hemal arch, that they become more and more divergent, and that ribs are added to their outer ends. Observe that the articulation of each rib is such that it appears to be spliced to the process which supports it. How many pairs of ribs are there? Observe that the neural spines of the rib-bearing vertebræ are reduced in length and modified in form to accommodate the bones which support the anterior dorsal fin. The latter bones, because they usually fit in between the neural spines, are called interneurals.

III. Spines and their Supports. - The part of the spinal column anterior to the ribs consists of several vertebræ solidly welded together, and so greatly modified as scarcely to be recognized as vertebræ at all. They are joined to the long dorsal process from the skull to the 
bony pectoral arch, and to the foremost interneurals, in such a manner as to give a very firm, bony support to the three defensive spines.

The joints at the bases of these spines, though not characteristic of fishes in general, but a peculiarity of a small group, show an interesting kind of animal mechanism, and are well worthy of an examination.

Examine first the attachments of the dorsal spine. It is fastened by a ring to the top of the third interneural. The first interneural is small, the second and third interneurals are grown together solidly into one piece (the buckler), and the notched tip of the backward process from the skull (the helmet) fits against the anterior edge of this piece. The dorsal spine arises from the third interneural, and a rudiment of another spine from the top of the second interneural. This rudiment is a small, oval bone, forked below. It is set against the base of the great spine in front, and acts as a sort of bolt, or fulcrum of support. The widened neural spines also contribute to the support of the great spine, as can be readily seen.

Examine one of the pectoral spines. Study the beautiful joint by which it is united to the pectoral arch. In how many directions is it movable?

Observe the great strength and solidity of this pectoral arch, and the comparative weakness and small size of the pelvic arch.

The catfish is a representative of the class Pisces, or fishes of the great branch Vertebrata (or back-boned animals).

Other Fishes of very different structure can readily be obtained for study in any locality. ${ }^{1}$ A common sucker, or a buffalo fish, is recommended for study, and

1 Use Jordan's Manual of the Vertebrates for identifying the species of fishes.

NEED. ZOÖL. -12 
for comparison with the catfish. Compare especially vith regard to the following points:-

1. The shape of its body.

2. The character of its body covering.

3. The shape of its mouth.

4. The number and position of bones bearing teeth.

5. The character of the gills and gill rakers.

6. The character of the dorsal and pectoral fins.

7. The shape and attachments of the air bladder.

8. The foremost vertebræ of the spinal column, etc.

\section{THE FROG.}

\section{(Rana.)}

Haunts and Habits. - In the springtime the musical efforts of this animal are a sufficient guide to the localities to be searched for

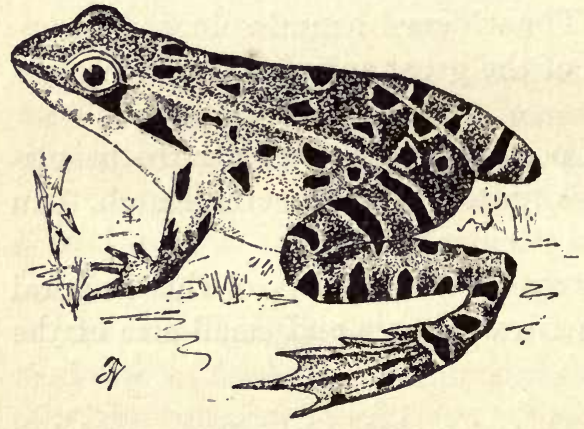

Common Frog (Rana virescens). specimens. In warm weather small frogs will be flushed from their resting places in the grass by walking rapidly alongside any brook or pond. They may be captured in a stout net. In cold weather live specimens may be obtained from dealers, or dredged up from the bottom of ponds. Specimens captured in autumn may be kept alive a long time without food, if kept in a cool, damp place; for in the winter season they are normally inactive, and take no food. 
The interesting habits of the frog should be studied in the field if opportunity offers.

Study of a Live Specimen. - Study the live frog in the laboratory. Observe:-

1. The stocky, humpbacked body.

2. The absence of tail and of fins.

3. The presence of well-developed legs.

4. The presence of eyelids. Touch the eye with a pencil, and watch the lids. Are they of one sort?

5. Its method of locomotion in water.

6. Its method of locomotion on land.

7. Its sitting posture.

8. Its breathing: what external parts participate?

Circulation of Blood. - Wrap the frog in a wet towel, leaving a hind foot protruding. Chloroform it, and examine with the microscope the circulation of blood in the web of its foot, as directed for the fin of a catfish.

Structure. - Give additional chloroform, and, when the frog is dead, study its structure. Note:-

1. The color and markings of the head and of the body; of the dorsal and ventral surfaces.

2. The smooth, moist, scaleless skin.

3. The prominent eyes, and behind them, on the sides of the head, the round tympanic membranes of the ears.

4. The wide mouth.

5. A pair of nostrils above the mouth.

Open the mouth and look into it. Observe:-

1. The fleshy lips which narrowly border the jaws.

2. The absence of teeth from the lower jaw.

3. The number, position, and arrangement of teeth in the upper jaw.

4. The long, fleshy tongue. Draw it forward, and find the point of its attachment. 
5. The mucilaginous saliva which covers the tongue. When a fly, or other insect suitable for food, comes near enough, the frog darts out this sticky tongue, and draws the entangled fly into its mouth.

Pass a bristle into the nostrils from the outside, and discover where they open into the mouth.

Cut a hole in the tympanic membrane, and insert a bristle into the cavity it covers, and push the bristle into the mouth. The wide tube by which it enters the mouth is the Eustachian tube.

The posterior, funnel-shaped part of the cavity seen on looking into the mouth is the pharynx. Its folded walls converge toward the esophagus.

On the floor of the pharynx is a narrow slit which leads into the trachea, and thence to the lungs. Pass a bristle into this slit.

Find a small, isolated patch of teeth on the roof of the mouth.

Dissection. - Dissect the frog under water. A prepared skeleton should be at hand for reference in locating bony parts.

Cut through the skin along the median ventral line, from the mandible to the posterior end of the body. Make a second cut at right angles to the first, entirely across the middle of the ventral surface, and turn back the four flaps of skin thus formed. This will expose the thin, muscular abdominal wall. Observe a dark vein showing through the abdominal muscle on the median line. Make a longitudinal cut through the body wall, a little to one side of the median line, so as to avoid injuring this vein, and continue the cut forward to the bony pectoral arch, or shoulder girdle. Then consult a skeleton, to see how, by cutting to one side of the median line, you may avoid injuring the elongated median bone 
of this girdle. Continue the cut forward to the base of the tongue. Stretch the fore legs out at right angles to the body, and pin them so. Turn back the edges of the last incision, and fully expose the organs of the body cavity.

Internal Features. - Perhaps the most conspicuous of the internal organs is the large, mottled reddish liver, which consists of a large double lobe on the right side of the body, and of a smaller single lobe on the left side. Immediately in front of the liver is the heart, inclosed in a thin, transparent sac, the pericardium. If the heart is still beating, the arterial system should be injected. ${ }^{1}$

Pinch up the pericardium with forceps, and cut it away with sharp scissors. Cut away also its attachments to the body wall, taking great care not to cut any blood vessels or other organs.

Pass a pipette or blowpipe through the mouth, into the trachea, and inflate the lungs to see their size and position.

I. Digestive Organs. - Pass a long probe through the mouth and pharynx into the esophagus, and thence backward into the long, white stomach, which lies just behind, or partly concealed by, the liver. From the posterior end of the stomach trace the intestine. It turns forward, downward, backward, then forms a spire on the right side of the body, and then, returning to the median line, enters an expanded terminal portion, the cloaca. Ducts from the reproductive and renal organs also enter this chamber. Observe the mesentery with which the intestine is invested, and through which its blood vessels pass. The position of the liver has been noticed: find the greenish gall bladder attached to one of its lobes, and find a duct leading from the gall bladder to the intestine. This duct will usually be made more evident by squeezing

1 For the method, see Appendix, p. 285. 
the contents of the gall bladder out into it. The pale or whitish compact mass lying between the stomach, intestine, and liver, is the pancreas. What is the relation between this organ and the duct of the gall bladder?

II. Reproductive Organs. - A pair of digitate, yellow fatty bodies are attached to the dorsal wall of the body cavity, behind the stomach, and close beside the median line. The paired reproductive organs lie just posterior to these,- - rounded yellow testes in the male; and folded or lobed, lighter colored ovaries in the female. In the breeding season, the ovaries may be found so distended with eggs as to fill out most of the body cavity. The oviducts, which convey the eggs to the cloaca, are very long and much convoluted tubes, having no connection with the ovary, but opening by a funnel-shaped orifice into the body cavity near the esophagus.

III. Renal Excretory Organs. - A pair of reddish brown kidneys lie on the dorsal side of the body cavity, near the cloaca; and ducts from these pass to the large, white, bilobed urinary bladder, which occupies the extreme posterior end of the body cavity, and which, when found empty, presents a crumpled appearance.

The small, roundish red body, dorsal to the cloaca, and near the anterior end of the kidneys, is the spleen.

IV. Circulatory Organs. - The central organ of circulation in the frog is the heart. In it find three divisions, a firm muscular, conical posterior division, the ventricle; and two anterior, thin-walled divisions, auricles. A cylindrical arterial trunk arises from the anterior end of the ventricle, and passes obliquely forward across the uppermost ventricle, and soon divides into two principal branches.

Now trace the principal arteries and veins. If the arterial system has been injected, there will be no difficulty in distinguishing between arteries and veins; if not, 
the arteries may usually be distinguished by their firmer walls and somewhat lighter color. No visible blood vessels should have been severed up to this point in the dissection. Begin with the venous system, and find the principal avenues by which the blood is returned to the heart, after being distributed throughout the tissues. Find again the vein that was seen through the thin abdominal wall before the body cavity was cut open. Trace this vein backward far enough to see the large branches coming up from the hind legs. Trace it also forward. Observe that it soon leaves the body wall, and descends through the body cavity to the liver, where it branches, sending one branch to each lobe of that organ. This is the ventral route to the liver; there is also a dorsal route through the kidney. Turn the organs that cover the kidney over to one side, and find a longitudinal vein coming from the posterior end of the body cavity, and passing along the external margin of the kidney, and dividing up into numerous branches, which enter the mass of the kidney. Then find a corresponding set of venous branchlets coming from the inner side of the kidney, meeting branchlets from the other kidney, and uniting into another large vein, which proceeds forward to the liver, receiving important branches from the viscera at several points. This is the portal vein. Trace it to the liver. Then draw the liver backward, and turn the ventricle over forward, and see the single large vein, the postcava, which conveys the blood from the liver into the venous sinus, and thence into the right auricle. Draw the heart gently backward, and see the two large veins (proecavo), which bring the blood into the same chamber from the anterior parts of the body. The blood flows from the auricle into the ventricle, and is forced out again, by the contraction of the ventricle, through the arterial trunk.

Trace now its outward course. The arterial trunk 
divides into two branches, each of which is made up of three aortic arches, which, curving dorsally, go a little way together, bound up in a mass of fatty and connective tissue. Carefully dissect away this tissue, and disclose the three arches of one side. The anterior (carotid) arch first leaves its fellows, and at once divides into two branches which go to the head. The posterior (pulmocutaneous) arch sends branches to the lung and to the skin. The larger middle aortic arch curves dorsally and posteriorly. Lift the stomach and adjacent organs a little away from the dorsal wall, and see this middle arch extending backward, and uniting with its fellow of the opposite side on the median line. Observe that the single dorsal aorta thus formed gives off at once a very large branch to the organs of the body cavity, itself extends posteriorly along the dorsal wall, and finally divides into the two iliac arteries, which go to the hind legs.

Trace now the three arches of one side back to their origin. Cut each off at the point of its separation from its fellows, and pass into it a bristle. Then with fine scissors lay each one open, cutting backward toward the ventricle. Compare the aortic arches of the frog with those of the catfish.

That the hindmost aortic arch conveys blood to the lung for aëration has already been noticed. From the lung a pulmonary vein conveys the aërated blood back to the left auricle of the heart, whence it passes into the ventricle, to be mixed with the venous current from the right auricle.

V. Respiratory Organs. - Cut the vein and artery connecting each lung with the vascular system, and trace the lungs forward to their union in the trachea. Dissect out the trachea, and trace it forward to the mouth. Observe that it passes through a notch between two posterior horns of a broad, flat cartilage in the floor of the mouth, the 
hyoid cartilage. Lay open the anterior part of the trachea, and note the structure of its walls.

Again inflate the lungs through the trachea, and study their structure. Observe that they are composed of relatively few and large air cells (or, more properly, air spaces), and that the walls of these do not afford a very great area over which the blood can be distributed for aëration. The distribution of the capillaries in the skin is such as to bring the blood near enough to the surface for partial aëration there. But the total supply of oxygen obtained from both sources is relatively small, and would be inadequate to any but a cold-blooded, sluggish animal.

The Nervous System. - Turn the organs of the body cavity gently to one side until the spinal column is visible. Observe the white spinal nerves extending out from it, along the body wall, just beneath the smooth, transparent peritoneum. Observe that each spinal nerve, near its origin, sends a branch ventrally into the body cavity to meet a very delicate nerve cord that extends longitudinally, ventral to the spinal column, and near the median plane of the body. Examine this nerve cord carefully with a lens to find minute ganglionic swellings on it at its junctions with the branches of the spinal nerves. Find also minute nerves arising from its ganglia, and extending to the internal organs. Trace it forward to the head. Find another similar nerve cord on the other side of the median plane. Find minute white commissural nerves connecting the ganglia of the two chains.

This double series of ganglia, with connecting commissures and radiating fibers, included within the body cavity and distributed to the nutritive organs, constitutes the sympathetic system. The cerebro-spinal system consists of brain and spinal column and radiating nerves. 
I. Spinal Nerves. - Cut off the esophagus near its origin, and remove the viscera. Note the absence of ribs from the walls of the body cavity. Make out ten pairs of spinal nerves, as follows :-

The nerves of the first pair curve ventrally and anteriorly, and are distributed to the lower jaw.

The nerves of the second and third pairs unite, and go to the fore legs. The nerves of the second pair are large and conspicuous, and extend laterally at right angles to the spinal column: those of the third pair are smaller, and bend anteriorly to meet those of the second. The two again divide and reunite repeatedly, to form a plexus (the brachial plexus).

The nerves of the fourth, fifth, and sixth pairs extend laterally and posteriorly, to be distributed to the body wall.

The nerves of the seventh, eighth, and ninth pairs go to the hind legs. They unite to form a plexus (the itiosacral plexus), which terminates in the large sciatic nerve of the thigh.

The nerves of the tenth pair are very small. They may be seen close beside the posterior end of the spinal column.

II. The Brain. - Remove the skin from above the cranium and from one side of the head. Dissect it free from the tympanic membrane with great care. Cut away the bony roof of the cranium, and with a gentle stream of water from a pipette wash out the soft substance that covers the brain and fills out the cavity. Make out the following parts :-

1. A pair of conical olfactory lobes, extending forward from the extreme anterior end, and tapering into the olfactory nerves.

2. Immediately behind these, the large, white, cerebral hemispheres, which make up the cerebrum. 
3. Behind these are a pair of conspicuous rounded eminences, well marked off from each other, and from the other parts. These are the optic lobes. The large optic nerves arise from these below, and cross each other before going to the eyes.

4. Behind the optic lobes, and on the median line, is a deep depression, the fourth ventricle. It is covered over with a thin plexus of blood vessels, which is easily stripped off, and is often torn away with the cranial wall. In front of the ventricle, and behind the optic lobes, is a single transverse band of nervous tissue. This is the cerebellum. The nervous mass which surrounds the ventricle on the sides and below is the medulla. It tapers posteriorly into the spinal cord.

5. There remains a portion of the brain between the cerebral hemispheres and the optic lobes which has not yet been mentioned. It is the midbrain. From its dorsal surface, between the posterior ends of the cerebral hemispheres, and on the median line, arises a single rounded prominence which is not composed of nervous tissue. It is the pineal gland.

6. About eight pairs of nerves arise from the ventral surface of the medulla: these are small, and exceedingly difficult to trace. The fifth and tenth cranial nerves are largest, and have each a ganglion not far out from their origin. These ganglia are each connected with forward prolongations from the longitudinal commissures of the sympathetic system.

7. The fact that the single cavity that has been seen in the brain thus far is called the fourth ventricle, will suggest that there are others. Two others will be exposed by cutting a horizontal slice from the top of the cerebrum: these are the two lateral ventricles of the forebrain. They occupy the cerebral hemispheres, and unite posteriorly around a median septum. The cavity formed 
by their union is continued posteriorly into the midbrain, and expands there into a narrow cavity, extending obliquely upward and downward, the third ventricle. A narrow, median canal, the iter, connects the third and fourth ventricles. A pair of round cavities, the optic ventricles, occupy the optic lobes, and are connected with the iter. If the brain be turned to one side, and drawn upward out of the cranium a little, there may be seen a downward prolongation from the midbrain toward the roof of the mouth. It is the pituitary body.

If the foregoing points in the study of the brain have not been made out satisfactorily in a fresh specimen, place a frog's head a few days in alcohol to harden, and with it try again.

The Ear.-In the ear observe the tympanum, from which the skin has been removed. Observe the opaque spot in it, and the surrounding transparent area. The opaque spot is the point of attachment of an elastic rod which extends across the cavity inside, and communicates with the inner ear. When sound waves fall on the tympanum, and cause it to vibrate, its vibrations are carried through the elastic rod to the inner ear, which is the true organ of hearing, and which is securely lodged within the bone of the skull. Dissect out this elastic rod. It is called the columella. It is sometimes partly ossified in the middle.

Appendages. - That there are two pairs of legs will have been noticed already. Which pair is most serviceable in locomotion? What peculiarity in its structure would indicate that a frog could jump well, were its habits entirely unknown? What other animals have you seen having the same peculiarity of structure, and corresponding ability to jump?

In fore and in hind leg find three principal divisions, - 
in the fore leg, named from the body outward, arm, forearm, and hand (for this limb is homologous with the upper limb or arm of man); and in the hind leg, thigh (or femur), shank, and foot.

Make drawings of both hand and foot as seen from above. Compare the two as to the number of digits or phalanges in each, and the number of joints in each digit. In the males the base of the inner digit of each hand is greatly swollen in appearance. Such a peculiarity of sex, occurring entirely apart from the sexual organs, is called a secondary sexual character.

Study of Superficial Leg Muscles. - Cut the skin around the base of one of the hind legs, dissect it free from the underlying muscles half the length of the thigh, and then strip it off over the foot like a stocking, wrong side out. Now study the arrangement of parts in this extremity. The whitish muscles now cover all other parts. Dissect apart, without freeing at their ends, several of the large muscles on the back of the femur, and find nerves and blood vessels and bone. Free at its edges the large muscle (gastrocnemius) of the back of the shank, and observe :-

1. The connective tissue enveloping all the muscles, and binding them together.

2. The connective tissue sheath enveloping each individual muscle.

3. The white, strong tendon, in which this muscle terminates at its outer end. Follow this tendon (tendo Achillis) outward, along the sole of the foot, and see it dividing, and its divisions coalescing with the tendons of other shorter muscles of the foot, and extending to the toes. Pull this tendon toward the body, and observe the effect on the foot.

4. The close attachment of the inner end of this muscle at the back of the knee joint. 
Three terms which apply to muscles need to be learned: (1) the thick, swollen central part is called the belly of the muscle; (2) that end of the muscle which is most fixed in position, and toward which, when it contracts, the muscle pulls, is called its origin; (3) the attachment of its other, freer end is called its insertion.

\section{Relations of Muscles, Blood Vessels, and Nerves.-} Dissect away the large muscles of the thigh and shank by cutting transversely through the belly of each, and dissecting each way, so as to find the origin and insertion of each, and having care not to cut blood vessels or nerves. Trace the great sciatic nerve of the thigh. Follow its two principal branches down into the foot. Find and distinguish two large, branching blood vessels in the thigh, the femoral artery and vein. This dissection, if thoughtfully performed, will enable you to answer the following questions :-

1. Where, with reference to the joints, are the thickest portions of the leg?

2. What give these points their thickness?

3. What advantage is there in the tendonous terminations of the muscles at the joints?

4. Where are the bones thickest?

5. What are the ridges on the bones for?

6. Which lie deeper in the muscles, arteries or veins?

7. Why are the principal nerves so remote from the surface?

8. Why are the insertions of these muscles all at their outer ends?

Separate the thigh and the shank at the knee joint, and observe the firm, white, elastic cartilage forming the articulating surface.

Dermis and Epidermis. - After the skin has been lying in water for half a day, observe that there is an outer 
layer (epidermis) in it, which tends to peel off from the thicker and vascular lower layer (dermis).

Study of the Skeleton. - With a prepared skeleton at hand for reference, study the separate parts of a disarticulated skeleton.

First, note the arrangement of parts in the skeleton : the central, vertebral axis, terminated in front by the skull, and supported by two bony arches and two pairs of jointed appendages.

I. The Spinal Column. - In the spinal column find ten separate vertebræ, and a long, unsegmented terminal portion (the urostyle).

Note the presence of a double row of stout lateral processes, and the absence of ribs. How many of the vertebræ bear lateral processes? Why are the lateral processes of the third and ninth vertebræ stronger than the others?

Above the bases of the lateral processes note the articulating processes (zygapophyses), and their method of uniting adjacent vertebræ.

On either side of the spinal column observe the row of large openings through which the spinal nerves emerge. What is the position of one of these openings in relation to the vertebræ nearest it?

Isolate one of the midvertebræ, and in it see :-

The large, central neural canal.

Ventral to this, the relatively small centrum (or body of the vertebra), with its anterior face concave, and its posterior face convex.

Two stout pedicels of bone, arising dorsolaterally to support the arch of the neural canal, and bearing (1) the single pair of stout lateral processes, and (2) the two pairs of articulating processes already noticed, and (3) on the median dorsal line a short neural spine. Draw.

Compare this vertebra with a typical vertebra of a fish. 
II. Bones of the Fore Limb. - In the fore limb find the following parts :

The single long bone of the arm, the humerus. Its shape is characteristic of long bones; therefore note that it is somewhat cylindrical, that it is hollow, and that it has an expanded articular surface at each end, with a shaft between.

The bone of the forearm, made up of two bones, radius and ulna, which are grown together (anchylosed).

In the bones of the hand, three series may be distinguished :

1. A series of very small, irregularly shaped, carpal bones, immediately succeeding the bones of the forearm.

2. A single transverse row of cylindrical metacarpal bones.

3. Several transverse and unequal rows of phalangeal bones, or phalanges, growing successively shorter toward the tips of the digits.

III. The Shoulder Girdle. - Study the pectoral arch, or shoulder girdle. Observe that its bones, together with their attached cartilages, form an incomplete ring around the body, that the two halves of the girdle meet on the median ventral line, and that the parts are obviously arranged for the support of a pair of limbs.

Observe that each half of the shoulder girdle is composed (essentially) of three bones, which meet around the cavity (glenoid fossa) into which the head of the humerus fits. One of these bones (the scapula) extends dorsally, and is supplemented by a broad cartilage on the dorsal surface. The other two extend ventrally to meet their fellows of the opposite side on the median ventral line. The larger posterior one is the coracoid. The slender, anterior one is the clavicle.

Posterior to the point of union of the two coracoids, a flat bone (the sternum), which does not belong to the shoulder girdle, extends posteriorly on the median ventral 
line; and a corresponding bone (the omosternum) extends anteriorly from the point of union of the two clavicles.

What attachment is there between the shoulder girdle and the spinal column?

IV. Bones of the Hind Limb. - The bones of the hind limb are as follows:

1. The single bone of the thigh is the femur.

2. The bone of the shank is the os cruris. It is made up of two bones, tibia and fibula, as indicated by the longitudinal grooves near its ends.

In the bones of the foot, three series may be distinguished, of which the first. consists of two long, curved tarsal bones, united at their cartilaginous tips. The other two series are called metatarsal and phalanges, and correspond in position and appearance to homologous parts of the hand.

V. The Pelvic Girdle. - Study the pelvic girdle. Observe its shape, position, and attachment to the spinal column. Its halves are very solidly welded together on the median line. Each half is composed of three bones, united about the socket (acetabulum), into which the head of the femur fits; and the bones, though solidly coherent, may be distinguished by examining the lateral surface at their point of union. (1) The long bone extended anteriorly to meet the lateral process from the ninth vertebra, and shaped like an inverted sled runner, is the ilium. (2) The bone that forms the ventral fifth of the socket (acetabulum), and, with its fellow, forms the ventral ridge of the pelvic girdle, is the pubis. (3) The bone that forms the posterior two fifths of the socket, and, with its fellow of the opposite side, forms the posterior ridge of the girdle, is the ischium.

Compare now shoulder and pelvic girdle, and fore and hind limb, and note the principal points of likeness and of difference between them. 
VI. The Skull. - The study of the vertebrate skull is well begun with the skull of the frog, which is wide and open, and in which all the bones can be seen from the outside.

Observe its triangular outline as seen from above, and the large orbital and nasal apertures. Observe the posterior opening into the cranium (foramen magnum), and the pair of smooth, articular surfaces (occipital condyles)

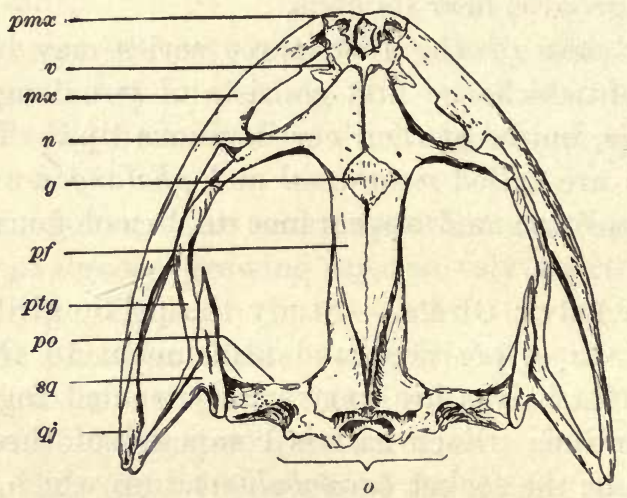

SKULl of BULlFrog (Rana catesbiana), dorsal view: $p m x$, premaxilla; $v$, vomer; $m x$, maxillary; $n$, nasal; $g$, girdle bone or sphenethmoid; $p f$, parietofrontal ; $p t g$, pterygoid ; $p o$, proötic ; $s q$, squamosal ; $q j$, quadratojugal; $o$, occipital region surrounding the foramen magnum.

close beside. These meet corresponding surfaces on the anterior end of the first vertebra.

The bones composing the skull are as follows:-

1. The bone which forms the back of the brain case, and immediately surrounds the foramen magnum, is the occipital.

2. The stout pillar of bone, which extends laterally at the base of the skull at right angles to the median line, is the prootic, so called because it lies in front of and covers the capsule of the inner ear. 
3. The hammer-shaped bone, which rests on the outer edge of the proötic, and extends its "handle" down to the posterior angle of the lower jaw, is the squamosal.

4. On the dorsal surface, three pairs of bones in front of the occipital meet on the median line. The first pair consists of two long, narrow bones, which cover almost the whole cranium. These are the parietofrontals.

5. In front of the last lies a pair of triangular nasals.

6. In front of the nasals is a pair of smaller bones (premaxillaries) which form the tip of the snout, which bear teeth, and which send narrow processes backward toward the nasals.

7. The border of the lower jaw is formed by the mandible, which consists of two rami (or branches) which meet on the median line in front.

8. The greater part of the border of the upper jaw is formed by a maxillary bone on either side, bearing abundant teeth.

9. Between the posterior end of maxillary and the "handle end" of the squamosal is a small bone (the quadratojugal) which completes the border of the upper jaw.

10. Looking at the ventral surface of the skull, a conspicuous T-shaped bone is seen extending along the floor of the cranium. It is the parasphenoid.

11. At its anterior end, a girdle bone (the sphenethmoid) surrounds the anterior third of the brain case.

12. Two slender palatines extend transversely outward to the maxillaries on either side. These lie ventral to the posterior border of the nasals.

13. Between the palatines and the premaxillaries are a pair of irregular vomers, each with a posterior process bearing teeth.

14. Lying just within the posterior angle of each jaw, as seen from below, is a conspicuous, three-rayed bone (the pterygoid). 
The cranium is of cartilage when first formed, and is not completely ossified in old specimens, as may be seen from the large spaces left in its lateral walls in prepared skeletons.

Make an enlarged, and if necessary diagrammatic, drawing of the frog's skull as seen from below, naming all the bones visible in the drawing.

Development. - Every student should study the life history of the frog. In the spring the eggs may be easily obtained from shallow pools in which frogs are heard croaking. Being as large as peas, and each with a darkcolored yolk surrounded by a layer of whitish albumen, and all suspended in large lumps of transparent, jelly-like substance, they are conspicuous and peculiar appearing objects. They may be looked for at the edges of the pools, amid the trash which collects there, and often partly hidden by it. These egg masses are popularly known as frog spawn.

The eggs, if carried home or to the laboratory, and kept in clean, cool water, will go on developing. If freshly laid eggs have been obtained, segmentation may be seen taking place in the yolk. Later, as the embryo develops, the yolk will appear oval in outline; and then, elongating more and more, an unmistakable head and tail will soon appear. At length the embryo becomes active, and breaks through the jelly-like mass, and is hatched. It attaches itself for a short time, by means of a pair of minute suckers near the mouth, to the jelly-like mass or to plants, but soon becomes a free-swimming tadpole. It then breathes by means of three pairs of external gills, which appear as minute tufts at the sides of the head. The water passes in at the mouth, and out through three pairs of gill slits located just in front of the gills.

If one of these small tadpoles be placed in a watch glass 
of water, and examined under low power of microscope, the circulation of the blood may be beautifully seen in its gills.

As the tadpole grows, a membranous fold (operculum) arises in front of the gills, and extends backward until it covers them. On the right side of the body, this fold becomes closely adherent by its posterior margin, thus closing the exit of the water on that side; but a transverse passage is developed below, so that all the water from both gill chambers passes out through the aperture remaining on the left side. As soon as the external gills are covered, they begin to disappear by absorption (atro$p h y$ ), and internal gills are developed on the inner side of the gill slits. Compare the structure of the tadpole, at this stage, with that of the fish.

Later a pair of legs appear on the sides of the base of the tail, at first beneath the skin, but soon becoming free. Another pair is developed beneath the operculum, and lungs begin to be developed within the body cavity. Then, by a final molting of the skin, the opercular membrane is shed, the fore legs are set free, and the eyes are fully exposed. Finally the gills are absorbed, and lungs become fully developed, and aquatic is exchanged for aërial respiration. The gill slits close, the tail is absorbed, and the tadpole has become a frog.

This brief account of the frog's life history touches only a few of the most salient points, all of which, and more than which, the careful student will see for himself.

Each student should dissect a large tadpole, and should compare the internal organs with those of an adult frog. Each student should find out what articles constitute the tadpole's vegetable diet, and should note, that, with the change to a diet of animal food in the adult, there is a great decrease in the relative length of the intestine. 
Each student should make a series of outline drawings, illustrating the life history of the frog.

The frog is a representative of the group Batrachia, of which tree frogs, toads, newts, efts, and salamanders are also members.

\section{THE TURTLE.}

Haunts and Habits. - The pond turtles or mud turtles (Pseudemys and Chrysemys), so abundant in our small inland lakes and sluggish streams, are recommended for study. In some places remote from water, the common

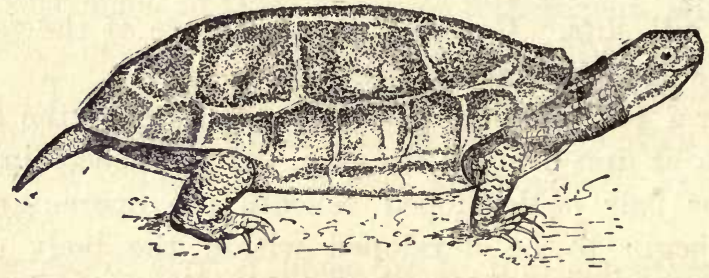

Mud TURTLe (Chrysemys picta).

box turtle (Cistudo) will be more easily obtainable. It is very often picked up in dry wood or fields.

The pond turtles are very shy, and somewhat difficult to secure alive by ordinary methods. They clamber out of the water upon the trunks of fallen trees along the banks of secluded ponds and streams, and lie in the sun for hours at a time, often scores of them together, of all ages and sizes; but when they are approached, they tumble precipitately back into the water, and disappear. They may be bought from fishermen. They may be dredged or raked up from the bottom with a large rake used from a boat. They may be caught with hook and line, but a stout line will be necessary. A small, compact piece of meat should be used for bait. A supply of speci- 
mens should be obtained while the weather is yet warm in autumn, and kept until needed. They may be kept alive for an indefinite length of time, without food, during cold weather. In the winter season they are normally inactive, and if kept in a moist, cool place, will need no looking after.

Study of a Live Specimen. - Study the turtle alive. After treating it to a good washing to remove the mud, take it into the laboratory, and study its locomotion:-

1. Its walking. Note the position of its legs with reference to the body, the distance between its lower surface and the surface on which it walks, its rate of speed.

2. Its swimming and diving. Place it in sufficient water, and observe how its legs are used in these acts.

Is its form well adapted for rapid locomotion of any sort?

Note how completely its head and appendages may be retracted within the shell.

Thrust a pencil toward the eye, and observe a thin, transparent membrane come out from the inner "corner," where it lies folded, sweep across the eyeball, and withdraw again. This is the third eyelid (or nictitating membrane).

Respiration takes place very slowly, but occasionally the animal may be seen to swallow a mouthful of air.

External Features. - Note among the external features the following:-

1. The relative size of head and body.

2. The hard shell or case which nearly incloses the body. It consists of a convex dorsal plate, the carapace, and a flat ventral plate, the plastron; and the two plates are united by a bony bridge at either side.

3. The color and markings of the wrinkled skin covering the neck and legs. Is any part of it scaly? 
Kill the animal with chloroform. The best way to do this speedily is to draw the head forcibly out with a tenaculum, open the mouth, find the opening into the trachea at the base of the tongue, and with a syringe or a large pipette inject into it, and through it into the lungs, a teaspoonful more or less of chloroform.

When the muscles are relaxed, draw out the head, noting the length of the neck and the position it assumes when retracted. Note the horizontal extension of the legs, their length, and range of movability. Find three principal divisions in each, as in the frog. Notice in the sides of the body the "pockets" into which the retracted legs fit.

Examine the head. Note its shape. Note the relative size and position of nostrils, eyes, and ears. Note the position of the nictitating membrane of the eye ; the color of the iris.

Open the mouth and examine the beak, which consists of the horny sheaths which incase the edges of the jaws. Observe how these sheaths fit together when closed. Find two nostril openings into the roof of the mouth; openings of two Eustachian tubes on the sides, back of the muscles which close the jaws (not easily seen from the front, better seen when the head is dissected); the opening into the trachea, on the floor of the mouth, and the esophagal opening behind it.

Observe that the horny sheaths of the jaws, and also the scales forming the external layer of the shell, are continuous with the skin of the body. Both are thickened outgrowths from its outer (epidermal) layer, similar in kind to the smaller scales found on certain parts of the skin.

Dissection. - With a saw or chisel cut through the bony bridges between carapace and plastron. Place the turtle on its back. Cut the plastron free from the skin 
all around the border, and carefully dissect the plastron free from all its attachments, and entirely remove it. See the points where it was connected by ligaments with the pectoral and pelvic arches. Muscles already severed from their origin on the plastron cover the bones of these arches. Dissect these muscles carefully away, noting that they are opposed in pairs on each half of each arch. Find nerves and blood vessels entering them internally. Avoid cutting any large branches of the blood vessels.

The peritoneum, covering the posterior part of the body cavity, should still be intact, and on its inner surface a pair of abdominal veins should be plainly seen.

The heart should be seen still pulsating in its thin pericardium, in the anterior part of the body.

The abundant transparent liquid which fills the spaces within pericardium and peritoneum is lymph.

Placing a thumb inside each half of the pectoral arch, press outward until its ligamentous attachment with the inside of the carapace is broken. Then draw the fore legs forward and outward, to separate the halves of the pectoral arch, and fasten them so.

I. The Heart. - Open the pericardium, and fully disclose the heart and its connections. Observe :-

1. A single large posterior ventricle.

2. A pair of smaller auricles.

3. White, elastic arteries arising from the ventricle.

4. Thinner-walled, darker-colored veins entering the auricles, and expanded, just before they enter, to form a contractile venous sinus.

Note the order of contraction, - first the venous sinus, then the auricle, then the ventricle. This wave of contraction pushes the blood forward, and indicates the direction in which it is flowing through these parts. If the blood vessels be now injected, they will be much more easily traced later. 
Divide the peritoneum along the median line, and disclose the internal organs. ${ }^{1}$

II. Digestive Organs. - Trace the digestive system, finding in order :-

1. Esophagus.

2. Stomach.

3. Intestine of three distinguishable parts :-

(a) Duodenum, into which ducts from the gall bladder of the liver and from the pancreas open.

(b) Small intestine.

(c) Large intestine; and at the junction of these two latter parts, a short, lateral, hollow process (the coecum). The spleen lies near the cæcum.

III. Renal and Reproductive Organs. - The reproductive organs cover the kidneys and often other parts. Find a pair of kidneys communicating posteriorly with a bilobed urinary bladder. Make a diagrammatic drawing of all these parts. Make a drawing of the liver, showing its right and left lobes connected with a transverse band.

IV. Veins and Arteries. - Trace the two anterior abdominal veins, seen through the peritoneum, before opening the body cavity, forward to the liver. Do they unite before entering the liver? Trace veins from the hindmost parts of the body to the kidneys, thence to the liver, and thence to the venous sinus. Find veins which come from anterior parts of the body, also entering the venous sinus.

Trace now the principal arteries. Observe that the two aortic arches and the pulmonary artery arise separately from the ventricle, and not from an arterial trunk, as in the frog. Trace the pulmonary artery to the lung, and

1 After dissecting two other vertebrates, the fish and the frog, the student should not now need further specific directions for finding and studying the nutritive and reproductive organs. He should rather let his knowledge of the structure of those vertebrates serve as a guide to the study of this one, and he should not fail diligently to compare this one with the other two at every point. 
the pulmonary vein back to the heart. Trace branches of the aortæ anteriorly to the head. Trace the aortæ themselves posteriorly, to see their union and subsequent division, and distribution to the various parts. Now make a diagram showing the general arrangement of the circulatory system.

V. Retractor and Protractor Muscles. - Study the action of the long retractor muscles which extend from the middle of the spinal column to the base of the skull, and of the protractor muscles, which extend from carapace and pectoral arch to the neck. Pull first on one and then on the other, and note the effect on the head and neck.

VI. Trachea and Lungs. - Extend the neck, and fasten it so. Dissect out the trachea and the lungs. Inflate the lungs, and keep them inflated by tying the trachea with a thread. Hang them up, and let them dry, and preserve them for comparison with the lungs of other vertebrates.

The narrow slit by which the trachea opens on the floor of the mouth is the glottis. Why does not food which is being swallowed get into the trachea?

VII. Spinal and Cranial Nerves and Brain.-Remove the viscera, and find spinal nerves. Compare in number and arrangement with those of the frog. Remove the roof of the cranium, and find cranial nerves and brain. In the brain find in order from the front, (1) olfactory lobes, (2) cerebral hemispheres, (3) midbrain, (4) optic lobes, (5) cerebellum, and (6) medulla.

Study of the Skeleton. - Study the shell of the turtle, especially in its relation to the bony skeleton. In a prepared skeleton of an adult turtle, note :-

1. That the pectoral and pelvic arches, and the bases of the legs, are contained within the shell.

2. That both arches are attached more or less closely at several points to both earapace and plastron. 
3. That the spinal column is coössified with the carapace, only the vertebræ of neck and tail remaining free and movable.

I. The Shell: Exoskeletal Parts. - Examine the plastron. On its ventral surface find six pairs of flat, horny plates, with two additional smaller pairs, forming the margins of the bridges meeting the carapace. On its dorsal or inner surface find four pairs of plates and one single plate of bone. Note that the boundaries of the horny plates on the ventral surface do not correspond to the boundaries of the bony plates on the dorsal surface. The horny plates, like the scales of other parts, are developed from the outer, epidermal layer of the skin, and are therefore called epidermal plates. The bony plates are developed from the deeper layer of the skin (dermis), and are called dermal plates.

Examine the carapace. Its convex surface is completely covered over with epidermal plates, as follows : -

On the median line, at the anterior edge, is a small, single nuchal plate (sometimes a pair of nuchal plates).

Posterior to this, on the median line, are five large central plates.

A pair of pygal plates meet on the median line, at the posterior edge.

The central plates are bordered laterally by four pairs of large centrolateral plates.

The margins of the shell between the nuchal and pygal plates are formed by eleven pairs of marginal plates.

Dermal plates are developed beneath the marginal nuchal and pygal epidermal plates, and correspond with them in position, in names, and in number, save that the nuchal and pygal plates are single.

The dermal and epidermal plates together constitute the outside skeleton or exoskeleton, as distinguished from the true internal skeleton (or endoskeleton). 
The relation between the plates which make up the shell can be better understood by separating them. If the specimen which was used for dissection, after being freed from most of its soft parts, be dipped into boiling water for a few minutes, the horny epidermal (tortoiseshell) plates may be readily stripped off. If then it be boiled thoroughly, the marginal nuchal and pygal dermal plates may be removed. There will then remain only the endoskeleton, forming still a considerable part of the concave surface of the carapace.

II. Endoskeletal Parts. - On the convex surface, as it is now exposed, there will be seen markings corresponding to the edges of the epidermal plates which have been stripped off. Observe that these markings do not at all correspond to the outlines of the plates of bone they overlie. These plates of bone are arranged in longitudinal series as follows:-

There is a central row of eight plates formed by the lateral expansion of the neural spines of eight of the vertebræ, and hence called neural plates.

There are two lateral rows, each of eight plates, formed by the expansion of eight pairs of ribs, and hence called costal plates.

III. The Spinal Column. - Study now the arrangement of bones, as seen on the concave side of the carapace. The spinal column marks the median line. In it are four distinguishable regions :-

1. A cervical region, extending from the head to the shoulder girdle. The cervical vertebræ bear no ribs, and are not attached directly to the carapace.

2. A dorsal region, of rib-bearing vertebræ, coössified with the carapace.

3. A sacral region, of two vertebræ, not attached directly to the carapace, bearing ribs which unite distally to form a facet for articulation with a bone of the pelvic arch. 
4. A terminal caudal region, of many small vertebræ, without developed ribs, tapering posteriorly to the tip.

The dorsal vertebræ are the ones concerned in the formation of the carapace. Observe that, of the ten dorsal vertebræ, each one, except the first and the last, bears a neural plate and a pair of costal plates. Observe that the ribs from the first dorsal attach to the costal plates of the second, and that the ribs from the tenth attach to the costal plates of the ninth. Notice that several of the anterior pairs of ribs appear to have moved forward until they articulate with the centra of two vertebræ. Notice the finely toothed sutures by which the costal plates meet each other.

How many of the points noted in the structure of the shell are directly conducive to its strength?

How many caudal vertebræ are there? How many cervical? Observe that the first cervical meets the skull by a single occipital condyle. Separate the cervical vertebræ, and note the great variety of articulating surfaces between the ends of adjacent centra.

IV. Girdles and Leg Bones. - In each half of the shoulder girdle there are three bones :-

1. The bone which extends from the shoulder dorsally, to meet the first costal plate, is the scapula.

2. The posterior of the two bones which extend from the shoulder toward the median line is the coracoid. It is horizontally flattened toward its inner end, there becoming somewhat triangular.

3. The anterior of the horizontal bones is the precoracoid.

In each half of the pelvic girdle there are three bones :-

1. The bone which extends from the acetabulum dorsally, to meet the sacral ribs, is the ilium.

2. The posterior of the two bones which extend from 
the acetabulum horizontally, toward the median line, is the ischium.

3. 'The anterior of the two horizontal bones is the pubis.

Between ischium and pubis is a large hole, the obturator foramen. Ischia and pubes of opposite sides meet in a median ventral symphysis.

In both fore and hind legs find the parts already found in the legs of the frog, observing the separation of the two bones of the forearm and the two of the shank, and the shortness of the tarsal bones.

Development. - The eggs of certain species of turtles (the eggs which are perhaps most easily found) are laid in early summer in sunny sandbars in rivers, lakes, and creeks. At night the mother turtle digs down into the sand, and hides away her eggs a foot or more beneath the surface, smooths the sand above them, and leaves them to be hatched by the warmth of the sand, absorbed from the sun's rays. Although the mother turtle has been careful to remove visible traces of their whereabouts, they may yet be found by very simple means. The disturbed sand in which they lie is much more readily penetrated by a stick than are other places on the bar. Hence, if a stick be pushed into the sand at short intervals along the line of the turtle's tracks, and a place be found where it enters very much more readily than elsewhere, that is the place to look for the "nest." The unmistakable tracks of the turtle across sunny bars of pure sand will seldom be followed in vain in May or June; for the turtles do not ordinarily frequent such places.

The young turtle which hatches from the egg is essentially like the adult, except in size. It differs somewhat in having its legs and pectoral and pelvic arches free from the shell. During later development the shell encroaches upon, and partially incloses, these parts. Young in all 
stages may be captured in the same situations with the adults.

No good conception of the life this animal leads can be obtained in the laboratory. After studying it there, the student should spend a day or two early in his summer vacation studying the animal in its native haunts, learning of its curious habits, and of the peculiar place it fills in the economy and society of nature.

The turtle is a representative of the class Reptilia (or reptiles).

Other Reptilia. - Lizards, snakes, and alligators also belong to the Reptilia.

\section{THE SNAKE.}

Lizards and Snakes present types of reptilian structure so markedly different from that seen in the turtle that the following outline is subjoined to enable the student to know how to proceed in case a study of either of these forms is to be undertaken. For guidance in studying the details of their structure, he is referred to the reference works mentioned elsewhere. This meager outline is written for the snake, but may be applied without much change to the study of any common lizard.

Study of the Live Specimen. - Get a garter snake (Eutania), or a black snake (Bascanion), or any other common harmless species, and study it alive. Notice the exceeding gracefulness of its movements, the slenderness of its flexuous form, the ease of its gliding motion, and the beauty and harmony of its coloration. Observe :-

1. The entire absence of limbs. How is its rapid progression effected?

2. The position it assumes when molested and brought to bay, and its method of defense. 
3. Protective resemblance; i.e., likeness in form and coloration to the natural objects by which it is surrounded when in its native haunts. Considering that the snake is a predacious animal, what are the advantages, both protective and offensive, of being inconspicuous?

External Features. - Place the snake and a small piece of sponge or bunch of cotton saturated with chloroform in a tight box or under a bell jar, and as soon as the snake is dead extend it lengthwise on the table and note its external features. Observe :-

1. The general form of the body.

2. The more or less distinct head.

3. The long tapering tail.

4. The complete covering of scales.

5. The relation of the scales to each other and to the underlying skin.

6. The form of the scales -

(a) On the head.

(b) On the back and sides.

(c) On the ventral surface of both body and tail. The wide ventral plate-like scales on which the body rests are the gastrosteges. The hindmost of the gastrosteges is the anal plate. Observe whether it is entire or bifid. The paired plates beneath the tail are the urosteges.

Search the eye for eyelids; the sides of the head for ears ; the front of the head for nostrils.

Dissection. - Stretch the snake back downward upon a board, and fasten it so with a tack through the tail and two others through the edges of the upper jaw. Leave the lower jaw free. With forceps pull this upward and sidewise, and note how loosely its halves (rami) are united at their tips. Note :-

1. The looseness of the hinge by which the lower jaw is attached to the cranium. 
2. The dilatability of the mouth and throat.

3. The position, shape, and direction of the teeth. Are they adapted for chewing food? In what condition does the snake swallow its prey?

With forceps draw the forked tongue from its sheath, and note its character and length.

Find behind the tongue a small opening into the trachea, the glottis, and behind the glottis the opening into the esophagus.

With sharp scissors split the abdominal wall down the median ventral line to the tail. Fasten the cut edges wide apart with tacks.

Internal Features. - Without further dissection make out the following parts:-

1. The heart lies in the central anterior portion of the body, inclosed within its thin transparent pericardial sac. The large conic posterior portion is the ventricle. The two lobes beside its anterior end are the auricles.

2. The brownish elongated organ lying along the left side of the body is the liver.

3. Beneath the liver is the stomach. Leading from the mouth to the stomach is the esophagus, and posterior to the stomach is the intestine.

4. Posterior to the liver, and lying close to the beginning of the intestine, is the dark gall bladder. Close beside it is the spherical spleen.

5. Posterior to these are the elongated, light-colored kidneys, one on either side, communicating with the exterior by a very long and much crimped duct.

6. Posterior to all these are the paired reproductive organs, each with a separate straight duct lying alongside that of the kidney.

Lungs and Blood Vessels. - From the glottis the ringed trachea may be traced back to the pink lung, which lies on 
the right side of the body. Insert a blowpipe into the glottis and inflate the lung. Observe a prominent branching pulmonary artery running along the inner side of the lung. Cut away the upper part of the pericardium and trace this artery back to the heart. Through it blood is conveyed from the heart into the lung for aëration.

Observe on the inner side of the liver a prominent vein coming from the posterior part of the body cavity, bringing the blood back to the heart. Trace outward from the heart the aorta (the principal artery), which arises from the ventricle between the auricles, bends upward and backward about the esophagus, and passes straight through the body cavity posteriorly, giving off branches which supply blood to all the parts.

The lung is single, but the rudiment of its undeveloped mate may be found by dissecting out the trachea. Dissect out the lung. Inflate it through the glottis, and tie the trachea with a thread to keep it inflated. Dry it, and compare it in structure with the lungs of the frog and the turtle.

Compare the snake with the turtle in respect to-

1. Means of locomotion.

2. Character of mouth parts.

3. Character of scales.

4. Shape of body cavity.

5. Relative development of internal organs.

\section{THE ENGLISH SPARROW.}

\section{(Passer domesticus.)}

An Interloper. - This bird and its haunts are too well known to need description. It was introduced into the United States about 1850, and has since overspread the whole country. It is the only bird to be found in many of 
our cities and towns. Because it is surely supplanting our more desirable native birds, the student is recommended to find a scientific use for as many specimens as possible.

Collecting. - There are many ways of obtaining live specimens. A few are suggested: the ingenious student will devise other, and perhaps better, means. A trap, consisting of a common wooden box, set with a figure-4 trigger, and baited with any kind of grain or with a crust of bread, will usually obtain specimens, but not

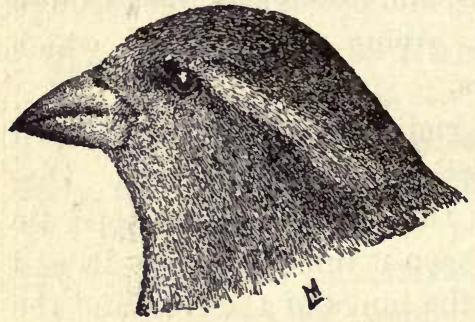

Female.

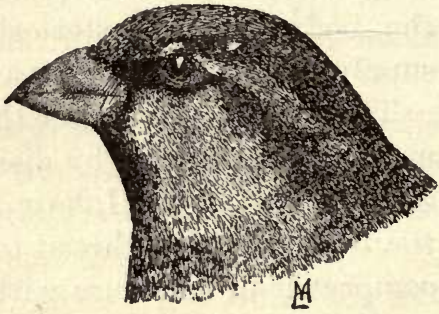

Male.

English Sparrow (Passer domesticus).

oftener than once in one place. Sparrows often roost in sheds and outbuildings, which may be closed after dark, and all the inmates secured. When found roosting in a vine or shrubbery, they may often be surrounded with a large sheet, and captured within it.

Field Study. - Study the bird in its relation to nature. On the street and on the lawn observe, as opportunity daily offers, the habits of the bird, until you are able to answer the following and related questions :-

1. Is the sparrow solitary, or sociable, in its habits?

2. What kind of a voice has it? Can it properly be said to sing? Has it different notes for different occasions, and can you discover what any of its notes mean? 
3. Can it hear well?

4. Is its sight as keen as your own?

5. What does it eat? It was imported in the hope that it would rid the country of certain insect pests. Do you find it eating insects at all?

6. If other species of birds are found in the same locality, how do the sparrows behave toward the other birds?

7. What kind of a nest does the sparrow build? At what season? Out of what materials? How put together? Where is it located?

8. How many eggs are laid in the nest? How long are these in hatching? How long before the little birds leave the nest? What do the fledgelings eat? How do they get their food? Is more than one brood reared each summer by a single pair?

9. What physical casualties of weather, temperature, etc., have you observed to destroy the eggs or young?

10. What are the natural enemies of the species?

11. Are the fatalities to the young more, or less, frequent than with other animals you have studied?

Study of a Live Specimen. - With a live bird in hand, note :-

1. The shape of its body. How is it adapted for progression through the air? How does the plumage of the body improve this adaptation?

2. The shape and attachment of its wings. What is their shape above? Below? What is their anterior outline when extended? Their posterior? Find three principal joints in one wing. Note the zigzag position these joints take, even in the extended wing. Note the membrane stretched between the first and second joints. Of what advantage is it for flying? Why are the wings attached at the dorsal side of the body? 
3. The action of the wings. How, in relation to the air, are they moved forward? Backward? How are they folded up?

4. The use of the tail. Permit the sparrow to fly about a closed room, and observe the rudder-like action of the tail. When the tail is inclined upward, downward, to right or to left, what is the corresponding direction taken in flight? How is the tail used in effecting a quick stop?

5. The shape and position of the legs. Note the zigzag position of the three principal joints. Note the position in standing, in perching, and in flight. Placing the feet in the perching position on one finger, note how the toes automatically close and open when the body is lowered toward the finger, or raised away from it.

6. The action of the legs. Does the sparrow walk? Slip a wide rubber band over the wings to hold them close, or, what will answer the same purpose, tie their tips together, and note how the bird gets about when using its legs alone.

7. Respiration. Note what parts of the body visibly expand and contract in breathing.

8. The eyes. What position do the eyelids assume when wide open; i.e., are there any "corners" to the sparrow's eye? Thrust a pencil toward the eye, and see the nictitating membrane dart out across the eyeball, and as quickly retreat again. Observe the round, black pupil in the center of the front of the eyeball, and the circular brown iris surrounding it. Take the bird into a dark place, and watch the pupil enlarge. Then bring it quickly out into the strong light again, and see it grow smaller.

Wet a small piece of cotton with chloroform, and hold it on the nostrils of the bird a moment, until it begins to doze. Then tie the cotton in place, add a few more drops of chloroform, and lay the bird down. In a few moments 
it will be quite dead, and, killed in this way, it will be in excellent condition for a detailed examination of its structure.

Naming of External Parts. - For purposes of description, the external parts of the bird are named as follows :-

I. The Head and Neck. - At the front of the head is the beak, composed of upper and lower mandibles. The line of meeting of the two mandibles is the commissure. Observe that in the sparrow the commissure is not straight, but angulated; i.e., bent downward posteriorly, as if the corners of the mouth were drawn downward. The corner of the mouth is called the rictus, and the bristles overhanging the rictus are called rictal bristles. The ridge of the upper mandible is called the culmen; and the keel of the lower mandible, the gonys. At the base of the upper mandible are the nostrils. The front part of the top of the head is the forehead, the top part is the crown, the back part is the occiput, and the back of the neck is the nape. The space between the eye and the rictus is the lore. Below and behind the eye, hidden by a tuft of loose feathers, is the ear. Lift up these feathers and find the auditory opening. Examine one of these feathers with a lens. What advantage is there in having these feathers less compact than the others? The front part of the under surface of the head is the chin. The front of the neck is the throat.

Make an enlarged outline drawing of the head and neck, naming all the parts upon the drawing.

II. The Body and Tail. - The dorsal surface of the body is the back. The tufts of feathers covering the bases of the wings dorsally are the scapulars. The prominent narrowed portion of the back immediately preceding the tail is called the rump. 'The long, soft feathers that overlap the tail above are the upper tail coverts. The long, 
stiff feathers of the tail are the rectrices (or tail feathers), oftenest called simply the tail in descriptions, though they are only a part of the exoskeleton of the tail. Beneath the rectrices are the long, soft under tail coverts. The small area of loose feathers just in front of the lower tail coverts is the crissum. The posterior part of the remaining lower surface is called the abdomen (or belly); and the anterior, more convex part, the breast.

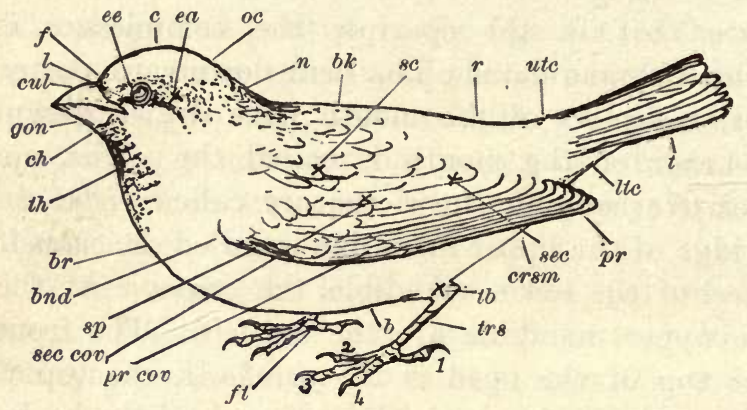

Diagram of Sparrow: $c u l$, culmen; $l$, lore; $f$, forehead; $e e$, eye; $c$, crown; $e a$, ear; $o c$, occiput; $n$, nape; $b k$, back; $r$, rump; $u t c$, upper tail coverts; $t$, tail ; ltc, lower tail coverts; crsm, crissum; $b$, belly; gon, gonys; $c h$, chin; th, throat; $b r$, breast; bnd, bend of the wing; sc, scapulars; pr, primaries; sec, secondaries; pr cov, primary coverts; sec cov, secondary coverts; $s p$, spurious quills ; $t b$, tibia ; trs, tarsus; $f t$, foot; $1,2,3$, and 4 , toes.

III. The Wings. - In a wing find parts corresponding to arm, forearm, and hand. The long feathers which grow on the most distal division, or hand, are the primaries. Those which grow on the middle division are secondaries. In some birds, but not in the sparrow, there are similar feathers growing on the proximal division, called tertiaries. The short, soft feathers which overlap the bases of the primaries and secondaries above and below are called upper or lower, primary or secondary coverts. At the bend of the wing, and overlapping the upper primary coverts, is a tuft of short quills (the spurious 
quills) growing upon the part of the hand which corresponds to the thumb. In the hollow beneath the wing, at its junction with the body, is a tuft of long, loose, soft feathers (the axillars).

Expand the wing, and arrange all the feathers naturally. Note the shape and curvature of the primaries and secondaries. Note their direction of overlapping. Find on the wing a series of feathers which shingle in the opposite direction. Observe the position of the coverts. See how beautifully each feather falls into its proper place when the wing is closed, how compactly the whole wing is nestled against the sides of the body, and how it is overlapped by the other plumage, and made to contribute to the symmetry of the bird.

IV. The Legs. - In. a leg, find thigh, shank, and foot. The foot consists of a long, slender tarsus, and four toes terminated by horny claws. The tarsus is made up of several tarsal bones solidly grown together (anchylosed). Note the directions the toes take, and the number of joints in each. What parts of the leg are feathered? What parts covered by scales? What kind of a covering has the lower surface of the foot?
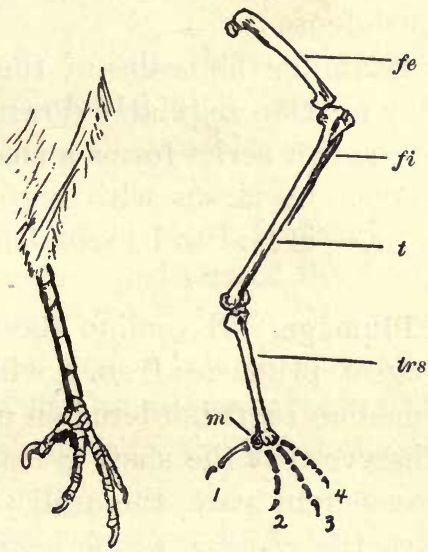

LeFT LEG OF SPARROW (from inner side, slightly reduced): $f e$, femur; $f i$, fibula; $t$, tibia; trs, tarsus or tarsometatarsus; $m$, an incomplete extra metatarsal at base of hind toe; $1,2,3,4$, toes.

Exoskeletal Modifications. - In this external examination of the bird, three modifications of exoskeleton will have been noticed. 
1. Horny sheaths covering the mandibles and claws. toes.

2. Epidermal scales (scutelloe) covering the tarsus and

3. Feathers covering the remaining exposed portions of the skin, and constituting the plumage.

But there are hidden areas of the skin which are bare. By separating the feathers, find one of these on the median line of the breast, and another on either side of the base of the neck.

Examine the stout, thick beak. Such a beak is well adapted to eating grain, - to breaking the husks and hulling out seeds. Examine the claws. Are they sharp enough to be of much service as defensive weapons? Are the feet strong enough to indicate that the claws are used for defense?

Examine the scales of the tarsus and toes. Note that they overlap regularly down the front and sides, and that a posterior series forms a sharp ridge down the back of the tarsus. A tarsus with regularly overlapping scales such as these is said to be scutellate.

Plumage. - Examine the plumage. Pluck one of the longest primaries from a wing, and examine it. Observe a median shaft bordered on either side by a web (or vane). Observe that the shaft is made up of two parts, - a lower transparent part, the quill (or calamus); and the opaque part, the rhachis, which bears the vanes. Make a cross section through the calamus, and another through the rhachis. What is the shape in cross section of the calamus? Of the rhachis? What is the condition of the interior of the calamus? Of the rhachis? Holding the rhachis horizontally, look at the cut end. Compare the position of the vanes in relation to the rhachis with that of the wings of the bird in relation to the body. Why should the vanes be attached to its upper side? 
Observe a longitudinal groove on the under side of the rhachis. Place a needle point in this groove, and push it along toward the calamus until it enters a small hole (umbilicus). Trace the vanes downward to their origin. Where is there another hole leading to the interior of the calamus?

Examine the vane with a lens. The thin, narrow linear plates of which it is made up are called barbs. Observe that each barb is fringed with similar smaller plates, called barbules, which, by their interlacing, form a true web, ana give capacity for much resistance to very weak filaments. If a piece of the vane be soaked for a time in strong alcohol, to remove air, a microscopic examination of its barbules will discover little hooks (hamuli) along a portion of their margins.

Pluck one of the small rictal bristles from just above the corner of the mouth. Examine it with lowest power of microscope, to make out calamus, rhachis, and partial vanes.

There is one other part present in many feathers. It may be found in one of the surface feathers of the breast or back. Examine one of these with a lens. Make out calamus, rhachis, and vanes, and find in addition an aftershaft arising from the summit of the calamus, behind the rhachis. Compare the aftershaft with the parts already studied.

The three feathers examined, together with nearly all others that are exposed on the surface, and that make up the contour of the bird, are contour feathers. The great variation seen in these is but an intimation of what may be expected in feathers of this class.

Down feathers lie beneath and between the contour feathers. Pluck the contour feathers one by one from a small space on the body, and the down feathers will remain. Examine one of them with a lens. Compare its 
barbs with the barbs of a contour feather. What is the probable use of these down feathers?

There are certain hairlike feathers (filoplumes) on the skin of birds. These are easily seen on a plucked fowl before singeing. They are not hairs, as a microscopic examination of one will prove. Birds do not have true hairs.

Other Structures. - Separate the feathers above the base of the tail, and find the oil can, a double, coneshaped gland, which secretes an oily fluid for "feather dressing." The bird, with its beak, presses a drop of oil from this gland, and distributes it over the tips of the feathers, in the familiar act of preening.

Examine the ear again, and note that the tympanic membrane is at the bottom of a short external auditory meatus, and that the skin of the head dips down into and lines this opening.

Holding the back of the head firmly with one hand, alternately raise and depress the upper mandible, and observe that it is movable upon the head.

Within the mouth find the single guarded opening of the nostrils. Find also the openings into the esophagus and into the glottis. Note the shape and character of the tongue.

Insert a tube into the glottis, and inflate the lungs. Note what portions of the body are expanded.

Dissection. - Prepare a freshly killed specimen for dissection. Fasten the specimen with tacks, back downward, on a shingle, with legs and wings fully extended. Part the feathers, and divide the skin along the median ventral line, from the neck to the tail, taking care not to cut through the thin abdominal muscles. Now loosen the skin from the sides of the body by holding the severed edge of the skin between a thumb and finger, 
and with a knife blade pushing the flesh away from the skin. At the anterior end of the first cut make a circular cut through the skin, about the base of the neck. Then carefully draw the skin of the neck forward over the head, wrong side out, and fasten it with a tack in front of the beak. While doing this, observe the position assumed by the retracted neck, and note again how much the feathers contribute to the beauty of the bird's outline, and improve its form for rapid passage through the air. Draw the skin out laterally on each side of the first median cut, and fasten it away from the sides of the body.

Pass a tube into the esophagus, and inflate the crop, a capacious expansion of the esophagus at the base of the neck. Tie a string about the esophagus to keep the crop inflated, for convenience in dissecting off the fat and integument which cover it.

Observe on each side of the neck a vein (the jugular vein), usually filled with blood, and dark-colored, and close beside it a white nerve (the vagus nerve).

I. Removal of the Body Wall. - On the median line of the breast observe the ventral edge of the sharp ridge (or keel) of the sternum, and on either side of it the thick muscles which cover the sternum. Posterior to the sternum, the internal organs are covered only by the thin wall of the abdomen. Sever the muscles from the keel by a single longitudinal cut on each side of it, keeping the knife close to the bone. Continue the cuts laterally around the posterior edge of the sternum, severing the attachment (origin) of a great flap of muscle. Lift up the loosened posterior end of this great muscle, and observe it separating from a smaller muscle, which has its origin in the angle between the horizontal part of the sternum and the keel. The larger muscle is the pectoralis major; the smaller one, the pectoralis minor. 
Dissect these breast muscles free from all attachments except their insertions, and, while doing so, look for veins, arteries, and nerves, entering the muscles near the shoulder.

The removal of the pectoral muscles discloses the enormously developed sternum, with its sharp keel and its lateral ribs. The V-shaped bone in front of the sternum is the wiskbone or merrythought, and is made up of the two clavicles grown solidly together at their inner ends. The paired stout bones extending from the shoulders to articulate with the anterior end of the sternum are the coracoids. Disarticulate and entirely remove the clavicles. Free the coracoids from the sternum, and turn them outward. With small scissors cut away the exposed abdominal wall, and cut forward through the ribs at the sides of the sternum. Then remove the sternum, avoiding blood vessels as much as possible. This will expose the internal organs. Again inflate the lungs through the glottis, and observe the large air sacs in the abdomen, communicating with them. Remove blood, which may collect about the organs, with a small damp sponge. Moisten the neck, if it dries and hardens too rapidly.

II. The Trachea. - Find at the base of the tongue a small U-shaped hyoid bone surrounding the front of the glottis, the long arms of the $U$ extending posteriorly behind the skull. Dissect it and the tongue free from their attachments to the lower jaw. The glottis opens into a slightly swollen cartilaginous antechamber of the trachea, called the larynx. At the posterior end of the trachea, where it divides into two small bronchi, is another slightly swollen portion (the syrinx). This latter is the principal voice organ in birds. Cut across the trachea half an inch in front of the bronchi into which it divides. Make a lateral eut with fine scissors along the sides of the trachea and bronchi, and turn down the ventral wall. 
Observe the thinner walls of the posterior portions of the syrinx. Observe the delicate vertical semilunar membrane projecting forward into the syrinx from the angle between the bronchi. By the vibration of this membrane, voice is produced.

Note the relative position of trachea and esophagus. How is the food, in passing through the mouth, kept from getting into the trachea through the glottis? .

III. Organs of Digestion. - Dissect out and remove the trachea and anterior ends of the bronchi. Then proceed to a dissection of the digestive system, disregarding the cutting of blood vessels; for the circulatory system will be studied later in an injected specimen.

Trace the alimentary canal, beginning at the mouth. The large crop, in the midst of the esophagus, is a sort of food reservoir in which the comminution of ingested food is begun. In its transparent walls may be seen bands of muscle fibers, which, contracting, give to the crop a sort of slow, churning motion; and this, together with the grinding action of the gravel usually found in the crop, and the softening action of secretions poured from glands in its walls, begins the reduction of the food.

A short distance posterior to the crop, the backward continuation of the esophagus enters the mottled glandular, slightly dilated stomach.

Close behind the stomach is the large gizzard, someimes called the muscular stomach. Note the shape of this organ, the satiny luster of its exterior, the thickness of its powerful muscular walls, the toughness of its fibrous inner coat, and the fine gravel mixed with its contents. This gravel takes the place of teeth, and assists in the final reduction of the food.

The intestine immediately succeeds the gizzard. The first long loop in it is called the duodenum. Into this part the duct from the inclosed whitish or pinkish pan- 
creas opens, and also the duct from the gall bladder, which is attached beneath the edge of one lobe of the liver.

Posteriorly the intestine opens into a widened terminal portion of the canal (the cloaca). Near the end of the intestine are two little lateral side branches, which end blindly, and are called coeca (or diverticuloe).

Cut off the esophagus near its anterior end, and the intestine near its posterior end. Dissect out the intervening part of the alimentary canal, liver, and pancreas, noting the dark-red spleen lying near the stomach, the mesentery looping up the intestine, and the blood vessels distributed to all the parts.

IV. The Heart. - Slit open the pericardium. Expose and examine the heart. Note its conical shape, and the firmer texture of its more muscular posterior end. The auricles (right and left) at the anterior end are distinguishable from the ventricles by their darker color, and by being marked off from the ventricles and from each other by delicate yellowish lines of fat. Prick a hole in each auricle, insert a pipette, and inflate to see their extent.

That there are two ventricles also (right and left), is not evident from the exterior. Snip off the posterior end of the heart with sharp scissors, and look at the cut surface. The cavities of the two ventricles will be at once apparent, - that of the left ventricle circular, and surrounded by yery thick, muscular walls; that of the right ventricle, crescent-shaped, and with thinner walls. Dissect out the heart and its connecting blood vessels, and fully expose the lungs.

V. The Lungs. - Pass a bristle into one of the lungs through its bronchus, and probe to find the openings by which the lungs communicate with the air sacs. Lay open the bronchus with fine scissors, and see how it is branched, and how its branches are distributed through the lung. Dissect out the lungs, and note how 
closely they are fitted into the dorsal part of the body cavity, and how deeply they are indented by the ribs.

VI. Renal and Reproductive Organs. - There yet remain in the posterior dorsal part of the body cavity the brownish, trilobed kidneys, partly hidden by the reproductive organs, - a pair of roundish or oval, light-colored testes, in the male; a single, larger ovary, often showing developing eggs, in the female. All these organs communicate by separate ducts with the cloaca. Remove the kidneys, noting their relations to the pelvic bones and to the sacral spinal nerves.

Concluding Work. - Find two regions in the spinal column in which the vertebræ are wider than in other parts. Observe that the spinal nerves issuing in these regions are larger than the others. To what parts are these spinal nerves distributed?

Cut the skin around the base of one of the legs, and pull it off like a stocking wrong side out. Dissect apart the muscles to find the mechanism by means of which the toes are clasped automatically when the bird sits perching. Of what advantage is this to the bird?

Loosen the bird, turn it over, and pull the skin entirely off from the head. The pockets in the skin, which are fitted down into external auditory openings, may readily be pulled out, but the attachment at the eyes will have to be cut. Then carefully cut away the top of the cranium, and the membranes that lie beneath it, closely covering the brain. Having fully exposed the brain, carefully lift it out, beginning at the anterior end, and severing the cranial nerves as soon as they are exposed. Place the brain at once in alcohol to harden for future study.

Study of the Circulatory System. - In an injected specimen $^{1}$ study the circulatory organs. The heart has

1 For method of injection see Appendix, p. 286. NEED. ZOöL. - 15 
already been studied, and its auricles and ventricles have been located.

I. The Venous System. - Trace first the veins. The right auricle receives all the venous blood from all parts of the body through three principal veins, - two proecavce (right and left) and one postcava. Find these three veins, and note the points at which they enter the auricle. Trace each of the præcavæ forward, and find each to be formed by the confluence of three veins, one coming from the head (the jugular), one from the wing (the brachial), and one from the great pectoral muscles (the pectoral). Observe that the postcava comes to the heart through the right lobe of the liver, receiving small branches in that organ. Posterior to the liver it is formed by the union of two (iliac) veins coming from the kidneys. Three other veins on each side bring the blood from the posterior parts of the body to the kidneys.

II. The Pulmonary System. - The blood collected in the right auricle descends through a valvular opening into the right ventricle. The right ventricle then contracts, and sends the blood out to the lungs through a pair of short pulmonary arteries (right and left). Find these arising together from the right auricle, but at once dividing, and going directly one to each lung.

From the lungs the blood, after aëration, flows back to the heart through a pair of pulmonary veins (right and left), which enter the left auricle separately. These will probably be more easily traced from the auricle out to the lungs.

III. The Arterial System. - The blood thus collected into the left auricle descends through a valvular opening into the left ventricle, whence it is expelled through a single large artery (the aorta) to all parts of the body by the contraction of the ventricle. Herein lies the explanation of the very thick muscular walls of this ventricle. 
Near its origin the aorta gives off a pair of large (innominate) branches, which go to right and left sides of the anterior part of the body. Each of these branches divides into three smaller arteries (carotid, brachial, and pectoral), corresponding to the three branches of each præcava. The aorta curves dorsally, and toward the right side, and is continued posteriorly through the body cavity as the dorsal aorta, giving off principal branches to all the important visceral organs, and to the legs.

The Skeleton. - Study the sparrow's skeleton from disarticulated bones. Have a mounted skeleton at hand for reference. Note the lightness of the bones. Hold some of them up to the light, and observe the air spaces in them. Note that the most striking peculiarities of the skeleton are in the bones of the pectoral and of the pelvic regions, modifications in the one region adapting the fore limbs for flight, and in the latter adapting the hind limbs for supporting the entire weight of the body in walking.

The axial part of the skeleton, as in all vertebrates, is the spinal column, with the skull at its anterior end.

I. The Skull. - Study the skull. Observe the large orbits dividing it into a posterior cranial region and an anterior facial region. Observe that the orbits are separated from each other by an incomplete interorbital septum. Observe that the cranial cavity opens widely into the posterior dorsal part of both orbits. This large opening was closed in life by a membrane, but the smaller ones beneath it are foramina for the exit of cranial nerves. At the back of the cranium find the foramen magnum, and just beneath this the single occipital condyle, a minute knob of bone for articulation with the first vertebra. On either side of the condyle are very minute foramina for the exit of other cranial nerves.

Note how the lines of the skull converge toward the 
point of the beak, giving the skull a slightly oblique, pyramidal form, the cranium forming the base of the pyramid.

The skull is composed of many bones, a large proportion of which will be found to be solidly coössified in all except

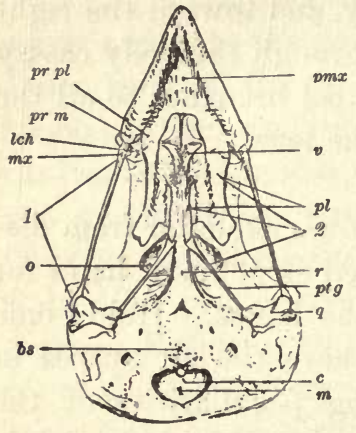

Skull of Sparrow, slightly enlarged (ventral view, mandible removed): $m$, foramen magnum; $c$, occipital condyle; $b s$, basisphenoid ; $r$, rostrum ; 1, quadratojugal bar ; 2, palato-pterygoid bar; $q$, quadrate; $p$ tg, pterygoid ; $p l$, palatine; $v$, vomer; lch, lachrymal; $m x$, maxillary portion of quadratojugal bar; $p m x$, premaxillary; $p r$ $p l$, palatine process of premaxillary; $p r m$, maxillary process of premaxillary; $o$, opening between orbits and cranial cavity (closed in life by membrane). immature specimens. Their outlines will not be distinguishable, but their location may be learned by reading the following description with skull in hand.

The region immediately surrounding the foramen magnum is formed of the occipital bones.

Four pairs of bones complete the dorsal surface of the skull. The bones of each pair meet on the median line.

1. The parietal bones form the greater part of the roof of the cranium, and present convex dorsal surfaces.

2. In front of these, the frontal bones cover the foremost part of the cranial cavity, and form the upper boundary, and most of the posterior boundary, of the orbits.

3. The nasal bones lie next in front of the frontals, and extend forward between, and partly surround posteriorly, the nasal openings.

4. The premaxillary bones complete the dorsal surface, and form the bony part of the upper mandible.

Looking at the side of the skull, note :-

1. The lachrymal bone, of irregular rhomboidal outline, set transversely to form the anterior wall of the orbit. 
2. The postorbital process of the frontal bone, projecting downward to form the postero-lateral rim of the orbit.

3. The squamosal bone, applied obliquely to the side of the cranium, just behind the postorbital process of the frontal.

4. The quadrate bone, a conspicuous bone connecting the lower jaw with the cranium, and freely articulated with both.

On the ventral surface of the skull, anterior to the occipital, are three distinguishable unpaired bones.

1. The basisphenoid forms the convex, most ventral portion of the cranium.

2. The rostrum is the narrow forward continuation of the basisphenoid, and appears as a thickening of the ventral edge of the interorbital septum.

3. The ethmoid is a small bone inclosed between the nasals and the lachrymals, and lying on the median line, at the anterior end of the rostrum.

The remaining bones of the ventral side of the skull are paired. They form two bony bars on each side, extending from the premaxillary in front to the quadrate behind. The premaxillary of each side on its ventral surface will be seen to send back two short horizontal processes of bone, one to meet each of these bars.

1. The outer or quadratojugal bar is a slender rod of bone forming the ventral border of the orbit. It extends from the outer or maxillary process of the premaxillary bone to the quadrate. It is composed of three bones wholly indistinguishable in the adult skull. These are (named from the front) maxilla, jugal, and quadratojugal.

2. The inner or palato-pterygoid bar is composed of the palatine and pterygoid bones, and extends from the inner or palatine process of the premaxillary back to the quadrate. It is not a straight and simple bar of bone, like the 
quadratojugal bar, but irregular, widely and irregularly expanded in its anterior part, and bent inward to fit against the rostrum.

The two bones composing this bar are readily distinguishable. The palatine is the broad, flat, anterior one which meets the rostrum by its inner edge. The pterygoid is the slender, posterior one, which has its inner end expanded to fit against the side of the rostrum, its outer end rounded for articulation with the quadrate.

Thus it will be seen that both upper and lower mandibles are articulated to the cranium by the quadrate. The other attachment of the upper mandible to the cranium is in the region of the nasal bones. Holding the cranium between the fingers, gently move the mandible up and down, and observe that the flexibility of the bones in this region, and not a distinct articulation, permits this motion. While moving the mandible, observe that the palatine and pterygoid slide forward and backward upon the rostrum, and the lower exterior corner of the lachrymal slides upon the maxillary.

A pair of minute bones (the vomers) meet on the median line between the palatine processes of the two premaxillaries, and in front of the two palatine bores. These are liable to be removed in the preparation of the skull, and so may not be found.

II. The Spinal Column. - Study the spinal column. Note the length and flexibility of the neck, the shortness of the tail, and the large number of anchylosed vertebra which meet the bones of the pelvic arch.

Four regions are distinguishable in the spinal column, but the boundaries between them are ill defined. Named from the front, these are the cervical, thoracic, sacral, and caudal regions.

The cervical vertebrce are those between the head and the foremost vertebra bearing a rib articulating with the 
sternum. Study a typical vertebra from near the middle of the cervical region. Note :-

1. Its relatively light centrum.

2. Its wide, neural arch, notched before and behind, with the neural spine small or absent.

3. Its articular processes (zygapophyses). How do these meet in adjacent vertebræ?

4. 'The saddle-shaped, articular faces of the centrum.

5. The wide, transverse processes at the sides of the anterior end, each perforated at its base by a wide foramen, and produced posteriorly into a long, slender point. This process is homologous with the ribs which arise in the same position on the vertebræ farther back.

The thoracic vertebro are those which bear ribs articulating with the sternum. Note the $\mathrm{Y}$-shaped processes uniting the tops of the neural spines of these vertebræ. Observe on all the vertebræ the lateral notches opposite the neural canal, for the exit of the spinal nerves.

These thoracic ribs consist of two portions : -

1. A vertebral portion, flattened and curved, having two articulating surfaces at its proximal end, - a head which articulates with the centrum of the vertebra, and a tubercle which articulates with the transverse process, - and having a flattened uncinate process which projects backward, overlapping the next succeeding rib.

2. A sternal portion, slender and nearly straight, ex. tending obliquely forward to articulate with the sternum.

Of what advantage is the joint in the middle of the rib? The series of overlapping uncinate processes?

The sacral vertebroe succeed the thoracic, and are solidly anchylosed, and support the bones of the pelvis. Observe that the first three and the last four of these have their lateral processes directed laterally, but in the intervening three or four these processes are directed dorsally.

The caudal vertebroe are the remaining free ones, with 
conspicuous neural and lateral processes, and the large, terminal, triangular pygostyle which supports the tail feathers (rectrices).

How many cervical vertebræ are there? How many of them bear evident ribs? How many thoracic vertebræ are there? How many thoracic ribs bear uncinate processes? How many sacral vertebræ are there? How many caudal? III. The Sternum. - Study the sternum. Note the fol-

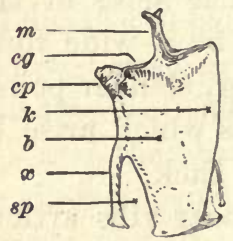

Sternum OF SPARROW FROM RIGHT SIDE (natural size): $b$, body ; $k$, keel ; $m$, manubrium or rostrum; $c g$, coracoid groove; $c p$, costal process; $x$, lateral xiphoid process; $s p$, space filled in life by membranes. lowing parts :-

1. A large, squarish, shovel-shaped body, which closely covers the thoracic cavity, and extends backward some distance over the abdomen.

2. A large, triangular keel, borne on the median ventral line of the body of the sternum. Note that both the body and the keel are composed of very thin plates of bone, with surfaces minutely roughened for the attachment of muscles, and strengthened by thickened margins.

3. A stout, median rostrum (or manubrium), forked at its tip, which projects forward, and obliquely upward from the base of the keel, at the front of the body of the sternum.

4. A pair of sharp, triangular costal processes projecting forward from the anterior angles of the body. The lateral borders of these processes are thickened to form the costal surfaces bearing facets for articulation with the sternal ends of the ribs.

5. Between the costal processes and the rostrum, a pair of coracoid grooves, in the anterior edge of the body of the sternum, meeting on the median line. These grooves are for articulation with corresponding ridges on the ends of the coracoid bones. 
6. Just behind the costal processes, a pair of conspicuous, slender lateral xiphoid processes, arising from the lateral margins of the body, and extending obliquely backward, to partially inclose a pair of triangular spaces which were in life closed by membrane.

IV. The Shoulder Girdle. - Study the shoulder girdle. Each half of it consists of the three usual bones, meeting to form the shoulder.

1. The scapula is a long, thin, and narrow bone, shaped somewhat like a sled runner, extended backward from the shoulder above the ribs. It is enlarged to form articular facets at the shoulder, and sharply pointed at the posterior end.

2. The coracoid is a stout, straight bone set in between the shoulder and the front of the sternum. How does its direction correspond with the direction in which the pectoral muscles pull?

3. The clavicle is a slender bone, shaped like a fishhook, with the hook turned toward the sternum. It is anchylosed at its hook end with its fellow of the opposite side, and the two together are commonly known as the furculum (merrythought, or wishbone).

V. Wing Bones. - Study the bones of the wing.

1. The humerus is the single stout bone of the arm.

2. The radius and ulna are the two bones of the forearm. They are entirely separate. The ulna is much the stouter. It has a blunt proximal (olecranon) process projecting back of the elbow joint, and its posterior edge is roughened for the attachment of the bases of the secondary quills.

3. The carpal, metacarpal, and phalangeal bones are peculiarly anchylosed in the adult. Two carpal bones remain free at the distal end of radius and ulna. Three distal carpal bones have fused with three metacarpals to form a conspicuous single bone, the carpo-metacarpus. 
The two component parts of this bone most easily recognizable are the elongated second and third metacarpals; the second is stout and straight, the third is slender and curved, and the two are fused only at their ends. The short and stumpy phalanges of three rudimentary digits are articulated with the carpo-metacarpus, - one (the thumb) at its anterior edge near its proximal end, the other two toward its distal end.

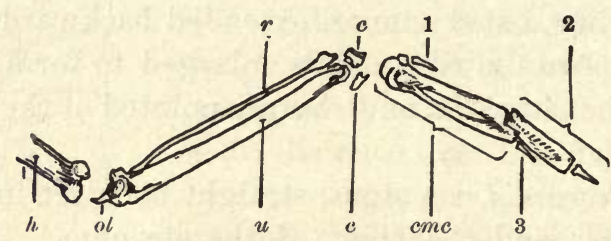

Wing Bones of SPARRow, slightly enlarged (ventral aspect of left wing) : $h$, humerus; $r$, radius; $u$, ulna ; ol, olecranon process of the ulna; $c$ and $c$, free carpal bones; cmc, carpo-metacarpus ; 1, 2, and 3, phalanges.

VI. The Pelvic Girdle. - Study the pelvic girdle. Each half of it is made up of the three usual bones, - ilium, ischium, and pubis, - meeting around the acetabulum, and solidly anchylosed together. The acetabulum is but a rim of bone, its bottom being membranous.

1. The ilium forms the front and upper walls, and a great part of the hinder wall of the acetabulum. The two ilia, together with the sacral vertebræ included between them, form the entire roof of the pelvis. Each ilium is attached along almost its entire length to the lateral processes of the sacral vertebra. An obliquely transverse line divides its dorsal surface into two parts, the anterior one concave, the posterior one convex. A lateral process from it overhangs the acetabulum, and articulates with a process on the femur.

2. The ischium forms a part of the hinder wall of the acetabulum, and extends thence directly backward. It is 
in part separated from the ilium by a large oval or oblong (ilio-sciatic) foramen.

3. The pubis forms part of the lower wall of the acetabulum, and extends thence obliquely downward and backward. It is in part separated from the ischium by a small, round (obturator) foramen.

VII. Leg Bones. - Study the bones of the leg.

1. The femur is the single bone of the thigh.

2. The tibia is the large bone of the shank; the fibula is the slender bone extending halfway down the outer side of the tibia. The proximal tarsal bones are fused with the distal end of the tibia, leaving the ankle joint, not between tibia and tarsal bones, but between the first and second series of tarsal bones.

3. The tarsal bones of the second series are fused with the metatarsal bones, to form the single bone which we have already designated as the tarsus (more strictly, the tarso-metatarsus).

At the distal end of the tarsus are the four toes. The hind toe is the first digit; the others are numbered second, third, and fourth, away from the median plane of the body. How many phalanges are there in each digit?

The Brain. - Study the external features of the brain. On the dorsal surface, note the parts seen, proceeding from the front, as follows:-

1. A pair of small, conical, olfactory lobes, at the anterior end.

2. A pair of large, smooth, pear-shaped cerebral hemispheres, meeting on the median plane.

3. A small, median, pineal body, immediately behind the hemispheres, and in the angle between them.

4. A pair of smooth, ovoid, optic lobes, behind and below the hemispheres.

5. A median, oval cerebellum, transversely furrowed, 
meeting the hemispheres in front, and overlapping the optic lobes at each side.

6. A large medulla, covered in front by the cerebellum, and narrowed posteriorly into the spinal cord.

On the ventral surface note the crossing of the optic nerves (optic chiasma), and just behind this, on the median line, a small process (the infundibulum), which was connected with the pituitary body before the removal of the brain.

The sparrow is a representative of the vertebrate class Aves (or birds).

Other Birds. - If material is at hand, and if time will permit, the further study of this interesting and important group is recommended. A hawk, a duck, a woodpecker, and a snipe are in most places obtainable; and these four are mentioned for further study, because they illustrate common types of bird structure. It will be interesting to compare a number of birds as to the following points of structure, noting in each case the exact adaptation of each structural peculiarity to the life and habits of the bird in which it is found. Note :-

1. The relative size and proportions of body, wings, and tail.

2. The character of the plumage.

3. The shape, size, and strength of beak and claws.

4. The number, insertion, and direction of the toes, and the amount of webbing between them.

5. The length and position of the neck and of the legs.

6. The size and position of the eyes.

In the field, note :-

1. Their haunts.

2. Their food, and manner of obtaining it.

3. Their flight. Learn to know a bird by this alone. The rapid, whistling flight of some ducks; the cycloid 
soaring of some hawks ; the airy, skimming flight of swallows; the shambling, silent flight of owls; the graceful sweeps made by the large woodpeckers between distant trees; the flitting of warblers, etc.,- - are very characteristic.

4. Their notes. Learn to recognize a bird by its voice alone. Learn to recognize the meaning in the different notes of some familiar birds.

5. Their attitudes. By the position in perching alone most birds may be known.

6 . Their nests. Observe the time of nesting; the number, size, color, and markings of the eggs ; and the location, material, and construction of the nests.

7. The times of departure and return of the migratory species.

If a small collection of bird skins is at hand, the work of identifying the species in it is commended as an excellent means of getting a practical acquaintance with the leading systematic peculiarities of a number of birds. ${ }^{1}$

\section{THE RABBIT.}

\section{(Lepus sylvaticus.)}

Haunts. - This animal lives in hedges, brush heaps, and brier patches on the borders of fields, orchards, and gardens. It is much hunted for food, and throughout the winter may usually be found in the market. But market specimens are usually so mutilated as to be unfit for study. Specimens for study may be easily captured alive by

1 Should any student wish to prepare a few bird skins for study, he will find full directions, well illustrated by plates, in Davie's Methods in the Art of Taxidermy. For further study, Coues's Key to North American Birds, and Davie's Nests and Eggs of North American Birds, are recommended. 
trapping. Light steel traps are usually efficient; but a heavily weighted box trap set with a figure-4 trigger, and baited with a cabbage stalk or a sweet potato, will answer equally well. As the rabbit is nocturnal, the traps should, of course, be set in the evening, and in places much frequented by rabbits, in the "runs" or paths they make through the grass or through the snow.

Habits. - A little time will be well spent in studying the rabbit in its relation to nature. A moonlight evening in winter, when the ground is frozen and covered with snow, and when food has become scarce, or hard to get, will afford a good opportunity. At such a time the rabbits become more venturesome in their search for food. They invade gardens, and search them over for stray tops of cabbage or celery left from the preceding autumn; they enter orchards, and gnaw the bark from unprotected young apple trees; they girdle wild crab apples and other small woodland trees in the same way; and they sometimes assemble and play together, dancing and scampering about in the snow, with no other apparent object than a good social time.

On a warm evening in spring they may be seen sitting by the roadside, nibbling the tender leaves of clover. At such a time they may be approached quietly. If alarmed, they will at once leap into cover, and disappear. In local:ties where they are much hunted on foot, they may be approached nearer on horseback.

At a distance, one may often be seen to rise up on its hind feet to its full length, and look about, as if for danger, with ears aloft. Near at hand, one, wishing to hide, will crouch low on the ground, with its ears extended flat along its back. In such a position it is very inconspicuous, especially if seen among dried grass and leaves, which its colors so closely imitate. 
In a rabbit hunt with dogs, a rabbit will certainly be seen to run in circles, repeatedly crossing its former tracks, throwing the dogs off the scent.

The simple "form" the rabbit makes for itself for a resting place in the grass; the retreats it finds in hollow logs and stumps, and in the deep burrows of other animals; and the shallow, fur-lined burrow which it makes for itself in dry, loose soil, for a home in which to rear its interesting brood, should all be studied in the field.

The live rabbit should be studied in the laboratory. Its postures should be noted. It should be determined whether the rabbit ever walks, how fore feet and hind feet are used in locomotion, in what direction it cannot see without turning its head, whether it shifts its ears to suit the direction from which a sound is coming, etc.

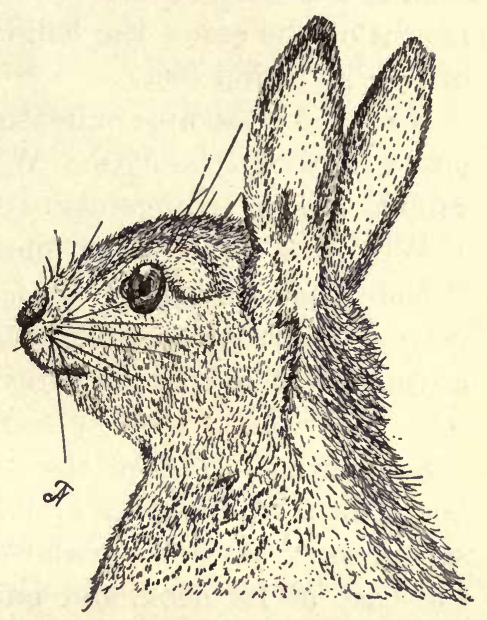

Gray RABbit (Lepus sylvaticus).

External Features. - Note its covering of hair. Observe that the hairs are of three principal sorts :-

1. Short, soft, kinky hairs, which make up the greater part of its coat, and which collectively constitute fur.

2. Fewer, longer, straight, black-tipped hairs, which protxude through the fur.

3. Long, stiff, tactile hairs (or whiskers) at the sides of the upper lip, and above and below the eyes, deep seated in the skin, and intimately connected with nerve endings.

Note the color of the fur at the surface, and next the 
skin. On what parts of the body is the hair longest? What exposed parts are bare, and why? Compare the color of upper and lower surfaces. What is the character of the hair on the soles of the feet?

Examine the claws. Are they well adapted for weapons of offense?

Note the length and position of the tail. Take the following measurements : the distance from the tip of the nose to the base of the tail ; the length of the tail; the height of the ears; the length of fore and hind legs and of fore and hind feet.

Note the close approximation of the ears, and the wide space between the eyes. What is the advantage to the rabbit, of this arrangement?

Why does a rabbit run more easily up hill than down?

Note that the upper lip is cleft below the nostrils, exposing the front teeth when the lips are retracted. The advantage of this in gnawing is very obvious.

Structure. - Dissect the rabbit on a broad piece of board, into which tacks may be driven. Use an injected specimen. ${ }^{1}$ Make a circular cut through the skin, around the base of its neck, and pull the skin forward over its head, wrong side out, carefully dissecting it free from the parts which lie beneath. At the base of the ears note the tubular, basal cartilage supporting each ear, and see also the attached muscles, which change the position of the ears. Cut off the ears : this will expose the external auditory canals. At the eyes, in removing the upper and lower lids with the skin, an imperfect third eyelid (or nictitating membrane) should be left behind. Remove the skin of the head entirely, breaking or cutting its attachments at the lips. Note the hairiness of the inside of the cheeks.

1 For a method of injection see Appendix, p. 286. 
I. The Teeth. - Placing the rabbit on its side, lay open the cavity of the mouth by a lateral cut midway between upper and lower jaws. This will expose the teeth. Observe that the teeth are of two sorts :-

1. Incisors (or gnawing teeth). These are the front teeth. They are long, and strong, curved teeth, with chisel-shaped, cutting edges. Observe that there is a large pair of incisors above, and another pair below, and a pair of very small supplementary incisors situated just behind the large pair in the upper jaw.

2. Molars (or grinding teeth). These are situated farther back, in the sides of both jaws, deeply imbedded in the bone. The upper ones and lower ones meet by flat, corrugated, grinding surfaces, between which the food is comminuted. There are six pairs above, five pairs below. Observe that the molars are set obliquely in the jaws. Is there any relation between their direction and the direction in which the jaws are moved in chewing? Note the absence of teeth, from a large space between incisors and molars, in both jaws.

II. The Tongue. - Continue the lateral cut backward across the angle of the mandible, cutting through the bone with bone snips or with stout scissors. Forcibly turn the severed ramus of the mandible outward, breaking its connection with its fellow, at the symphysis, in front. This will expose the buccal cavity and the tongue.

Study the tongue. Observe that it is thick and muscular, attached posteriorly to the floor of the mouth, and produced anteriorly to a flattened, tapering tip. Observe that the surface of the free, anterior part is soft and delicate, while that of the posterior part, which rubs against the ruof of the mouth, is rough and firm. The soft part is dotted over with minute taste papillæ. On either side of the tongue, on its sloping edge, just opposite the last molar tooth, there is a small, oval area (papilla NEED. zoör. -16 
foliata), which is crossed by minute, oblique, parallel lines. There are some relatively large taste buds imbedided in this part. Between the two oval areas of opposite sides, and a little farther back, there are four large papillæ (circumvallate papilloe) arranged in a posteriorly convex curve, two on either side of the median line. Each of these papillæ is surrounded by a circular groove.

III. The Palate and Adjacent Parts. - Study the palate. It is the narrow, median strip or area along the roof of the mouth. Its anterior portion, which is raised into transverse ridges against which the tongue rubs, is called the hard palate. Its smooth, soft, posterior half is called the soft palate. It ends behind in a free border.

Just behind the small upper incisors are a pair of minute pores opening into small canals which extend upward, connecting the cavities of the nose and the mouth.

A pair of small pits at the sides of the soft palate, near its hinder border, are the tonsils.

The pharynx is the backward continuation of the mouth beyond the soft palate. The nasal chamber opens into it above the soft palate.

The Eustachian tubes, coming from the ear, open on the sides of the posterior nasal chamber within, about the middle of the soft palate. Split the soft palate longitudinally, turn apart the severed edges, and find the two openings.

IV. The Salivary Glands. - Find the salivary glands. They are four pairs of large, pinkish, reddish, or whitish, lobulate bodies which secrete saliva, and pour it into the mouth through small salivary ducts:-

1. The parotid gland is the largest. It lies in front of, and just below, the external auditory canal. Its duct runs forward at first, just beneath the skin, and opens on the inside of the cheek, opposite the second uprer molar tooth. 
2. The infraorbital gland lies just below, and in front of, the eye, partly within the lower border of the orbital space. Its duct descends to open near the duct from the parotid.

3. The submaxillary gland lies close to its fellow of the opposite side, between the angles of the lower jaw. Its duct extends forward, and opens on the floor of the mouth, about halfway between the base of the tongue and the lower incisors, and quite near the median line.

4. The sublingual gland is a small, elongated, flat gland, lying close to the inner side of the mandible, anterior to the base of the tongue. Its very minute duct opens also on the floor of the mouth.

V. Hyoid Bone and Glottis. - The hyoid bone lies deeply imbedded in the flesh between the angles of the lower jaw. It furnishes important attachments for muscles of the neck. Its position may be determined by feeling with the fingers.

The pharynx is narrowed posteriorly into the esophagus. On its floor, near the commencement of the esophagus, is the opening of the glottis (or larynx). The glottis stands widely open, and its entrance is guarded by an erect flap of cartilage, the epiglottis. When food is swallowed, the epiglottis is depressed, and forms a bridge over the glottis, across which the food slides safely into the esophagus. Depress the epiglottis, and study its action.

VI. Thorax and Abdomen. - Extend the hind legs backward, and the fore legs forward, and fasten them so with a tack through each foot. Observe two fairly well defined regions in the body of the rabbit: (1) a thorax with its walls supported by ribs, and (2) an abdomen with soft, thin, muscular walls. Divide the skin along the median ventral line for the entire length of the body, and strip it back, away from the sides. Cut away the ventral muscular wall of the abdomen. 
Niake a longitudinal lateral cut through the middle of the ribs, and remove the ventral wall of the thorax, dissecting it carefully away from its attachments to the internal organs.

The diaphraym is the transverse muscular partition found attached to the posterior borders of the ribs. It is the boundary between thorax and abdomen. Lift up its severed ventral margin, and note its shape, convex toward the thorax, and concave toward the abdomen. Observe a thin tendon at its center. The muscular fibers composing it arise from the walls of the body cavity, and converge toward their insertion into this central tendon. When these contract, they draw the tendon posteriorly, increasing the capacity of the thorax.

Internal Features. - The large, dark-colored liver lies close against the posterior side of the diaphragm. The capacious stomach lies partly concealed by the liver, and posteriorly nearly the entire cavity of the abdomen is filled with intestine, slung from the dorsal side of the cavity in folds of the mesentery.

The pink lungs, lying free in the thoracic cavity, rest against the anterior surface of the diaphragm. The heart, within its pericardium, lies between the lungs, its apex normally resting upon the diaphragm.

Note the following parallelisms in the linings of thoracic and abdominal cavities. The abdomen is lined with a thin, transparent, and closely adherent membrane (the peritoneum), which, on the dorsal side, is reflected ventrally in a double fold (the mesentery) enveloping the viscera. The thoracic cavity is lined with a similar membrane (the pleura), which is also reflected ventrally from the dorsal side to form a double fold (the mediastinum), which, at the base of each lung, is reflected completely over it, so as to inclose it as within a bag. Between the two lungs there 
is thus left a mediastinal cavity, within which the heart and its pericardium lie. The pleura lining the thorax and covering the lung may be readily seen when lifted with a needle point.

The Digestive System. - The organs of digestion have been noted as far as the esophagus. The esophagus descends straight through the thorax, perforating the diaphragm, and entering the stomach on its concave anterior border. Note the shape and size of the stomach, the point at which the esophagus meets it, and the point at which the intestine springs from it. At the origin of the intestine is the pylorus, an internal valvular fold which guards the passage, and prevents the premature exit of the food. The first part of the intestine is the duodenum, a narrow portion extended along the right side of the abdominal cavity, and folded upon itself, to form a long, narrow loop. Into this part the ducts from the gall bladder and the pancreas open. The gall bladder is situated under one of the five lobes of the liver, and is of a dark-bluish color. Its duct (usually appearing brownish in color) extends posteriorly to open into the duodenum, not far from the pylorus. The duct is about an inch and a half long. It may be made very plain by squeezing the contents of the gall bladder out into it.

The pancreas is whitish in color, and diffuse in form. It is a loosely aggregated mass, completely surrounded by the duodenal loop. Its short white duct opens near the middle of the distal half of the duodenum.

The small intestine is the long posterior continuation of the duodenum. It is of about uniform diameter, and is looped up in numerous folds of the mesentery.

The cocum is the long lateral pouch into the end of which the intestine opens. It is the most conspicuous part of the digestive tract, on account of its ventral posi- 
tion and its great size. It is a sort of food rescrvoir. It ends blindly in a narrow, thick-walled, finger-shaped process (the vermiform appendage).

The large intestine completes the alimentary canal. It is distinctly sacculated at its anterior end, becoming smooth posteriorly.

These organs can be freely examined in place. Their attacbments should not be severed until after the blood vessels have been studied.

The spleen is a dark-red body lying behind the stomach, and attached to its left end.

Renal Excretory System. - A pair of compact, brownish, bean-shaped kidneys lie closely attached to the dorsal wall of the abdominal cavity. Notice that the right one is anterior to its fellow. Observe a large artery entering, and a large vein leaving, each kidney. Observe also a long white duct (a ureter) extending posteriorly from each kidney, to open into the urinary bladder, a whitish membranous sac lying ventral to the posterior end of the large intestine. Associated with the afferent duct of the bladder are the passages from the reproductive organs; and the external aperture for these is separate from the anal aperture.

The Circulatory System is very similar to that of a bird. The heart is four-chambered, consisting of right and left auricles and ventricles. The boundaries of these chambers are evident from the outside; but the heart should be dissected later, to show the relative thickness of the walls of these chambers, and the valves, which prevent the return of blood at the entrance to the ventricles and to the aorta.

I. The Venous System. - The blood is brought to the heart through right and left procavoe and the single large postcava. These three vessels enter the right 
auricle. The principal branches of each præcava are three: (1) a jugular vein coming from the head; (2) a subclavian vein coming from the shoulder and fore limb; and (3) a mammary vein coming from the ventral wall of the thorax. The principal branches of the postcava are the short, wide hepatic veins entering it in the liver, the renal veins coming from the kidneys, the spermatic (or ovarian) veins (according to sex) coming from the reproductive organs, and the large external iliac veins coming from the hind limbs. The last-named are called femoral veins posterior to the abdominal cavity.

Another set of veins, constituting the portal system, collects the blood from the digestive organs of the abdominal cavity, and carries it through the portal vein to the liver. This blood percolates through the substance of the liver before being collected again into the hepatic veins.

II. The Pulmonary System. - The blood collected into the right auricle descends, through an opening guarded by a valve, into the right ventricle, whence it is expelled to the lungs through the pulmonary arteries. These arise together from the anterior border of the ventral surface of the auricle, and, arching about the left auricle, separate, and go direct to the lungs. After distribution through the capillaries in the walls of the air cells of the lungs, the blood is collected into the pulmonary veins, and returned directly to the left auricle. The pulmonary artery and vein and connecting capillaries constitute the pulmonary system. The obvious purpose of this part of the circulatory system is the aëration of the blood.

III. The Arterial System. - From the left auricle the blood descends, through an orifice guarded by a valve, into the left ventricle, whence it is expelled through the aorta. The aorta curves dorsally and toward the left side of the body, and then extends posteriorly beneath the dorsal wall and above the viscera. It gives off ante- 
riorly near its origin a large innominate artery, and a little farther out from the heart a smaller left subclavian artery, which goes to the left shoulder, and thence to the fore limb. A branch of the subclavian, which runs along the inner side of the ventral wall of the thorax, is the mammary artery. The innominate artery soon divides off a left carotid artery, and then bifurcates into right carotid and right subclavian arteries.

That part of the aorta which extends posteriorly beyond the arch is called the dorsal aorta. It gives off in the thorax a series of small intercostal arteries, which extend laterally along the inner walls of the thorax, one behind each rib. Its principal branches in the abdomen are three single arteries, which pass ventrally through the mesentery to the digestive organs, and three paired arteries.

The foremost of the single arteries (the coliac artery) arises close behind the diaphragm, and its branches are distributed to the liver, stomach, and spleen; the second (the anterior mesenteric artery) arises a short distance behind the first. Its branches supply the greater part of the intestine. The third (the posterior mesenteric artery) is small. It arises toward the posterior end of the abdominal cavity. Its branches are distributed to the hinder end of the intestine.

Of the paired arteries, the foremost are the large renal arteries, which go to the kidneys. The second are the very small spermatic (or ovarian) arteries, which go to the reproductive organs. The hindmost are the very large common iliac arteries, into which the dorsal aorta seems to divide. Posterior to the body cavity, these are called femoral arteries. Between the spermatic and common iliac arteries, several small lumbar arteries arise on the dorsal side of the aorta, to be distributed right and left to the dorsal abdominal wall, and to the thick muscles of the back. 
It should be noted that the venous and arterial systems roughly correspond to each other in the distribution of their parts.

The Respiratory System. - That the lungs are enveloped in the pleura, that they are attached at their anterior end, and float freely behind, within the thoracic cavity, have already been noted. That they communicate anteriorly with a pair of bronchi, which unite into the trachea, will have been noticed in the dissection of the blood vessels. How many lobes are there in the right lung? In the left?

Observe that bronchi and trachea are made up of a series of cartilaginous rings. On which side of the trachea are these rings thickest, and why? Note the absence of any distinguishable syrinx at the division of the trachea into bronchi. The voice organ in the rabbit is the larynx, developed at the anterior end of the trachea. The epiglottis stands at its anterior ventral border. It is slightly wider and firmer than other parts of the trachea. Dissect the larynx free from all its lateral attachments, and observe that it is composed chiefly of two rings of cartilage. The anterior one is wide in front, but incomplete dorsally. It is called the thyroid cartilage. The posterior one is a complete ring, wider on its dorsal side. It is called the cricoid cartilage.

Make a median ventral slit down the larynx, and draw apart the severed edges. Observe the thin sheets of muscle and connective tissue which bind the cartilages together. Two little nodules of cartilage within the larynx, and on the dorsal side, are the arytenoids.

The two shallow, lateral depressions on the inner side of the walls of the larynx are the ventrisles. The pair of delicate folds which form the posterior boundaries of the ventricles are the vocal cords. These are folds of the 
mucous membrane, or inside skin (which lines all the cavi. ties of the body that have open communication with the exterior), strengthened by slender elastic ligaments. They are attached posteriorly to the arytenoids, by rotation of which they are stretched across the tube of the larynx. When fully stretched, the opening between them is but a narrow vertical cleft. In this position they vibrate readily in a passing current of air expelled from the lungs, and they thus produce voice. A pair of folds of similar appearance, at the anterior boundaries of the ventricles, are the false vocal cords.

The Lacteal System. - The thoracic duct is a slender, thin-walled tube which extends through the thorax lengthwise, close to, but a little above, the dorsal aorta. It is formed by the union of numerous small vessels, called lacteals, in the anterior part of the mesentery, in the abdominal cavity. It perforates the diaphragm, and passes directly forward to the anterior end of the thoracic cavity, where it widens somewhat, and turns inward, to open into the left præcava, near to its subclavian branch. It receives in its course other lymphatic vessels from nearly all parts of the body. These vessels form a sort of drainage system for the tissues. The lymph they bring, and the liquid products of digestion brought by the lacteals from the intestine, are carried by the thoracic duct, and emptied into the venous system, to mix and commingle with the blood.

The pale, soft, glandular-appearing body, through which the curved anterior end of the thoracic duct passes before entering the præcava, is the thymus.

Spinal and Sympathetic Nerves.- The spinal nerves may be seen through pleura and peritoneum, in the dorsal wall of the body cavity.

A double chain of sympathetic ganglia extends along 
close beside, and ventral to, the spinal column. The ganglia are connected with one another, and with the roots of the spinal nerves, by commissural nerves. These are very difficult of dissection.

Removal of the Brain. - Cut away the top of the cranium, and expose the brain fully. The elongate oval olfactory lobes at its anterior end will be conspicuous. Cut these off as far forward as possible, and gently lift the brain out of the cranial cavity, on a thin, narrow blade of metal, watching closely, and severing the roots of the cranial nerves as fast as they appear, leaving as great a portion of each as possible attached to the brain. Twelve pairs of cranial nerves should be found during this operation. Proceeding from the front, these are :-

1. The olfactory nerves, the roots of which were cut off at the anterior end of the olfactory lobes of the brain.

2. The optic nerves, large and conspicuous, at first diverging but little, as they extend forward from their point of crossing on the median ventral line.

3. Two pairs of slender nerves, appearing behind the crossing of the optic nerves.

4. The trigeminal nerves, very large and conspicuous, arising a little farther back, and a little more remote from the median ventral line.

5. Two pairs of slender nerves, close behind the trigeminal, the anterior pair somewhat nearer the median line.

6. The auditory nerves, which are large, and which arise a short distance behind the trigeminal, but farther from the median line.

7. Two pairs of rather small nerves, which arise close behind, and a little above, the auditory nerves. The larger pair of these are the vagus nerves. 
8. Two pairs, which arise, by many slender rootlets, from the ventral surface of the hindmost part of the brain, rootlets of one pair in part from the anterior end of the spinal cord.

Parts of the Brain. - Cut off the spinal cord, and place the brain in a little alcohol, for a superficial examination of its parts. On the dorsal side, note the large, smooth, cerebral hemispheres immediately behind the olfactory lobes, and in the posterior angle between them, on the median line, the pineal body. Posterior to the hemispheres, the cerebellum covers the greater part of the dorsal surface. It is made up of a large, transversely ridged, central lobe; a pair of oblique, lateral lobes; and, on its outer edges, a pair of small, rounded, floccular lobes. The dorsal surface of the medulla appears behind the central lobe of the cerebellum.

On the ventral surface observe the olfactory lobes, extending backward, beneath the anterior end of the hemispheres. Observe that a large, oval, temporal lobe is marked off on the ventral surface by a shallow groove from the remainder, of each hemisphere. Observe the crossing of the optic nerves. They may be traced outward and backward to the concealed optic lobes by turning the temporal lobes of the hemispheres aside. Close behind the crossing of the optic nerves find a narrow median slit, the aperture of the infundibulum, leading down into the pituitary body, which was probably left behind in the base of the cranium when the brain was removed. The floccular and lateral lobes of the cerebellum are visible on either side, and these are connected across the ventral surface by a stout band of nerve fibers. The medulla, tapering posteriorly, and studded with numerous nerve roots, forms the remaining posterior part of the ventral surface. 
The Skeleton. - The axial part consists of the spinal column (composed of vertebrce) and of the skull. The bones of the whole axial series are perforated, and so placed together, end to end, as to form a canal, which lodges and protects the central parts of the nervous system, - brain and spinal cord. The vertebral series also forms a very strong yet flexible support for all other parts of the body.

I. Vertebræ and Ribs. - The vertebræ may be considered as forming five groups: (1) cervical (or neck) vertebroe; (2) thoracic (or chest) vertebroe, which bear movably articulated ribs; (3) lumbar (or back) vertebroe, without ribs, the largest of the series; (4) sacral vertebroe, which are fused together, and support the bones of the pelvis; and (5) caudal (or tail) vertebroe. How many vertebræ are there in each of these five groups?

Examine one of the middle lumbar vertebræ as a type, and in it find the usual parts, - centrum, neural arch, neural spine, transverse processes, and articulur processes. Find also a median ventral process (hypapophysis) projecting downward directly from the centrum. A pair of flat plates of bone (epiphyses) may be found applied to the ends of the centrum, if the vertebra be that of a young animal. These become anchylosed with the centrum with age.

The transverse processes of the cervical vertebræ are broad and flat and perforated, and the series of perforations forms an imperfect canal for the passage of a nerve and an artery. The parts of the transverse processes outside the perforations are homologous with the ribs of the vertebræ farther back.

Note that each distinguishable rib has two articulations with its vertebra, - a head, which meets the centrum; and a tubercle, which meets the transverse process. The space inclosed between these two articulations corresponds 
roughly to the perforation in the transverse process of the cervical vertebra. Examine one of the ribs near the middle of the series, and note its shape, position, and range of movability. Note that it has a sternal as well as a vertebral portion, and note that the sternal portion is more or less cartilaginous. Note that the central part of the sternum, to which the ribs attach at their distal end, is transversely segmented. Observe that the foremost segment (the manubrium) is large, and is produced anteriorly in a prominent keel. Observe that the hindmost segment (the xiphisternum) is a slender rod of bone, supporting a broad, flat cartilage. Which ribs are shortest? Which longest? Which have no sternal portion? Which have but one articulation with their corresponding vertebræ? Which articulate partially with other than their own vertebræ?

Note the decrease in size of the vertebræ posterior to the first sacral, and the gradual disappearance of all the processes.

II. Atlas and Axis. - The first and second cervical vertebræ show special adaptive modifications, and have received special names. The first is the atlas. It bears the skull upon two concave, articular surfaces, which meet the occipital condyles of the skull. It has no centrum ; or, rather, its centrum is probably the odontoid process of the second vertebra. A transverse ligament divides the very large perforation; and the division of it anterior to the ligament is occupied by this odontoid process, around which the atlas rotates. The spinal cord occupies the space posterior to the ligament.

The second vertebra is the axis. It has a broad, flat centrum, produced anteriorly into the conical odontoid process. A suture between this process and the centrum is readily seen in young rabbits, and indicates that the process has become attached to the second vertebra, while 
its position indicates that it may have belonged originally to the first.

Study the action of atlas and axis, and note that the head can be nodded backward and forward on the atlas, but that, in its rotation, the atlas turns round the odontoid process of the axis.

III. The Skull. - In the skull, note again the direction of the teeth and their position in the jaws. Note the articulation of the lower jaw or mandible with the remainder of the skull. Observe the two rounded occipital condyles beside the foramen magnum. Observe that the orbits communicate through the interorbital foramen. Note that the bones of the top of the cranium meet each other by jagged sutures.

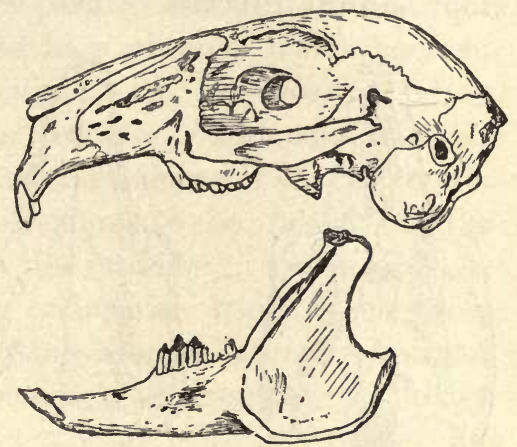

Skull of Rabbit (side view).

The following bones should be readily distinguishable in an adult skull. The occipital forms a complete bony ring around the foramen magnum. It is formed originally of a number of separate occipital bones. Proceeding forward on the dorsal surface, a small median interparietal bone will be found fitted in between the front of the occipital and the posterior angle between the two parietals, which meet by a median suture directly in front. The parietals form the greater part of the roof of the cranial cavity. Anterior to the parietals, a pair of large frontals complete the roof of the cranium in front, and send out a large crescentic process above each orbit, and form the dorsal third of the orbital wall. The frontals meet by a median dorsal suture. Anterior to the fron- 
tals, two long, narrow nasals complete the median dorsal surface, and form the bony support of the snout. 'The two stout bones which carry the upper incisors, and which are situated beneath the nasals, and meet on the median line in front, are the premaxillaries. Behind them are the maxillaries, large and irregular, forming the greater part of the skeleton of the upper jaw. Ventrally they bear the upper molars; and each sends out a stout lateral process, which forms part of the anterior
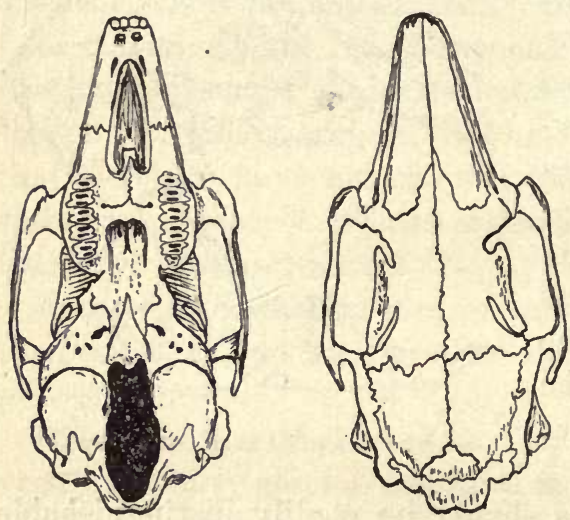

SkULL of RABBIT (dorsal and ventral views of cranium). boundary of the orbit.

The nasal cavity lies beneath the nasals and above the maxillaries and premaxillaries. Looking into it from the front, a number of thin, irregular plates of bone (the turbinals) will be seen. The anterior of these, the more delicate and complex in structure, are developed from the maxillaries, and are called the maxillo-turbinals. The posterior are developed from the (concealed) ethmoid, and are called ethmoturbinals. The ethmoid terminates posteriorly in a transverse cribriform plate, set in the anterior end of the cranial cavity. This plate may be seen in a skull from which the roof of the cranial cavity has been removed. It is perforated for the passage of the branches of the olfactory nerves to the nose. Within the nasal cavity, the terminations of these nerves are distributed through the mucous membrane, which covers the turbinal bones. The great extent of surface over which 
nerve endings can come into contact with the air corresponds with the keen sense of smell possessed by the rabbit.

The lachrymal bone of each side forms a large part of the anterior wall of the orbit, and joins the frontal by a suture above.

The squamosal bones form the greater part of the convex lateral walls of the cranial cavity, and send out a stout lateral process to form part of the posterior border of the orbit. The flattened bars of bone which connect this process of the squamosal with the corresponding backward process from the maxillary, and complete the outer border of the orbits, are the malars (or cheek bones).

Two (composite) bones remain to be found on the median ventral surface of the cranium. These are the basisphenoid, which has a triangular body (seen from below) and two flattened, wing-shaped, lateral processes, and which is situated immediately in front of the occipital; and the presphenoid, a narrow bone in front of the basisphenoid, extended upward into a thin median plate between the orbits, and perforated by the interorbital foramen.

The pterygoids are two narrow, vertical plates of bone, attached to the base of the skull at the lateral junction of the two sphenoids. Each has a free posterior border, which ends below in a curved process.

The palatines are two nearly vertical plates of bone, which extend forward from the pterygoids, form the lateral walls of the posterior nasal opening, and meet each other on the median line of the roof of the mouth by horizontal platelike processes.

IV. Shoulder Girdle and Arm Bones. - In the shoulder girdle the three usual bones of each side may not be at first recognizable. The scapula is a large, flat, triangular bone, expanded at the end which forms the apex of the 
triangle, and hollowed there to form a_cavity, into which the head of the humerus fits. The coracoid is not a separate bone in the adult rabbit, but only a curved process attached to the scapula, and overhanging the head of the humerus. The clavicle is a slender, incomplete bone, developed within a ligament which extends from the sternum to the scapula.

The bones of the fore limb are humerus, radius, ulna, carpal and metacarpal bones, and phalanges. All these are easily recognizable. The humerus is the single bone of the upper arm. The ulna is the larger of the two bones of the forearm. Its enlarged proximal end bears the olecranon process, which forms the angle at the elbow. Both radius and ulna have a thick cap or transverse plate of bone (epiphysis) more or less completely coössified with the shaft of the bone. The small carpal bones are arranged in two transverse rows, - three bones in the proximal row, and four in the distal row, - with a single minute, roundish bone between the rows, on the median line. The metacarpals are a transverse series of elongated bones (the inner one short); and the phalanges (or finger bones) are two in the inner digit or thumb, and three in each of the other digits.

V. Pelvic Girdle and Leg Bones. - In the pelvic girdle the usual three bones of each side are, as usual, fused with each other, and firmly attached to the sacral vertebræ. The two sides of the girdle are united also in a ventral symphysis. Each of the three takes part in the formation of the deep cup-shaped acetabulum, in the sides of which the boundaries between them may readily be seen in young specimens. The ilium forms the anterior part of the girdle on each side. It is broadly flattened in front, narrowed behind, and it forms about half of the acetabulum. The ischium is posterior and dorsal, and forms about one third of the acetabulum. Its posterior portion 
is flattened and thickened at the margin, to form the tuberosity of the ischium. The pubis is ventral. It is separated in part from the ischium by the large, oval obturator foramen; but the ventral symphysis, uniting the two halves of the pelvic girdle, is formed of both ischium and pubis on each side, and the boundary line between them is not discoverable except in very young specimens.

The bones of the hind limb are femur, tibia, fibula, tarsal, metatarsal, and phalanges, and a few small sesamoid bones, developed in the tendons at some of the joints, and not forming a part of the skeleton proper. The largest of these sesamoid bones is the patella (or kneepan), developed in front of the knee joint in the tendon of the extensor muscles of the leg.

The femur is the single bone of the thigh. The large bone of the shank is the tibia; the small one, distinct at its proximal end, but fused with the tibia distally, is the fibula. The tarsus, like the carpus, consists of two transverse rows of small bones, with a single bone between the two rows. - The proximal row consists of two relatively large bones, the distal row of three smaller ones, while the single bone between the rows is at the inner side of the foot. The metacarpals are a transverse series of four elongated bones, and the phalanges are three in each digit. The first digit of the foot, corresponding to the great toe, is wanting.

The rabbit is a representative of the vertebrate class Mammalia (the mammals, or milk-givers).

A cat or dog may well be studied, as showing the carnivorous type of mammalian structure; and a bat, as showing the adaptation of mammalian structure to aërial locomotion. 


\section{THE LIFE PROCESS IN VERTEBRATES.}

The life process is essentially the same in all animals, differing in different animals only in the means by which it is carried out. The perfection of the means - the adaptation of the means to new and higher conditions of life - has made the vertebrates the dominant group among animals.

I. Nutrition. - The organs subservient to nutrition have been grouped as organs (1) of digestion, (2) of circulation, (3) of respiration, and (4) of excretion; and to these might be added (5) organs of prehension, for grasping food, and (6) organs of mastication, for chewing it, although the organs of the last two groups are not exclusively subservient to the nutritive function, and are not present in all vertebrates.

1. Digestion takes place in the alimentary canal, parts of which are specialized for the reduction of the food, and other parts for the absorption of it when digested. Four digestive secretions are poured upon the food normally in its course, - saliva, from the salivary glands; gastric juice, from glands in the walls of the stomach; bile, from the gall bladder of the liver; and pancreatic juice, from the pancreas. The greater part of the digested food is absorbed through the walls of the intestine, to be passed into the circulation. In the highest vertebrates it is collected by the lacteals of the mesentery into the thoracic duct, and poured thence directly into the venous system.

2. Circulation is effected through a closed system of blood vessels, consisting of the heart, arteries, veins, and capillaries. Through this system the food dissolved in the blood is carried to every vascular part of all the tissues. The three types of circulation found in the vertebrates studied are roughly outlined in the accompanying dia- 
gram. Their relation to the digestive, respiratory, and renal organs is shown very diagrammatically.

3. Respiration is effected by means of gills or of lungs. In those vertebrates which have naked, moist skins, it is probable that considerable air is absorbed directly through the skin.

When the blood has been replenished and aërated, materials have been supplied for all the chemical changes

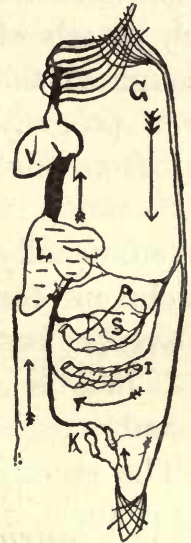

Fish or Tadpole.

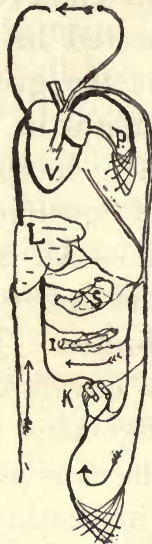

Adult Frog.

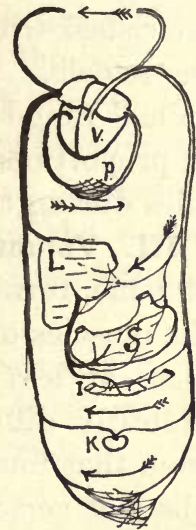

Rabbit.

Comparative Diagram of Circulation, showing in a General Way The Course and Distribution of the Blood: $V$, ventricle; $G$, gills; $P$, lungs and pulmonary vessels; $L$, liver; $S$, stomach; $I$, intestine; $K$, kidney. Black vessels carry venous blood; light ones, arterial blood. Arrows indicate the course of circulation.

(metabolism) which take place in the tissues. The constructive processes (anabolism), by which the food becomes tissue; and the destructive processes (katabolism), by which the tissue becomes waste water, carbonic acid, etc., - are, so far as we know, the same in all animals; and the end of this building-up and tumbling-down of organic molecules, in "continual round of change," is the production of heat, motion, nerve force, etc., necessary to the animal's life and activities. 
4. Excretion is performed by the skin, the lungs, and the kidneys.

II. Reproduction. - As in all other animals except protozoans, reproduction in vertebrates is by means of eggs. The sexes are distinct in all, and the eggs are fertilized either within or without the body of the parent. In the mammals the eggs are retained and developed within a specialized part of the oviduct, the uterus (or womb). 'The young are born after their embryonic life is past, and are nourished with milk secreted in the mammary glands of the female. Throughout the group, and throughout the animal kingdom, the decrease in the number of progeny is proportionate with their increased security from enemies during the period of development.

III. Voluntary Motion. - An internal skeleton, usually of bone, furnishes support and points of attachment for the muscles of the vertebrates. The muscles overlie, and more or less completely envelop, the bones. This is a radically different arrangement of skeleton and muscle from that found in crustaceans and insects. The muscle fibers of vertebrates are insheathed together in connective tissue, and often inserted into tendons, affording them greater unity and efficacy of action.

The limbs of vertebrates are never more than two pairs, and may be entirely wanting. They are usually developed for locomotion: as fins for swimming; wings for flying; legs for walking, running, leaping, etc. Locomotion is aided in fishes by unpaired fins, and by the stout, muscular tail ; and in some reptiles (snakes), by the movement of the spinal column and ribs. Movable tactile organs, such as the barbels of fishes and the "whiskers" of mammals, are often present. Some of the most clumsy, ungainly, armor-encumbered animals, as well as some of the fleetest and most graceful on land, in air, or in water, are found among the vertebrates. 
IV. Sensation. - The position of the central nervous system (i.e., of the brain and spinal cord) in vertebrates, dorsal to the center of the bony axis of the skeleton, and inclosed within a dorsal, neural canal, is very characteristic of the group. In the lowest, the brain is but little developed at the anterior end of the spinal cord; but, as we ascend the vertebrate scale, it becomes more and more highly specialized. The cerebral hemispheres, which are the seat of intelligence, reach their relative maximum development in man. The spinal and cranial nerves are distributed to all the muscles of the body, to the skin, and certain of them to the blood vessels and to the internal organs; and all these parts are thus placed in communication with the nerve centers. A double series of sympathetic ganglia extends along the dorsal wall of the body cavity, and sends nerves to the digestive and reproductive organs.

The five senses of man are probably possessed in varying degrees by all other vertebrates, and each of the five is probably keener in some other animal than in man.

Of the higher possibilities of the vertebrate brain it is impossible to speak here. Volumes would be required to adequately summarize the wonderful and infinitely varied instincts of fishes, batrachians, reptiles, birds, and mammals. A few of these have been pointed out in the cases of the types studied: others invite study in every locality, on every hand. Such study will not be amiss if it lead to the study of the instincts that move men. ${ }^{1}$ It will be especially valuable if the student see, that in proportion as man learns to govern his instinctive impulses, and becomes a creature of ideals, he ascends above the level of the brute.

1 For a good discussion of this subject, the student is referred to the closing chapters of Chadbourne's Instinct in Animals and in Man. 
Evolution. - In animal structure the student cannot fail to discover increasing complexity. That there is not one single complete and uniform series from the lowest to the highest, is true; but that there is more or less regular gradation, is unmistakable. In the embryonic life of one of the higher animals there is corresponding gradation. In the development of the original single cell (the oüsperm) there is increasing complexity of structure, and the main types of structure found in other animals lower in the series are one by one roughly repeated. Geology presents a corresponding gradation in the forms of life which have appeared at different periods of the earth's history, and plainly shows that the present fauna of the earth is not like that of any preceding geologic period. The fossil remains of animals preserved in the rocks show in a general way that the simpler forms appeared first, and that the most complex are of most recent introduction. These facts, and others, seem to indicate that there has been a continual progressive development of animals from simple, primitive forms; and such development is denoted by the term evolution. A partial ex. planation of the manner in which evolution may have come about is found in the law of natural selection, which assumes that indefinite variations in animals are continually occurring, and shows that such variations in structure as fit an animal better for maintaining its place in nature will be preserved through successive generations, and may become permanent. ${ }^{1}$

Animals and Plants. - In the foregoing pages plant life has been but incidentally referred to, yet enough has been said to suggest the close interdependence of plants

1 For a concise and able exposition of this law, the student is recommended to read the chapter on "Natural Selection" in Morgan's Animal Life and Intelligence. 
and animals. If a like study of typical plants were made, it would reveal a corresponding gradation in form and function from the lowest to the highest. It would lead us to the conclusion that the plant life of the present is related to that of the past by direct descent. We should find protoplasm the physical basis of plant life, and the cell the unit of plant structure; and at the bottom of the series we should discover that there are free plant cells which move about by pseudopodia and by cilia, and so combine in themselves the characters by which we commonly distinguish animals from plants, that we are almost unable to determine what characters predominate. We thus come to the conclusion that life is a unit, and that the higher and familiar forms are at extremes of the divergent paths along which it has progressed.

The study of animals should lead to a better understanding of man in his physical relationships. Not the remotest object of the foregoing course is, that it shall serve as an introduction to the elementary study of human anatomy and physiology. The lowest animals have some points of structure or of function in common with man; and these points become more numerous and more apparent as we ascend the animal scale, until the greater part of all that is written in the chapter concerning the rabbit will apply almost equally well to the study of the human body. The human body is governed by the same laws, subject to many of the same necessities, and influenced by many of the same instincts, as affect other animal bodies; and the student should know that it is on the normal healthful activity of this animal body that all the possibilities of happiness and usefulness in human life depend. 


\section{ECHINODERMS.}

\section{THE STARFISH.}

\section{(Asterias.)}

Haunts and Habits. - Dwellers by the sea are familiar with the curious red "sea stars," "starfishes," or "five fingers," as they are popularly known, which settle in troops upon the beaches at times, with the wash of currents and tides. Along the northern coast of New England they are very common. They should be studied alive if possible, and in their native haunts; for, from the dried or alcoholic specimens common in collections, one will obtain but a poor notion of the life these creatures lead. Upon the beach one may see them sprawling flat upon the sand, or slowly crawling over and among the rocks with their arms, which are so rigid in preserved specimens, bent in a great variety of positions. One may sometimes be found with its arms folded about an oyster or other mollusk on which it is feeding.

Study of the Live Specimen. ${ }^{1}-1$. Observe a fringe of active cylindrical worm-like process about the tip of each arm of a moving starfish. These are its tube feet. In an

1 Live starfishes may be brought into the laboratory and kept alive for several days if kept in a sufficient quantity of sea water, or if the supply of oxygen in the water be once in a while renewed (as by dipping and pouring it back into the vessel from some little height above the surface). They may be had alive at some distance in the interior if shipped in kegs of sea water, and studied very soon after their arrival. 
upturned arm note that these spring from a groove which extends along the lower side of the arm its entire length. Observe that these tube feet are pushed out and drawn in

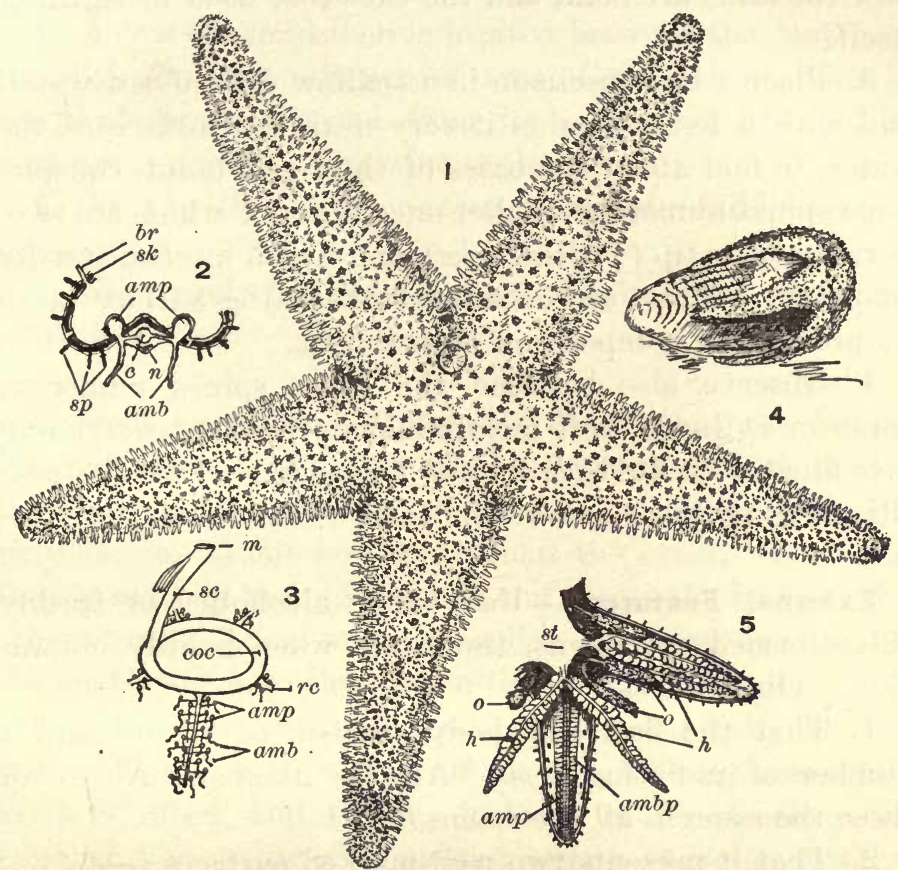

Starfish. - 1. Starfish (Asterias vulgaris), a large dried specimen one half natural size. 2. Diagram of cross section of oral part of an arm: $b r$, branchial tentacle; $s k$, calcareous plate of skeleton (in heavy black); $s p$, spines (those designated are on an adambulacral plate); amp, ampullæ; $c$, radial canal; $n$, radial nerve; $a m b$, ambulacra, or tube feet. 3 . Diagram of water-vascular system: $m$, madreporite; $s c$, stone canal ; coc, circumoral canal; $r c$, radial canal; $a m p$, ampullæ; $a m b$, ambulacra. 4. Starfish infolding an oyster preparatory to eating it. 5. Diagram of parts of digestive and reproductive organs, etc.: $s t$, stomach; $h$, hepatic cæca; $o$, ovaries; $a m p$, ampullæ; $a m b p$, ambulacral plates as seen when ampullæ are removed.

and turned about freely, and that in locomotion they are advanced in the direction in which the animal is moving, attached by means of terminal disks, and then contracted, 
drawing the body of the animal forward with a slow, gliding motion.

2. Turn an active starfish upside down, and observe how the arms are bent, and the tube feet used in righting itself.

3. Place a live specimen in a shallow dish of sea water, and with a lens examine it very near the surface of the water, to find about the bases of the rigid, blunt, conspicuous spines numerous smaller ones, some of which are twoparted at the tip (pedicellarioe), and which are continually snapping. These are believed to keep the surface clean by preventing a deposition of sediment.

4. Observe also between the blunt spines numerous conic or cylindric soft membranous processes, protruding sacs filled with fluid (branchial tentacles). Test the sensitiveness of these and of the tube feet to touch.

External Features. - Use either alcoholic ${ }^{1}$ or freshly chloroformed specimens, the latter when readily obtainable. Observe :-

1. That the flattened body consists of a disk and a number of radiating arms. Are the number and size of these the same in all specimens?

2. That it presents two well-marked surfaces :-

(a) A flat surface on which it crawls, in the center of which is the mouth, and from this fact called the oral surface.

(b) A concave upper aboral surface.

On the oral surface note :-

1. The round mouth, with the thin crumpled walls of the stomach often seen protruding from it.

2. The deep and wide grooves extending from the mouth to the tip of each arm. As these lodge the tube feet, or ambulacra, they are called ambulacral grooves.

${ }^{1}$ If alcoholic specimens have acquired a disagreeable smell, this may be overcome by adding a few drops of oil cassia to the alcohol. 
3. The slender and somewhat movable spines which border the grooves, and which may be approximated to cover the retracted tube feet.

On the aboral surface note:

1. A low convex tubercle located between the center of the disk and the junction of two of the arms. This is the madreporite (named from its superficial likeness to madrepore coral). Examine with a lens.

2. At the tip of each arm a minute reddish spot, the eye.

3. Note again the arrangement of spines and branchial tentacles.

Internal Anatomy. - Divide the crust along the lateral margins and across the tip of the two arms which border the madreporite between oral and aboral surfaces, being very careful to cut no deeper than the crust. Continue the cut entirely around the disk and across the bases of the other arms. Then make a shallow, circular cut around the madreporite, so that, when the loosened aboral crust is lifted, this will remain in place. Then carefully lift the crust, beginning at the end of an arm, looking beneath it as it is lifted, and freeing it from all its attachments. Observe that a pair of glandular organs (hepatic coeca) in each arm lifts with the crust, being suspended from it by membrane (mesentery). Along with these, and lying above them, may be found also a pair of paler and more granular reproductive organs. As the crust is lifted, the hepatic cæca may be traced to their union in the base of the arms before entering the stomach. The reproductive organs may be traced to their (ovi- or sperm-) ducts, which diverge on reaching the disk, each passing to meet at its external aperture the duct of a similar organ in the adjacent arm. As the crust of the disk is lifted, there may be found the narrow terminal portion of the 
alimentary canal attached at its minute anal opening on the aboral surface.

The Digestive System. - With the aboral crust properly removed, the digestive organs will be fully disclosed. Oral and aboral openings of the alimentary canal have been noted. By probing with a stiff wax-tipped bristle through the mouth, learn how restricted are esophageal and intestinal areas of the alimentary eanal, and how very capacious and wide is the stomach. In the latter find:-

1. A loose, baggy oral portion which may be protruded through the mouth, and which has muscles for its retraction. In feeding, the starfish commonly protrudes this portion out of its mouth and in between the valves of the shell, and digests the oyster there.

2. An aboral portion of more definite shape, with which the hepatic cæca communicate. Probe the cæca.

The Water-Vascular System. - Study this in an injected specimen. ${ }^{1}$ Observe :-

1. A vessel extending downward from the madreporite beside the stomach toward the mouth. This is the stone canal, so called because calcareous matter is found in its walls.

2. Circumoral canal, into which the stone canal opens.

3. A series of radial canals extending outward from the circumoral canal, lodged deep in the ambulacral groove on the underside of each arm.

4. A double row of round water sacs called ampulloe within each arm on its floor on either side of a median ridge.

5. Two double rows of ambulacra, or tube feet, in corresponding position on the oral surface of each ray. Snip

1 The water-vascular system may be injected by inserting a cannula into each radial canal near the tip of the arm, and injecting toward the disk, forcing the water out at the madreporite. 
off the tip of a tube foot, and, by probing through it with a slender bristle, determine its relation to the ampullæ above. Determine the relation of the ampullæ to the radial canal. Pull off a tube foot entire, and dissect it in a drop of clove oil or glycerine, under a lens, to see the delicate muscle fibers in its walls, and the oblique fibers near its tip, which are inserted into the middle of the terminal disk. How does the starfish maintain its foothold?

Circulatory System. - Beside the stone canal, there may be seen in a starfish that has been opened alive a delicate pulsating tube, sometimes called the heart. The blood vessels which run out from this are so minute as to be traceable only by sectioning.

Nervous System. - A portion of the nervous system may be seen on the oral surface without dissection, as it is covered only by transparent epithelium. Find :-

1. A circumoral nerve wing.

2. Radial nerves extending out from the latter along the oral side of the radial canals to the tip of the arms.

3. Masses of nerve tissue, called ganglia, at the junction of the radial nerves with the circumoral ring.

4. A pigmented spot, called the eye, at the distal end of each radial nerve.

The Body Wall. - If almost any portion of the body wall be examined in cross section, about three layers will be distinguished in it.

1. A tough outer membranous layer of epithelium covering the whole animal except the spines.

2. A middle layer of connective tissue, in which are imbedded the calcareous plates which make up the hard parts of the skeleton.

3. A thin lining layer of peritoneal epithelium. This 
is pushed out through holes in the middle layer to line the branchial tentacles, and is infolded to form the mesenteries. Pass a slender probe into a branchial tentacle.

Boil a portion of an arm in potash solution, to remove the connective tissue which holds together the calcareous plates. When these seem about ready to fall apart, wash and separate them, to see how they are put together. Find :

1. A double row of ambulacral plates, meeting by their ends at an obtuse angle to form the gable roof of the ambulacral furrow.

2. On either side a bordering row of adambulacral plates.

3. Other plates irregularly disposed in other portions of the body wall.

What is the shape of the plates of all these sorts, and how are they put together?

Between the walls of the alimentary canal and the body walls is a distinct body cavity which the blood (hemolymph) occupies. The hepatic cæca and the reproductive organs are extended laterally into it, as already noted.

Life Process. - Only in the details for carrying out the vital processes do we find anything new or unusual in the starfish.

I. Nutrition. - The digesting of a mollusk in its own shell without having been swallowed is unusual; but, when we remember that digesting is mainly dissolving preparatory to absorbing, we see that the difference is merely one of position. Digested food passes directly into the blood by osmosis, and is carried with currents set up by the feebly pulsating circulatory apparatus. In the branchial tentacles it is properly exposed for aëration; and in all the tissues, as ever, its constituents are selected by the individual cells for use. 
II. Reproduction. - Ova and sperms in immense numbers escape into the water, where fertilization takes place. The resulting oösperm in its development passes through the segmentation and gastrulation stages described for the snail (pp. 158, 159), the irregularities there noted being absent from the more typical development of the starfish. The gastrula develops into curious larval forms (Bipinnaria and Brachiolaria), for description of which the student is referred to the larger text-books of zoölogy. The larval forms are strictly bilateral. Were it not for the persistent bilaterality of the water-vascular system, the symmetry of the adult would be radial. The change from larval to adult form is so great as to simulate metamorphosis.

Lost parts, especially arms, are readily reproduced.

Voluntary Motion and Sensation present no important phases not already noted in preceding pages.

The starfish is a representative of the large group Echinodermata, a group which has no fresh-water representative. Other echinoderms are crinoids, sea urchins, and sea cucumbers.

NEED, ZOöL. - 18 



\section{APPENDIX.}

\section{PREREQUISITES.}

In order to use this book advantageously, there will be needed:-

1. In Charge of the Course. - A teacher with some time and opportunities at his disposal for acquainting himself and his classes with the fauna of his locality.

2. In the Laboratory. - Plenty of light; plain desks or tables at which students may work; a few good microscopes, with the usual accessories, - slips, covers, watch glasses, pipettes, ${ }^{1}$ etc.; the simple reagents described on pp. 276 and 277 ; a water supply; receptacles for organic refuse. 1

3. In the Hands of every Student. - A good lens; a scalpel; a small pair of sharp-pointed dissecting scissors; several dissecting needles; ${ }^{1}$ a small forceps; ${ }^{1}$ bristles for probing; ${ }^{1}$ notebooks and pencils, for descriptions and drawings.

4. In the Library. - $\mathrm{A}$ few good books of reference. All of the following are recommended:-

Lang's Text-book of Comparative Anatomy. Recent and standard, but expensive. (Macmillan \& Co., New York.)

Marshall and Hurst's Practical Zoölogy. \$3.50. (G. P. Putnam's Sons, New York; Smith, Elder, \& Co., London.)

McMurrich's Invertebrate Morphology. \$4. (H. Holt \& Co., New York.)

Thomson's Study of Animal Life. \$1.50. (Charles Scribner's Sons, New York.)

Jordan's Manual of the Vertebrates. \$2.50. (A. C. McClurg \& Co., Chicago.)

Edward Potts's Monograph of the Fresh Water Sponges. \$1. (Obtainable from the author, at 228 South Third Street, Philadelphia.) .Comstock's Manual for the Study of Insects. \$3.75 net. This book is especially commended to the general student of entomology. (Comstock Publishing Co., Ithaca, N.Y.)

1 See note on cheap apparatus, p. 287. 
French's Butterflies of the Eastern United States. \$2. (J. B. Lippincott Co., Philadelphia.)

Stoke's Microscopical Praxis. \$1.50. (E. Bigelow, Portland, Conn.) Darwin's Vegetable Mould and Earthworms. \$1.50. (I. Appleton \& Co., New York.)

Tryon's Structural and Systematic Conchology. (Obtainable through the Academy of Sciences, Philadelphia.)

Coues's Key to North American Birds. \$7.50. (Estes \& Lauriat, Boston.)

Mivart's American Types of Animal Life. \$2. (Little, Brown, \& Co., Boston.)

Wilder and Gage's Anatomical Technology. \$4.50. (A. S. Barnes \& Co., New York.)

Chadbourne's Instinct. \$2.50. (G. P. Putnam's Sons, New York.) Morgan's Animal Life and Intelligence. \$4. (Ginn \& Co., Boston.)

Davie's Nests and Eggs of North American Birds. (Oliver Davie \& Co., Columbus, O.)

Davie's Methods in the Art of Taxidermy. The best book of its kind that has yet appeared. (Oliver Davie \& Co., Columbus, O.) Bates's Naturalist on the Amazons. \$1.50. A zoölogical classic. (Roberts Bros., Boston.)

\section{REAGENTS.}

The following reagents and mounting media should be kept in well-stoppered bottles, always available for use. They should be used sparingly; but a quantity of any reagent, once used, should never be poured back into the stock bottle.

Normal Salt Solution. - This is a $\frac{3}{4}$-per-cent solution of common salt in water. It is useful as a mounting medium in which to examine, microscopically, fresh tissues, which would, like blood corpuscles, be destroyed by the osmotic action of pure water.

Magenta. - A strong aqueous solution. This is useful for staining fresh tissues for microscopic examination.

Methyl Green. - A strong aqueous solution, improved by the addition of 1 per cent acetic acid. This is a good and permanent stain for either fresh or preserved tissues. It stains nuclei deeply, and is therefore very useful for examining amœba, paramecium, etc.

Hydrochloric Acid.-Diluted with water, this is very useful for 
decalcifying the armor of crustaceans, the shells of mollusks, and the bones of vertebrates.

Nitric Acid. - This acid may be used for decalcifying, but it is more expensive than hydrochloric. A 10-per-cent solution is useful for macerating other tissues preparatory to a dissection of the nervous system. If the bodies of small animals are kept in it for two or three days, its destructive action on other tissues will leave the nerves more easily accessible. Strong nitric acid is used for isolating the spicules of fresh-water sponges.

Glycerine. - This is a very useful fluid in which to examine small objects microscopically. A 25-per-cent solution greatly increases the transparency of small objects soaked in it, making the structure more evident.

Canada Balsam. - A sirupy solution, made by dissolving the dried resin in turpentine or xylol, is an invaluable medium for making permanent mounts of microscopic objects. Both air and water must first be removed from the objects to be mounted in it. Hard, dry objects, such as the claws of insects and the isolated spicules of sponges, may be placed in a drop of balsam on a slip, heated gently over an alcohol lamp or Bunsen burner to expel all air, and covered with a thin cover slip; but a less direct method must be employed in mounting soft tissues. These must be covered first with weak, and afterward with strong, alcohol, to remove the water they contain. They must then be removed from alcohol into turpentine or xylol for clearing. They may then be placed in a drop of balsam on a slide, and at once covered.

Chloroform is very useful for removing excess of balsam from slips.

Alcohol. - The use of alcohol in dehydrating tissues for mounting in balsam has already been stated. But one other of its many uses in the laboratory will be mentioned here,-its use in preserving specimens. In this use its action is the sarne as in the preparation of specimens for mounting. It preserves objects by removing the water from them. It removes the water by osmosis, and it is therefore weakened every time it is used by just so much water as it takes from the tissues. Two grades of alcohol should ordinarily be used for preserving specimens, - a weaker grade, in which the dehydration is begun, and a stronger grade, into which they may be transferred from the weaker, for permanent preservation. Alcohol of 70 to 80 per cent strength, after osmotic action has ceased, is strong enough for permanent preservation.

Turpentine, Xylol, Chloroform, Ether, etc., are used in their commercial form, as directed in the text. 


\section{DIRECTIONS FOR THE PREPARATION OF MATERIAL FOR STUDY.}

The following directions are placed in the Appendix, because it has not been found practical to have them carried out by beginners in zoölogy. They are therefore intended for the teacher or for his assistants. Anticipating that this book will fall into the hands of some teachers who are not at all familiar with zoölogical laboratory methods, a few of the simplest are given in the following notes, with much detail which would be unnecessary were all who are called upon to teach zoölogy fitted for the task by a laboratory training. If the methods given below are not in all cases the best methods known to science, they are believed to be the best that can be well applied with such equipment as is usually provided for elementary work in zoölogy.

I. On finding Amœba. - The amœba lives in the superficial ooze of ponds and ditches everywhere, but it is not often very abundant. It may be most easily obtained from shallow pools. To get it, scrape up the superficial ooze from the bottom of the pool, avoiding the mud that underlies the ooze, and place in a shallow dish with water. Allow the ooze to stand undisturbed for a day or two. The amœbas will then have come to the top of the ooze, whence they may be taken up with a dropping tube. Place small drops - water, ooze, sediment and all - on separate glass slips, and cover each with a thin glass cover slip. The sediment in the drops will prevent the cover slips from crushing the amœbas. The slips may then be searched quite rapidly, and amœbas recognized, with a power of 250 diameters. A practiced eye will recognize them with much lower power; but the eye that does not know just what to look for may pass them over even with this amount of magnification. Higher powers cannot be used in searching the field over without too great expenditure of time. The beginner's trouble comes from the unlikeness of the clear jelly-like mass spreading over the glass slip to anything commonly denoted by the term "animal."

Amobas are found also in the slime that covers the stems and leaves of some submerged plants, and in the thin scum on the surface of the water. The slime or the scum may be collected, and treated in the same way as the ooze mentioned in the foregoing paragraph.

It is well to make separate collections from several places, to insure finding amœbas. 
II. Paramecium Culture. - Put a small bunch of hay into a tumbler of pond water, and allow it to stand in a warm, well-lighted place (not in the direct sunlight) for a few days or a week. This will usually be an unfailing source of slipper animalcules. Drops of water taken from the surface will be seen teeming with active minute white specks visible to the unaided eye. The water of a vase in which flowers have been kept too long will often furnish an abundant supply.

These creatures swim so freely, that it is often difficult to keep one in the field of the microscope. If a small tuft of fine cotton fibers be lowered into the drop upon the slip before it is covered, some of the animals are likely to be entangled in the meshes of the cotton, where they may be studied alive. The cotton also supports the cover glass, so that the animals are not crushed.

If their feeding is to be watched, finely powdered carmine or indigo should also be put into the drop before it is covered.

A method of retaining paramecium within the field for examination, which usually proves more satisfactory, is to mount the animalcule in a drop of gum solution made by boiling cherry, peach, or plum gum in water, and diluting to the desired fluidity, and covering. The gum retains the animal, restricts somewhat the action of the cilia, and its refractive properties render some structures more evident.

III. On finding Fresh-water Sponges. ${ }^{1}$ - The collector will need, first of all, to know that an animal may be fixed in position, and green in color.

The sponge recommended for study in this course (Myenia fluviatilis) may be looked for in the clear water of ponds and lakes and quietly flowing bayous. It will hardly be found in muddy water or in shallow water over a mud bottom. It grows in compact or lobed cushion-like masses (often several inches in diameter) upon the stones of the bottom, upon "water-logged" timbers, upon boughs drooping in the water, etc. It is of a yellowish or brownish or green color. It may be distinguished (under a lens) from vegetable growths of similar appearance by the absence in it of leaves and of long, threadlike fibers, and by the presence of osteoles, of bristling spicule points, and (in autumn) of gemmules. Although it is cosmopolitan in its range, there do not appear to be many localities of great abundance of it. It should therefore be definitely located in advance of need, so that fresh specimens may be at once obtainable when needed for class use.

1 The author has drawn largely upon the excellent monograph by Edward Potts for the directions found in this and the next following sections. 
In collecting, it is not enough to tear a way the top of the sponge : gemmules are most abundant in its deepest parts. A sharp hatchet, with which a chip bearing the entire sponge may be detached from submerged timbers, will therefore be found very serviceable. A broad, dull knife blade may be used for detaching such as grow on large stones. Specimens will be gathered most quickly by wading with high boots in shallow water, and cutting them free from chunks and stones which lie on the bottom. They will be collected most easily when found growing upon partly submerged boughs of trees, which may be drawn out of the water.

Specimens may be preserved in alcohol. The skeletal framework will be readily preserved by drying the specimens in situations sheltered from the direct rays of the sun.

IV. On preparing Gemmules and Spicules for Examination. - Dissect out with needles half a dozen gemmules from the sarcode or from the dried sponge mass. Place them together on the center of a clean glass slip, and cover them with a drop of boiling nitric acid. After five minutes (more or less, as may prove necessary time for rendering their outer coat transparent without destroying it) wash off the acid by running successive drops of water across the slide while holding it in an inclined position. Then cut two or three of the gemmules in halves or in quarters, so as to expose the edges of their outer coat. Then remove the water, as much as possible with blotting paper, and the remainder by adding strong alcohol. Renew the alcohol once or twice; then remove it with blotting paper, and cover the gemmules with a drop of turpentine or benzole. After allowing a few moments for the gemmules to become penetrated with the oil, remove excess of it with blotting paper, and add a drop of balsam and a cover glass, and the preparation will be properly and permanently made.

Place bits of the sponge containing skeletal spicules, and several gemmules, together in a small test tube, and boil them for several minutes in a few drops of nitric acid: the spicules will alone remain undissolved. Fill up the test tube with water, heat gently, and set aside. The spicules will settle to the bottom. After they have settled, hold the test tube slightly inclined, and roll it slowly between the fingers to collect the spicules to one spot on the bottom. Holding one end of a small glass tube closed with the finger, push the open end down inside the test tube to this spot, and then lift the finger at the top sufficiently to adinit a drop of water at the bottom. This drop will carry into the tube a load of spicules, which may be transferred to the center of a clean slip. After the water has evaporated, and left 
the spicules deposited upon the slip, heat the slip gently to make sure of the drying, cover the spicules with a drop of balsam, add the cover glass, and the preparation is complete.

V. On "Germinating" the Gemmules. - "To obtain the young spongillæ, it is only necessary to get a portion of an old living specimen bearing statoblasts (gemmules), and, having taken out a few of the latter, to roll them gently between the folds of a towel, to free them from all extra material as much as possible. Place them in a watch glass, so as not to touch each other, with a little water, in a saucer or small dish filled with small shot to keep the saucer upright, and, covering them with a glass shade, transfer the whole to a window bench opposite to the light. In a few days the young spongilla may be observed (from its white color) issuing from the statoblast (gemmule), and gluing the latter as well as itself to the watch glass, when it is ready for transfer to the field of the microscope for examination, care being taken that it is never uncovered by water, which may be replenished as often as necessary." - H. J. CARTer, Esq., of Devonshire, England, in Annals and Magazine of Natural History for 1882, p. 365 .

"If a few of them (gemmules) are removed from a fresh sponge, placed in an open stage tank (or watch glass) covered with water (preferably rain water), and protected from dust and too rapid evaporation by a cover of common glass, and placed upon a window ledge but not in direct sunlight, the following phenomena may be confidently expected.

"We are supposed to be working with gemmules heavier than water, beneath which they are allowed to rest quietly. If in a few days or hours some of the gemmules are found fixed where they lie, it is probable that germination has begun. On removing the preparation to the stage of the microscope, the instrument being fixed in vertical position, the initial stages of the development of a sponge can be daily or hourly watched under low powers of magnification.

"A creamy white granular film first appears, and gradually surrounds the gemmule, then widens, spreading irregularly in various directions, reminding one of the appearance of a giant amoba. At first nearly uniform in texture and density, it will soon be seen that the interior portion is more compact than the superficies, a very delicate film being set off around and over it, puffed up at one subcentral point into a greatly elongated rounded cone, open at the extremity. Here at this early stage is a complete sponge. The water with its contained nutriment is already being drawn in through almost invisible pores, and, after feeding the young cells, is thrown out at the 
surnmit of the cone, technically the 'chimney,' just described. This motion in the transparent fluid would be quite unperceived but for an occasional larger particle, which may be seen to come wandering along beneath the covering film until, reaching the 'chimney, it is suddenly puffed out as from a volcano. If the young sponge is very carefully fed with finely powdered carmine, or other suitable (insoluble) coloring matter, the course of circulation may more readily be followed." - Edward Potrs, in The Microscope, vol. x. p. 163.

VI. On Hydra Culture. - The hydra lives in shallow ponds and permanent pools in still water. In warm weather it is often found near the surface, attached to the stems of reeds, or pendent from the lower surface of floating leaves. In winter it will more often be found attached to leaves, that have fallen on the bottom. Its narrow, cylindrical body is about half an inch long, its tentacles are of equal length, and its color is pale brown, or, in another species, clear green. The leaves, etc., should be drawn out of the water, and their surfaces examined with a lens. The hydras, if present, will be much contracted after being disturbed; but the tentacles do not entirely disappear when contracted, but remain as a circle of fleshy knobs about the free end of the hydra, and these will serve for recognition. If the leaves be placed in a jar of water, the hydras will extend themselves again in a few minutes.

Perhaps the surest way to find them is to place the leaves, etc., in a shallow white dish or plate in water for a few minutes. If present, they will extend themselves when quiet, and may easily be seen upon a white background. Though not abundant anywhere, there is hardly a locality that will not furnish a good supply after a proper search. They are very apt to be found year after year in the same places.

Hydras for class use should be collected a week or more before they are to be used. They may be kept in a jar of water, or aquarium, in which some small aquatic plants are placed. They will need to be supplied with food. They eat readily small crustaceans not larger than cyclops, daphnia, etc.; also protozoans and microscopic plants. If the jar in which they are to be kept be taken to the field and filled with the water in which they are found, and a few of the plants to which they adhere, sufficient food to keep them for a long time will probably be taken up with the water and the plants. None of the larger animals (e.g., snails) which feed on hydras should be left in the jar.

Many of the hydras will attach themselves to the sides of the jar, on the side toward the light. When wanted for study, they may be dislodged by pushing a knife blade between their bases and the glass, and taken up with a dropping tube. 
VII. On Mounting Insects. ${ }^{1}-\mathrm{A}$ few simple directions will be sufficient guide to the preparation of the few life-history boxes mentioned in this book. The steps in the process are (1) the fixing of the specimens on pins; (2) the thorough drying of them; and (3) the mounting of them, under glass, in a box of some sort, tightly sealed to keep out pests.

Most specimens may be fixed on pins run vertically through the thorax two thirds of their length. Beetles (with wings closed) should have the pins run through the center of the left wing cover, and obliquely downward through the body. Minute specimens may be fixed with mucilage on a narrow strip of white paper, through which the pin may be stuck. Pins of uniform length (preferably insect pins) should be used, and the mounted specimens should stand at the same height on all the pins. When the wings of an insect are to be spread and dried so, a setting board is necessary. The pin is run through the insect in the usual way. The body is placed in a groove in the setting board, and the wings are spread horizontally upon the board, and held in position by strips of paper pinned across their tips.

The best boxes for preserving insect specimens are lined on the bottom with sheet cork, into which the pins can easily be pushed. Thin disks, of uniform size, cut from common bottle corks, and glued to the bottom of the box, will generally answer the student's purpose. A bit of gum camphor should be placed in the box, and the top and all cracks tightly sealed, if the preparation is to be permanent.

VIII. On Dissecting under Water. - Small animals not covered with hair or feathers are best dissected under water. Delicate parts are floated into view, and more easily separated and more easily recognized under water.

Excellent dissecting pans are made by pouring melted wax or paraffine into a shallow vessel to harden on the bottom and form a thin layer, to which the specimens may be pinned down. A piece of thin board wedged fast in the bottom of a pan with vertical sides will answer every purpose.

The structure of small parts may often be better made out by " teasing"; i.e., by tearing apart with needles on a slip in a drop of water, or, better, of dilute glycerine.

1 Part F of Bulletin No. 39, United States National Museum, entitled Directions for Collecting and Preserving Insects, contains full and explicit directions, as well as a fund of suggestions, as to methods of rearing insects, references to entomological literature, etc. It may be had for the asking, and a copy should be in every school library. 
IX. On Injections. - Blood vessels and other tubular organs and ducts are much more easily studied if first filled with some colored substance which renders them more conspicuous. The following Starch Injection Mass is recommended for filling such vessels :-

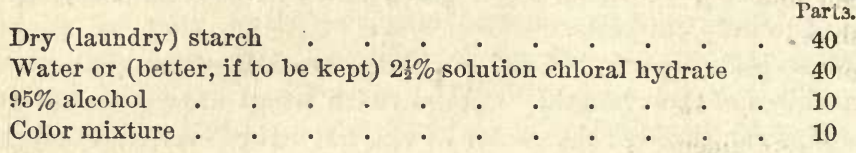

These should be thoroughly mixed and the mixture strained through cheese-cloth.

It is easily prepared, easily used, and, on the whole, gives very satisfactory results. A syringe of some sort may be necessary for forcing the mass into the vessels to be injected. A cannula should be attached by a short bit of rubber tubing to the end of the syringe. The cannula is for insertion into the end of the vessel to be injected. It may readily be made of a piece of glass tubing drawn to a point, with a constriction made near the point to hold a ligature from slipping off when tied around it. It is well to have several cannulre with nozzles of different sizes. A rubber bulb on a cannula made from a glass tube will answer ordinarily for any animal not larger than a cat.

The formula for the color mixture mentioned in the above is as follows :-

Dry color (vermilion, red lead, Berlin blue, ultramarine blue, Parts. chrome yellow, orange, or green) . . . . . . 3 Glycerine • • • • . . . . . • . . 3 $95 \%$ alcohol . . . . . . . . . . . 3

These should first be thoroughly mixed by grinding together in a mortar.

This starch mass will keep indefinitely in a well-stoppered bottle, and only needs to be shaken to be ready for use. In using it, the syringe is first filled with it. The cannula is attached to the syringe, filled by pushing on the piston slightly, inserted into the end of the vessel to be injected, and ligatured fast by a soft cotton string tied around the outside of the vessel. The vessel is then filled by a steady, gentle pressure upon the piston of the syringe.

A very convenient instrument for passing the ligature around the vessel to be tied, may be made by pushing the point of a darning needle into a wooden handle, heating the eye end of the needle red-hot and bending it into a shallow hook. The needle can be threaded with 
the ligature, which may then be easily passed around the vessel in proper position for tying.

$\mathrm{x}$. How to inject the Catfish. - Anæsthetize the fish by placing it in a small quantity of water to which a little chloroform or ether has been added. As soon as it is quiet, cut off the dorsal spine. Place the fish on its back, and open the body cavity by a median ventral slit. Continue the cut forward through the bones of the pectoral arch, taking care not to injure the internal organs. Separate the cut edges by pressing down on both pectoral spines at once, thus disclosing the heart lying in its pericardial sac.

In a specimen intended for complete dissection, it will be convenjent to inject only that part of the circulatory system which carries venous blood. Before the blood vessels can be filled with the injection mass, they must be emptied of their contents. To get the blood out, make a slit with fine scissors in the ventricle, another in the venous sinus, another in each of the veins entering the liver from behind, and another in the vein entering each kidney from behind. Sop up all the blood that can be induced to flow from these incisions, with a soft sponge moistened with water, or, better, with normal salt solution. Then inject. Fill the syringe with the injection mass well shaken. Insert its cannula into the arterial bulb through the slit in the ventricle, ligature the nozzle of the cannula, and inject forward to fill the branchial aorta and its branches. Withdraw the cannula, and tighten the ligature to prevent the escape of the injection. Insert the cannula in turn in each of the other incisions, ligature, and inject backward. A very small cannula may be needed for injecting the veins which return the blood to the kidneys. If the operation be properly performed, the arteries (except the branchial) may be recognized in dissecting by their not being injected.

XI. How to inject the Frog or the Turtle. - Anæsthetize the frog with chloroform or ether. Open the abdominal cavity by a median ventral incision. Continue the cut forward through the shoulder girdle a little to one side of the median line. Fasten the edges of the cut apart, and disclose the heart. With sharp scissors snip off the point of the ventricle, and remove the blood with a moist sponge.

The arterial system of the frog is very easily injected. Insert the cannula through the ventricle into the base of the arterial trunk, ligature, and inject forward. Nothing more will be necessary for filling the arterial half of the circulatory system, and this will answer our present purpose.

After opening the body of the turtle as directed in the text (p. 200), the method of procedure is practically the same as for the frog. 
XII. How to inject a Sparrow. - After anæsthetizing the sparrow with chloroform, the heart stops very quickly, and rapid work will be necessary to find it still beating when the body cavity is opened. It should be beating when the tip of the ventricles is cut off, in order that as much blood as possible may be removed preparatory to a good injection of the arterial system. The topography of the skeleton should be first studied as a guide to removal of the ventral wall of the thorax.

As soon as the sparrow is quiet, make a transverse cut through the abdominal wall behind the sternum, and a longitudinal cut along each side of the thorax through the sternal ribs and coracoid. Raise the sternum, open the pericardium, and snip off the apex of the ventricles with sharp scissors. Sop up and remove the blood with a moist sponge. Insert a small cannula through the right ventricle into the base of the pulmonary artery, ligature, and inject. Insert a larger cannula through the left ventricle into the base of the aorta, ligature around the ventricle, and inject.

XIII. How to inject the Rabbit. - Both arteries and veins should be injected in the rabbit, but with different colors. Red for arteries, and blue for veins, are most commonly used.

The more quickly the blood vessels are opened after administering chloroform, the better in general will be the results. As soon as the animal is quiet, plunge one blade of a pair of stout, sharp-pointed scissors through the abdominal wall in the wide ventral notch between the ribs. Push the blade forward for two inches, keeping the point of it close under the ribs, and then bring the blades together, making a median ventral cut through the sternum. Draw apart the edges of the cut, slit open the pericardium, and snip off the apex of the ventricles, and make a slit in each of the auricles. Continue the ventral cut posteriorly for two inches along the abdomen. Turn the liver forward, and slit open the portal vein where it enters the posterior border of the liver.

Cut away the posterior part of the ventral wall of the thorax, and by liberal use of a moistened sponge assist the escape of the blood.

1. The Arteries. Inject the pulmonary arteries by passing a small cannula through the right ventricle into their base. Inject the remaining arteries through a larger cannula passed through the left ventricle into the base of the aorta.

2. The Veins. Using another color, inject the pulmonary veins by a small cannula passed through the left auricle into their base. Inject the three cavæ with a larger cannula passed through the right 
auricle into their bases. Inject the portal vein and its branches through a small cannula posteriorly directed into the slit previously made to let out the blood.

XIV. On Preparing Skeletons. - The cleaning of bones is not attractive work, but it is made comparatively an easy matter by the process described below (taken from Wilder and Gage's "Anatomical Technology"), and the intrinsic value for study of the disarticulated skeletons thus secured makes it well worth while. There is much that can be learned, too, as easily in the preparation of a skeleton as in any other way, of the relations of the bones to each other and to the muscles and tendons.

The "liquid soap" used in this process is made by mixing and liquefying :-

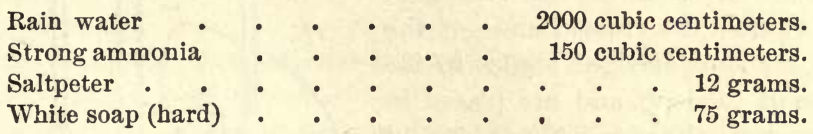

The process consists in (1) removing the skin, viscera, and the greater part of the muscles from the skeleton; (2) boiling the skeleton for forty minutes in a mixture of liquid soap one part, and water four parts; (3) boiling the skeleton again for thirty minutes in a mixture of equal parts of liquid soap and water; and (4) cooling the skeleton by immersing in cold water, and cleaning, rinsing, and drying the bones. The time of boiling here given is about the time required in the preparation of a rabbit skeleton. Less time will be required to complete the boiling of smaller skeletons.

XV. On Cheap Apparatus. - In addition to the pieces of simple apparatus mentioned in the text, the following are given as having proved serviceable :-

Dissecting needles may be made by pushing with pliers the eye end of common sewing needles into wooden handles.

A simple forceps, which the author has often preferred to use in the handling of minute objects, is made by trimming a narrow strip of sheet brass or tin to a point at each end, and bending the points together and parallel.

Bristles of the ordinary sort, obtainable from a harness maker, may be tipped with paraffine or sealing wax.

Ordinary earthenware jars of several gallons' capacity serve well as receptacles for organic refuse in the laboratory.

$A$ serviceable net for collecting fresh-water sponges by scraping submerged timbers is made by attaching a circular wire frame to the back 
of a common garden hoe, and suspending a bag from it, so as to collect the material loosened by the blade of the hoe.

The accompanying cut sufficiently

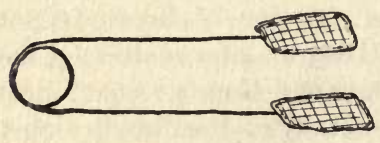

A Collecting Forceps. explains a small coilecting forceps which is useful for picking live bees, wasps, and the like, from flowers. The frame is of wire. The blades are covered with netting.

The water net figured herewith is made of a loop of heavy wire, a wooden handle, a strip of muslin, a shallow bag of grasscloth or scrim or other netting, and some small wire for binding and bracing. The loop of wire is formed as shown in the figure: the crossed ends of the wire are bent at right angles to the plane of the loop, and are placed in grooves in the sides of one end of the handle, and are wrapped there securely with smaller wire. Two grooves are filed in the wire of the loop at different points for the secure attachment of the braces, as shown in the figure. The narrow band of muslin is sewed to the loop, and the netting bag to the muslin, and the net is complete. It is quickly used, and easily cleaned by a backward push through the water.

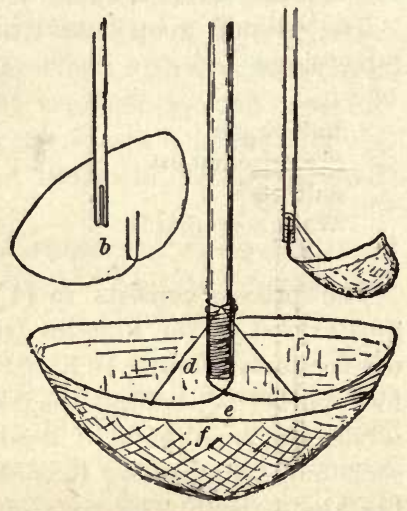

Water Net: $a$, handle; $b$, loop of wire; $c$, completed net, side view; $N$, completed net, from above; $d$, brace; $e$, muslin band; $f$, netting bottom.

\section{ACCENTUATED LIST OF THE TECHNICAL TERMS USED IN THIS BOOK, TOGETHER WITH THEIR ETYMOL- OGY AND SYNONYMY.}

ab-do'-men (Lat. abdomen), belly.

ab-o'-ral (Lat. $a b$, from, and os, oris, mouth).

ac-e-tab'-u-lum (Lat. acetabulum, vinegar vessel ?).

ad-am-bu-la'-cral (Lat. ad, to, and ambulacrum), next to the ambulacra. ad-duc'-tor (Lat. ad, to or toward, and ducere, to draw).

$\mathrm{ad}^{\prime}$-i-pose (Lat. adeps, adiposus, fat), fatty.

a-ër-a'-tion (Lat. aër, air), exposure to air; oxygenation. 
ag'-gre-gate (Lat. ad, to or together, and gregare, to collect into a flock). al-i-men'-ta-ry (Lat. alimentarius, from alere, to nourish). al'-u-let (Lat. alula, dim. of ala, a wing). am-bu-la'-crum, pl. ambulacra (Lat. ambulacrum, an alley). a-mœ'-ba, pl. amœbas (Gr. amoibe, a change), the proteus animalcule. a-mœ'-boid (Gr. amoibe, change, and eidos, form), like the amœba. am-pul'-la, pl. ampulloe (Lat. ampulla, a flask). a-nab'-0-lism (Gr. anabole, something heaped up), constructive metabolism; assimilation.

an-æs'-the-tize (Gr. an, privative, and aisthēsis, feeling or sensation). $\mathbf{a}^{\prime}$-nal (Lat. anus, the posterior opening of the alimentary canal). a-nal'-o-gous (Gr. analogos, according to due ratio). an'-chy-lose (Gr. angkuloun, to stiffen), fuse; coössify. an-i-mal'-cule (Lat. animal, and dim. ule), an infusorian; a microscopic animal.

an-ten'-na, pl. antennae (Lat. antenna, a sail yard), the feeler of an insect. an-ten'-nule, dim. of antenna.

an-te-or'-bit-al (Lat. ante, before, and orbis, a circle), in front of the orbit. an-te'-ri-or (Lat. anterior, comp. of ante, before), fore; front.

$\mathbf{a}^{\prime}$-nus (Lat. anus), vent.

a-or'-ta, pl. aortoe (Gr. aortē).

$a^{\prime}$-pex (Lat. apex), tip or point.

a-quif'-er-ous (Lat. aqua, water, and ferre, to carry), conducting water. A-rach'-ni-da (Gr. arachne, a spider), spiders.

ar'-te-ry (Lat. arteria).

Ar-throp'-o-da (Gr. arthron, joint, and pous, podos, foot), joint-footed animals.

a-ryt'-e-noid (Gr. arutaina, a ladle, and eidos, form).

as-sim'-i-late (Lat. $a d$, to, and similare, to make like), to convert into a like substance.

as-sim'-i-la-tion (Lat. assimilatio, from ad, to, and similare, to make like), anabolism; constructive metabolism.

at'-las (Gr. Atlas, the god who bears up the pillars of heaven), first vertebra of the neck, sustaining the skull, whence the name. at'-ro-phy (Gr. an, privative, and trephein, to nourish), a wasting-away. $\mathrm{au}^{\prime}$-di-to-ry (Lat. auditorius, from audire, to hear), pertaining to the

sense or organs of hearing. $\mathrm{au}^{\prime}$-ri-cle (Lat. auris, ear, and dim. suffix).

$\mathbf{A}^{\prime}$-ves (Lat. sing. avis, a bird), birds.

ax'-i-al (Lat. axis).

ax'-il-lar (Lat. axilla, armpit).

bar'-bel (Fr. barbel, dim. of Lat. barbus, a beard).

wn.n. zoöL. - 19 
bar'-bule (Lat. barbula, dim. of barbus, a beard). ba-si-sphe'-noid (compounded of basal and sphenoid, q.v.).

Ba-tra'-chi-a (Gr. batrachos, a frog), amphibia. bi'-fid (Lat. bis, twice, and findere, fidi, to split), cleft or parted. bi-fur'-ca-ted (Lat. bis, twice, and Eng. furcate, forked). bi-lat'-er-al (Lat. bis, twice, and latus, side), pertaining to two sides. Bi-pin-na'-ri-a (Lat. bis, twice, and pinna, feather). bi-ro'-tu-late (Lat. bis, twice, and rotula, a little wheel). bi'-valve (Lat. bis, twice, and valva, valve). blas'-tu-la (Gr. blastos, a sprout). brach'-i-al (Lat. brachium, arm), pertaining to the fore limb.

Brach-i-o-1a'-ri-a (Lat. dim. of brachium, arm, and -aria), larva of a starfish.

bran'-chi-al (Lat. branchia, a gill), pertaining to the branchiæ or gills. bran-chi-os'-te-gal (Gr. brangchion, gill, and stegein, to cover). bron'-chus, pl. bronchi (Gr. brongchos, windpipe). buc'-cal (Lat. bucca, cheek), pertaining to the mouth. cæ'-cum, pl. caca (Lat. coecus, blind). cal'-a-mus (Lat. calamus, a reed). cal-ca'-re-ous (Lat. calx, lime), containing carbonate of lime. cap'-il-1a-ry (Lat. capillus, a hair). car'-a-pace (Fr. carapace), carapax; shell; shield. car'-di-nal (Lat. cardo, a hinge), pertaining to the hinge in the shell of Unio.

ca-rot'-id (Gr. karos, heavy sleep).

car'-po-met-a-car'-pus (compounded of Gr. karpos, wrist, and metakarpion, beyond the wrist), the single large bone of the bird's hand, formed by the coössification of carpal and metacarpal bones. car'-pus (Gr. karpos, wrist). car'-ti-lage (Lat. cartilago). cau'-dal (Lat. cauda, tail), pertaining to the tail. cen'-trum, pl. centra (Lat. centrum), the body of a vertebra. ce-phal'-ic (Gr. kephale, head), pertaining to the head or brain. ceph-a-10-tho'-rax (Gr. kephale, head, and thörax, the chest). cer-e-bel'-lum (Lat. dim. of cerebrum, the brain). cer'-e-brum (Lat. cerebrum), the hemispheres of the forebrain. cer'-vi-cal (Lat. cervix, neck).

chi-as'-ma (Gr. chiasma, two lines placed crosswise), optic commissure. chi'-tin (Gr. chitōn, a corselet). chlor'-a-gogue (Gr. chlöros, light green, and agein, to lead). chrys'-a-lid, pl. chrysalids chrys'-a-lis, pl. chrysalides $\}$ (Gr. chrusos, gold). 
cil'-i-a (Lat. sing. cilium, an eyelash).

cir-cum-o'-ral (Lat. circum, around, and os, oris, mouth).

cir-cum-val'-late (Lat. circumvallare, to surround with a wall).

clav'-i-cle (Lat. clavicula, a little key), the collar bone.

cli-tel'-lum (Lat. clitello, a pack saddle).

clo-a'-ca (Lat. clocica, a sewer).

co-a-lesce' (Lat. con, with, and alescere, to grow up), unite; fuse - join.

Cœ-len-te-ra'-ta (Gr. koilos, hollow, and enteron, intestine).

cœ'-li-ac (Gr. koilia, belly), pertaining to the abdomen.

Co-le-op'-te-ra (Gr. koleon, a sheath, and pteron, a wing).

col-u-mel'-la (Lat. dim. of columen, a column).

com'-mis-sure (Lat. commisura, a joining together).

con-cen'-tric (Lat. con, together with, and centrum, center), having a common center.

con'-dyle (Lat. condylus, from Gr. kondos, a head or knob).

con-ju-ga'-tion (Lat. con, together, and jungere, to join).

con-tour' (Fr. contour, outline).

con-tract'-ile (Lat. con, together, and trahere, to draw).

cor'-a-coid (Gr. korax, a crow, and eidos, form : from a fancied resem-

blance of the human coracoid process to a crow's beak).

cor'-ne-a (Lat. corneus, horny).

cor'-pus-cle (Lat. dim. of corpus, body).

$\cos ^{\prime}$-ta (Lat. costa, a rib).

cov'-erts (Lat. con, with, and operire, to cover).

cox'-a, pl. coxce (Lat. coxa, the hip).

cra'-ni-um (Gr. kranion, skull), the brain case.

cre-mas'-ter (Gr. kremastēr, a suspender).

crib'-ri-form (Lat. cribrum, a sieve, and forma, form).

cri'-coid (Gr. krikos, a ring, and eidos, form).

cris'-sum (Lat. crisso, to move the haunches), the under tail coverts of

a bird; feathers around the cloaca.

crys'-tal-line (Lat. crystallum; Gr. krustallos, ice, crystal).

cu'-bi-tus (Lat. cubitus, elbow).

cul'-men (Lat. culmen, from celsus, lofty).

der'-mis (Gr. derma, skin), cutis.

dex'-tral (Gr. dexiteros, pertaining to the right hand).

di'-a-phragm (Gr. dia, through, and phrassein, to fence or inclose).

dif-fer-en-ti-a'-tion (Lat. dis, apart, and ferre, to carry).

di-gest' (Lat. digerere, to separate, to dissolve).

dig'-it (Lat. digitus, a finger).

dig'-i-tate (Lat. digitus, a finger), having an arrangement like that of the fingers on the hand. 
di-œ'-cious (Gr. dis, twice, and oikos, house), having the two sexual elements produced by two separate individuals of the same species. Dip'-te-ra (Gr. dis, two, and pteron, a wing).

dis-ar-tic'-u-late (Lat. dis, apart, and articulus, dim. of artus, a joint), to sunder; to separate at the joint.

dis-coid'-al (Gr. diskos, a round plate, and eidos, form), disk-shaped. dis'-tal (Lat. distare, to stand apart), remote from the point of attachment.

di-ver-tic'-u-lum, pl. diverticula (Lat. diverticulum), a blind tube extending outward from a large tube.

dor'-sal (Lat. dorsum, back), tergal; opposed to ventral.

du-0-de'-num (Lat. duodeni, of twelve each: the human duodenum is in length about equal to the breadth of twelve fingers, hence the name), anterior part of small intestine.

E-chi-no-der'-ma-ta (Gr. echinos, sea urchin, and derma, skin). ec'-to-derm (Gr. ektos, outside, and derma, skin). ec'-to-sarc (Gr. ektos, outside, and sarx, flesh). e-gest' (Lat. e, out, and gerere, to carry), to void. el'-y-tron, el'-y-trum, pl. elytra (Gr. elutron, a sheath). em'-bry-o (Lat. embryo, Gr. embruon).

em-bry-01'-0-gy (Gr. embruon, embryo, and logos, a discourse), the study of the development of embryos.

en'-do-derm (Gr. entos, within, and derma, skin).

en'-do-sarc (Gr. entos, within, and sarx, flesh). en-do-skel'-e-ton (Gr. endon, within, and skeleton, a dry body). en-dos-mo'-sis (Gr. endon, within, and osmos, a thrusting). en-to-mol'-o-gy (Gr. entomon, an insect, and logos, a discourse). ep-i-der'-mis (Gr. epi, upon, and derma, skin), cuticle. ep-i-glot'-tis (Gr. epi, upon, and glotta, a tongue). e-piph'-y-sis, pl. epiphyses (Gr. epi, upon, phuein, to grow). e-soph'-a-gus (Gr. oisophagos), gullet. eth'-moid (Gr. èthmos, a sieve, and eidos, form). Eu-sta'-chi-an, discovered by Eustachius, an Italian physician. ev-o-lu'-tion (Lat. evolvere, to roll out of, to unfold). ex-cre'-tion (Lat. excernere, to sift out, to discharge). ex-o-skel'-e-ton (Gr. exō, outside, and skeleton, a dry body), outside skeleton.

ex-sert'-ed (Lat. exserere, to stretch forth), projecting beyond some other part.

ex-ten'-si-ble (Lat. ex, out, and tendere, to stretch), capable of being extended.

ex-u'-vi-a, pl. exuvịa (Lat. exuere, to draw out, to pull off). 
fac'et (Fr. dim. of face).

fau'-na (Lat. Fauni, rural deities), the animals of any place or period taken collectively.

fem'-0-ral (Lat. femur, thigh).

fe'-mur, pl. femora (Lat. femur), thigh.

fer-ti-li-za'-tion (Lat. ferre, to bear), fecundation; impregnation.

$\mathrm{fib}^{\prime}$-u-la, pl. fibulce (Lat. fibula, that which binds together; named

from the human splint-like fibula).

fil'-a-ment (Lat. filum, a thread).

fil'-i-form (Lat. filum, a thread, and forma, form).

fi'-10-plume (Lat. filum, a thread, and pluma, a soft feather).

floc'-cu-lar (Lat. flocculus, dim. of floccus, a lock of wool).

fo-li-a'-ta (Lat. from folium, a leaf).

fo-ra'-men, pl. foram'ina (Lat. foramen, a perforation).

fos'-sa, pl. fossa (Lat. fossa, a pit, from fodere, to dig).

fron'-tal (Lat. frontale, an ornament for the forehead).

fur'-cu-lum (Lat. furculum, dim. of furca, a fork), wishbone.

ga'-le-a, pl. galece (Lat. galea, a helmet).

gan'-gli-on, pl. ganglia (Lat. ganglion, Gr. ganglion, a swelling).

gas'-tric (Gr. gastēr, stomach).

gas-troc-ne'-mi-us (Gr. gastroknēmia, calf of the leg).

gas-tros'-tege (Gr. gastēr, stomach, and stegè, roof).

gem'-mule (Lat. dim. of gemma, a gem).

gle'-noid (Gr. glēene, a cavity, and eidos, form).

glo-chid'-i-um (Gr. glöchis, the point of an arrow).

glot'-tis (Gr. from glōtta, glōssa, a tongue).

go'-nys (Gr. gōnia, an angle).

hal-te'-res (Gr. haltēres, dumb-bells), balancers.

ham'-u-li, pl. (Lat. dim. of hamus, a hook).

he'-mal (Gr. haima, blood)

He-mip'-te-ra (Gr. hèmi, half, and pteron, a wing), bugs.

hem'-i-sphere (Gr. hêmi, half, and sphaira, a sphere).

hem'-o-lymph (Gr. haima, blood, and lymph).

he-pat'-ic (Lat. hepar, the liver).

her-maph'-ro-dite (Gr. Hermaphroditos, son of Hermes and Aphrodite

[myth]), being of both sexes.

Hex-ap'-0-da (Gr. hex, six, and pous, podos, foot), six-footed insects.

ho-mol'-0-gous (Gr. homologos, agreeing).

ho-mol'-o-gy (Gr. homologia, agreement), correspondence, in structure and origin.

hu'-me-rus (Lat. humerus).

hy'-dra, Eng. pl. hydras (Lat. hydra, water). 
Hy-me-nop'-te-ra (Gr. humēn, membrane, and pteron, a wing), the membrane-winged insects.

hy'-oid (Gr., the letter $v$, and eidos, form).

hy-pa-poph'-y-sis (Gr. hupo, under, and apophusis, a process of a bone). hy'-po-stome (Gr. hupo, under, and stoma, mouth).

il'-i-o-sci-at'-ic (compounded of ilium and sciatic, q.v.).

il'-i-um (Lat. ilia, groin, flank, small intestine).

i-ma'-go (Lat. imago, an image), the perfect insect; adult. in-ci'-sor (Lat. in, in, and cadere, to cut), a gnawing tooth. in-fra-or'-bit-al (Lat. infra, beneath, and orbis, a circle). in-fun-dib'-u-lum (Lat. infundibulum, a funnel). in-gest' (Lat. in, in, and gerere, to bear or carry). in-glu'-vi-es (Lat. ingluvies), crop. in-nom'-i-nate (Lat. in, not, and nominatus, named). in'-sect (Lat. insectus, from insecare, to cut in). in'-te-grate (Lat. integrare, to make whole). in-ter-cos'-tal (Lat. inter, between, and costa, a rib). in-ter-neu'-ral (Lat. inter, between, and Gr. neuron, a nerve), between the neurals.

in-ter-or'-bit-al (Lat. inter, between, and orbis, a circle), between the orbits.

in-ter-pa-ri'-e-tal (Lat. inter, between, and parietal, q.v.). in-tes'-tine (Iat. intestinus, from intus, the inside). . $\mathrm{i}^{\prime}$-ris (Lat. iris, the rainbow). is'-chi-um, pl. ischia (Gr. ischion, the hip joint). isth'-mus (Lat. isthmus, a narrow neck of land). $i^{\prime}$-ter (Lat. iter), a passage. ju'-gal (Lat. jugum, a yoke). ju'-gu-lar (Lat. jugulum, the throat).

ka-tab'-o-lism (Gr. kata, down, and ballein, to throw), destructive metabolism.

$1 a^{\prime}-$ bi-al, pertaining to the lips.

$\left.\begin{array}{l}\text { la'-bi-um } \\ 1 a^{\prime} \text {-brum }\end{array}\right\}$ (Lat. labium, lip).

lach'-ry-mal (Lat. lachryma, a tear).

la-cin'-i-a (Lat. lacinia, a lappet or flap).

lac'-te-al (Lat. lac, lactis, milk).

lar'-va (Lat. larva, ghost, specter).

lar'-ynx (Gr. larungx, the larynx).

lat'-er-al (Lat. latus, side), pertaining to the side.

Lep-i-dop'-te-ra (Gr. lepis, a scale, and pteron, a wing), scaly-winged insects. 
lig'-a-ment (Lat. ligare, to bind).

lig'-u-la (dim. of Lat. lingua, a tongue).

lob'-u-late (Gr. lobos, a rounded projection).

lore (Lat. lorum, a strap), space between beak and eye in birds.

lum'-bar (Lat. lumbus, loin).

mad'-re-po-rite (Lat. mater, mother, and Gr. pōros, a soft stone).

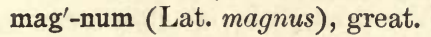

$\mathrm{ma}^{\prime}$-lar (Lat. mala, the cheek).

Mal-pi'-ghi-an, discovered by Malpighi.

mam'-mal (Lat. mamma, a breast).

Mam-ma'-li-a, the animals which nourish their young with milk.

mam'-ma-ry (Lat. mamma, a breast, a glandular organ for secreting

milk), pertaining to the mammary glands.

man'-di-ble (Lat. mandere, to chew).

man'-tle (Lat. mantellum, a cloth or cloak).

ma-nu'-bri-um (Lat. from manus, hand).

ma'-trix, pl. matrices (Lat. matrix, mother).

max-il'-la, pl. maxilla (dim. of Lat. mala, a jaw).

max'-il-1a-ry (Lat. maxilla, a little jaw).

max-il'-li-ped (Lat. maxilla, jaw, and pes, pedis, foot).

me-a'-tus (Lat. meare, to go), a passage.

me'-di-an (Lat. medius, middle).

me-di-as-ti'-num (Lat. mediastinus = medius).

me-dul'-la (Lat. medulla, marrow), the hindbrain: written also medulla oblongata.

mes'-en-ter-y (Gr. mesos, middle, and enteron, intestine).

mes-0-ster'-num (Gr. mesos, middle, and sternon, breast).

mes-0-tho'-rax (Gr. mesos, middle, and thōrax, chest).

me-tab'-0-lism (Gr. metabole, change), the constructive and destruc-

tive changes which take place within the cell, a process known

only through its results.

met-a-car'-pus (Gr. meta, beyond, and karpos, wrist).

met-a-mor'-pho-sis, pl. metamorphoses (Gr. meta, beyond, over, and

morphe, form, shape), the structural changes which take place

in an animal after it emerges from the egg.

met-a-no'-tum (Gr. meta, beyond, hind, and nōtos, back).

met-a-ster'-num (Gr. meta, beyond, and sternon, breast).

me-tas'-to-ma (Gr. meta, behind, and stoma, mouth).

met-a-tar'-sus (Gr. meta, beyond, and tarsos, tarsus).

met-a-tho'-rax (Gr. meta, beyond, and thörax, chest).

met-a-zo'-an (Gr. meta, beyond, and zōon, animal), one of the "higher" animals; any animal, not a protozoan; a many-celled animal. 
mo'-lar (Lat. molere, to grind), a grinding tooth.

Mol-lus'-ca (Lat. mollis, soft), mollusks.

mo'-tile (Lat. movere), having power of motion.

mu'-cous (Lat. mucus, mucus).

Myr-i-ap'-o-da (Gr. murios, numberless, and pous, podos, foot).

na'-sal (Lat. nasus, the nose), pertaining to the nose.

ne-phrid'-i-a (Gr. nephros, kidney).

neu'-ral (Gr. neuron, a nerve), pertaining to the nervous system or some

part of it.

nic'-ti-tat-ing (Lat. nictare, to wink).

no'-dus (Lat. nodus, a knot):

no'-tum (Gr. nōtos, back).

nu'-chal (Lat. nucha, the nape).

nu'-cle-us (Lat. dim. of nux, nucis, a nut).

nymph (Lat. Nympha [myth.], goddess of meadows, waters, forests, etc.).

$\mathrm{ob}^{\prime}$-tu-ra-tor (Lat. obturare, to stop up).

oc'-ci-put (Lat. ob, against or back of, and capul, head).

o-cel'-lus, pl. ocelli (Lat. dim. of oculus, eye).

oc-u-lo-mo'-tor (Lat. oculus, the eye, and movere, to move).

0-don'-a-ta (Gr. odous, odontos, a tooth).

o-don'-toid (Gr. odous, a tooth, and eidos, form).

o-lec'-ra-non (Gr. ōlene, elbow, and kranion, head).

ol-fac'-to-ry (Lat. olere, to smell, and facere, to make), pertaining to

the sense of smell.

0-mo-ster'-num (Gr. ōmos, shoulder, and sternon, breast).

$0^{\prime}-0 \ddot{-}$-sperm (Gr. ōon, egg, and sperma, seed), the fertilized ovum.

o-per'-cu-lum (Lat. from operire, to cover).

op'-tic (Gr. optikos, belonging to sight), pertaining to the eye.

$o^{\prime}$-ral (Lat. os, oris, mouth), pertaining to the mouth.

or'-bit (Lat. orbis, a circle).

or'-i-fice (Lat. os, mouth, and facere, to make).

Or-thop'-te-ra (Gr. orthos, straight, and pteron, a wing), the straight-

winged insects.

os cru'-ris (Lat. os, bone, and cruris, leg).

os-mo'-sis (Gr. ōsmos, impulse).

os'-si-fy (Lat. os, ossis, a bone), to become bone.

os'-si-cle (Lat. dim. of os, a bone), a little bone.

os'-te-ole (Lat. dim. of ostium, mouth).

os-te-ol'-o-gy (Gr. osteon, bone, and logos, discourse).

$o^{\prime}$-va-ry (Lat. ovarium, from ovum, egg).

$o^{\prime}$-vate (Lat. ovum, egg), egg-shaped.

$0^{\prime}$-vi-duct (Lat. ovum, egg, and ductus, duct, tube). 
0-vi-pos'-i-tor (Lat. ovum, egg, and ponere, to place).

$o^{\prime}$-vum (Lat. ovum), egg.

pal'-ate (Lat. palatum), the roof of the mouth.

pal'-a-tine (Lat. palatum, the roof of the mouth), the bones supporting

the palate.

pal'-li-al (Lat. pallium, a mantle).

pal'-pus, pl. palpi (Lat. palpus), feeler.

pan'-cre-as (Gr. pangkreas, pancreas, from pas, all, and kreas, flesh).

pa-pil'-la, pl. papilloe (Lat. papilla), a pimple-like projection.

par-a-me'-ci-um (Gr. para, beside, and mēkos, strength).

par-a-sphe'-noid (Gr. para, beside, and sphenoid, q.v.).

pa-ri'-e-tal (Lat. paries, a wall).

pa-rot'-id (Gr. para, beside, and ous, ōtos, the ear).

pa-tel'-la (Lat. dim. of patena, a pan), the kneepan.

pec'-ti-na-ted (Lat. pecten, a comb), toothed, like a comb.

pec'-to-ral (Lat. pectus, breast), pertaining to the breast.

ped'-i-cel (Lat. pediculus, dim. of pes, pedis, foot).

ped-i-cel-la'-ri-a, pl. pedicellarioe (Lat. pedicellus, pedicel, and -aria).

pel'-vis (Lat. pelvis, a basin).

per-i-car'-di-um (Gr. peri, around, and kardia, the heart).

per'-i-stome (Gr. peri, around, and stoma, mouth).

per-i-to-ne'-um (Gr. peri, around, and teinein, to stretch).

pha-lan'-ges, pl. of phalanx (Gr. phalangx, phalanx).

phar'-ynx (Gr. pharungx).

pi'-ne-al (Lat. pinea, the cone of a pine).

Pis'-ces (Lat. pl. of piscis, a fish), fishes.

pi-tu'-i-ta-ry (Lat. pituita, phlegm, mucus). This body was once erroneously supposed to secrete the mucus of the nostrils.

plas'-ma (Gr. plasma).

plas'-tron (Fr. plastron, a breastplate).

pleu'-rum, pl. pleura (Gr. pleura, the side).

plex'-us (Lat. plexus), a twining or twisting; a network.

por'-tal (Lat. porta, a gate), the gateway of the liver, the portal vein.

post'-ca-va, pl. postcavoe (Lat. post, after, and cavus, hollow), posterior

vena cava or ascending vena cava.

pos-te'-ri-or (Lat. comp. of posterus, coming after), hinder ; opposed to anterior.

post-or'-bit-al (Lat. post, after or behind, and orbis, a circle).

præ'-ca-va, pl. procavoe (Lat. proe, before, and cavus, hollow), anterior

vena cava or descending vena cava.

pre-cor'-a-coid (Lat. proe, before, and coracoid, q.v.).

pre-max'-il-la-rv (Lat. prae, before, and maxilla, jaw). 
pre-0-per'-cu-lum (Lat. pra, before, and operculum, a covering). pre-sphe'-noid (Lat. proe, before, and sphenoid, q.v.). pri'-ma-ries (Lat. primus, the first).

pro-bos'-cis, pl. probos'cides (Gr. pro, before, and boskein, to feed). pro-neph'-ros (Gr. pro, before, and nephros, kidney). pro-no'-tum (Gr. pro, before, and nōtos, back). pro-ö'-tic (Gr. pro, before, and ous, òtos, ear). pro-ster'-num (Gr. pro, before, and sternon, breast). pro-sto'-mi-um (Gr. pro, before, and stoma, mouth). pro-tho'-rax (Gr. pro, before, and thōrax, thorax). pro'-to-plasm (Gr. prōtos, first, and plasma, form). Pro-to-zo'-a (Gr. prōtos, first, and zōon, animal). pro-tract'-or (Lat. pro, forward, and trahere, to draw). pro-ven-tric'-u-lus (Lat. pro, forward, and ventriculus, stomach). prox'-i-mal (Lat. proximus, nearest), nearest the point of a'iachment, or nearest the median point or plane.

pseu-do-po'-di-a (Gr. pseudès, false, and pous, podos, foot), false feet. pter-o-stig'-ma (Gr. pteron, a wing, and stigma, a spot).

pter'-y-goid (Gr. pterux, a wing, and eidos, form).

$\mathrm{pu}^{\prime}$-bis, pl. pubes (Lat. pubis).

pul-mo-cu-ta'-ne-ous (Lat. pulmo, a lung, and Eng. cutaneous, pertaining to the skin).

pul'-mo-na-ry (Lat. pulmo, lung), pertaining to the lungs. pul-vil'-lus, pl. pulvilli (Lat. pulvillus), a little cushion.

pu'-pa, pl. pupce (Lat. pupa, a doll, a puppet).

pu'-pil (Lat. pupilla, originally dim. of pupa, a girl), the circular opening through the iris.

py'-gal (Gr. puge, the rump).

py'-go-style (Gr. puge, rump, and stulos, a pillar or stylet for writing). py-10'-rus (Lat. pylorus, a gatekeeper).

quad'-rate (Lat. quadratum, quadrangular). ra'-di-us, pl. radii (Lat. radius, a staff or rod). $\mathrm{rad}^{\prime}$-u-1a, pl. raduloe (Lat. radula, a scraper, from radere, to scrape). $\mathrm{ra}^{\prime}$-mus, pl. rami (Lat. ramus, a branch). rec'-tri-ces (pl. of Lat. rectrix, a governess), tail feathers. $\mathrm{re}^{\prime}$-nal (Lat. renes, the kidneys), pertaining to the kidneys. Rep-til'-i-a (Lat. reptilis, from repere, to creep), reptiles. re-tract'-or (Lat. re, back, and trahere, to draw). re-trorse' (Lat. retro, back, and vertere, to turn). rha'-chis (Gr. rachis, a dorsal ridge or spine), shaft. ric'-tus (Lat. ringi, rictus, to open wide the mouth), the gape. ros'-trum (Lat. rostrum, a beak). 
sac'-cu-la-ted (Lat. sacculus, dim. of saccus, a sack), bearing little sacs. $\mathrm{sa}^{\prime}$-crum, the Latin name for the anchylosed human sacral vertebræ. sal'-i-va-ry (Lat. saliva, spittle), pertaining to the saliva. sar'-code (Gr. sarx, flesh, and eidos, form). scap'-u-la, pl. scapula (Lat. scapula), shoulder blade. sci-at'-ic (Iat. sciaticus), pertaining to the hip.

scle-rot'-ic (Gr. skleros, hard). scu-tel'-la, pl. scutellae (Lat. fem. dim. of scutum, a shield). scu'-tel-late (Lat. scutella, a dish or plate), covered with scutella, overlapping plate-like scales.

sec'-ond-a-ries, pl. of secondary (Lat. secundarius, second). seg-men-ta ${ }^{i}$-tion (Lat. segmentum, segment, from secare, to cut). seg'-ment (Lat. segmentum, from secare, to cut off), somite; ring; joint. sep'-tum, pl. septa (Lat. septum, a fence or partition), a partition. ser'-ra-ted (Lat. serra, a saw), toothed, like a saw.

ses'-a-moid (Gr. sēsamon, a kind of seed, and eidos, form), seedlike (?) bones formed in the tendons. ses'-sile (Lat. sessum, seated, from sedere, to sit). $\mathrm{se}^{\prime}$-ta, pl. setoe (Lat. seta), a bristle. sin'-is-tral (Lat. sinister, the left hand), pertaining to the left-hand side; turning toward the left.

si'-nus, Eng. pl. sinuses (Lat. sinus), a curve; a hollow.

si'-phon (Lat. sipho, Gr. siphōn, a bent tube for the transference of water).

skel'-e-ton (Gr. skeleton, a dried body).

sperm (Lat. sperma, seed), spermatozoa; the male reproductive element. sper'-ma-ry (Lat. sperma, seed), testicle.

sper-mat'-ic (Lat. spermaticus, pertaining to spermatic fluid). sphe'-noid (Gr. sphen, a wedge, and eidos, form).

spic'-ule (Lat. dim. of spica, a dart). spir'-a-cle (Lat. spirare, to breathe). spleen (Gr. splēn). spu'-ri-ous (Lat. spurius), false; whence the spurious quills constitute what is sometimes called the "false wing."

squa-mo'-sal (Lat. squama, a scale). ster'-num (Lat. from Gr. sternon, breast). stri'-a-ted (Lat. stria, a channel), marked with fine grooves or lines. strid-u-la'-tion (Lat. stridulare, to creak). sty'-let (Lat. stylus, a style [writing instrument]). sub-cla'-vi-an (Lat. sub, under, and clavicle, a little key), beneath the clavicle.

sub-cos'-tal (Lat. sub, under, and costa, a rib). 
sub-gen'-i-tal (Lat. sub, under, and genitalis, the genital organs). sub-lin'-gual (Lat. sub, under, and lingua, a tongue). sub-max'-il-1a-ry (Lat. sub, under, and maxilla, a jaw). sub-me'-di-an (Lat. sub, under, and medius, the middle). sub-quad'-rate (Lat. sub, under, and quadratum, quadrangular), some. what four-angled.

suc-to'-ri-al (Lat. sugere, suctum, to suck), adapted for sucking. su'-ture (Lat. sutura, a seam). swim'-mer-et, abdominal swimming appendage. sym'-phy-sis (Gr. sumphuein, to grow together), coalescence; fusion; coössification.

syr'-inx (Gr. suringx, a pipe). tac'-tile (Lat. tangere, tactum, to touch). tar'-so-met-a-tar'-sus (compounded of tarsus and metatarsus; the name for the single bone formed by the fusion of these). tar'-sus, pl. tarsi (Gr. tarsos, the flat of the foot). teg'-mi-na (Lat. pl. of tegmen, from tegere, tectum, to cover). tel'-son (Gr. telson, a limit), the terminal joint of the abdomen of Crustacea.

ten'-don (Lat. tendere, to stretch). te-nac'-u-lum (Lat. tenere, to hold). ten'-ta-cle (Lat. tentare, to feel). ter'-gum, pl. terga (I.at. tergum), back.

ter'-mi-nal (Lat. terminare, to put an end to), on the end. ter'-ti-a-ries, pl. of tertiary (Lat. tertius, the third). tes'-tis, pl. testes (Lat. testis), spermary. tho-rac'-ic, pertaining to the thorax. tho'-rax (Gr. thōrax, the chest). thy'-mus (Gr. thumos). thy'-roid (Gr. thureos, a shield, and eidos, form). $\mathrm{tib}^{\prime}-\mathrm{i}-\mathrm{a}$, pl. tibice (Lat. tibia, the shin bone, also a pipe or flute which was originally made of bone).

tra'-che-a, pl. tracheo (Lat. trachea), the windpipe; also air tubes of insects.

trans-verse' (Lat. trans, across, and vertere, to turn), across the long axis. tri-gem'-i-nal (Lat. tri, three, and geminus, a twin).

tri-un'-gu-lin (Lat. tri, three, and unguis, a claw). tro-chan'-ter (Gr. trochantêr, a runner).

trun'-ca-ted (Lat. truncare, to cut short), appearing as if cut off squarely at the tip.

tu'-ber-cle (Lat. tuber, from tumere, to swell, and dim. cle, little), a small knob-like prominence. 
tur'-bi-nal (Lat. turbo, a top).

tym'-pa-num, pl. tympani (Lat. tympanum, a drum head).

typ'-i-cal (Lat. typicus), expressing the essential characteristics of a type.

ul'-na (Lat. ulna, the elbow).

um-bi-li'-cus (Lat. umbilicus, the navel), an opening into the calamus of a feather.

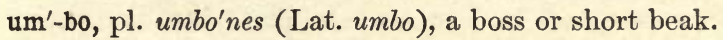

un'-ci-nate (Lat. uncus, a hook).

u-ni-cel'-lu-lar (Lat. unus, one, and cella, a cell), one-celled.

$\mathbf{u}^{\prime}$-ni-valve (Lat. unus, one, and valva, fold).

u-re'-ter (Gr. ouron, urine).

$\mathbf{u}^{\prime}$-ri-na-ry (Lat. urina, urine), pertaining to the urine.

$\mathbf{u}^{\prime}$-ro-stege (Gr. oura, tail, and stegè, roof).

$\mathbf{u}^{\prime}$-ro-style (Gr. oura, tail, and stulos, pillar, style [for writing]), a styliform process at the posterior extremity of the vertebral column.

$\mathbf{u}^{\prime}$-te-rus (Lat. uterus), the womb.

vac'-u-ole (Lat. vacuus, empty).

$\mathrm{va}^{\prime}$-gus (Lat. vagus, wandering, called also the pneumo-gastric nerve). vane (O. Eng. fane, a weathercock).

vas'-cu-lar (Lat. vasculum, dim. of vas, a vessel), containing vessels.

vein (Lat. vena): veinule and veinlet are its diminutives.

ven'-tral (Lat. venter, the belly).

ven'-tri-cle (Lat. ventriculus, dim. of venter).

ver'-mi-form (Lat. vermis, a worm, and forma, form), shaped like a worm.

ver'-te-bra, pl. vertebrce (Lat. vertere, to turn).

ves'-i-cle (Lat. vesicula, dim. of vesica, a bladder), a cyst.

ves'-ti-bule (Lat. vestibulum, a place of entrance).

vis'-ce-ra (Lat. pl. of viscus), the entrails; internal organs.

vo'-mer (Lat. vomer).

xiph-i-ster'-num (Gr. xiphos, a sword, and sternum, q.v.).

xiph'-oid (Gr. xiphos, a sword, and eidos, form).

zyg-a-poph'-y-sis, pl. zygapophyses (Gr. zungon, a yoke, and apophysis, process of a bone), one of the articular processes of a vertebra. 


\section{SUGGESTIONS TO THE TEACHER.}

Some knowledge of the difficulties encountered by one who would attempt a well-balanced elementary courso in zoölogy, in some of our secondary schools at the present time, prompts this final word to the teacher.

I would recommend the teacher, first of all, to note the amount of work outlined in the foregoing pages, and to consider whether it may all be done in the time at the disposal of his class. Having often found that a particular animal, when wanted alive for study, is not to be had, I have mentioned several types to which each outline may be applied, and have perhaps added more outlines in brief than so elementary a course requires; yet I trust the advantage of this will be apparent when selections are to be made. For a short course it might be more profitable to study only the part relating to insects or the part relating to vertebrates, rather than to attempt to "go through" the book.

I would suggest that the teacher arrange his work so as to have an hour of freedom from teaching preceding the hour for zoölogy, which may be spent in preparing for the recitation. The hour will be anything but vacant if devoted to the preparation for the hour to follow it.

I would suggest that the teacher spend the first hour of the session in familiarizing his pupils with the microscope, - with its parts and their use. I would give them each a slide with some object of simple outlines mounted on it, and iustruct them in moving the object into the field, in finding it with low and with high powers, and I would require an outline drawing of it.

Then I would proceed at once to the study of amoba, paramecium, sponge, and hydra, passing over this part as rapidly as proved consistent with the mastering of the fundamental ideas of zoölogy which these types are well adapted to introduce. For this part of the study, I would provide all the material, and present it as demonstrations, requiring of the pupils only that they study it and make drawings showing all they are able to make out, naming the parts and explaining their action; and that they make note of the habits and habitat of these animals.

Then I would begin, as early as possible in the term (all the material of this book is arranged with reference to beginning the course in early autumn), the study of insects. And for the remainder of the 
course I would require that all the work outlined in the text be done by the student, and that the greater part of it be done by each student for every animal studied. Just how much dissecting and how much field work, etc., should be required, will have to be determined in accordance with the abilities and needs of individual classes. Some of the larger dissections may be made as demonstrations by the teacher or assistants ; but I consider it absolutely necessary that each student should study the structure of every type, and record his observations in some permanent form, notes, drawings, or preparations of illustrative material. While freely acknowledging the great value of original drawings, however crude, I think it should be borne in mind that the student who has no aptitude for this art may find continual drawing as irksome as it is unsatisfactory to him. I have found students, wholly incapable of making a presentabs drawing, able to make beautiful preparations of material for demonstrations and for collections. The true ends of scientific instruction will not be promoted by keeping any student long at work which he cannot make pleasant or satisfactory.

The field work suggested in this book forms an important feature of it, yet not so important, I am persuaded, as it should be made. I would require of the students, that, in so far as is possible, they collect all their own material for study. The observations made while doing this will not be among the least valuable things learned about animals in the course. And I would not discourage the collection of cabinet specimens. This has its place. There is one benefit to be had from a thorough study of types, and there is another benefit to be had from personal contact with nature in a great variety of forms. I would go out with the students often, and direct their observations in the field. Making use of the haunts of animals most accessible for study, I would assign simple tasks of outdoor observation, requiring little time, and I would not limit these to observations on the types studied in the course. Many a teacher neglects abundant opportunity for doing this. Material for such study is at the very doors of a majority of the schools in which elementary zoölogy is taught. Our higher institutions of learning, located often in the heart of great cities, by establishing seaside and lakeside laboratories, get, at a great expenditure of time and money, that which the secondary schools may have if they choose, without expense, as a part of their daily life. And who shall say that the study of animals in their relation to nature is of more worth in one school or in the other?

I urge as most important, that the teacher maintain strictest supervision of all work, that there may be no idling in the field, no smat- 
tering in the laboratory, and as little as may be of memorized second-hand information in the classroom. Definite results should be required of every excursion made by students to the field. Quiet, careful, and diligent work should be insisted on in the laboratory. Scrupulous neatness should be maintained. Every student should be required to keep his table clean and his specimens fresh, and to entirely remove from the laboratory all materials in his charge that are liable to become offensive.

Lastly I would urge the teacher to acquaint himself with the entire fauna of his own locality. Doubtless in many localities other types than those mentioned in this book are better and more available for study: such he is recommended to find and use by his friend and fellow-worker,

The Author. 


\section{N D E X.}

Abdomen, of asellus, 125.

of back-swimmer, 62 .

of beetle, 76 .

of bumblebee, 65 .

of butterfly, 42 .

of cicada, 60 .

of crawfish, 114.

of cyclops, 127.

of dragon fly, 45 .

of fly, 83 .

of grasshopper, 51 .

of mussel, 145 .

of pupa, 92 .

of rabbit, 243.

of sparrow, 216, 221.

of spider, 108.

Acridium. See Schistocera.

Air sac of snail, 156.

Alimentary canal. See Digestive organs.

Amœba, 12, 278.

Amœboid blood, 137.

Analogy, 45.

Anasa, 57.

Antenna, of crustacean, 118,125, 127 . of insect, 39 .

Antennule, 118, 125, 127.

Aorta. See Arteries.

Aperture. See Sponge gemmules.

Arachnida, 105-109.

Arm bones, of frog, 192.

of rabbit, 257.

of turtle, 206.

Arteries, of crawfish, 119.

of fish, 163, 168.

of frog, 182, 184.

of mussel, 146.

of rabbit, 247 .

of sparrow, 226 .

of turtle, 202.

Arthropoda, 128.

Asellus, 125.

Asilus, 85.
Asterias, 266, 267.

Aves, 211.

Backbone. See Spinal column.

Back-swimmer, 61.

Barbels, 162.

Batrachia, 178, 198.

Beak, 215.

Bee killer, 85.

Beetle, 74.

blister, 74 .

Harpalus, 78.

larvæ, 79 .

locust borer, 78 .

red milkweed, 78 .

soldier, 77.

whirligig, 79.

Birds, 211, 236.

Blastula, 159.

Blood, of fish, 163.

of insects, 52, 94 .

of worm, 137.

Blood vessel. See Circulatory organs.

Bluebottle fly, 80 .

Body cavity, of starfish, 272. of worm, 136.

Bone. See Skeleton.

Books of reference, 275.

Brachystola, 52.

Brain. See Nervous system.

Branch, 128.

Branchial chamber, of crawfish, 113 of fish, 170 .

of mussel, 144.

Budding, 27.

Bumblebee, 63.

Butterfly, 36.

cabbage, $86,89,92$.

clover, 36.

egg, 88,90 .

larva, 88, 90.

milkweed, 104. 
Butterfly, pupa, 89, 92.

skipper, 103.

sulphur, 36.

swallow-tail, 102.

Cambarus, 111.

Cantharidin, 75 .

Carapace, of crawfish, 144.

of cyclops, 126 .

of turtle, 199.

Carolina locust, 48.

Catfish, 161.

Cell, 18.

Centiped, 109.

Cephalothorax, of crawfish, 114. of cyclops, 127. of spider, 108.

Chauliognathus, 77.

Chilopod, 109.

Chrysemys, 198.

Cicada, 59.

Chloragogue cells, 137.

Circulation, demonstration of, 125 , $163,179$.

Circulatory organs, of crustaceans, 119.

of fish, 168 .

of frog, 182.

of insects, 52 .

of mussel, 146.

of rabbit, 246.

of sparrow, 225 .

of starfish, 271.

of turtle, 201, 202.

of worm, 134.

Class, 128.

Classification, 101, 127.

Clitellum, 133.

Cœlenterata, 22-33.

Coleoptera, 74, 79.

Colias. See Eurymus.

Collar of snail, 156.

Collecting insects, 34 .

Colony, 69.

Columella, 188. See also Shell of snail.

Comb, 73.

Condyle. See Skull.

Conjugation, 17.

Cranium. See Skull.

Crawfish, 111.

Cremaster, 89.

Crustaceans, 111-128.

Cyanide bottle, 35 .

Cyclops, 126.
Development, of blister beetle, 76 . of bumblebee, 68 .

of cabbage butterfly, 88 .

of crawfish, 123.

of dragon fly, 47 .

of fly, 83 .

of frog, 196.

of grasshopper, 55 .

of mussel, 152.

of snail, 157.

of spider, 109.

of sponge gemmules, 24 .

of turtle, 207.

of wasp, 71, 73 .

of worm, 138.

Diaphragm, 244.

Differentiation, 25.

Digestive organs, of crawfish, 121. of fish, 167 .

of frog, 181.

of insect, 53, 94 .

of mussel, 147.

of rabbit, 245.

of snake, 210.

of sparrow, 223.

of starfish, 270 .

of turtle, 202.

of worm, 134.

Diplax, 42.

Diptera, 80,86 .

Directions for preparation of material for study, 278.

Dissosteira, 48.

Division of labor, 32 .

Dorsal vessel, 52,94 .

Dragon fly, 42.

Ear sac of mussel, 153.

Earthworm, 130.

Echinodermata, 266-273.

Ectoderm, 28.

Ectosarc, 13, 19.

Egg capsules, of snail, 160 . of worm, 139.

Egg sacs, 127.

Embryology, 158, 160, 196.

Endoderm, 28.

Endosarc, 13, 19.

Endoskeleton, 122, 205.

Epicauta, 74.

Epiglottis, 243.

Esophagus. See Digestive organs.

Eurymus, 36.

Eustachian tube, 180, 242.

Evolution, 264. 
Excretory organs, of crawfish, 122. of fish, 169 .

of frog, 182.

of grasshopper, 54 .

of mussel, 147.

of rabbit, 246.

of sparrow, 225 .

of turtle, 202.

of worm, 136.

Exoskeleton, 204, 217.

Eye, of crawfish, 119.

of fish, 172 .

of insects, 39 .

of snail, 156.

of starfish, 269 .

Family, 103.

Feathers, 218.

Feeding, of amoba, 14, 15.

of bumblebee, 63 .

of butterfly, 37 .

of crawfish, 112.

of dragon fly, 43 .

of earthworm, 130.

of fly, 80 .

of frog, 180 .

of grasshopper, 49 .

of hydra, 26.

of paramecium, 21.

of rabbit, 238.

of sparrow, 213.

of squash bug, 58 .

of starfish, 270.

Fertilization, 30.

Fins, 162, 166.

Fish, 161.

Foot, of frog, 192.

of insect, 41.

of mussel, 142.

of rabbit, 240 .

of snail, 155.

of sparrow, 214.

of spider, 108.

Foramen magnum. See Skull.

Fresh-water sponge, 22.

Frog, 178.

Gastrula, 159.

Gemmules, 23, 280, 281.

Genus, 102.

Gill, of crawfish, 120. of fish, 170 . of mussel, 144.

Glochidia, 152.

Glottis. See Larynx.
Grasshopper, 48.

Green gland, 122.

Harvest fly, 59 .

Haunts and habits, of amœba, 278 of asellus, 125.

of back-swimmer, 61 .

of bee killer, 85 .

of beetles, 77-79.

of blister beetle, 74 .

of bumblebee, 63 .

of butterfly (cabbage), 86 .

of butterfly (sulphur), 36 .

of catfish, 161 .

of centiped, 109.

of cicada, 59 .

of crawfish, 111.

of cyclops, 126.

of dragon fly, 42.

of earthworm, 131.

of fly, 80 .

of frog, 178.

of grasshopper, 48 .

of hydra, 282.

of mussel (river), 140.

of paramecium, 279.

of rabbit, 237.

of snail (pond), 154.

of sparrow, 212 .

of spider, 105.

of sponge (fresh-water), 279.

of squash bug, 57 .

of starfish, 266 .

of turtle, 198.

of wasp (mud), 70.

of wasp (paper), 72.

Head, of blister beetle, 75 .

of bumblebee, 64 .

of butterfly, 39 .

of dragon fly, 74 .

of fish, 162 .

of fly, 81 .

of grasshopper, 49 .

of larva, 90.

of pupa, 92 .

of sparrow, 215.

of turtle, 199.

Heart. See Circulatory organs.

Hemiptera, 57, 62.

Hermaphroditism, 30 .

Hinge ligament, 141.

Homology, 45, 123.

Honeybee, 73.

Hydra, 26, 282.

Hymenoptera, 63, 74. 
Hyoid bone, 185, 222, 243.

Hypostome, 27.

Ictalurus, 161.

Insects, 34-110. collecting, 34.

Intestine. See Digestive organs.

Kidney. See Excretory organs.

Labial palpi

Labium

Labrum See Mouth parts.

Lacinia

Lacteal system, 250.

Larva, 68, 88, 90, 96.

Larynx, 222, 243.

Lasso cells, 28.

Lateral line, 166.

Leg bones, of frog, 193.

of rabbit, 259.

of sparrow, 235 .

of turtle, 207.

Legs, of bird, 217. of crawfish, 116.

of frog, 188.

of insect, 40.

of rabbit, 240 .

of turtle, 200.

Lens. See Eye.

Lepidoptera, 36, 42, 86, 93, 102, $104,128$.

Lepus, 237.

Life history. See Development.

Life process, in amœba, 15.

in hydra, 30.

in insects, 93.

in mussel, 150.

in sponge, 25.

in starfish, 272.

in vertebrates, 260 .

Limnea, 154.

Lizard, 208.

Locomotion, in amœba, 14.

in crustaceans, 113, 126.

in earthworm, 132.

in fish, 162.

in hydra, 26.

in insects, 97.

in mussel, 142.

in paramecium, 19.

in snail, 156.

in sparrow, 214.

in starfish, 267.

Locust, 48. See also Cicada.
Lucitia, 80.

Lumbricus, 130.

Lung. See Respiratory organs.

Malpighian tube. See Digestive organs of insect.

Mammalia, 237-259.

Mantle, 142, 143, 155.

Maxilla. See Mouth parts.

Maxilliped, 117.

Mesentery, 167, 181, 224, 244, 245.

Metabolism, 151, 261.

Metamorphosis, 69, 96.

Metastoma, 118.

Mollusca, 140-160.

Mouth, of fish, 165.

of frog, 179, 180 .

of hydra, 28.

of mussel, 147.

of rabbit, 241.

of snail, 156.

of snake, 209.

of starfish, 268.

of turtle, 200 .

of worm, 139.

Mouth parts of insects, 39, 44, 49, $65,82,91,108$.

Mud dauber, 70.

Mud wasp, 70.

Mucous membrane, 250.

Muscles, of crawfish, 121.

of fish, 174 .

of frog, 189.

of insects, 97.

of mussel, 144.

of sparrow, 225 .

of starfish, $270,271$.

of turtle, 203.

of worm, 136.

Mussel, 140.

Myenia, 22.

Myriapoda, 109, 110.

Neck, of sparrow, 215, 221. of turtle, 200.

Nephridium of worm, 136.

Nerve collar, of crawfish, 122.

of insects, 55 .

of worm, 136.

Nervous system, of crawfish, 122.

of fish, 170-173.

of frog, 185.

of insect, 55, 98 .

of mussel, 147.

of rabbit, 250 . 
Nervous system, of sparrow, 235. of starfish, 271.

of turtle, 185. of worm, 136.

Nest, of bumblebee, 67 . of paper wasp, 72 .

Nucleus, 15, 18, 20.

Nutrition, in amœba, 16. in hydra, 30. in insects, 93. in mussel, 150. in vertebrates, 260 .

Nymph, 46, 96.

Odonata, 42-48.

Order, 104.

Organ, 32.

Orthoptera, 48-57.

Ovum, 29.

Palate. See Mouth.

Pallial line, 149.

Pancreas. See Digestive organs.

Paper wasp, 72.

Paramecium, 18.

Passer, 211.

Pectoral arch. See Shoulder girdle.

Pelvic girdle, of fish, 166. of frog, 193. of rabbit, 258. of sparrow, 234 . of turtle, 207.

Pericardium. See Circulatory organs.

Peristome, 20.

Pharynx, 165, 242.

Piscus, 161, 178.

Plastron, 204.

Plumage, 218.

Proboscis. See Mouth parts.

Pronephros, 169.

Protozoa, 12, 21.

Pseudemys, 198.

Rabbit, 237.

Radius. See Arm bones.

Radula, 157.

Rana, 178.

Reagents, 276.

Reproduction, in amœba, 17.

in hydra, 31 .

in insects, 96 .

in starfish, 273.

in vertebrates, 262 .

vegetative, 27.
Reproductive organs, of crawfish, 121.

of fish, 167.

of frog, 182.

of grasshopper, 53.

of hydra, 27,29 .

of mussel, 148.

of starfish, 269 .

of turtle, 202.

of worm, 135.

Reptilia, 198-211.

Respiration, in amœba, 16. in cyclops, 127.

Respiratory organs, of crawfish, 116 . of fish, 170.

of grasshopper, 53.

of insects, 94 .

of mussel, 151.

of rabbit, 249 .

of snail, 156.

of snake, 210 .

of sparrow, $222,224$.

of spider, 108.

of turtle, 203.

Rib, 176, 205, 231, 254.

Robber fly, 85 .

Rostrum, of bugs, 58 . of crawfish, 114 .

Scapula. See Shoulder girdle.

Schistocera, 52.

Segmental organ. See Nephridium of worm.

Segmentation, of arthropods, 39, $113,133,134$.

of oösperm, 158, 196.

Sensation, in amœba, 18.

in hydra, 32 .

in insect, 98.

in mussel, 153.

in vertebrates, 263.

Serial homology, 123.

Setæ, 132.

Shell, of mussel, 148.

of snail, 155.

of turtle, 203.

Shoulder girdle, of fish, 166.

of frog, 192.

of rabbit, 257 .

of sparrow, 233 .

of turtle, 206.

Siphon, 144.

Skeleton, of crawfish, 114, 122. of fish, 175 .

of frog, 191. 
Skeleton, of insect, 38.
of rabbit, 253.
of sparrow, 227.
of turtle, 203.

Skin, of fish, 161.

of frog, 190.

of insect, 38, 92 .

of rabbit, 239.

of sparrow, 217.

of turtle, 204.

of worm, 136.

Skull, of fish, 171.

of frog, 194.

of rabbit, 255 .

of sparrow, 227.

Snail, 154.

Snake, 208.

Sparrow, 211.

Specialization, 21, 33.

Species, 102.

Sperms, 29, 137.

Spicules, 23, 280.

Spider, 105.

Spinal column, of fish, 169.

of frog, 191.

of rabbit, 253 .

of sparrow, 230 .

of turtle, 205.

Spinal cord. See Nervous system.

Spiracle of insect, 42,51 .

Spleen, 168, 182, 224, 24 (i.

Sponge, 22.

gemmules, 23, 280, 281

Squash bug, 57.

Starfish, 266.

Sternum, of frog, 192.

of rabbit, 254 .

of sparrow, 232.

Stomach. See Digestive organs.

Stylets, 125.

Swimmer, 115.

Syrinx, 222.
Tarsus. See Font.

Teasing, 283.

Teeth. See Mouth.

Telson, 114.

Test of strength of beetle, 79 .

Tetraopes, 78.

Thoracic duct, 250.

Thorax, of insects, 40 . of rabbit, 243.

Thousand-legs, 110.

Thymus, 250.

Tissue, 32 .

Tongue. See Mouth.

Trachea. See Respiratory organs

Tracheal gills, 47, 94.

Tracheal tube, 53, 94.

Turtle, 198.

Ulna. See Arm bones.

Unbo, 141.

Unio, 140.

Uterus, 262.

Vacuole (vesicle?), 15, 20

Vegetative reproduction, 27.

Veins, of fish, 163, 168.

of frog, 183.

of mussel, 146.

of rabbit, 246.

of sparrow, 226 .

of turtle, 202.

Vermiform appendage, 246.

Vertebra. See Spinal column.

Voluntary motion, in amœba, 17.

in hydra, 31.

in insect, 97.

in mussel, 152.

in vertebrates, 262 .

Water-vascular system, 270.

Wing, 213, 216.

Wing bones, 233.

Worm, 130. 






15577041

QI4?

N4

Educ.

Lib. 
